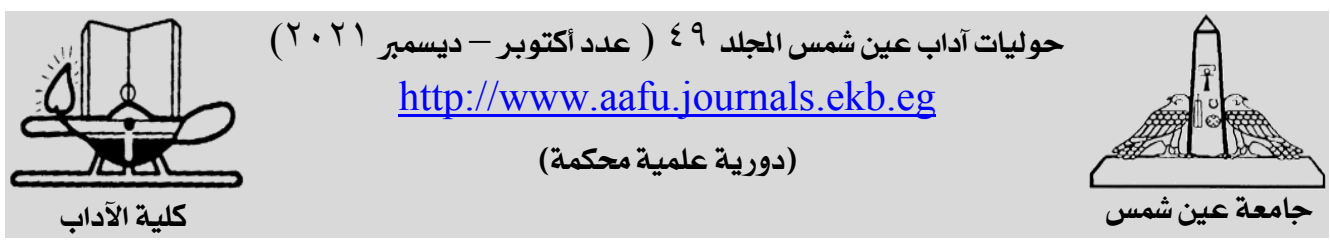

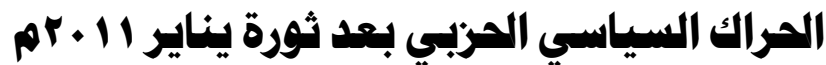

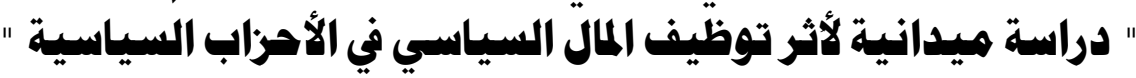

\section{عبدالحميا يونس زيد}

كلية الخدمة الاجتماعية - جامعة الفيوم - الفيوم

سعت الدراسة الر اهنة للبحث في أهمية دراسة وتحليل و اقع ومستقل الأحزاب

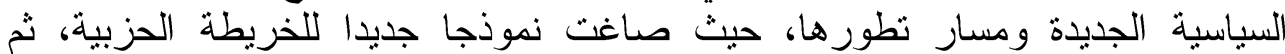

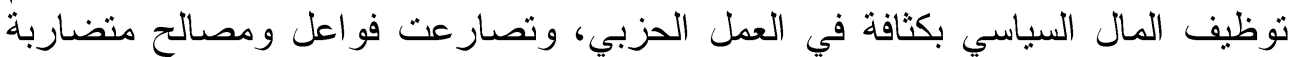

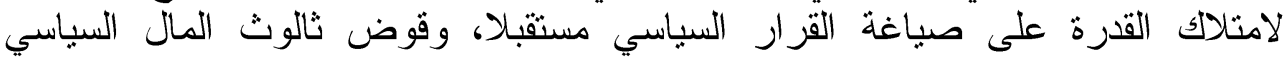

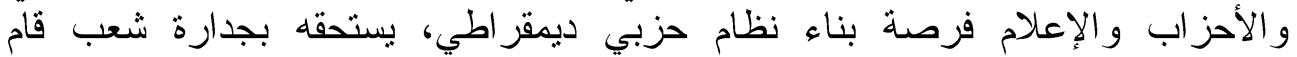
بثورثين، متخلصا من الاستبداد السياسي و الهوس الأنسام الديني. ووفقا لهذا الفه، تستهف الدارة اسة محاولة الكثف عن تأثثر عملية توظيف المال

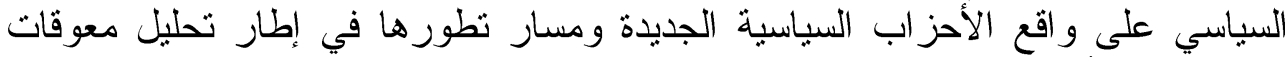

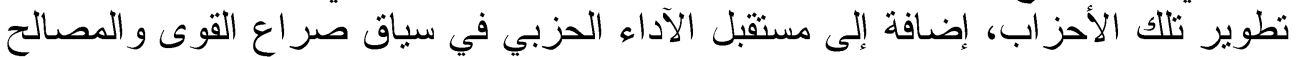

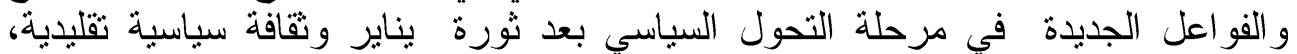

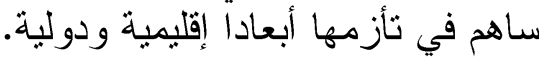
وقد اعتمدت هذه الدر اسة على المدادة المدل التحليلي المستند إلى در اسة حالات معمقة طبقت على ثلاث وعشرين من قيادات الأحزاب مجتمع البحث و المرشحين على قو ائهر

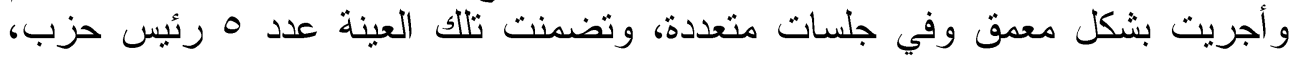

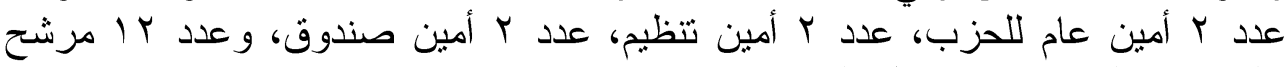

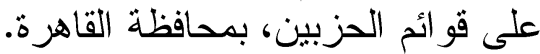

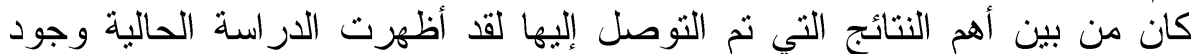

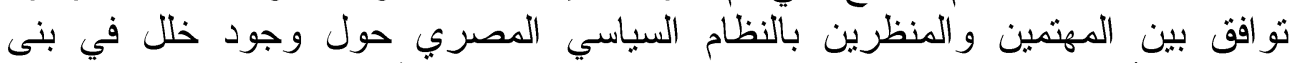
ووظيفة الأحز اب السياسية دون استثناء قبل ثورة يناير، مما أسس تحديا جوهريا لتطوير النظام الحزبي، وكان سببا في تحول تنظيم المطالبات نحو الحركات الإجتماعية

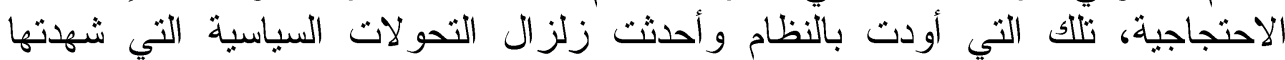
مصر • وجاء الانهيار السياسي كنتيجة لعدم اهنمام النظام بيناء مؤسسات سياسية فاعلة وقد لأند جاءت ثللك النتائج منو افقة مع رؤية " هنتنجتون " النظرية، حيث يذهب إلى الهى أن الانهيار

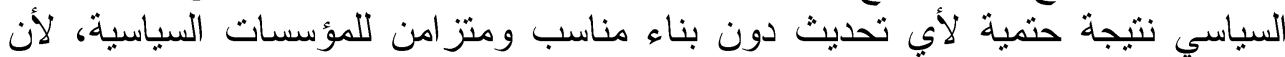

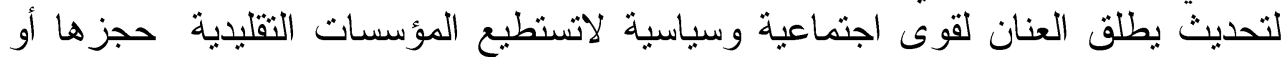
السيطرة عليها ومن ثم لايمكن تجنب الانهيار السياسي. لإن.

جميع حقوق الطبع والنشر محفوظة لحولية كلية الآداب - جامعة عين شمس آr.r. C) 
تأتي ضرورة تطوير الأحز اب من حيث الفكر و البناء و الآداء و الممارسة في كونها

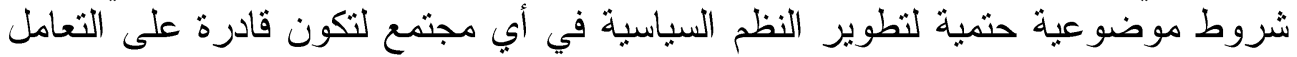

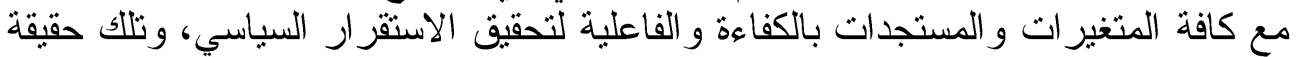

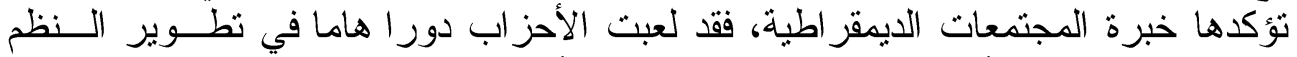

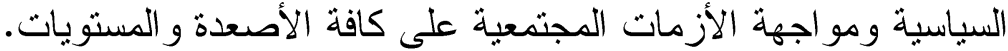

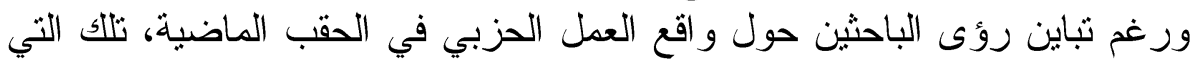

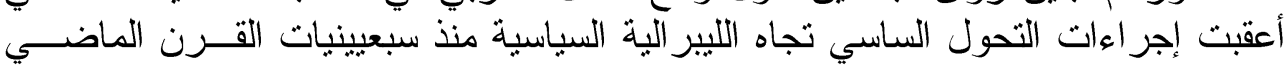

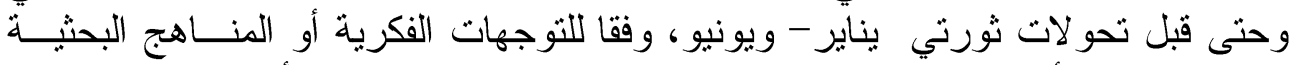

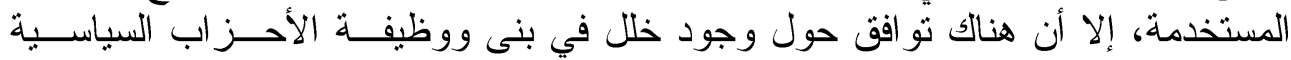

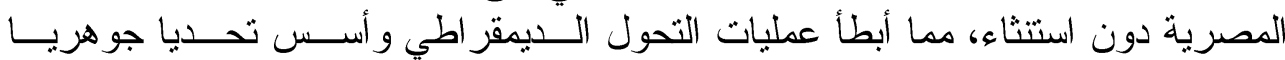

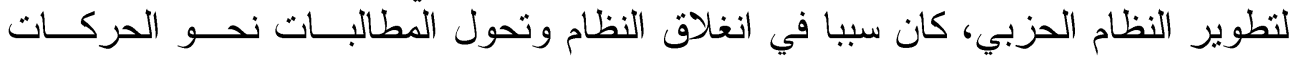

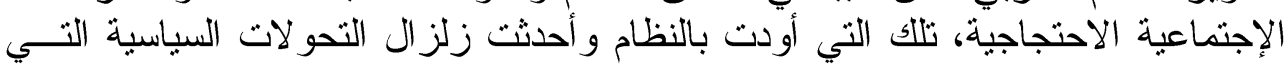

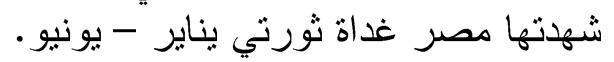

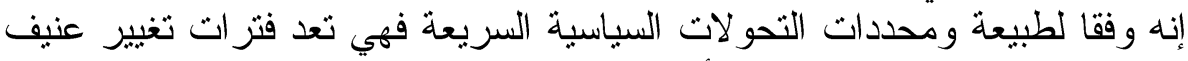

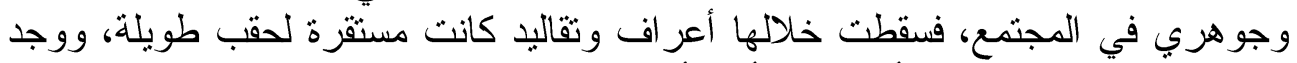

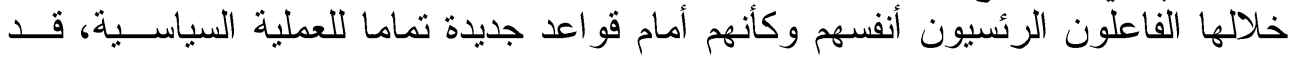

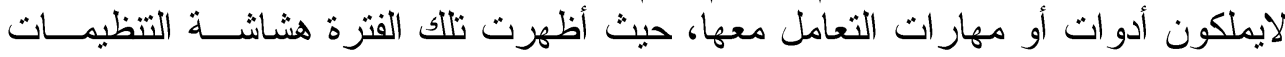

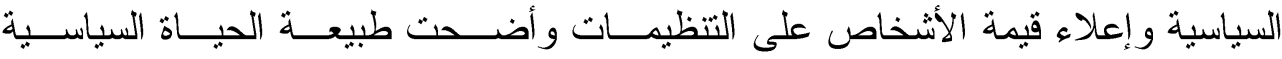
و استمر ارها بشكل عام في المجتمع على على الألى المحك.

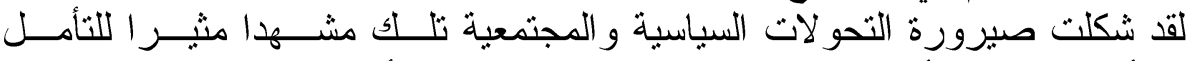

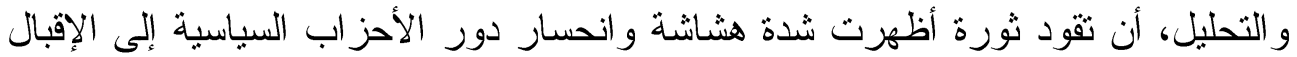

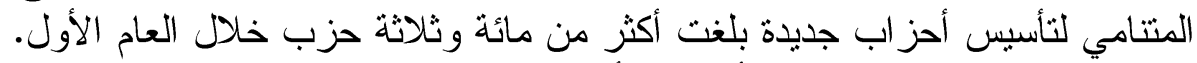

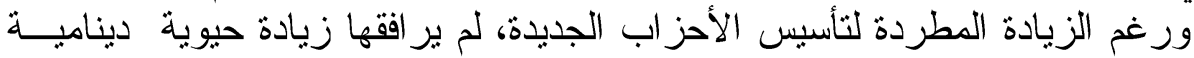

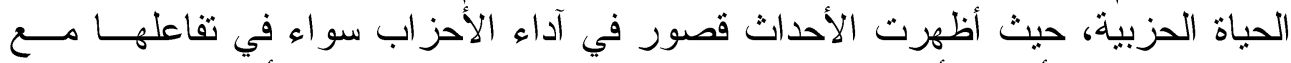

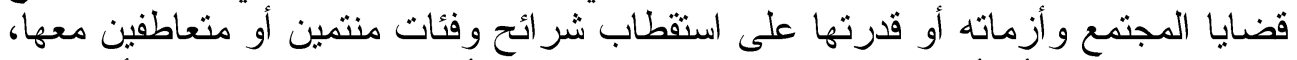

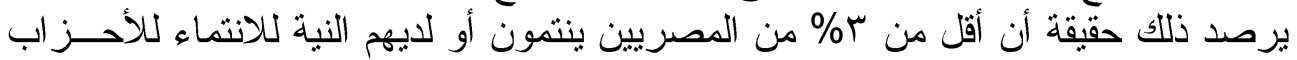

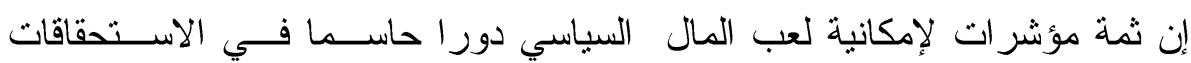

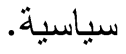

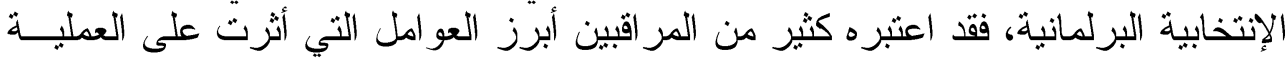

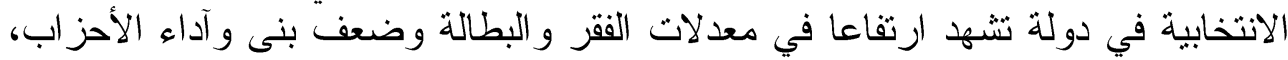

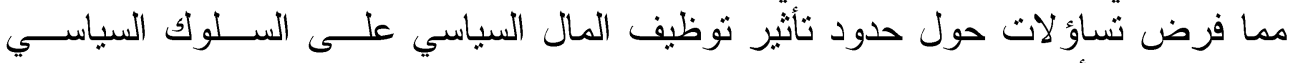

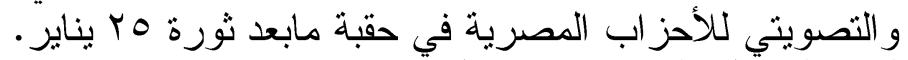

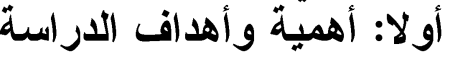

تزتيبا على ماسبق، جاءت أهمبة در اسة وتحليل و اقع ومستقل الأحز اب السياســبة

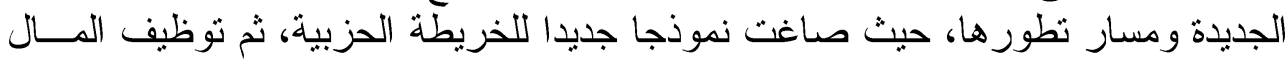

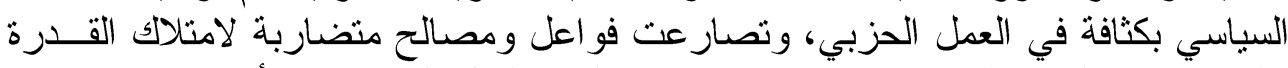

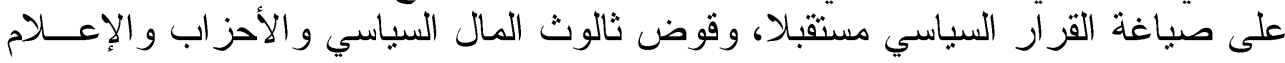

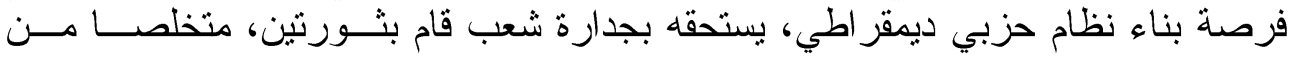
الاستبداد السياسي و الهوس الديني. دئي 


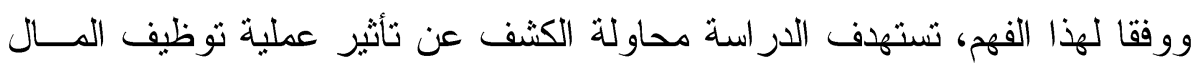

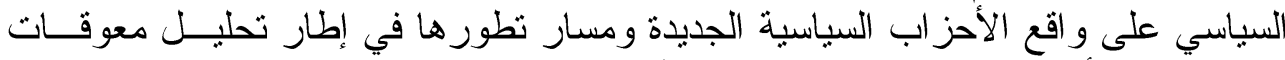

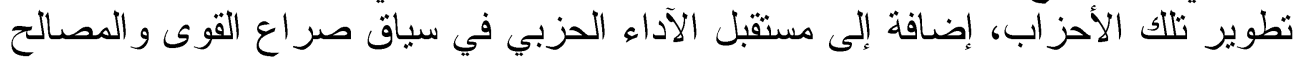

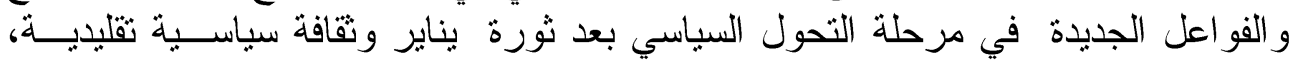
ساهم في تأزمها أبعادا إقليمية ودولية.

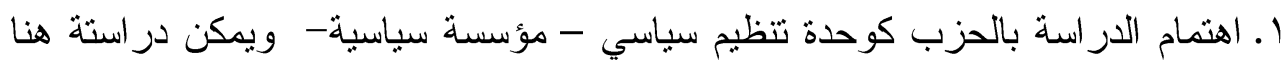

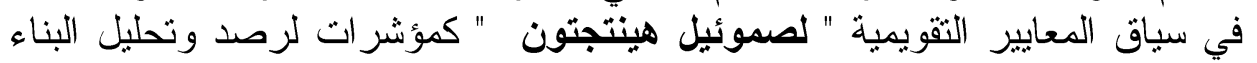

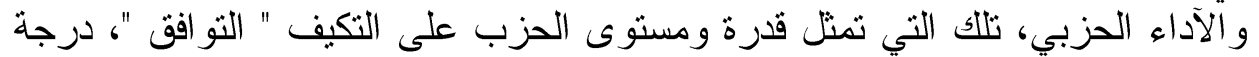

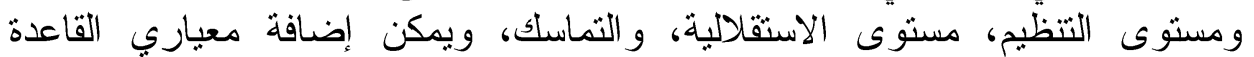

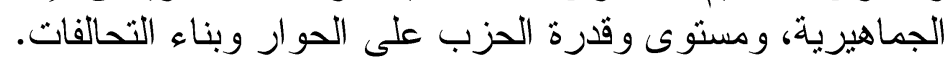

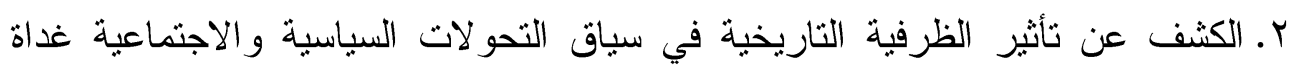
الثورة.

r. الكثف عن البعد الإقليمي و الدولي وصراع المصالح الاقليمية وتحالفاتها الداخلية ومدى تأثير ها على الحياة الحزبية.

ع. الاهنمام بالميكانيزمات غير الرسمية في دائرة العلاقات داخل وبين الكيانات السياسية،

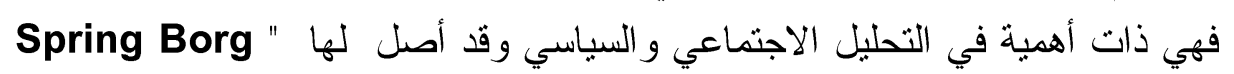
Robert

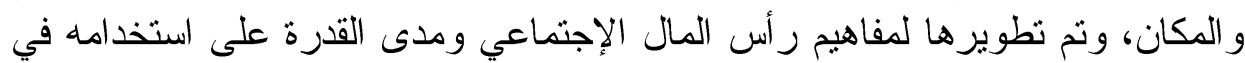

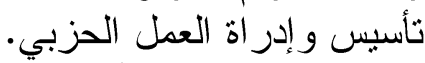

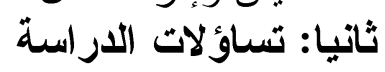

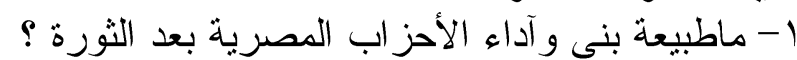
r- ماتأثير دوائر العلاقات غير آلاهز الرسمية و الثقافة السياسية التقليدية على تشكيل و آداء

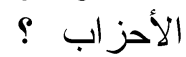

ץ- ما تأثير توظيف المال السياسي في تغيير السلوك الحزبي ؟ الإبي

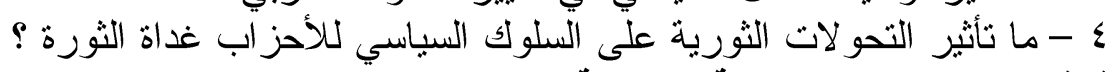

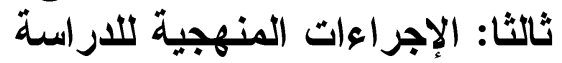

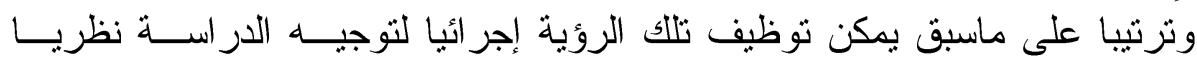

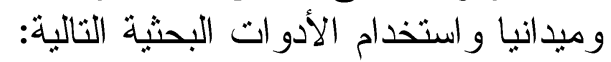

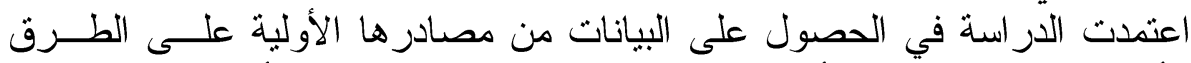

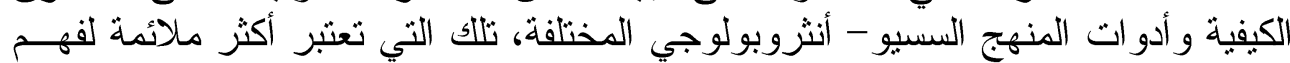

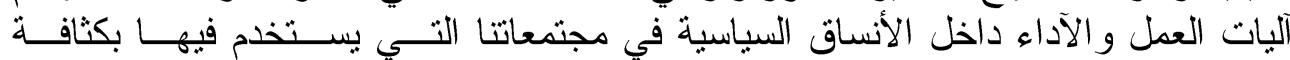

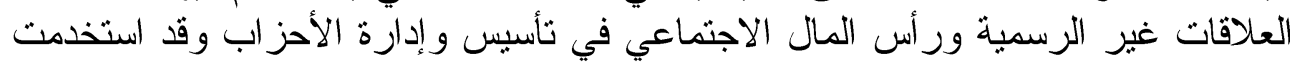

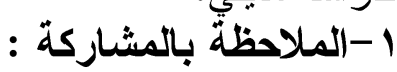

و التي استهدفت معايشة مجتمع البحث في موسم العمل السياسي وهي الفترة الزمنية

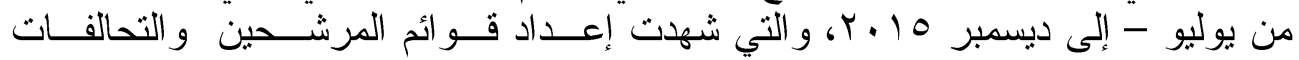




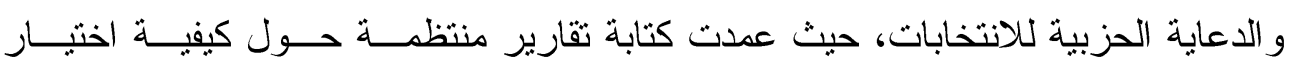

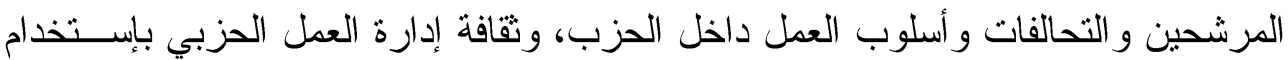

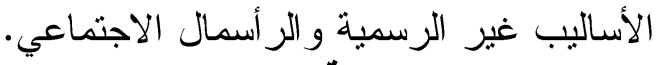

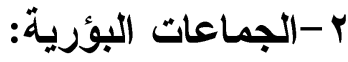

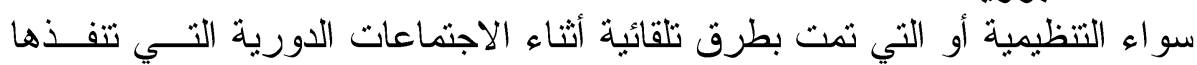

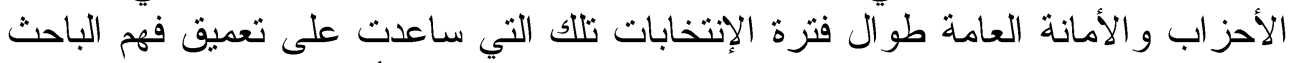

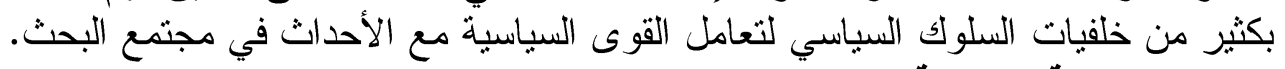
ب-دليل مقابلة مفتوحة: خليات

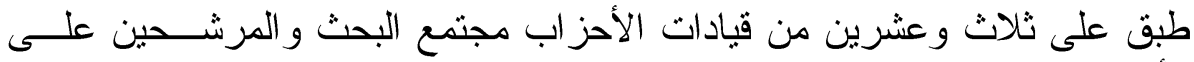

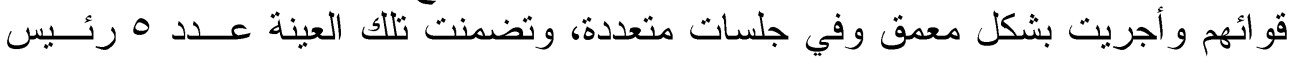

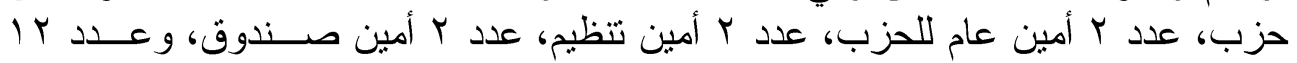
مرشح على قو ائم الحزبين. رابعا: مفاهيم الدراسة

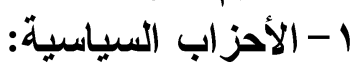

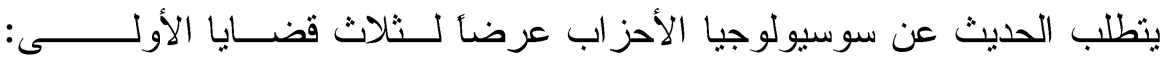

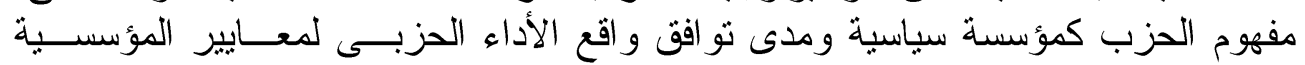

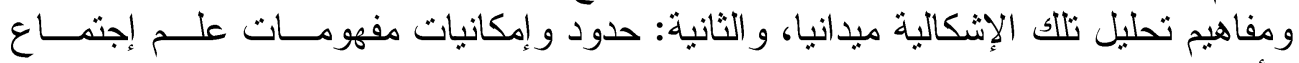

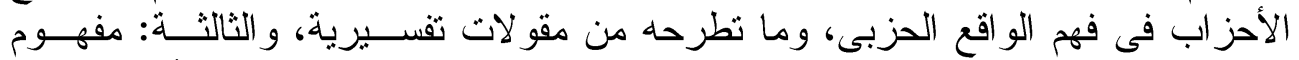

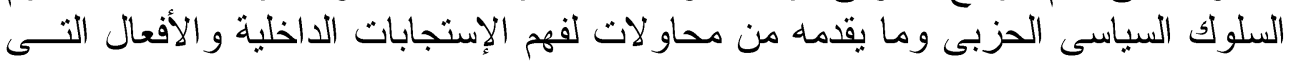

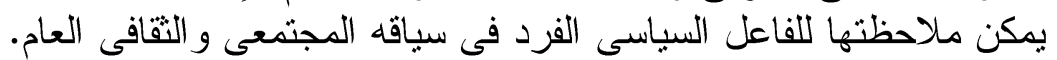

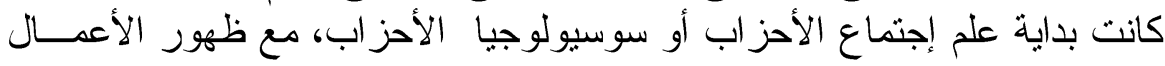

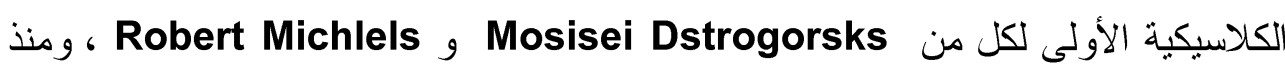

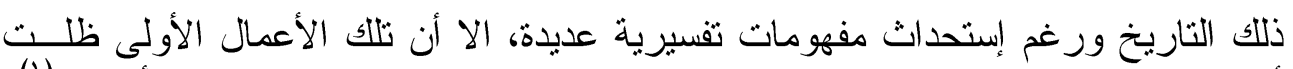

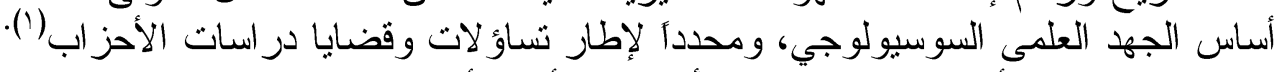

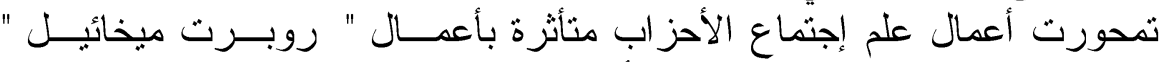

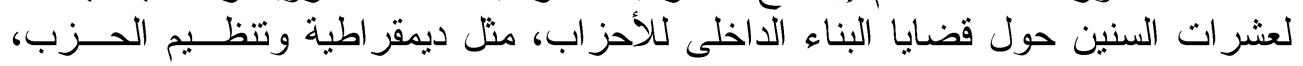

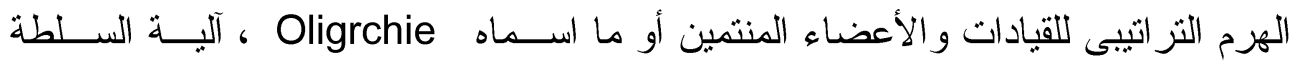
و التحكم داخل الحزب، إختيار وتصعيد النخب الداخلية، فضاء التجنيد و التعبئسـة، وكــللك الته

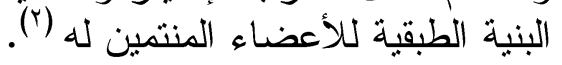

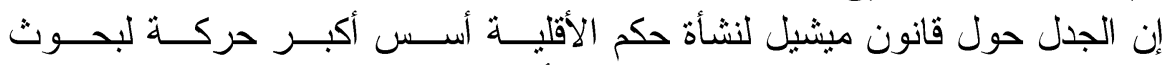

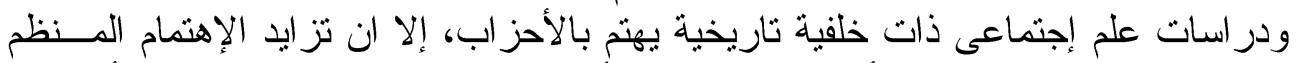

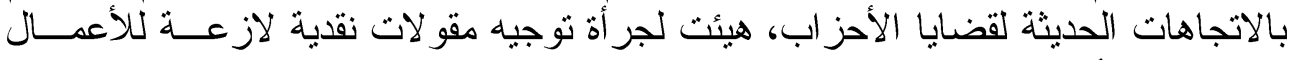

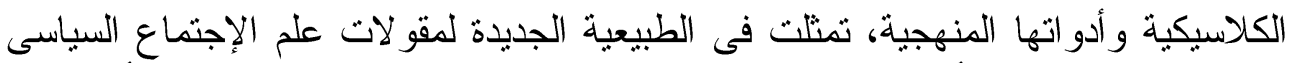

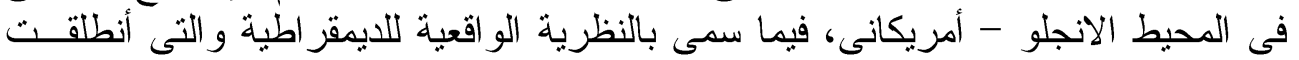

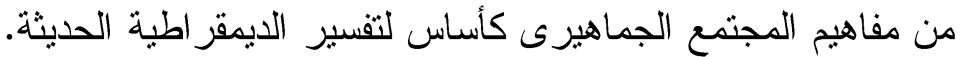

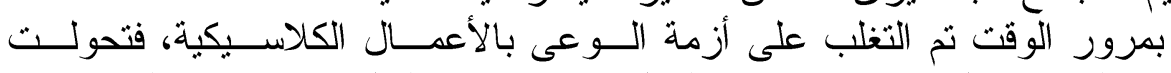

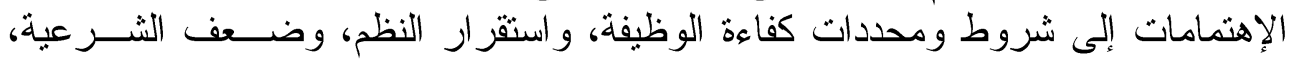

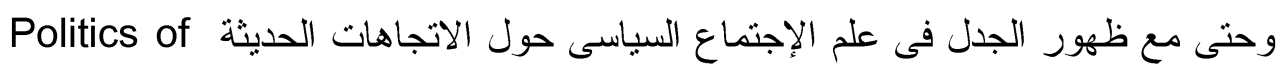




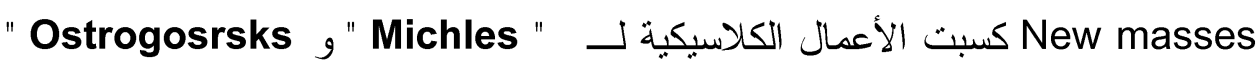

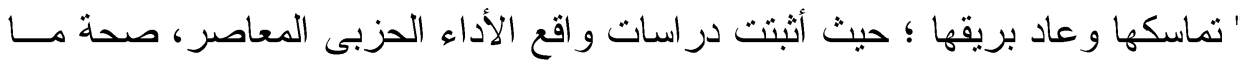

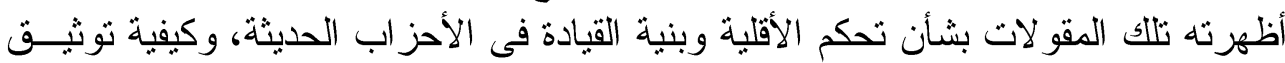

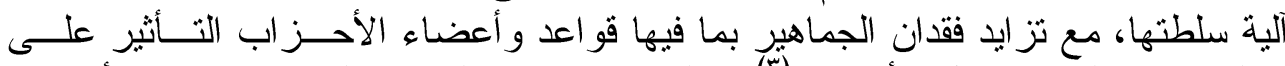

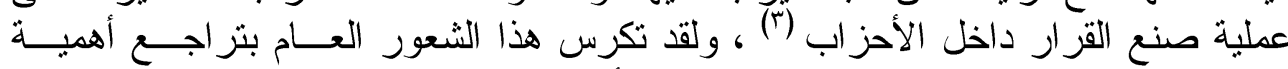

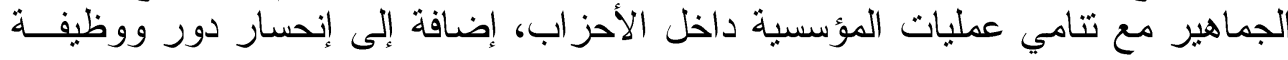

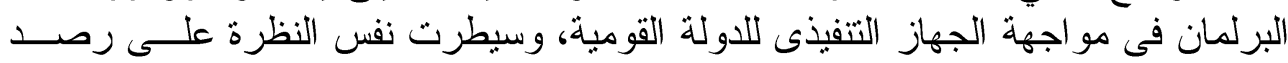

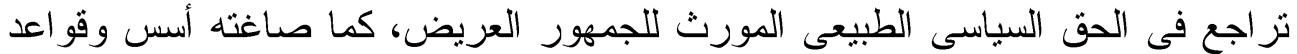

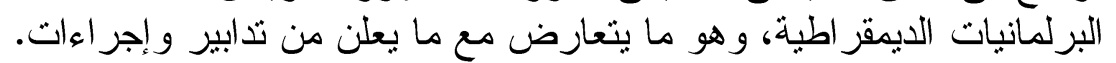

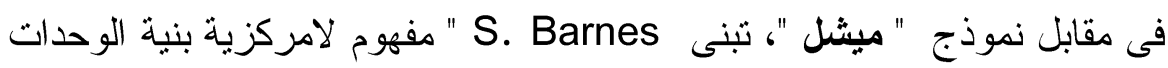

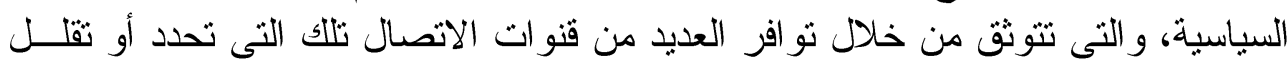

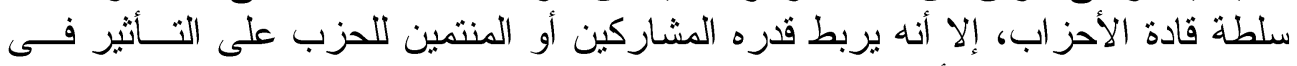

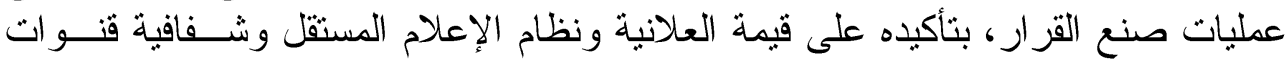

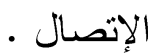

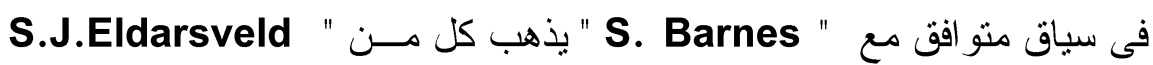

S.M Lipset

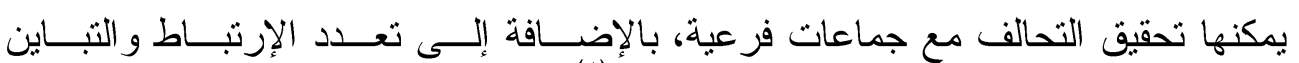
الإجتماعى مما يؤدى إلى ثقئ ثقليص حكم الأقلية ؛

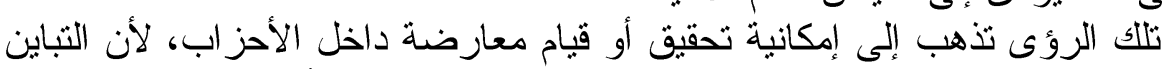

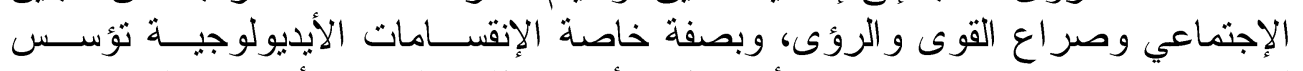

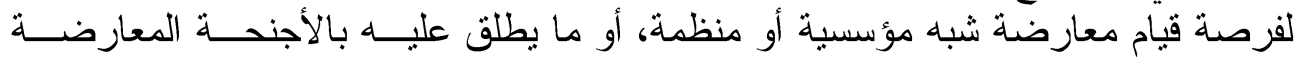

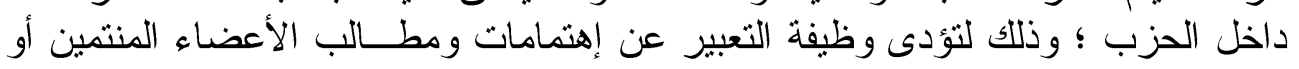

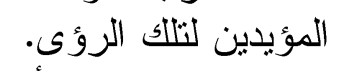

فى سياق تأكيده على تأثير الظروف التاريخية على تشكيل الديمقر اطية الحديثة

يشير" ماكس فيبر Max Weber إلى أن المجنمع الجماهيرى Massengesellschaft

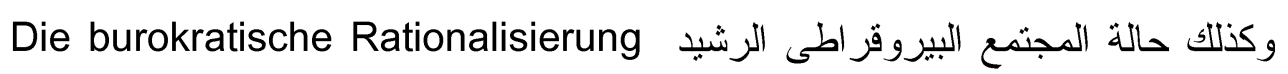
der gesellschaft

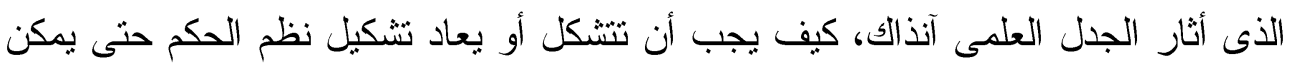

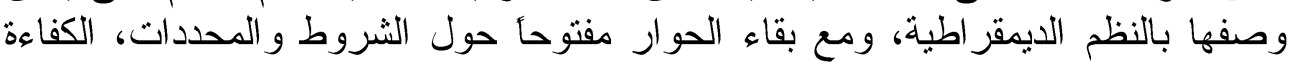

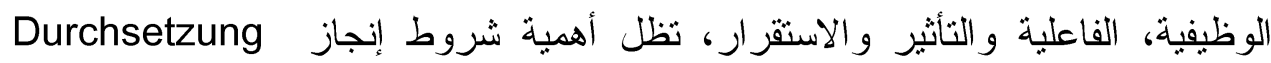
و تأمين مبادىء شرعية الديمقر اطية فى ممارسة النظم السياسية وحكم الشعب من وجهة و السبب كما يذهب الرواد الأوائل فى الإتجاهات الكلاسكية، هو أن النمط الســائد نظره باقية.

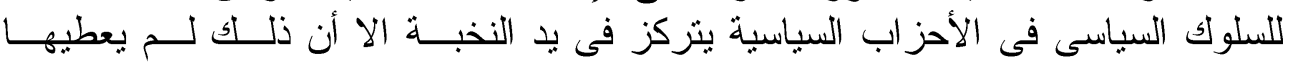

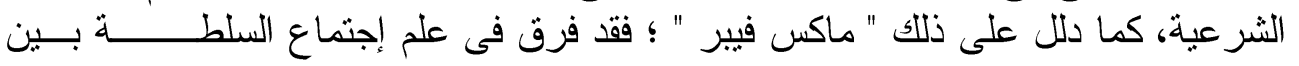


أحز اب الأعيــان Patronage و الأحــز اب العقائديـــ Honoratioron و والأحــز اب

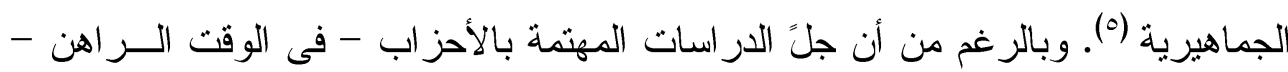

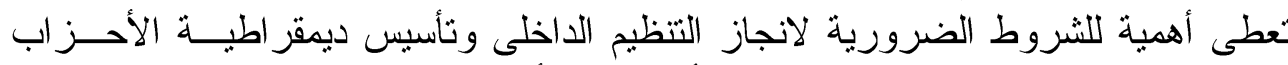

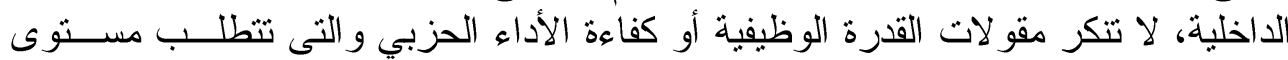

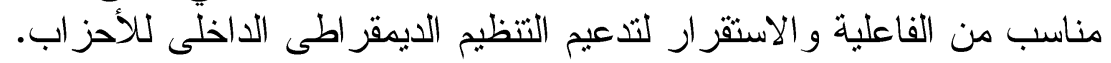

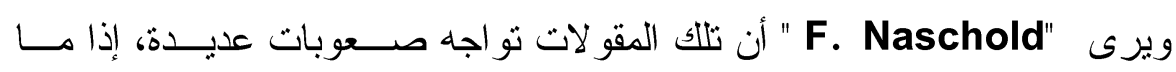

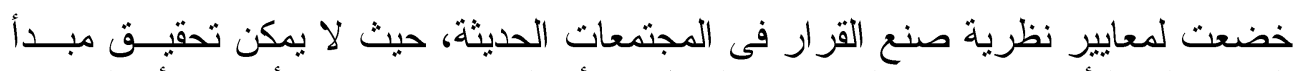

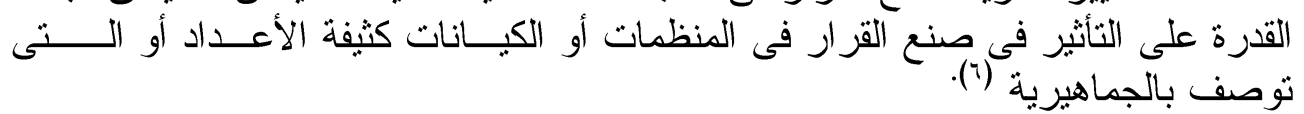

فالأحز اب السياسية في المجتمعات تعد أحد أشكال الحريات الفردية و الجماعية تلكي

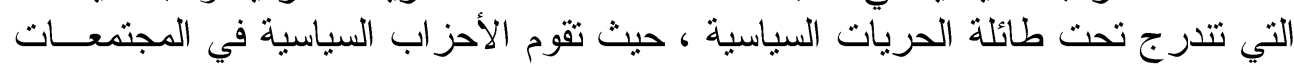

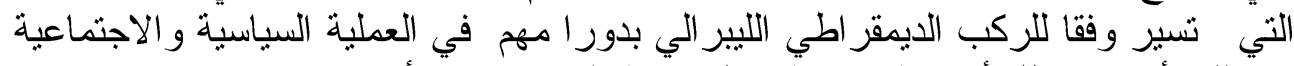

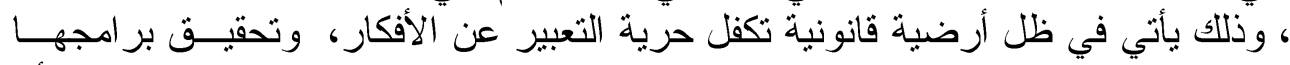

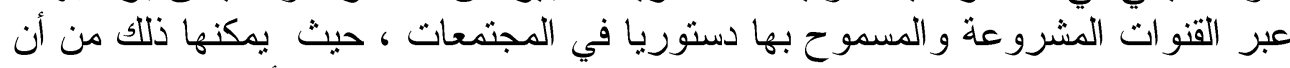

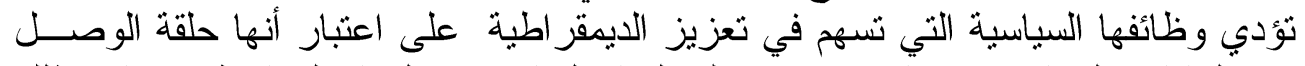

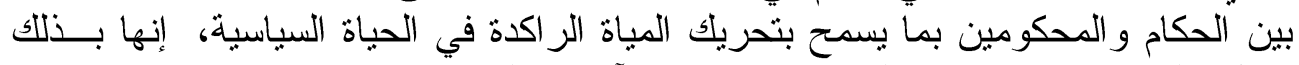

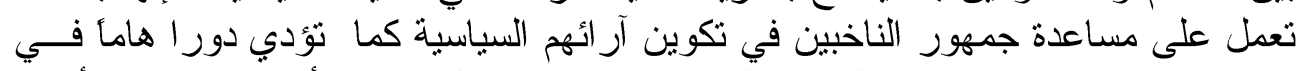

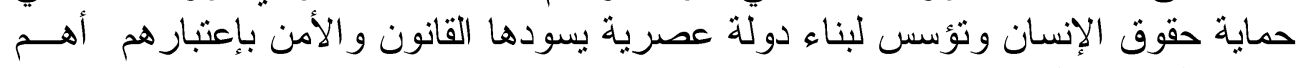

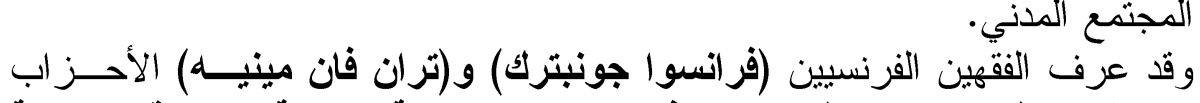
ركائز المجتمع المدني.

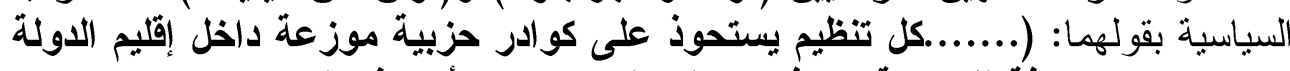

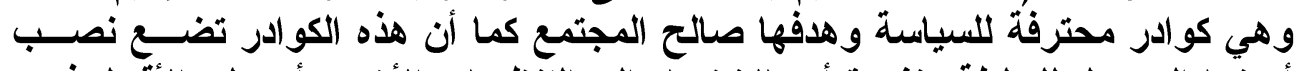

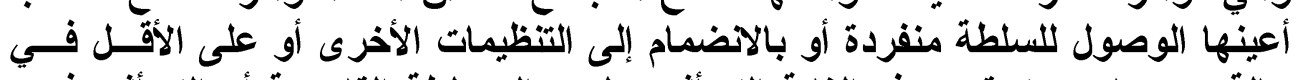

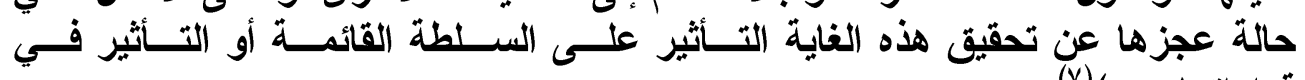

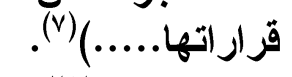

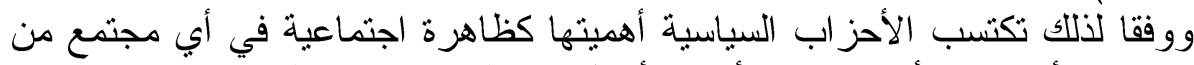

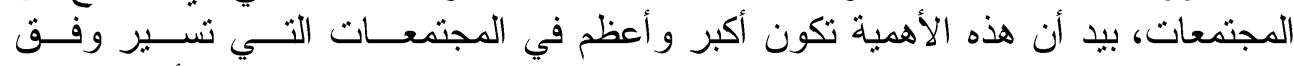

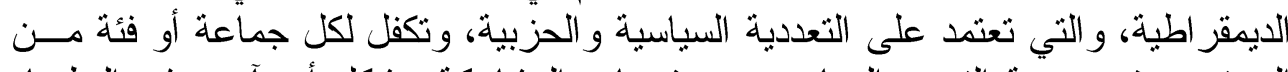

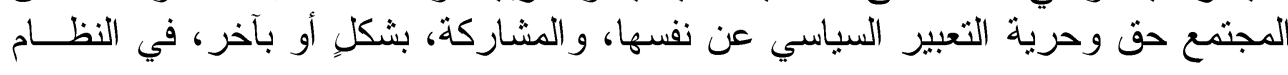

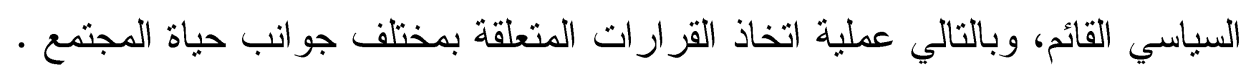

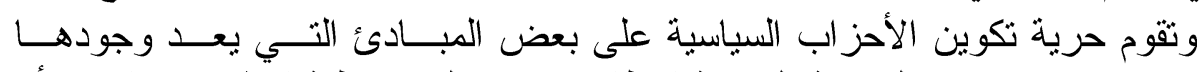

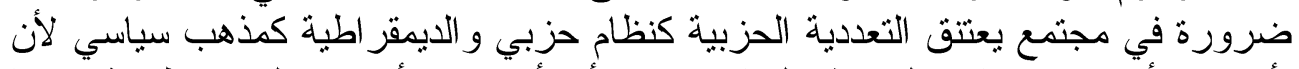

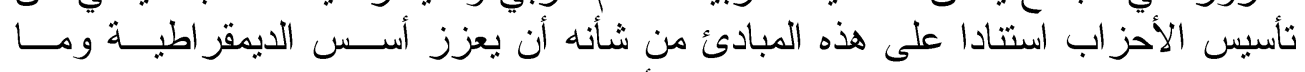

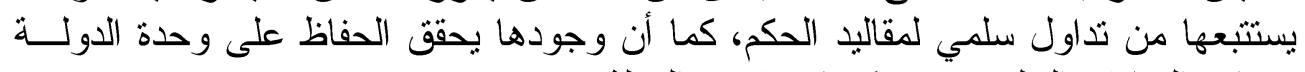

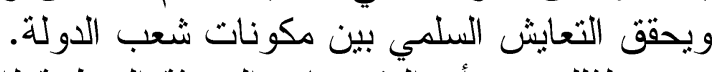

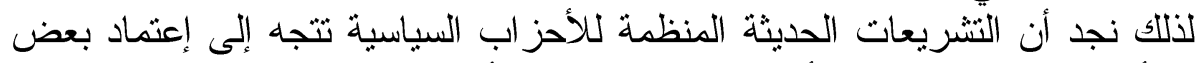

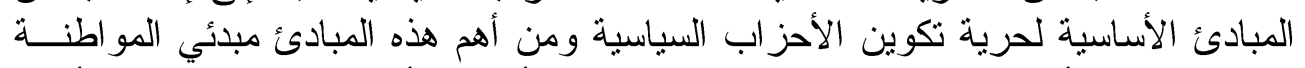

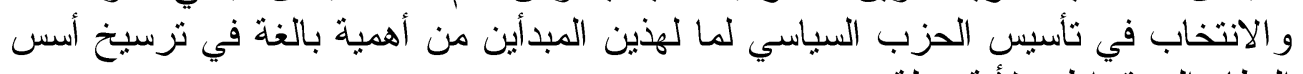

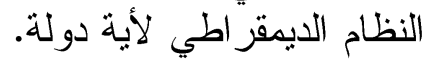




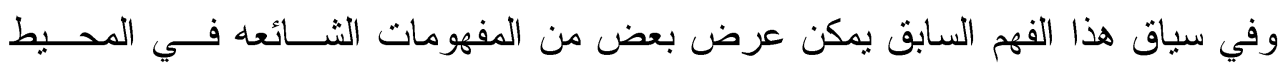

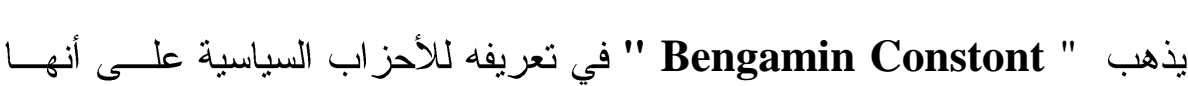

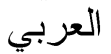

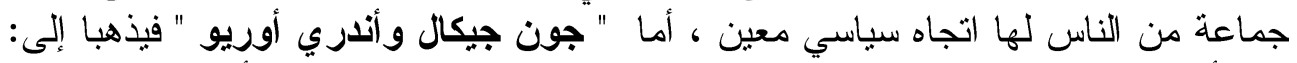

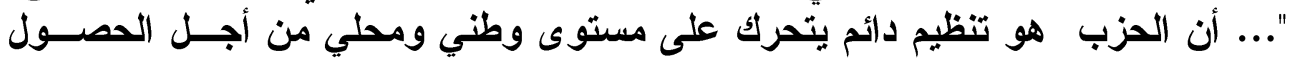

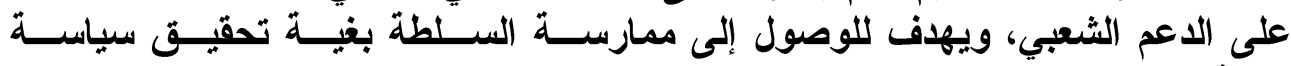
وفي ذات السياق تظهر إثكالية أخرى في تعريف الأحزاب السياسية وهي إلتبــاس

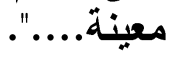

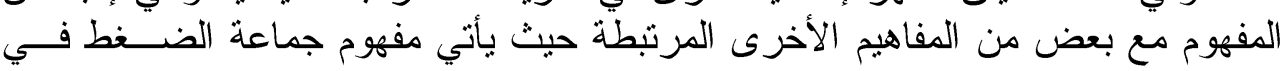

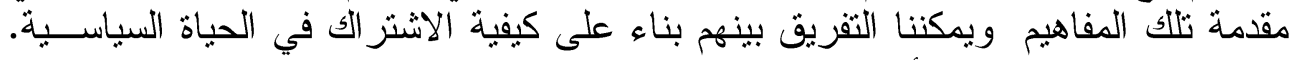

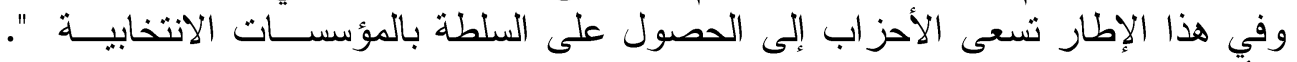

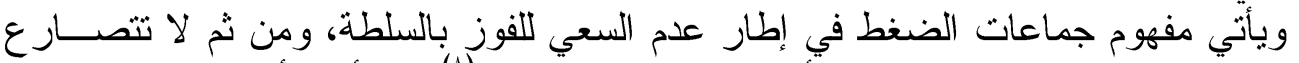

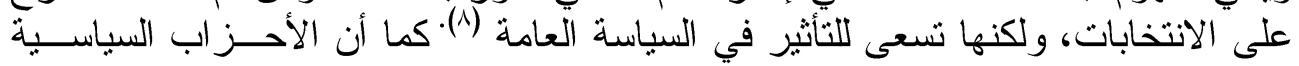

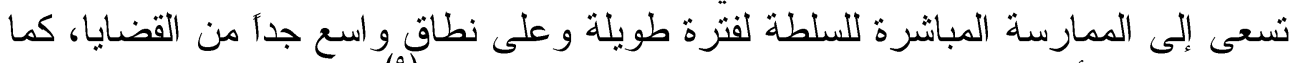

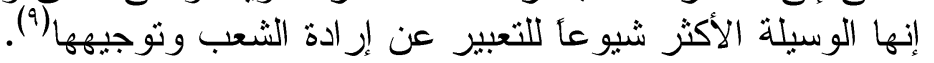

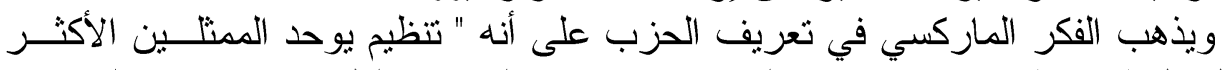

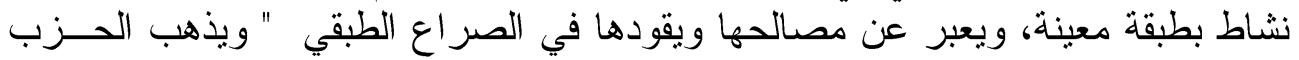

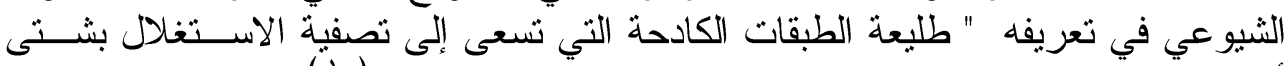

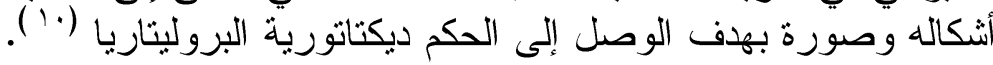

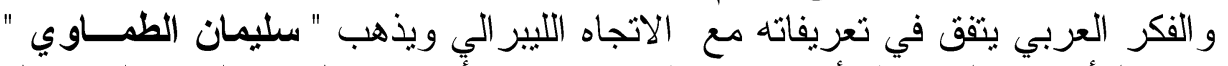

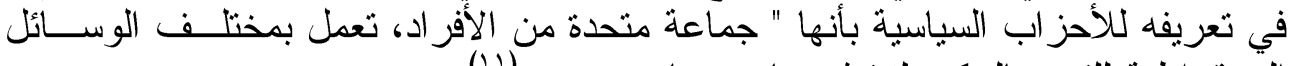

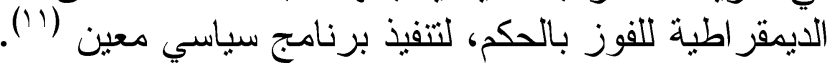

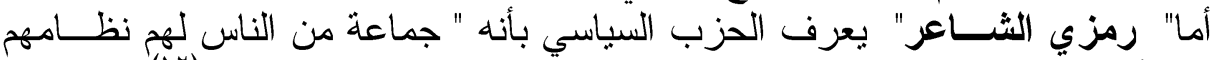

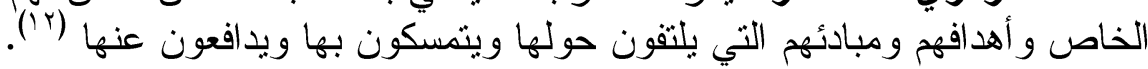

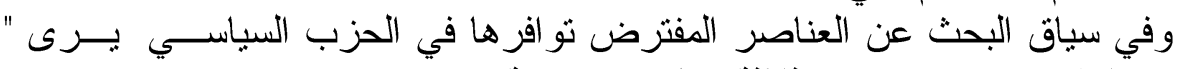

انطونيو جر امشي ضرورة وجود ثلاثة عناصر رئيسية:

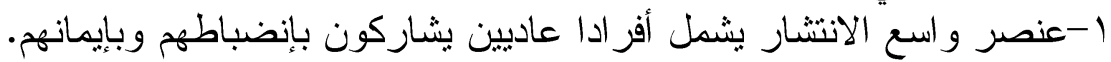

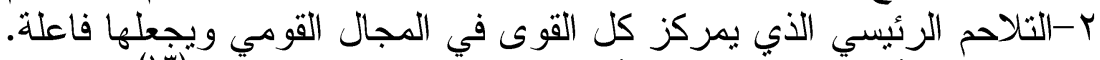

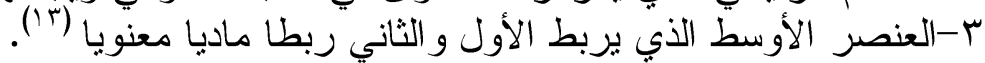

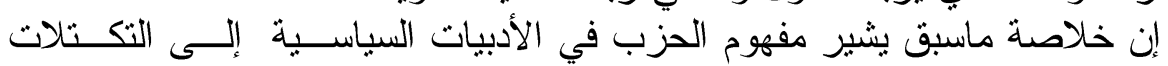

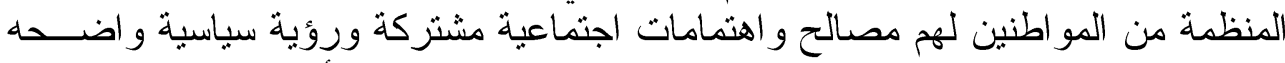

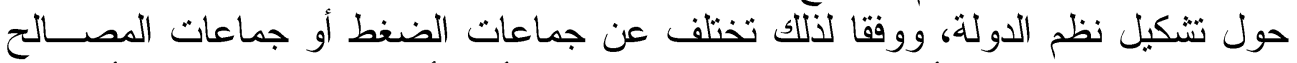

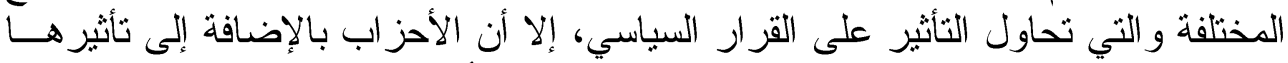

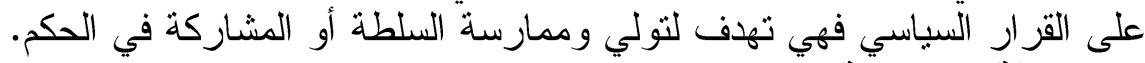

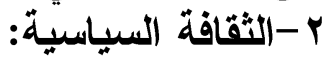

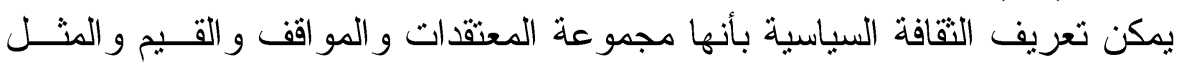

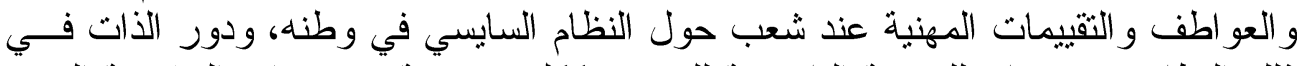

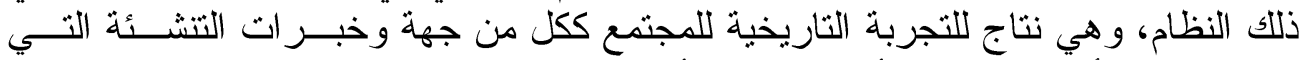

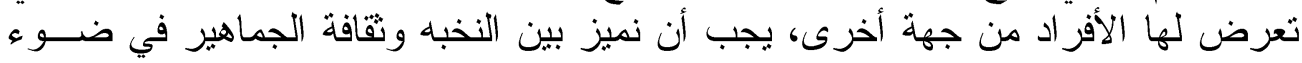




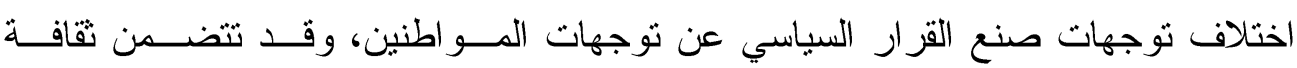

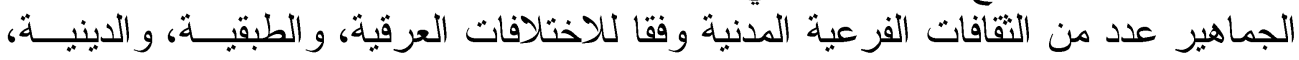

وقد عرض " لاري دايمون " تصنيفا لعناصر النقافة السياسية كما يلي :

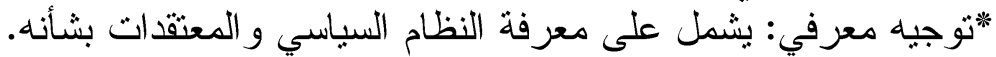

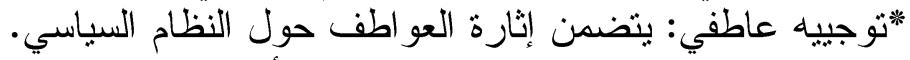

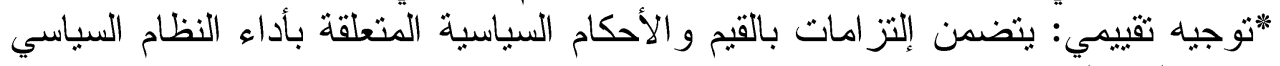

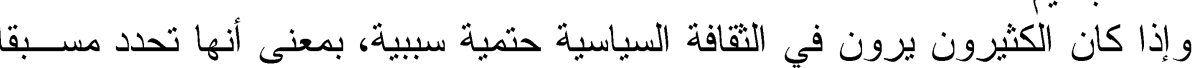
ومدى صلته بالقير.

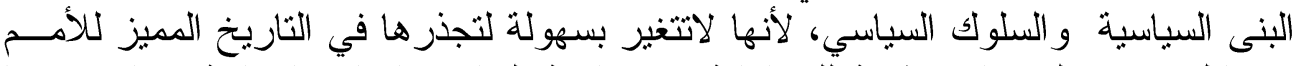

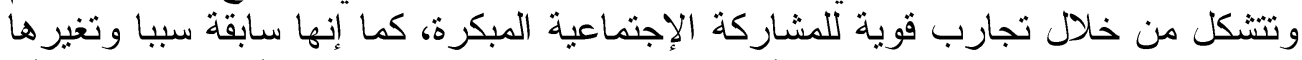

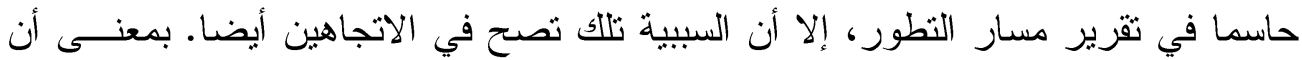

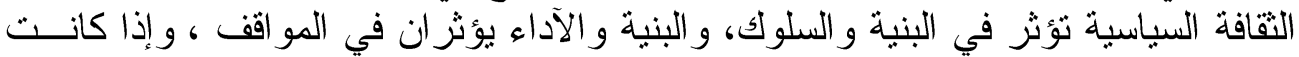

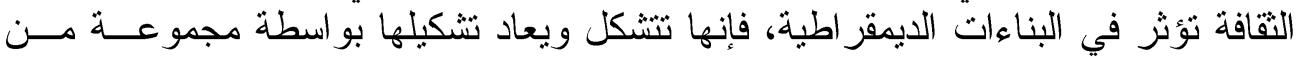

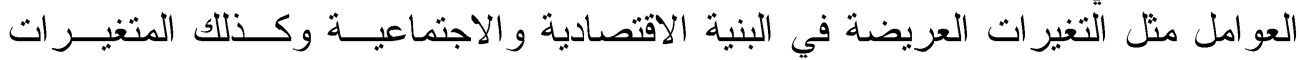

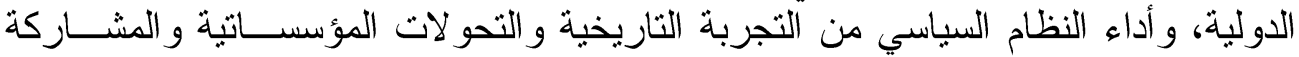
السياسية.

مانود التأكبد عليه هنا، أنه لايجب أن تجعلنا الرؤى السابقة نقـــول بــأن الثقافـــة

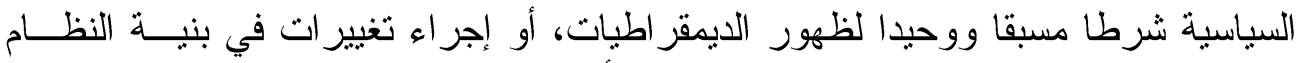

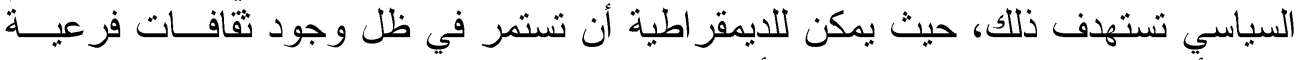

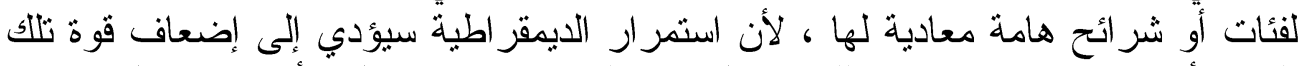

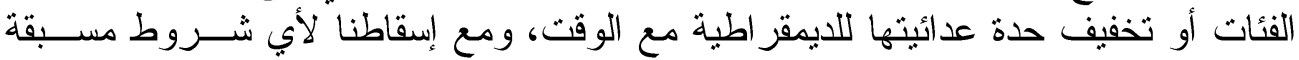

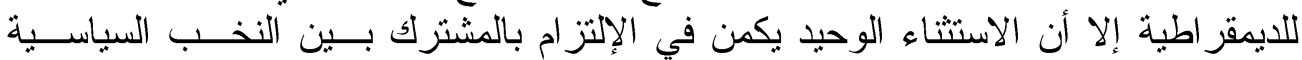

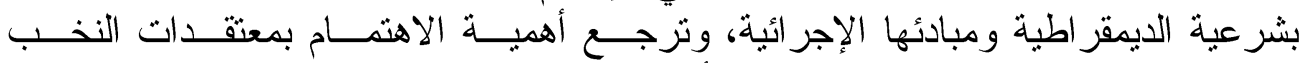

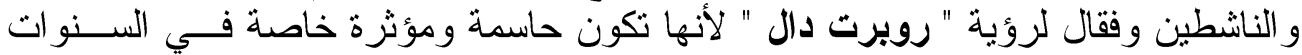

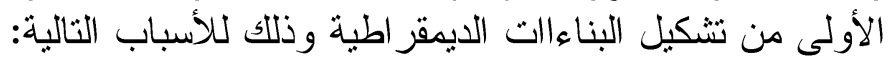

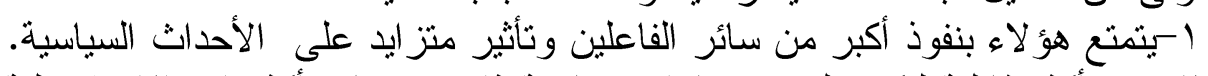

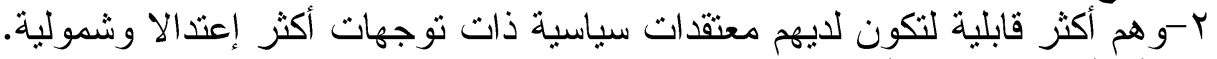

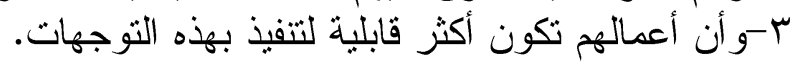

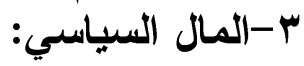

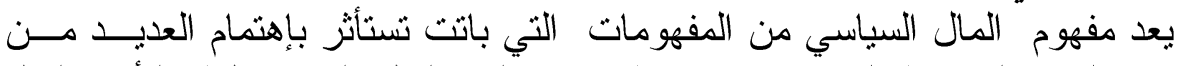

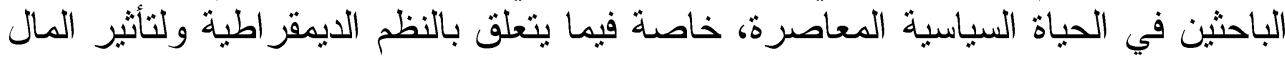

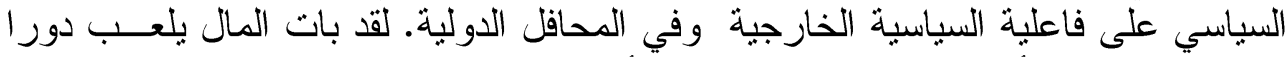

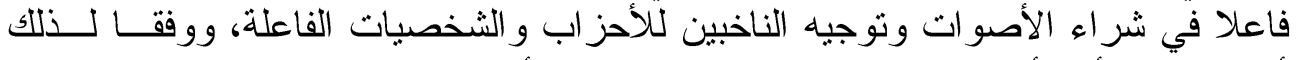

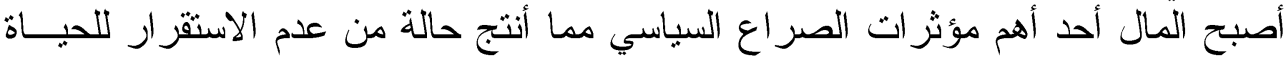

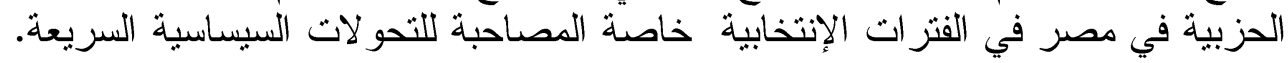

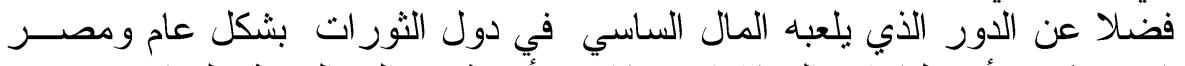

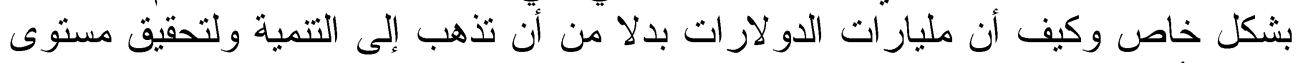
معيشة أفضل لقطاعات واسعه من المجتمعات العربية، تذهب إلى تدمير الاستثرار سياسيا 


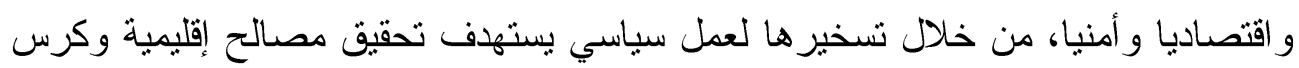
العنف المجنمعي.

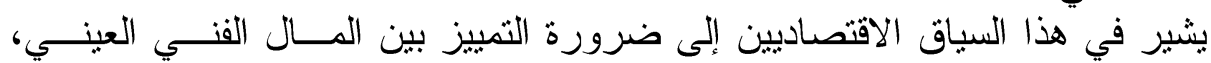

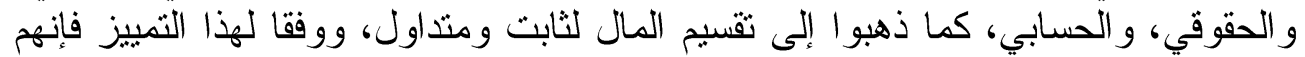

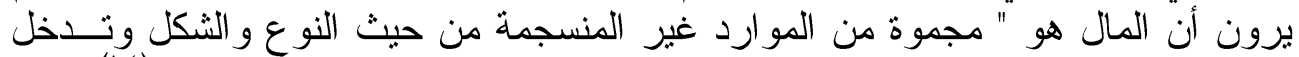

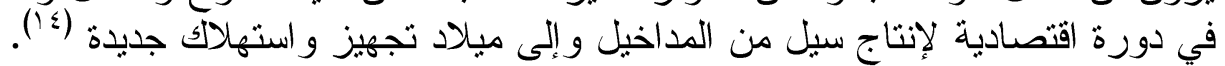

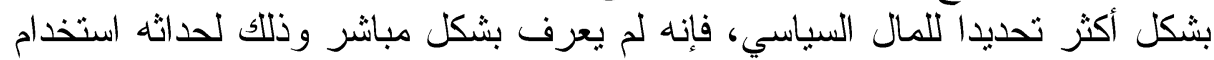

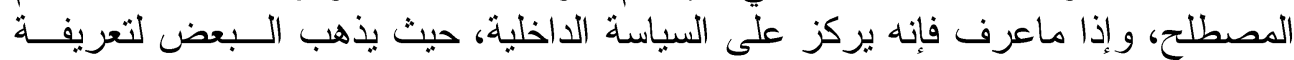

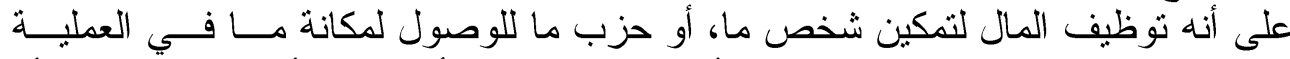

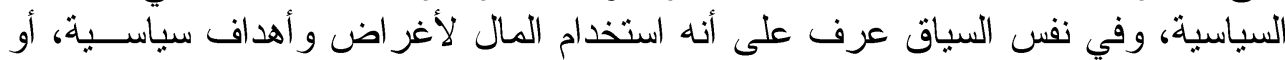

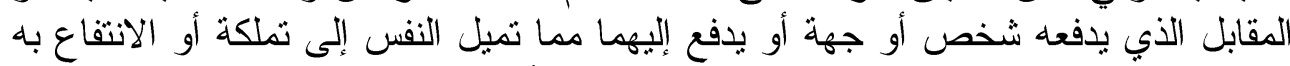

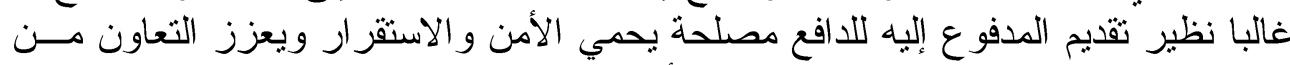

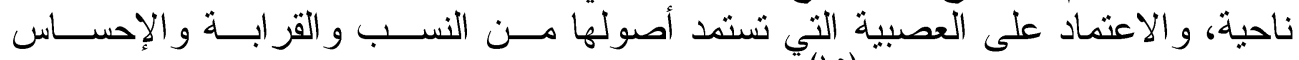

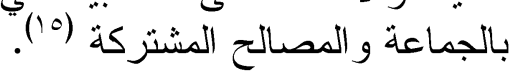

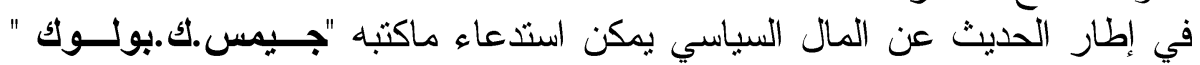

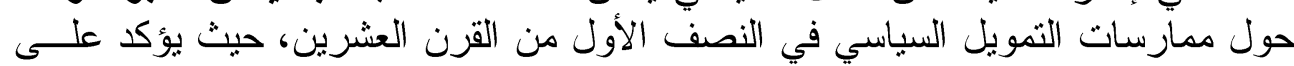

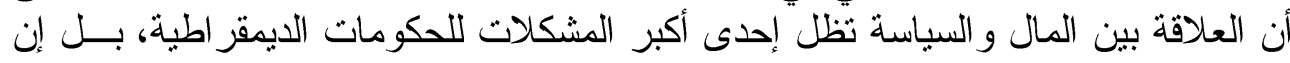

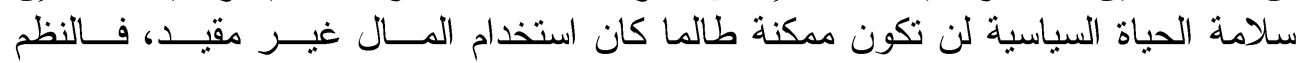

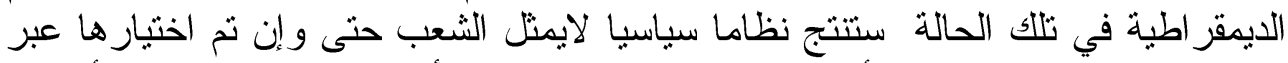

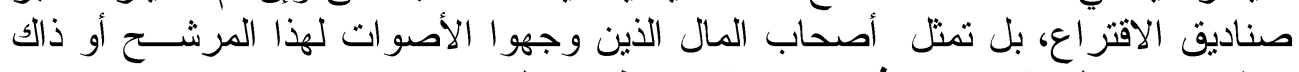

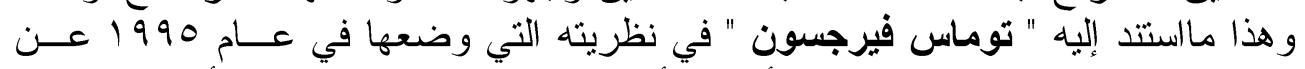

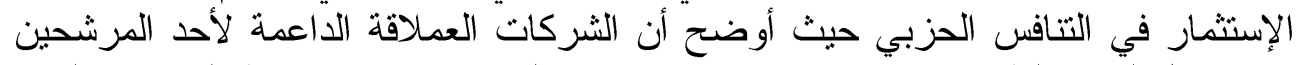

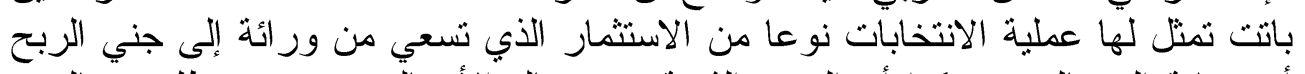

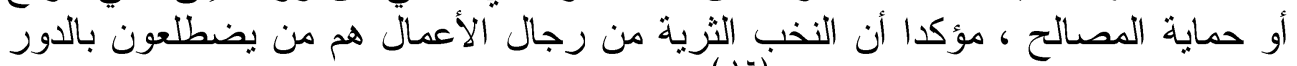

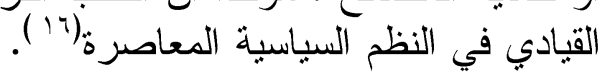

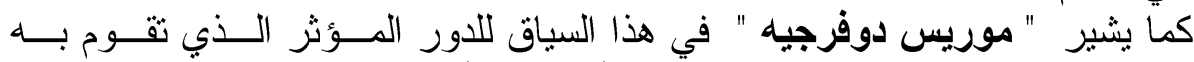

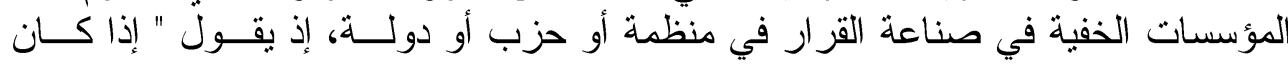

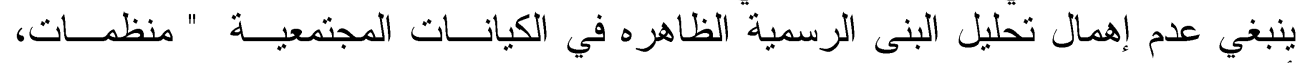

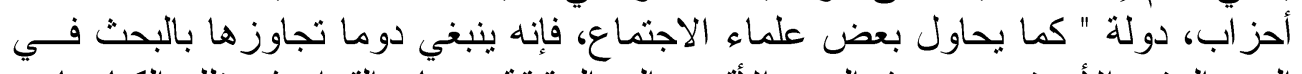

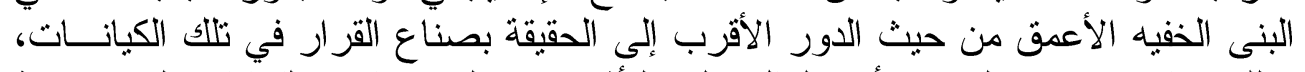

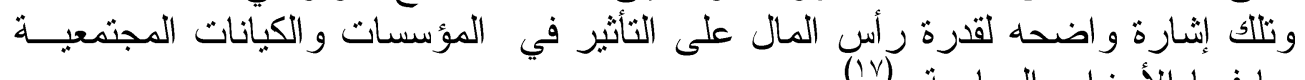

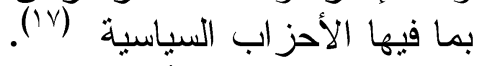

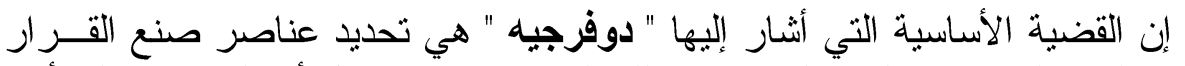

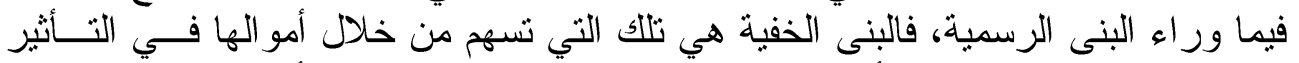

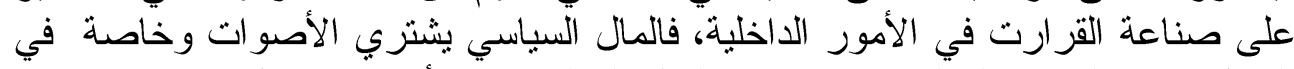

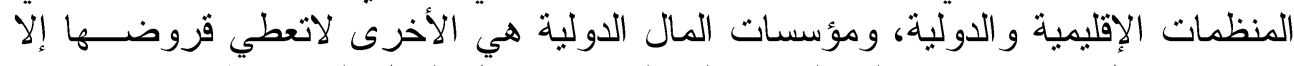

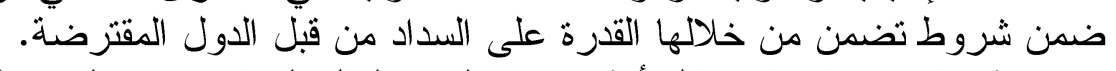

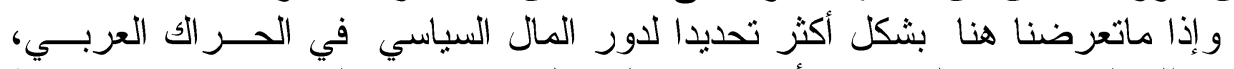

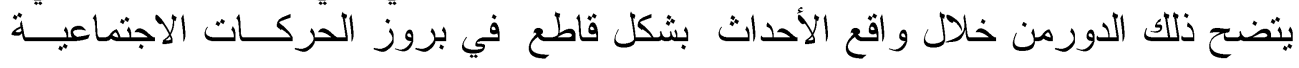


الاحتجاجية على الساحة العربية بشكل جلي، فالحديث عن مدى تلقائية موجـــة الأحسـداث

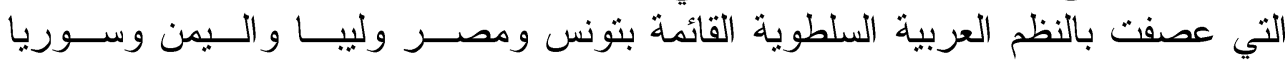

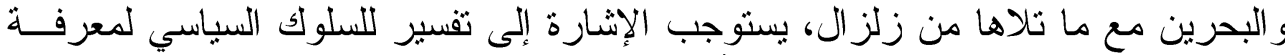

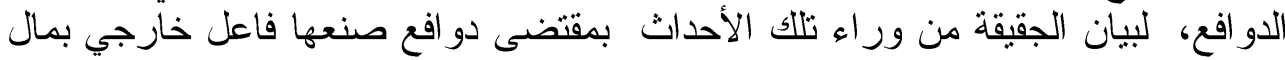

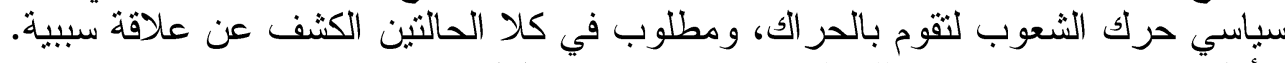
الأول: يستبعد من قاموس تلأك الحركات تعبير " مخططات خارجية حتى و إن كانت حقيقة

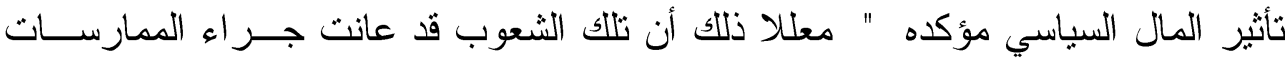

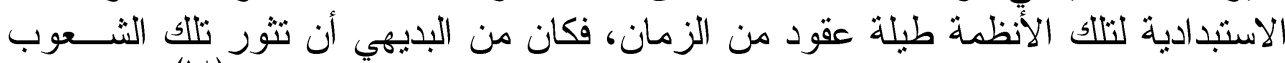

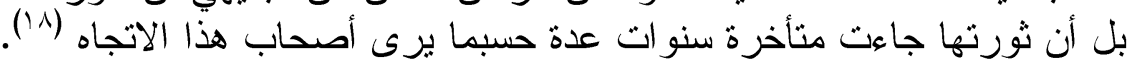

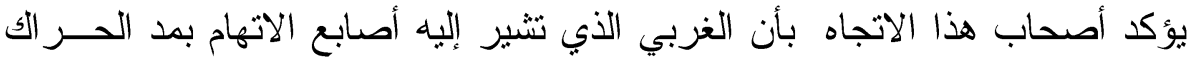

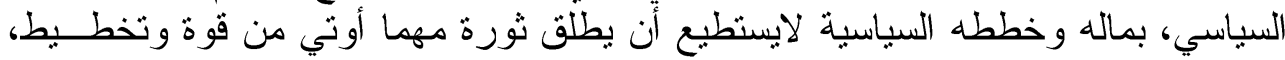

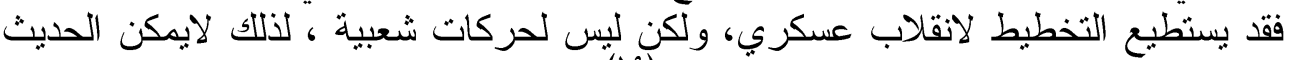

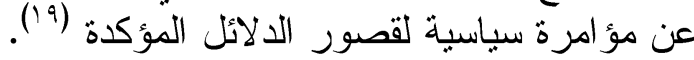

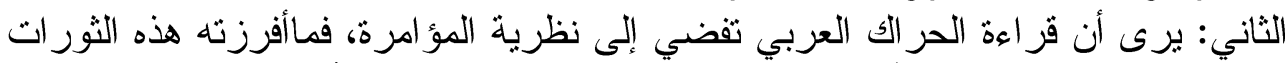

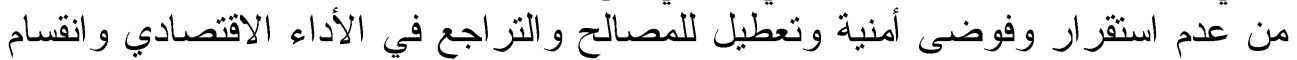

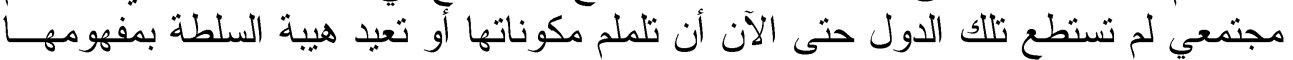

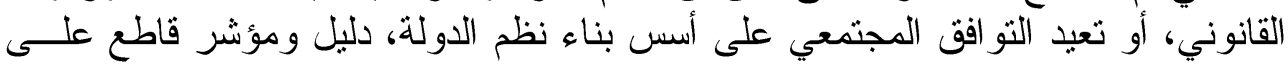

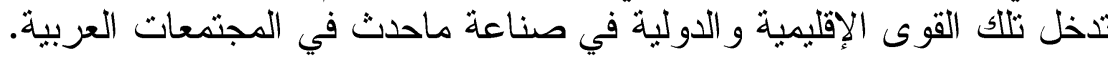

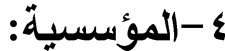

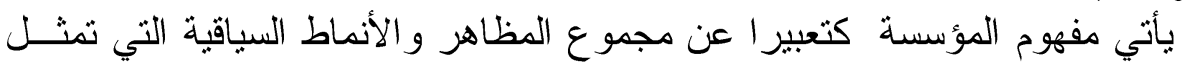

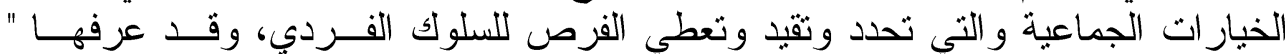

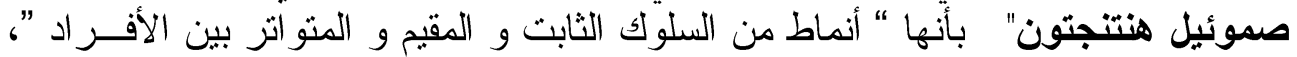

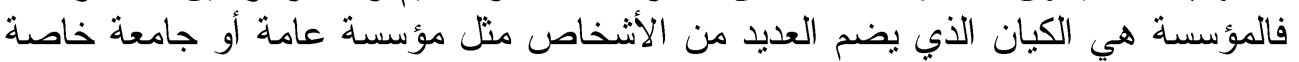

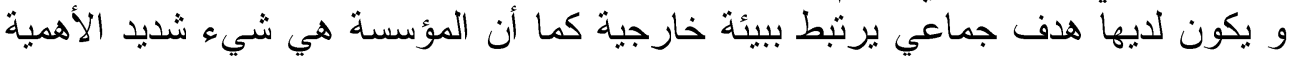

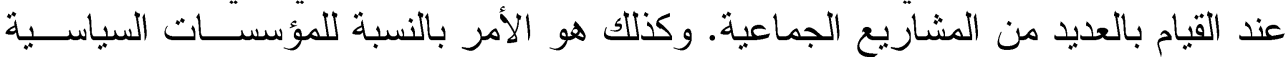

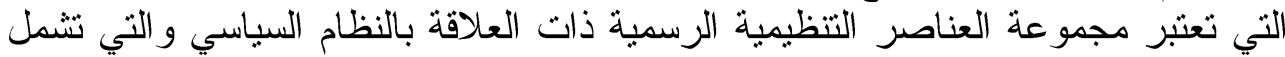

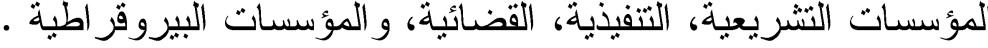

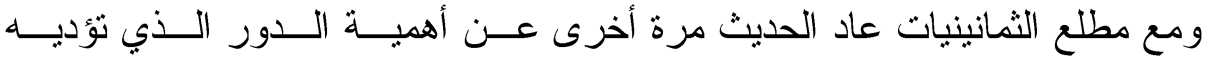

المؤسسات في تقسير الظو اهز السياسية وهو ما تمثل في ظهور " المؤسسية الجديــدة " "

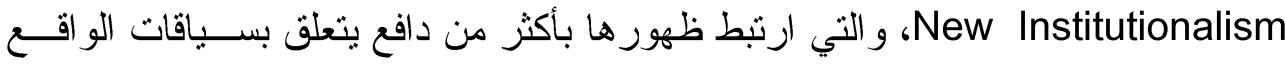
و التي تمثلت في:

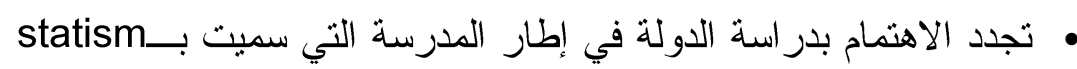

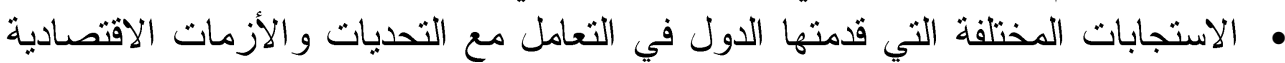
خلال السبعينيات و الثمانيات من القرن الماضي، و التي لعبت المؤسسات دورًا كبيرًا فيها.

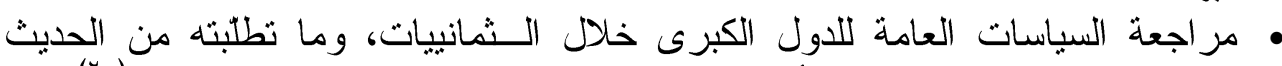

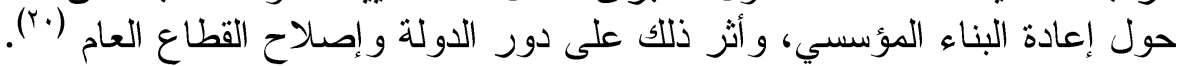


أما مفهوم المؤسسة كما يذهب "هارت فيل Hartfiel" فيعنى " أى منظمة أو هيئة Oranisation محددة لمسار وطريقة العمل ونوزيع الوظائف على المشاركين فى العمل بتحقيق وظيفة

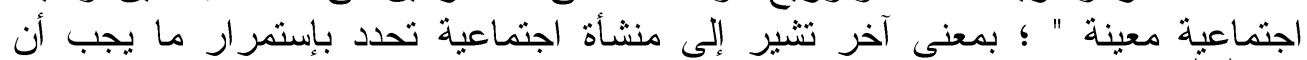

" Institution ist eine soziale Einrichtung, die auf dauer bestimmt, was getan werden muss.

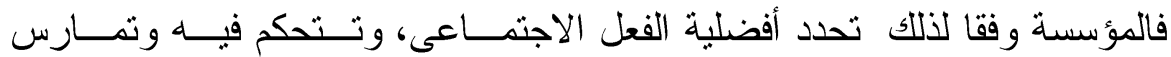

بالضرورة تأثير معيارى Normativ wirkung ، وبذلك تؤدى وظيفتين رئيستين، أولهما

للناس (أعضاء المجنمع) و التى أنشأت من أجل حاجاتهم الطبيعيــة، Bedurfnisnatur

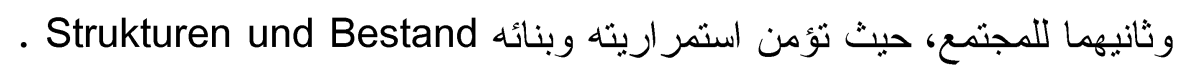

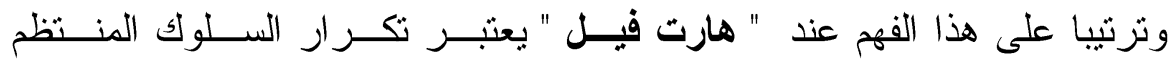
Wiederkehrende Regelmassigkeiten

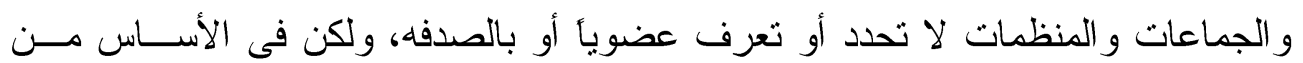

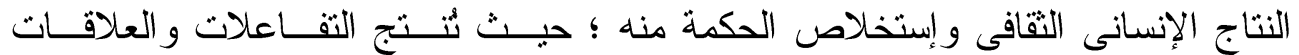

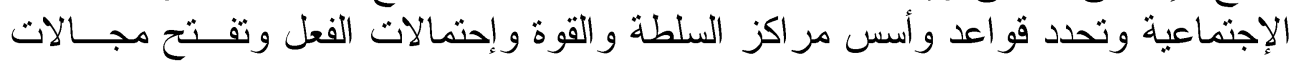
وفرص حرية الأفر اد بصفة عاعة وأنة

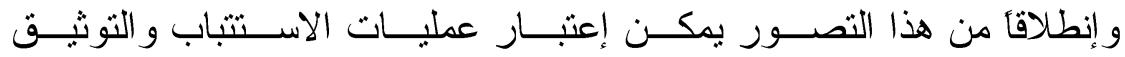

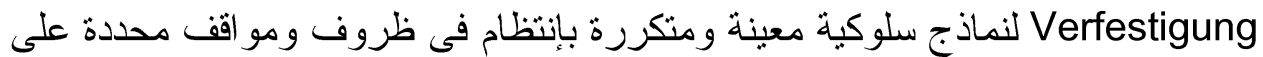

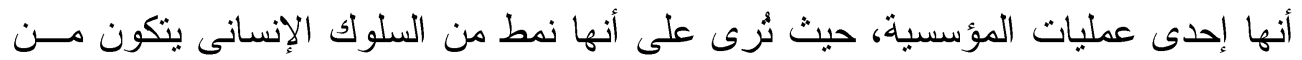

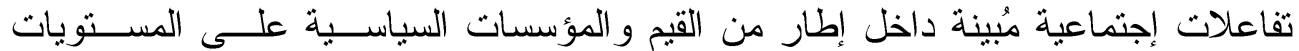

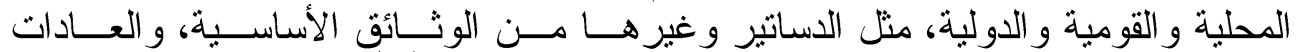

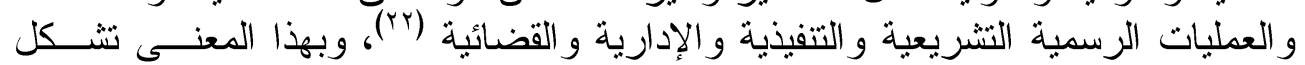

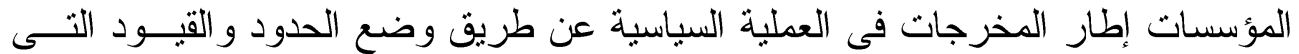

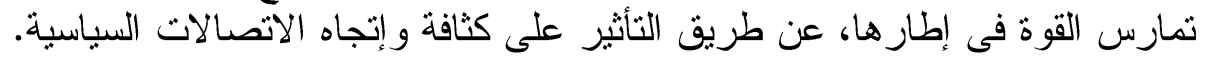

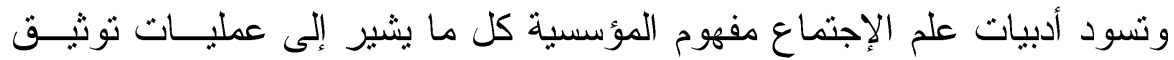
و إستقر ار السلطة السياسية عن طريق البناء البيروقر اطى، وكذلك إقامسـة نظــام منكامـلـل

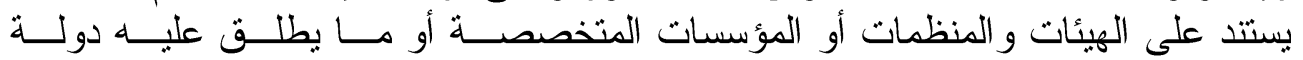
المؤسسات وسيادة القانون.

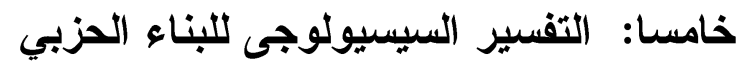

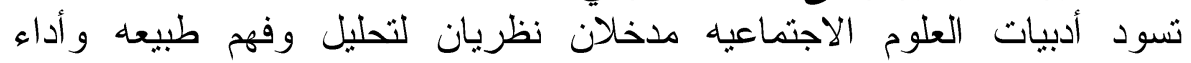

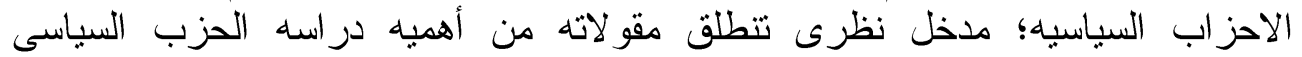

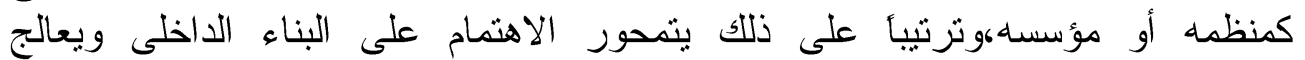

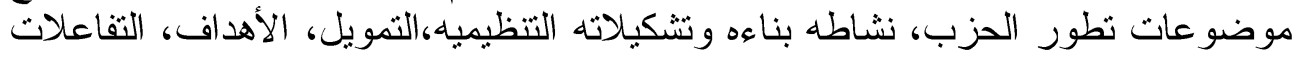

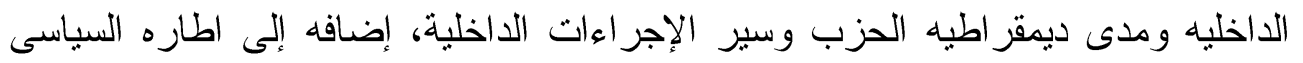


و الاجنماعى. فى مقابل ذللك بركز المدخل النظرى الثانى على إعتبار الحزب مشاركي نشط فى عمليه التنافس الحزبى Aktiv Teilnehmer، ووفقأ لذلك يكون محور تركيزه على تحليل العلاقه التقاعليه ببن الأحزاب في ضو ضوء السياق العام للنظام السياسى للاولة.

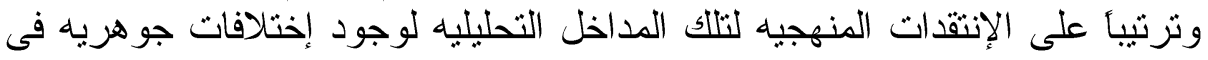

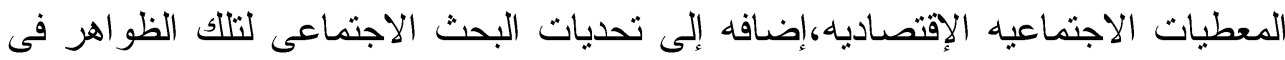

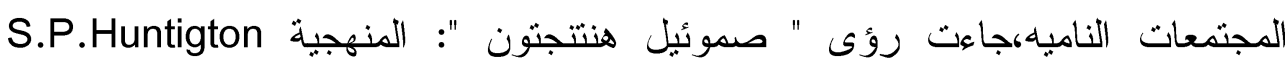

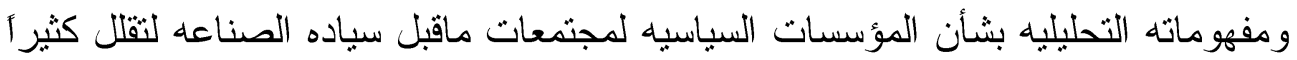

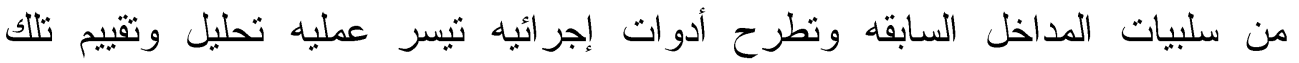

$$
\text { المؤسسات الحزبية. }
$$

و على الرغم من أن "هنتجتون" أغفل العو امل الاجتماعية و الاقتصادية وكذا الأبعاد

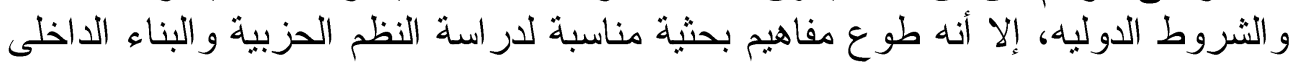

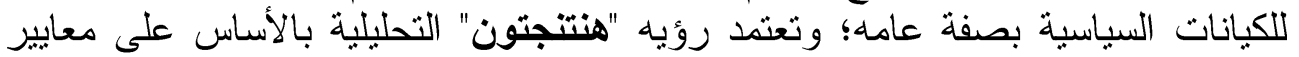

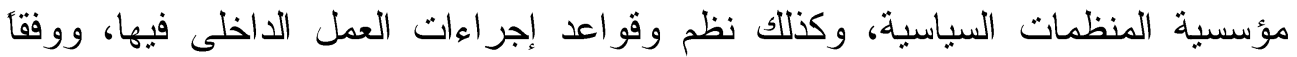
لذلك يمكن تحليل أو دراسه مستوى مؤسسية الحزب أو أو المنظمه في ضوى ضوء إنجاز اتها

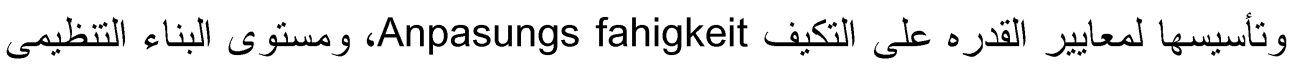

الداخلى Komplexitat und Verflechtung in der innestrukturK و الاستقلالية Autonomie der Partein Partein Koharenz ؛ ووفقا لذلك لا تعتبر الأحزاب أو المؤسسات التى تعتمد على التى

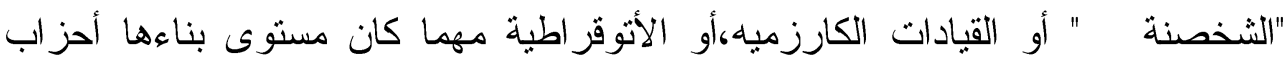
تتمتع بسمة المؤسسية ؛ حيث يذهب إلى أن الإنهيار السياسي سيكون نتيجة حتمية لأنى

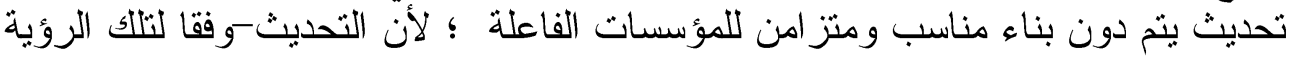

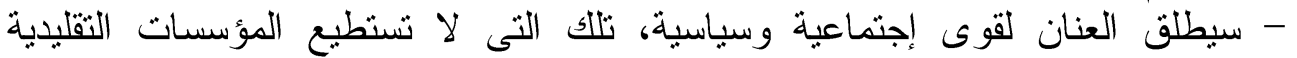
حجزها و السيطرة عليها، و عليه لا بمكن تجنب الانهيار السياسي المؤكد.

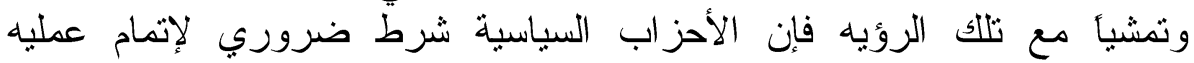

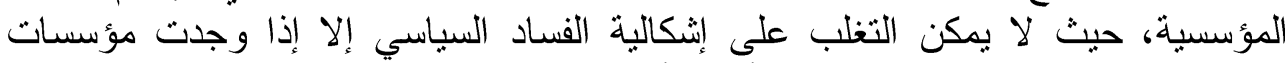

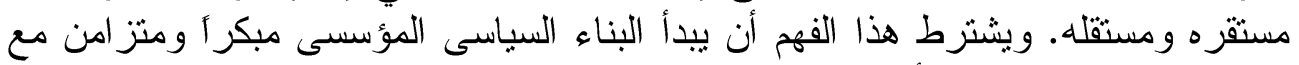

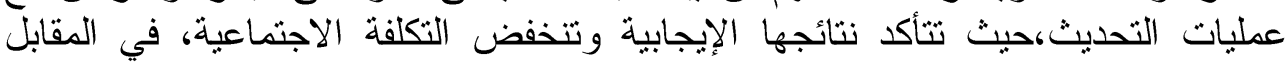

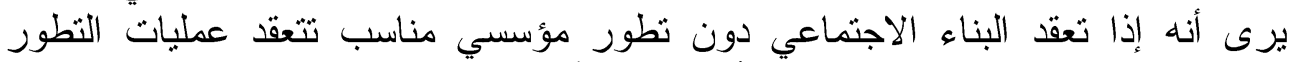

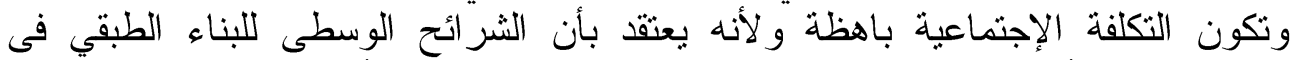

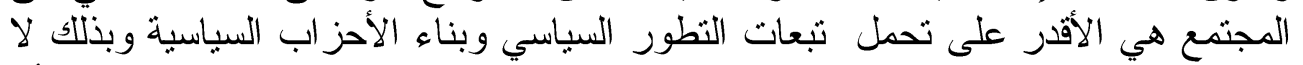

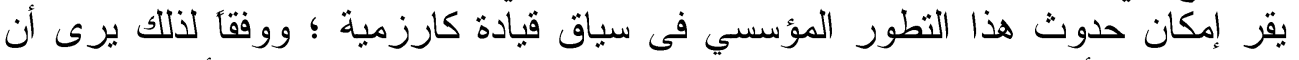

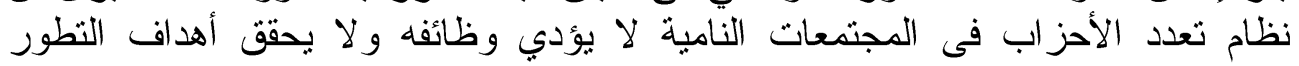
و التحديث السياسي بسبب الضعف الضئ المؤسسي.

فيى السياق ذاته يؤكد بسام طيبى" Bassam Tibi " على أهمية المحددات

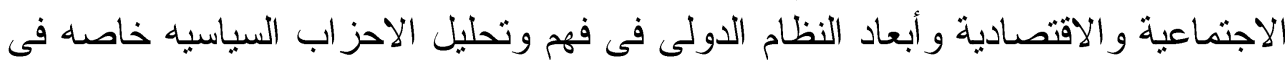

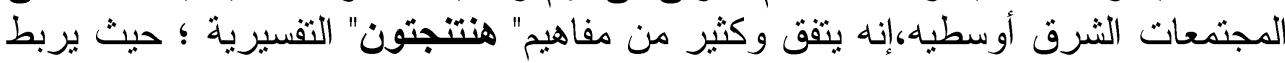

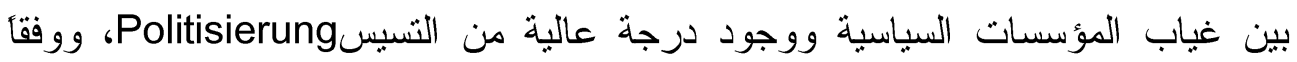


لتلك الرؤيه فإن غياب المؤسسات الحزبية النشطة والفاعلة سوف تشتت مصدر القوة السياسية وستجعل السلطه آلية مثتاقلة Transitorisch بما بعنى سهولة الحصول عليها

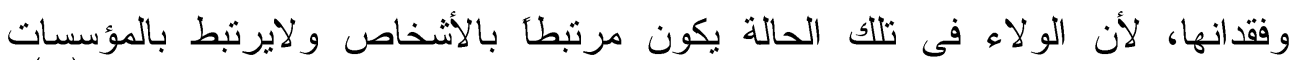

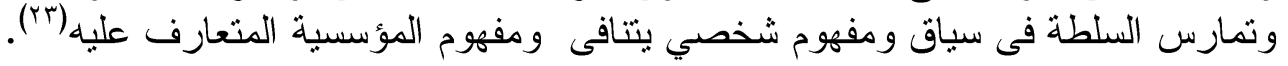

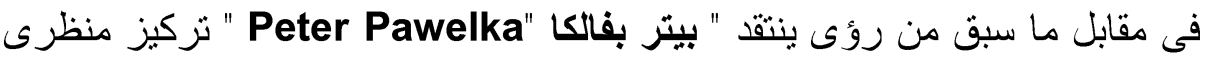

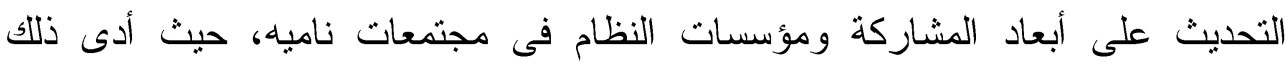

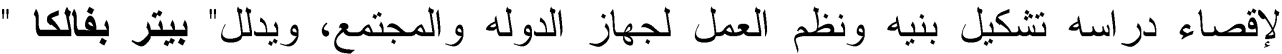

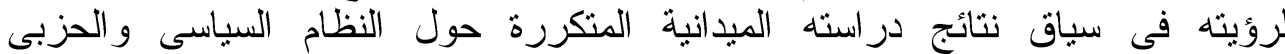

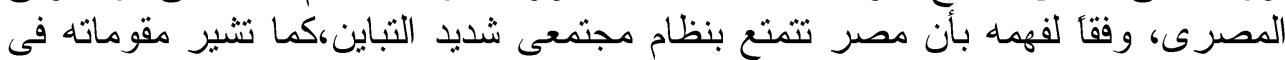

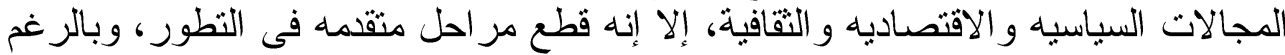

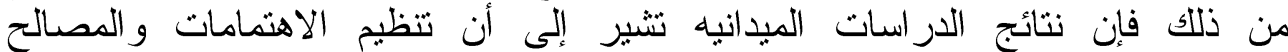

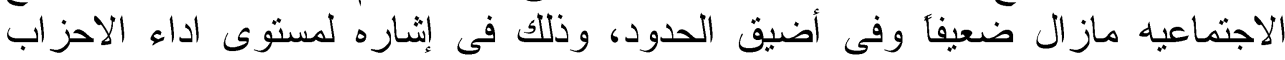
السباسيه لوظائفها.

فى سياق رافض وناقد لمجمل الرؤى النظرية المفسرة للظاهرة الحزبية سو اء فى

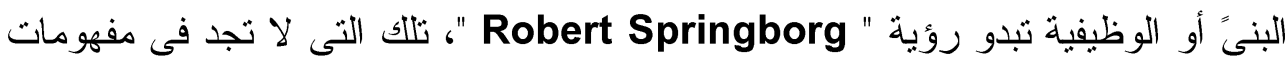

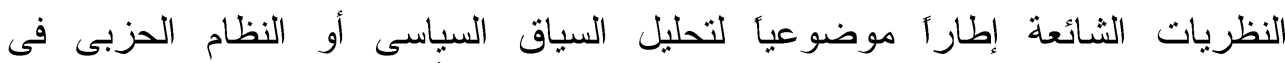

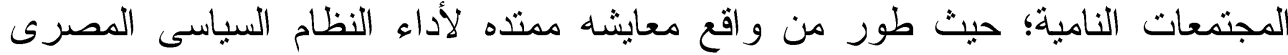

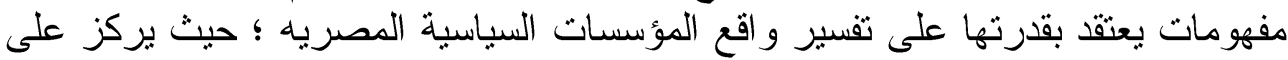

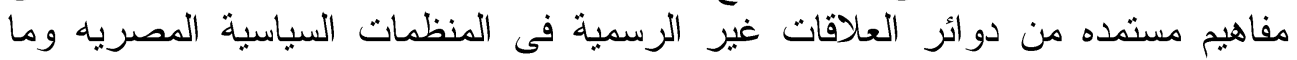

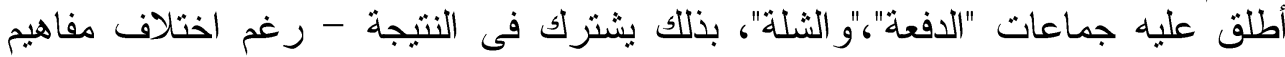
التحليل- مع فريدمان بيتنر" Friedman Buttner " الذى يذهب إلى عدم إستقرار المؤسسات السياسية فى مصر بائه بالرغم من وجود نظام سياسى شبه مستقر لحقبه زمنيه

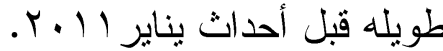
ترنياً على ماسبق من مقولات ورؤى نظرية ومنهجية لتحليل واقع وطبيعة

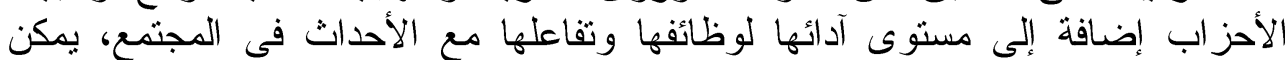

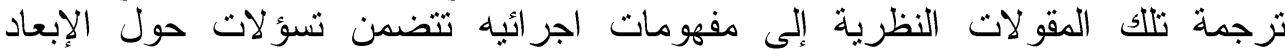

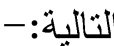

ا-القاعدة الاجتماعية للأحز اب Die Sozile Basis der Parteien dحاول هذا المعبار توضيح ملامح القاعده الاجتماعيه للحزب السياسى، أى صياغه حدود الطبيعه الاجنماعيه

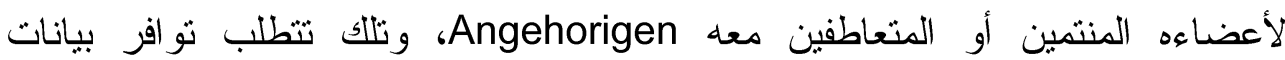

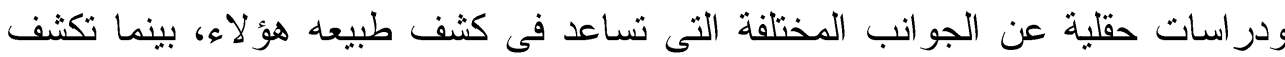

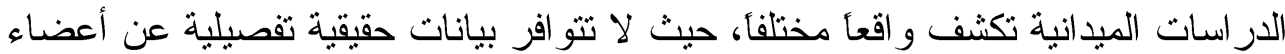

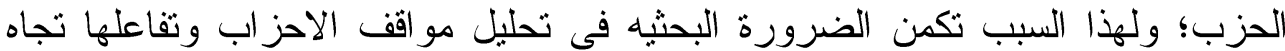

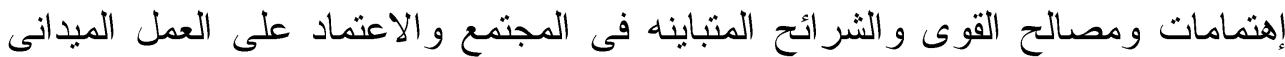

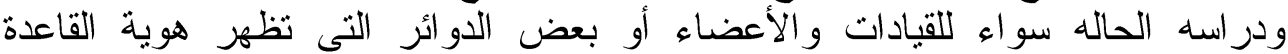

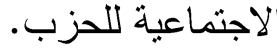




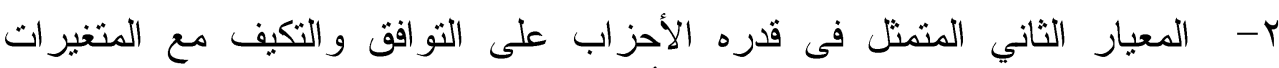

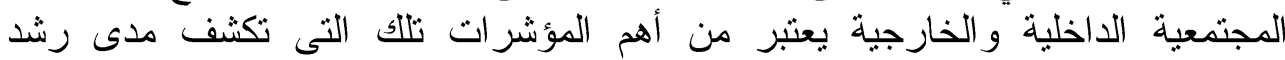
Rational

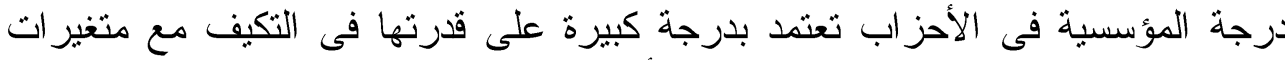

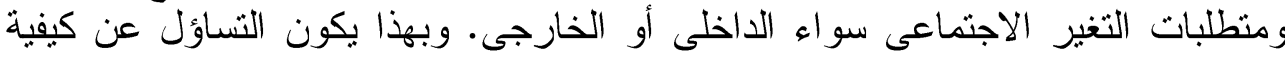

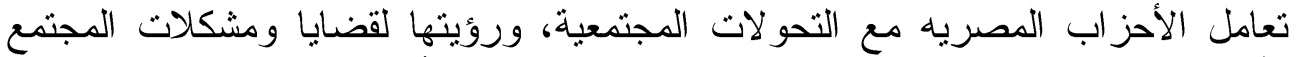

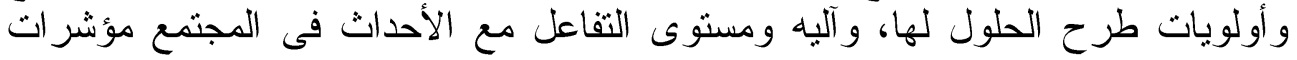

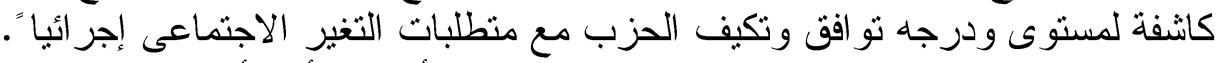

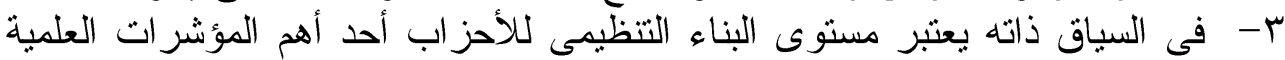

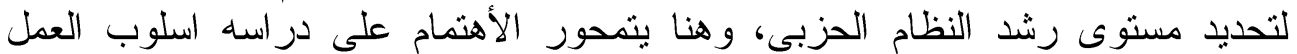

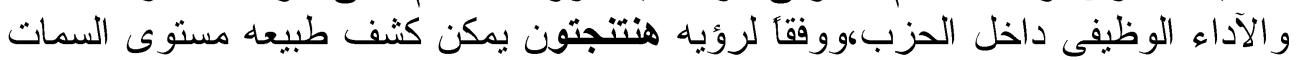
المعياريه تلك، حيث يذهب إلى أن ألى منظمه إما أن تكون بسيطه أحاديه أو تتكون من

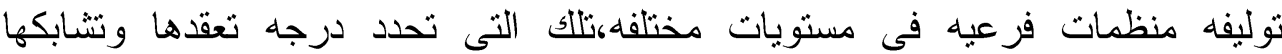
التنظيمى، وتزتبط طردياً بدرجه المؤسسيه فيها، وعليه ونيه يخرج من نطاق المؤسسيه

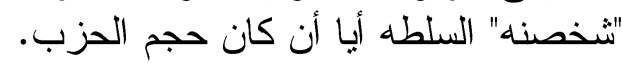

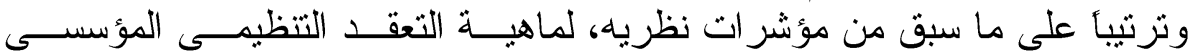

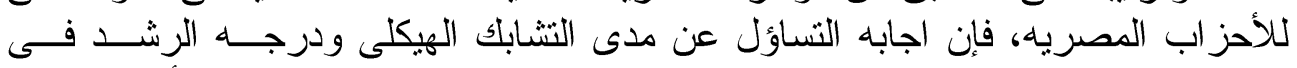

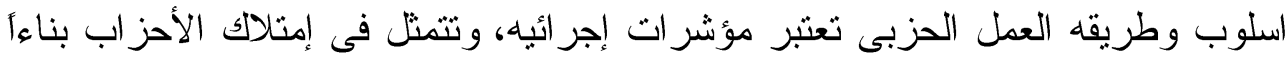

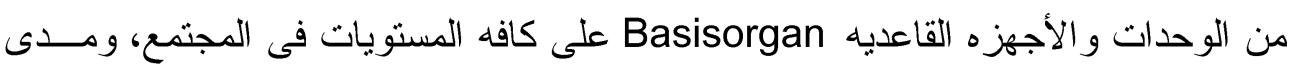

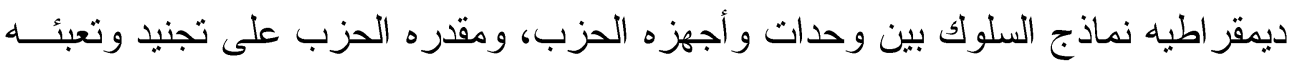
كو ادر مدربه جديده فاعله سياسيا.

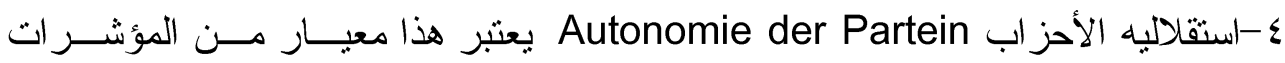

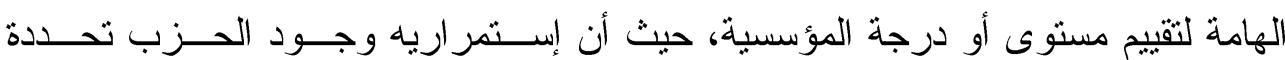

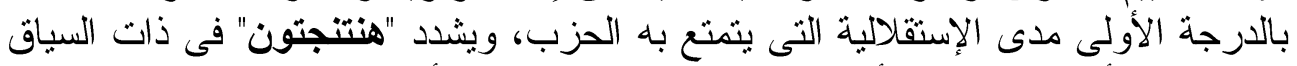

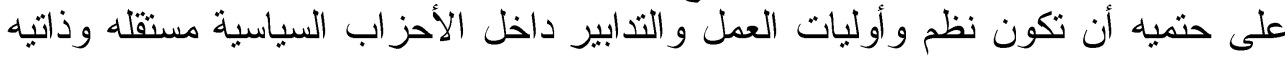

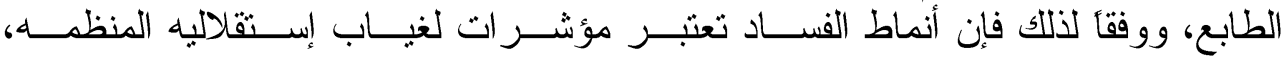

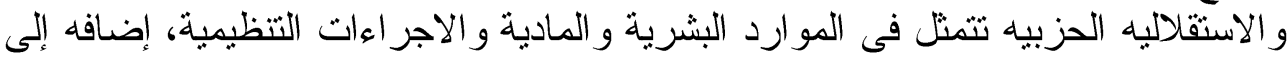

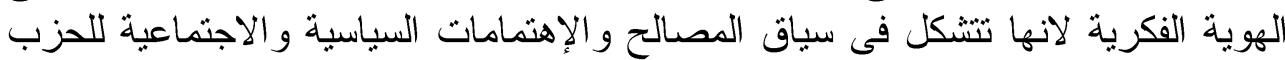

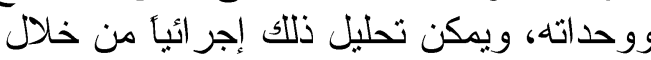

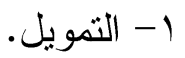

r- r- بعبئه وتجنيد أعضاء وقيادات وكو ادر حزبية.

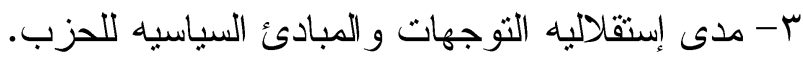
ع- طرح الرؤى للقضايا و المشكلات المجنمعبه و الحلول التوليه المناسبه لها. ه- التماسك "Parteien Koharenz" حيث أضحى مفهوم التماسك من المعايير الإجرائية الكاشفة لطبيعة البناء الحزبي، فهو دلالة القدرة الحزبية على تخطى الأزمات إطلار "Konfliktfahigkeit" إطار الثقافه السياسيه وحدود وطبيعه التعدديه و النظام الحزبى؛ و نوضيحأ لمعنى المفهوم يشير "هارت فيل" "Hart Fiel" بأنه رابطه الأعضاء النفسيه و الإجتماعيه الطوعيه وطيه وطيه وطيه 
(الإختياريه) التى ثربطه بالجماعه أو المنظمه الإجتماعيه بروابط ثابته وثثيقه الصله

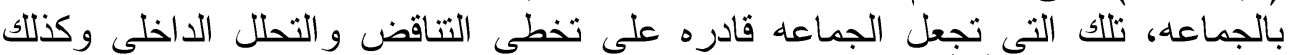

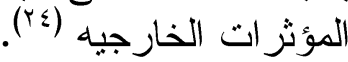
وفقأ لذلك ينشأ الإختلاف و الإنقسام الإجنماعى من وجود الإهنمامات و المصالح

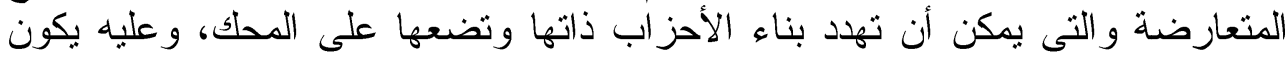

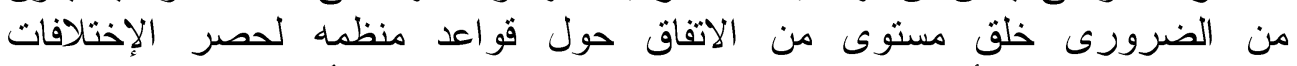
و الإنقسامات لحدها الأدنى ؛ وهذا ما جعل "هينتجنتون" يشدد على الأنى أن التماسك يمثل القدره

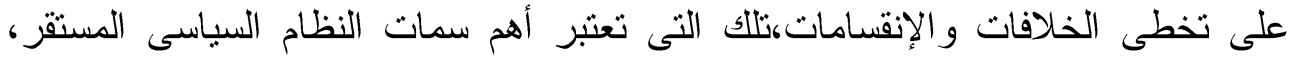

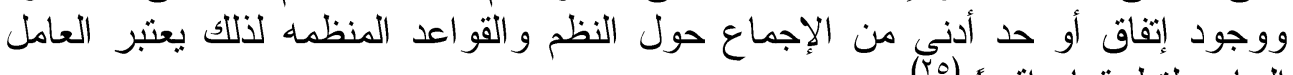

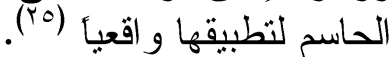

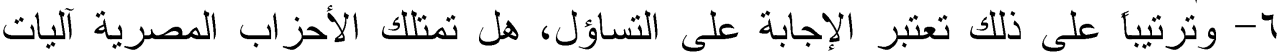

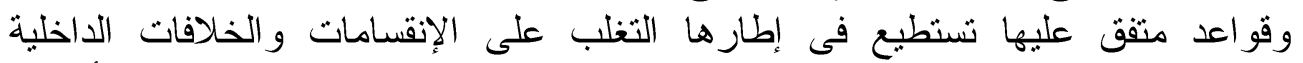

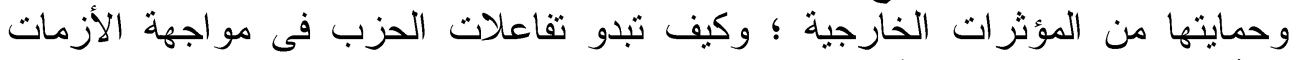

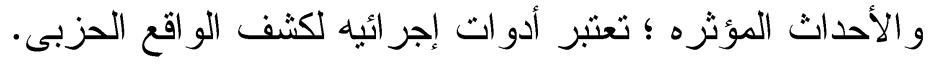

Politische Dialogs معيار قدره الحزب على الحوار وبناء التحالفات السياسية التعزية.

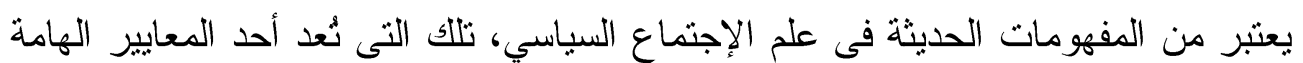

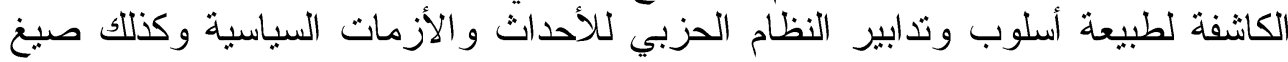

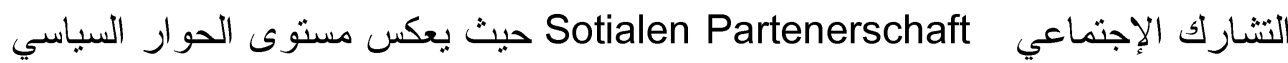
بين الأحزاب المتنافسة وبين القوى الإجنماعية مستوى آخر من رشد الإند النظام الحزبي

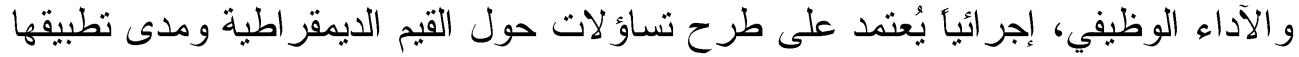

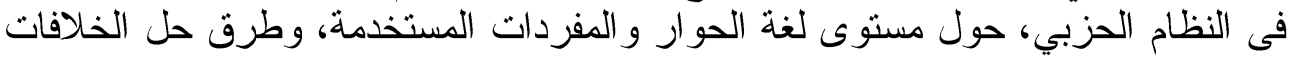

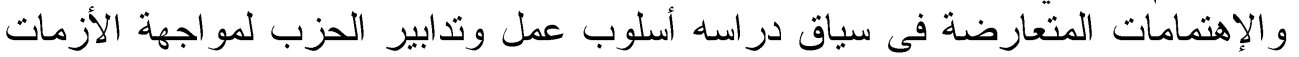
و الأحداث وصياغه التحالفات.

و هناك عدة اتجاهات نظرية تقسر ظهور ونشأة الأحزاب السياسية ومدى قدرتها

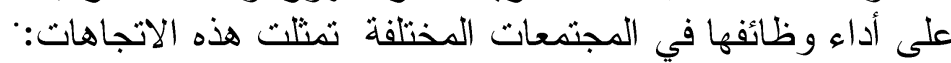
1-النظرية المؤسسية:

تشير أدبيات العلوم الإجنماعية إلى أن المؤسسية في مجملها أنها أنماط من السلوك النوك

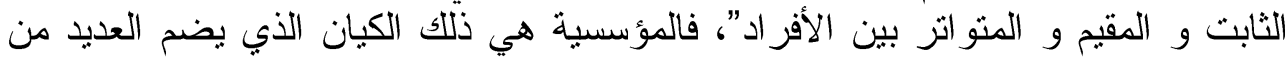

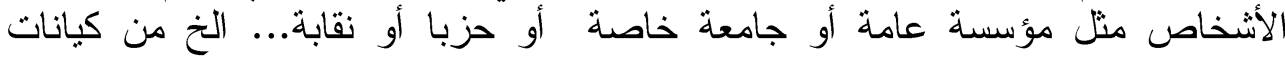

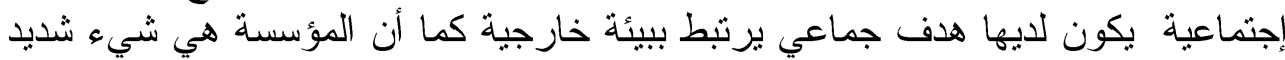

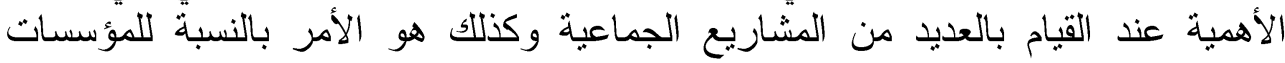

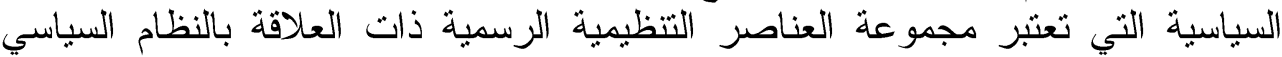

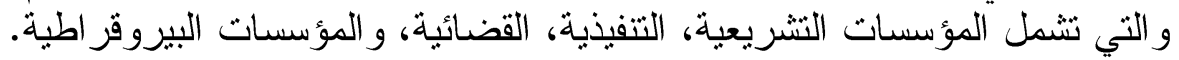

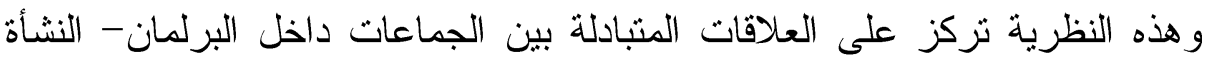

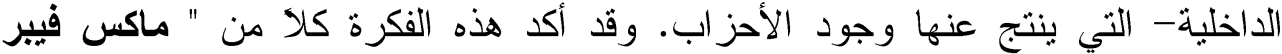

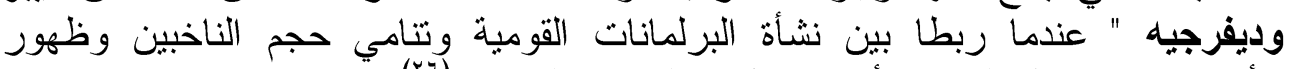

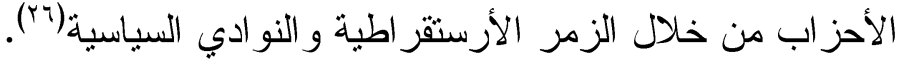




\begin{tabular}{|c|c|}
\hline ( عدد أكتوبر - ديسمبر اY · (Y) & حوليات آداب عين شمس - المجلد 9 ؟ \\
\hline
\end{tabular}

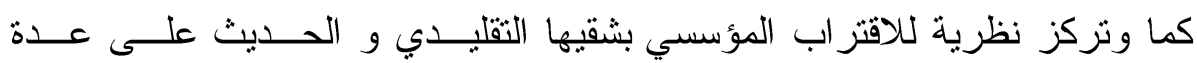
خصائص من بينها ما يلي: • تحليل الظاهرة السياسية بشكل عميق من مختلف الجوانب. • تصنيف معنى و وظائف المؤسسة. • • الاهتمام بالتحليل القيمي للمؤسسات.

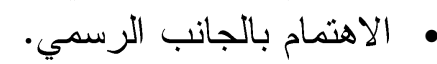

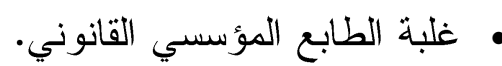
• الاهنمام بتطور المؤسسات عبر التاريخ. • اعتبار المؤسسة وحدة أساسية للتحليل. • القدرة على در اسة المؤسسة كوحدة واحدة أو مجز أة إلى عدة وحدات.

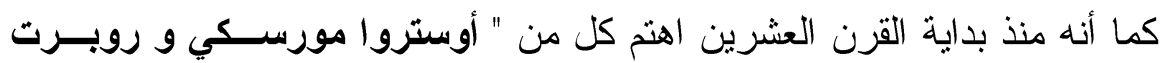

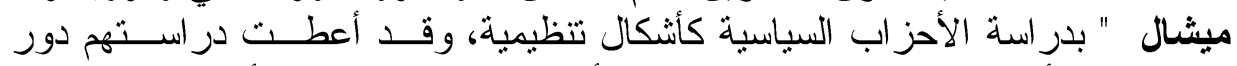

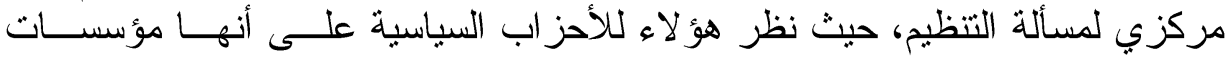

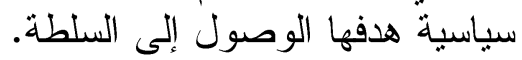
r-نظرية التبعية:

تركز نظرية التبعية على دور العوامل الخارجية في نشكيل الهياكل و التطورات

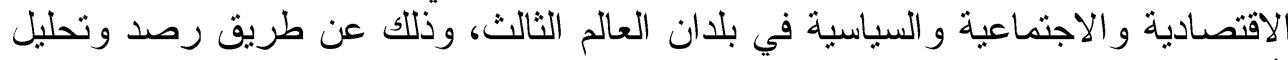

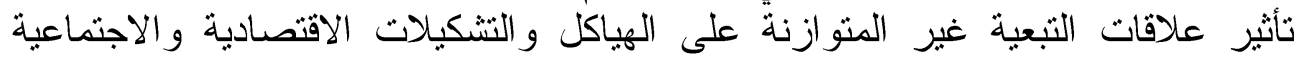

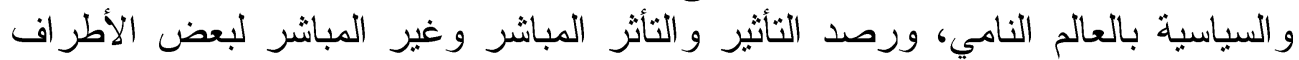

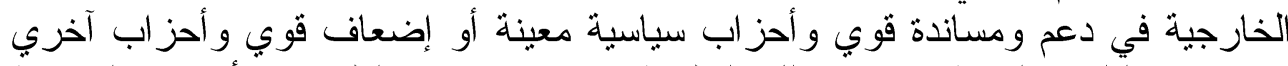

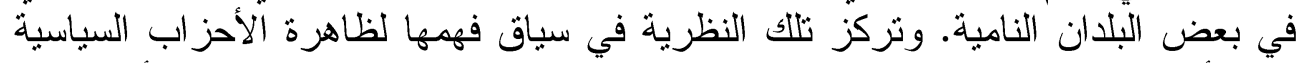

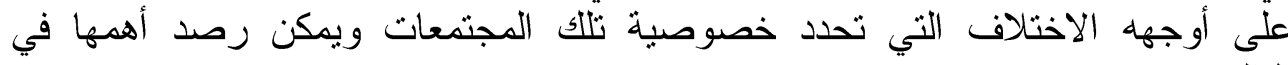
التالي:

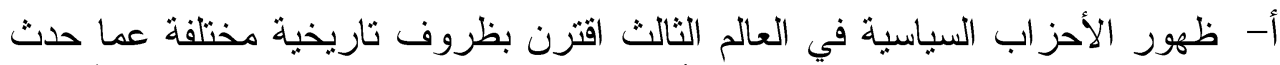

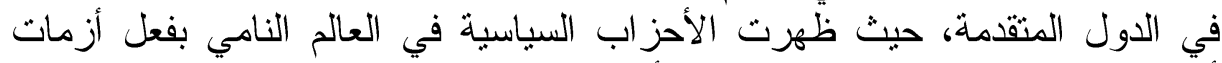

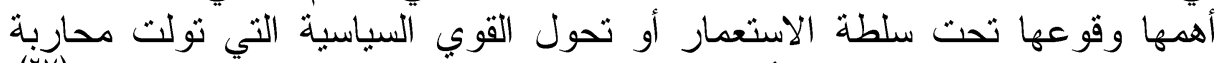

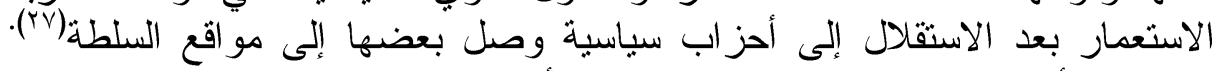

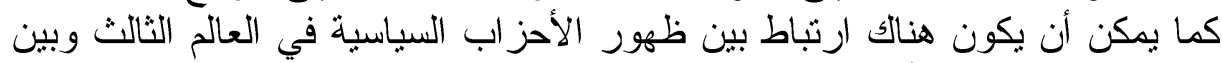

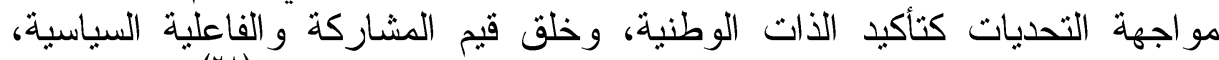

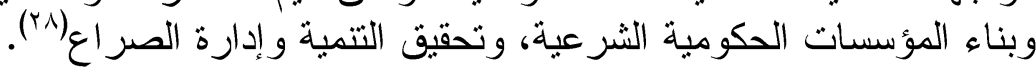

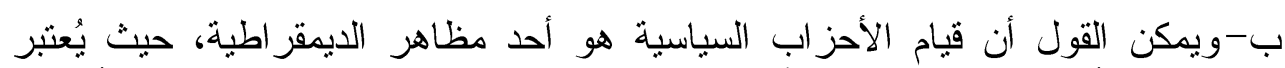

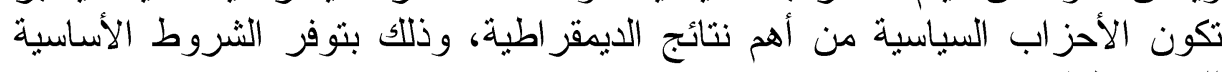
للايمقر اطية.

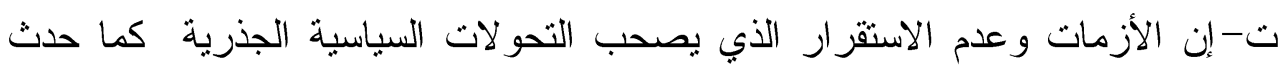

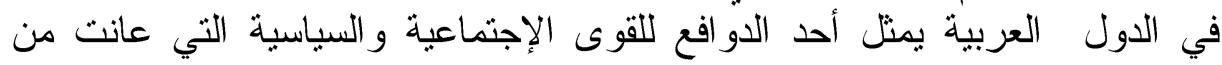


سبطرة نظم الحكم السلطوية لفترات طويلة لبناء وتأسبس كيانات و أحزاب سياسية، أملا في المشاركة في صناعة القرار أو احتكار السلطة.

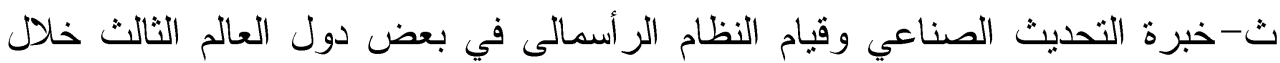

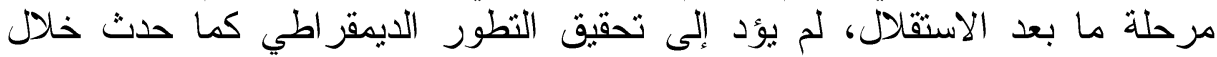

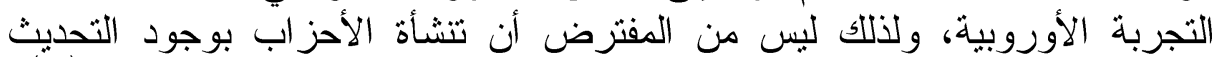

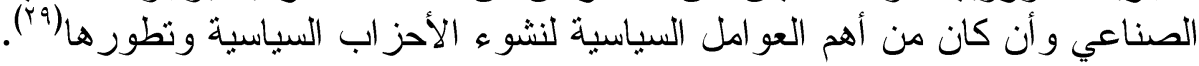

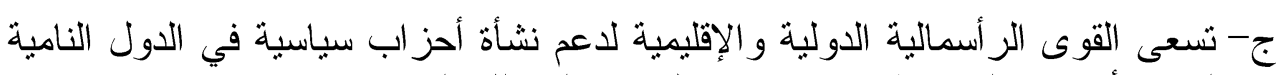

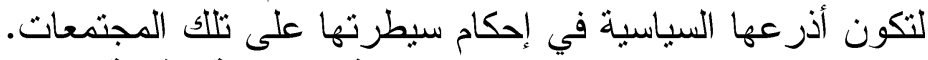

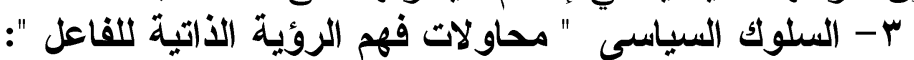

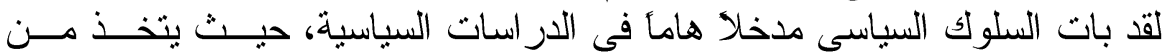

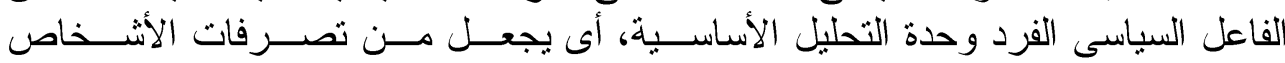

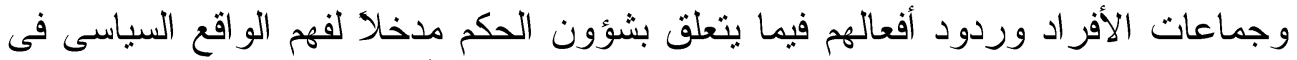

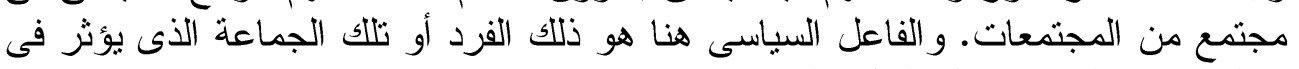
عملية صنع القر ار داخل النظام السياسى.

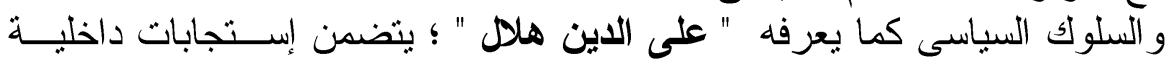

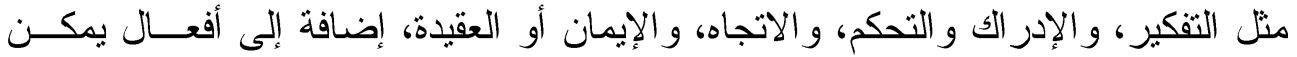

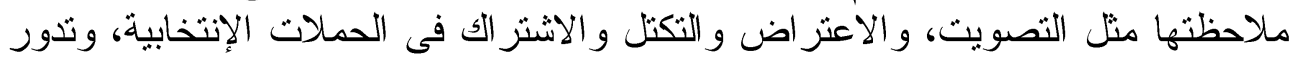

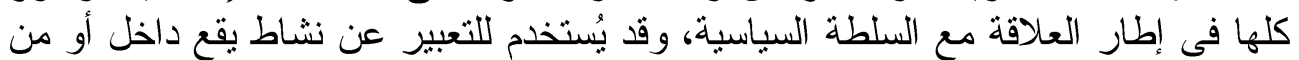

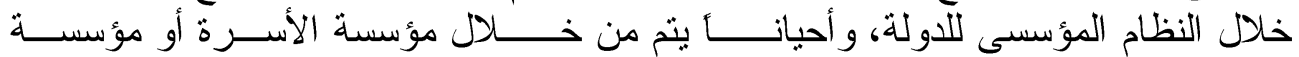

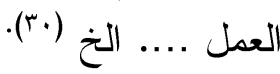

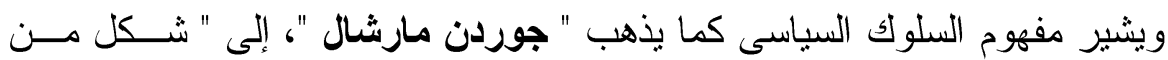
أشكال إنخر اط الفرد أو الجماعة في العملية السياسية "، أو أى نشاط يمكن أن تترتب عاليه

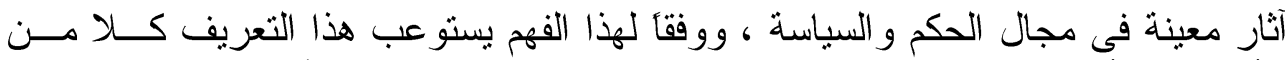

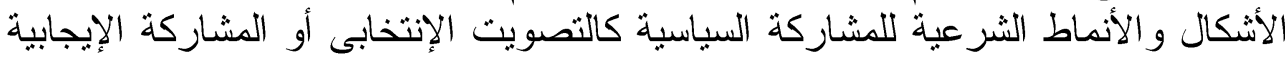

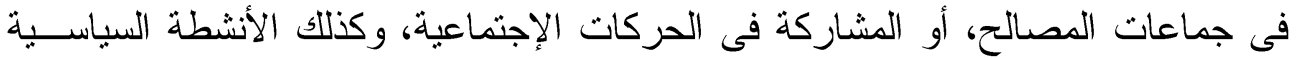

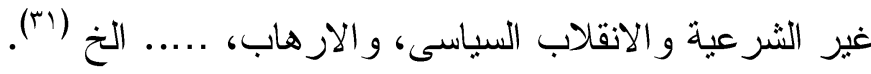

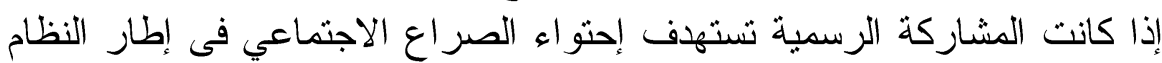

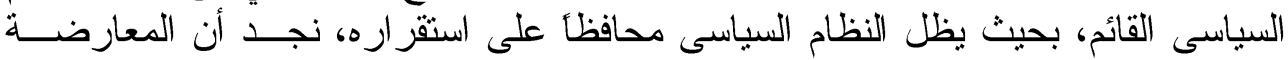

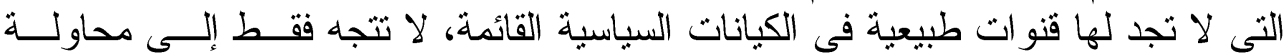

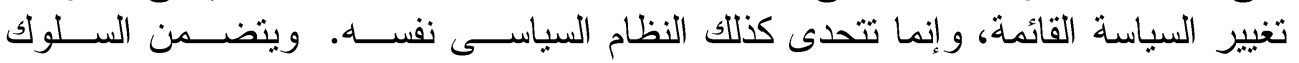

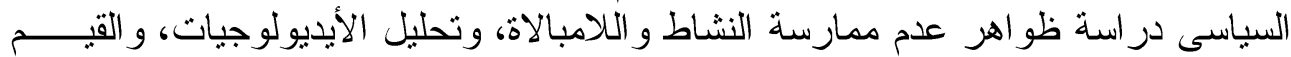
و الاتجاهات السياسية بوصفها تمثل أساس المشاركة فى المجال المال السياسي.

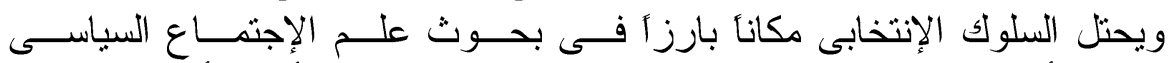

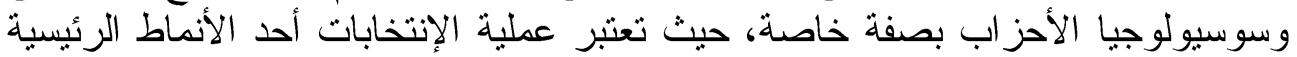

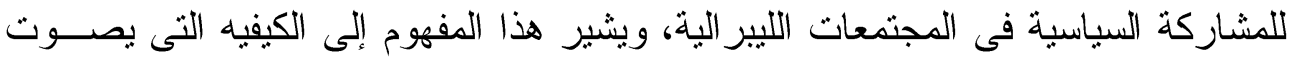

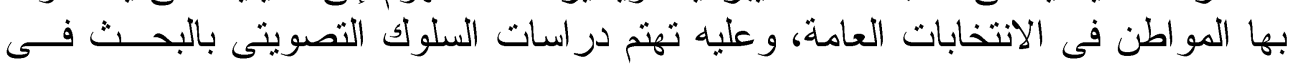

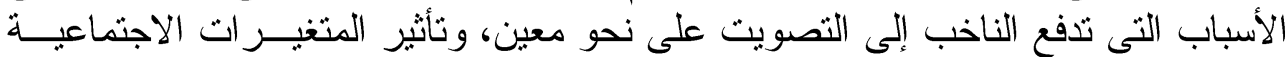

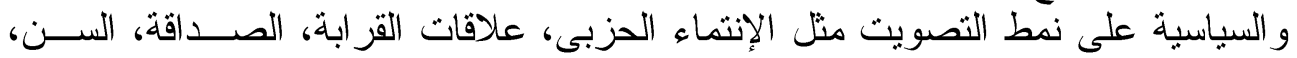




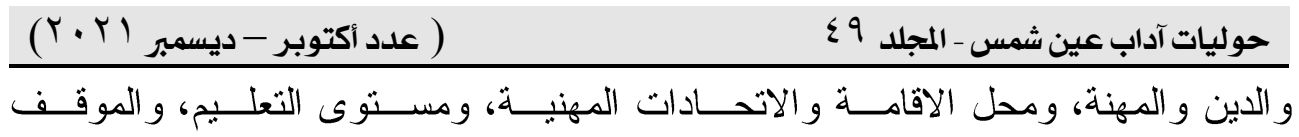

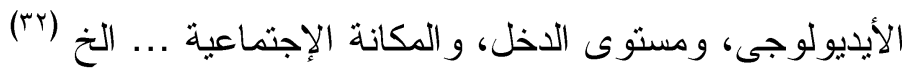

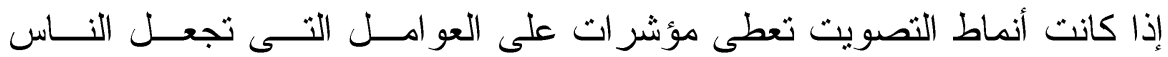

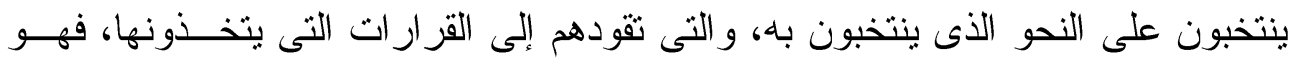

يمثل المكون الرئيسى للسلوك السياسى العام للفاعل السياسى سو اءع كان فئى فردأ أو جماعة.

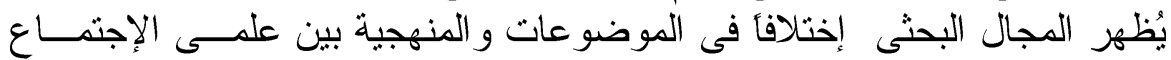

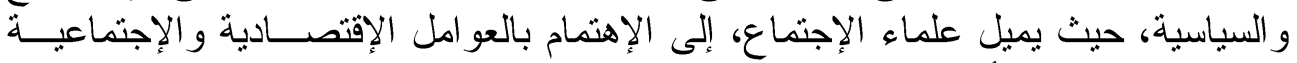

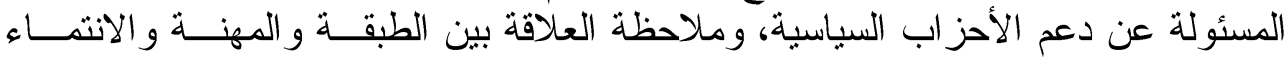

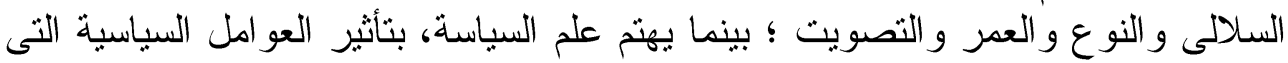

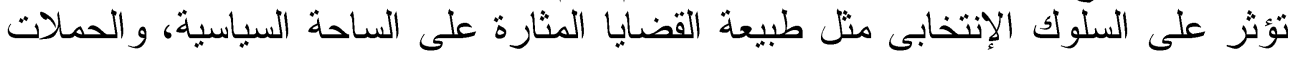

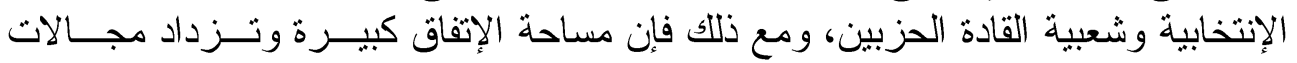
البحث تداخلا و التحامأ.

فى هذا السياق بعرض جوردون مارشال أربعة نماذج للاتجاهات المنهجية فـى

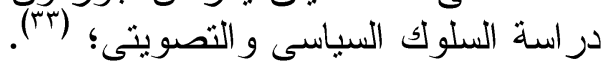

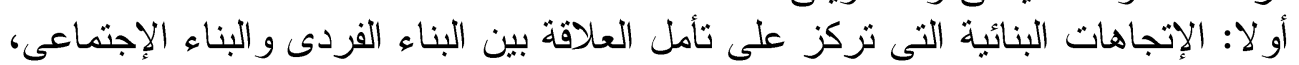

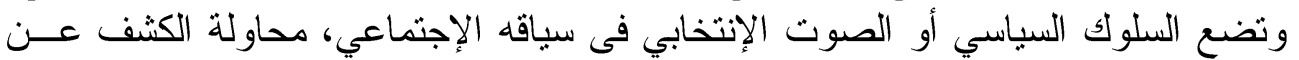

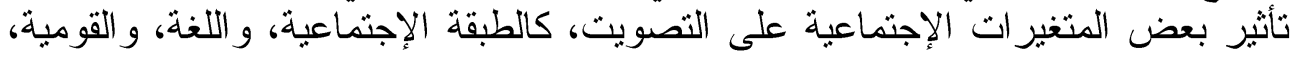
و الدين و الفروق الريفية الحنية الحضرية.

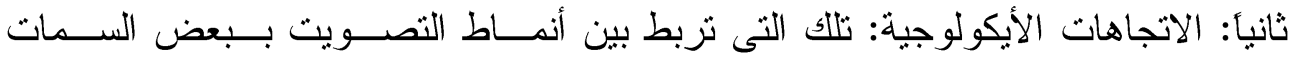

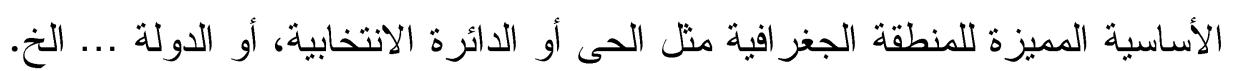

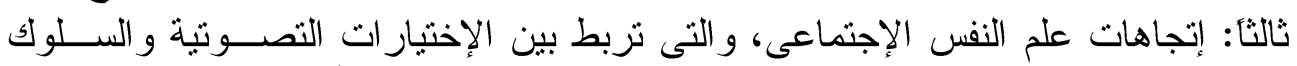

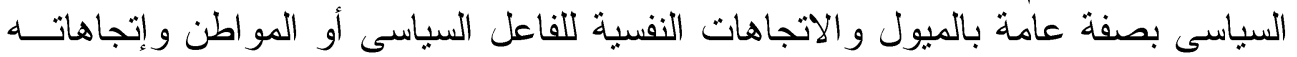
من المرشحين. رابعأ: إتجاهات البحث العقلي الرشيد، و التى تحاول تقسير السلوك السياسي و التصـــــيتي

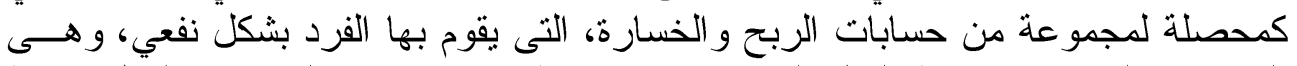

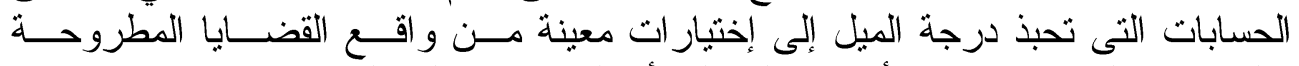

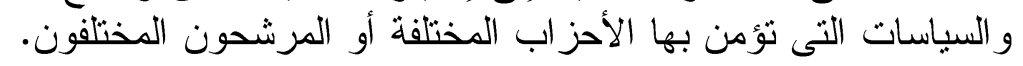

ويشير" آرثرفيشر Arthur fischer وهاتز أولريخ كـور

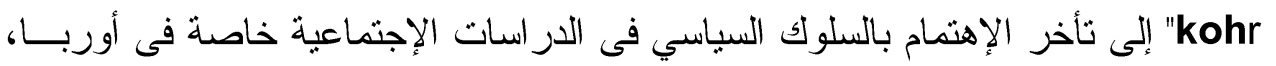

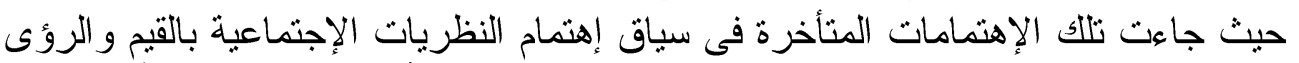

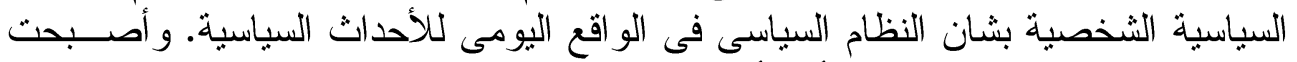

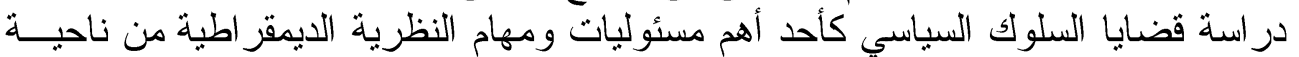

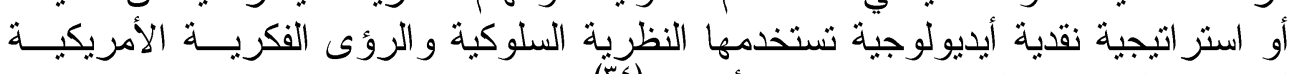

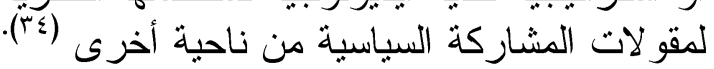

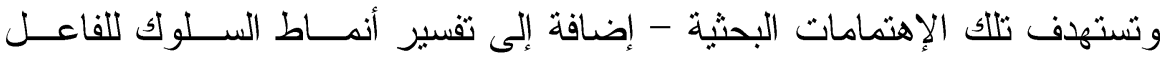

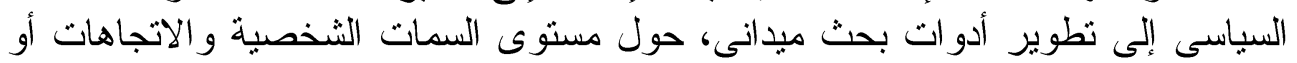

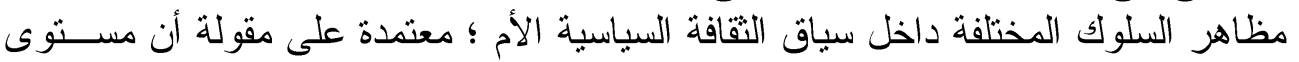

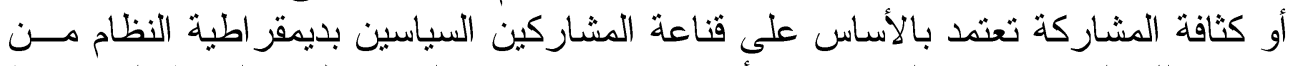

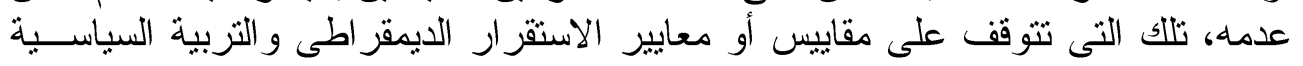




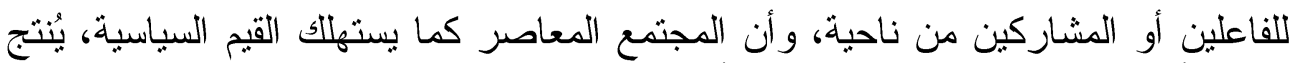

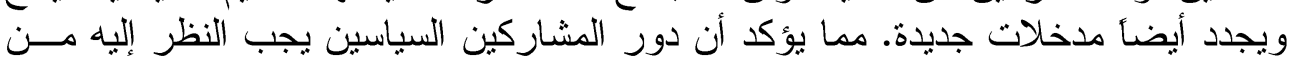

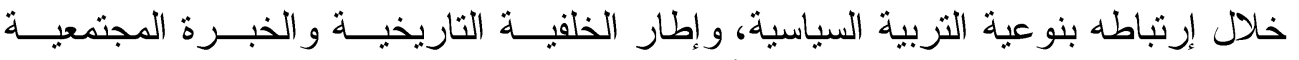

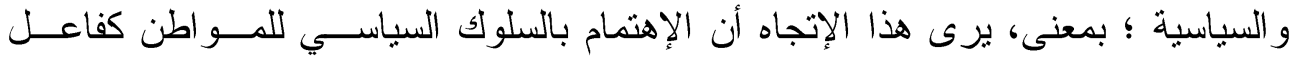

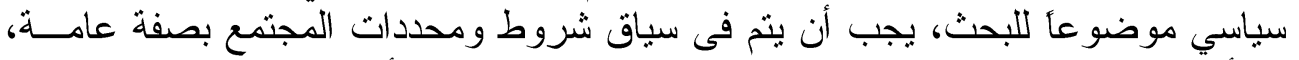

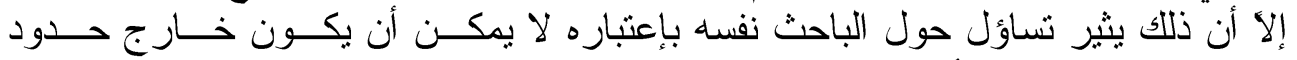

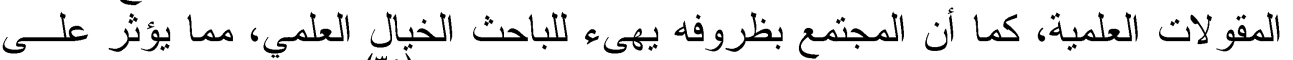

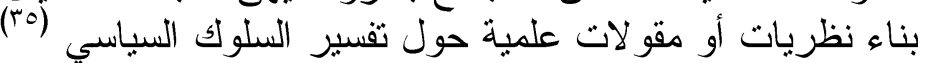

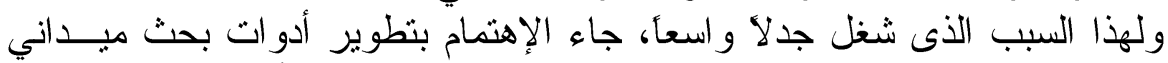

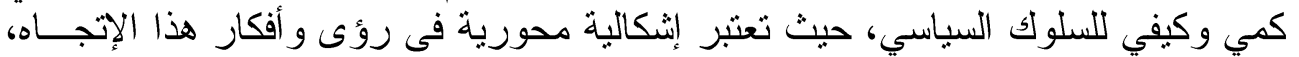

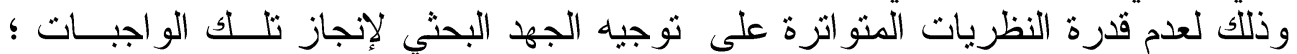

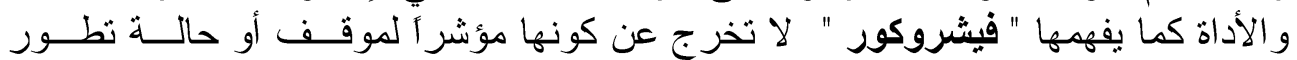

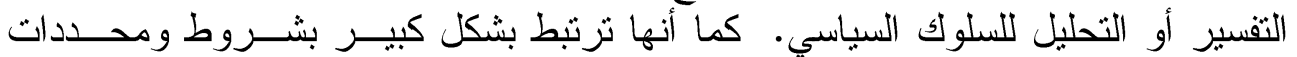

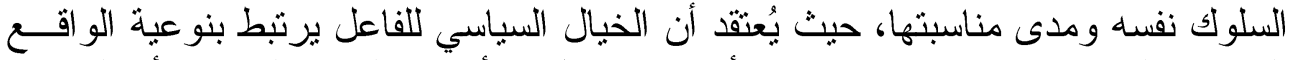

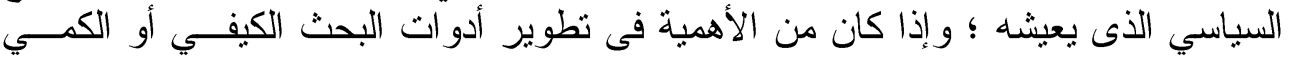

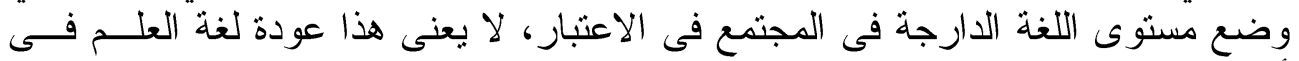
أدو ات البحث العلمى و التحليل السياسى إلى لغة النة العامة الدارجة.

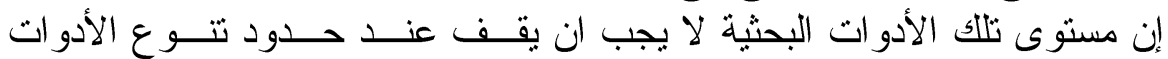

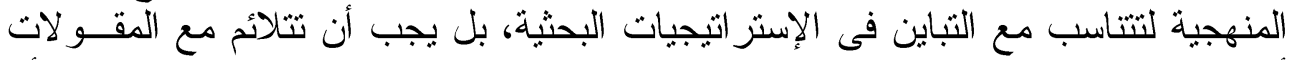

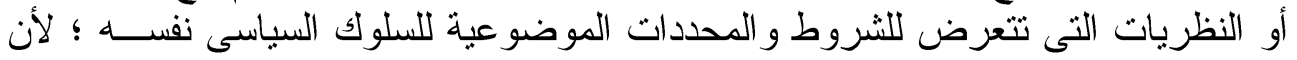

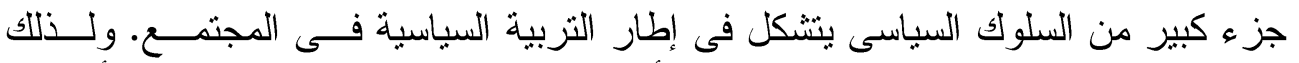

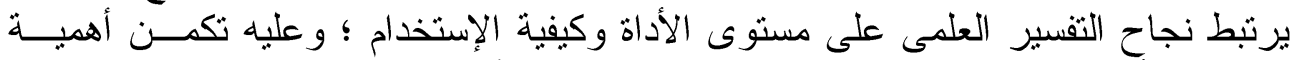

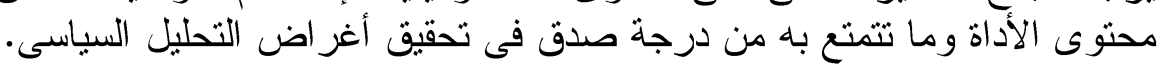

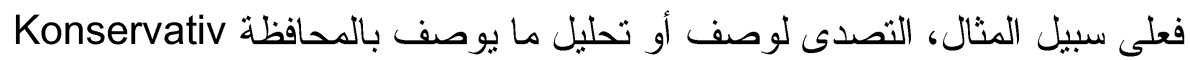

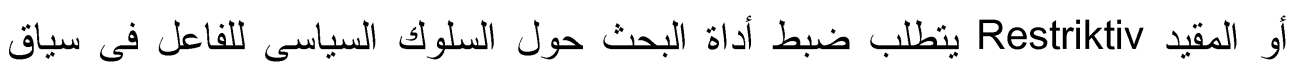

Politische تشكلها بالمكون المجنمى، و إطار القيمة والمعنى للمكون السياسى Bildung

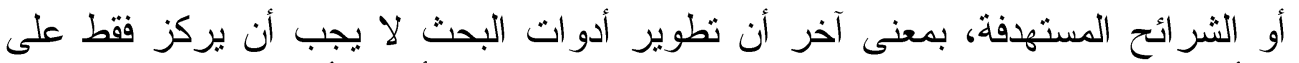

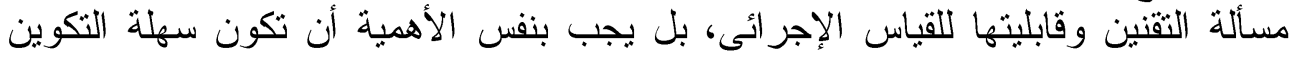
وقابلة للنطبيق في كل الأحو ال.

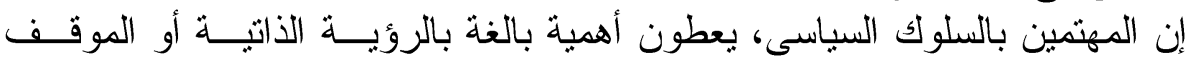

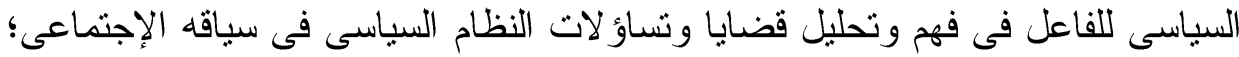
Die Bedeutung von Einstellung fur das verstandnis politischen verhaltens.

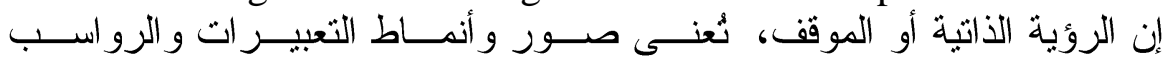

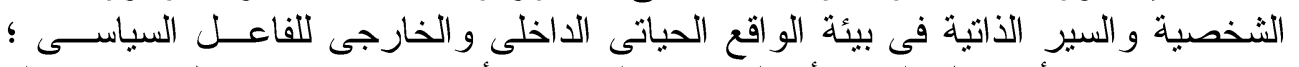

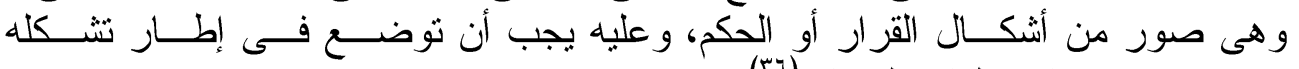

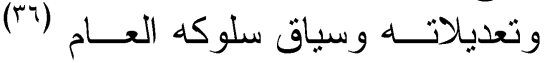




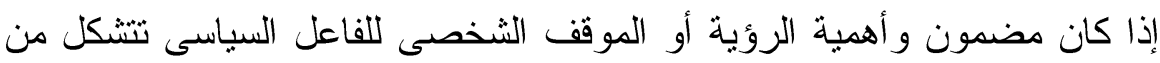

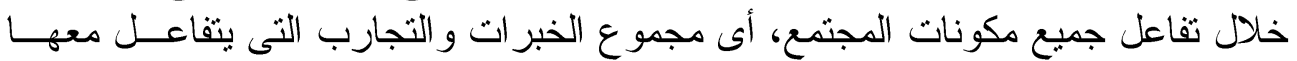

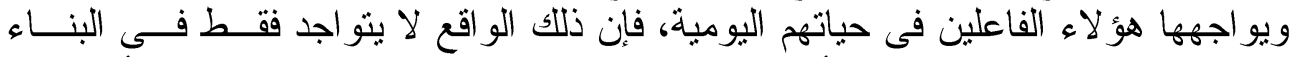

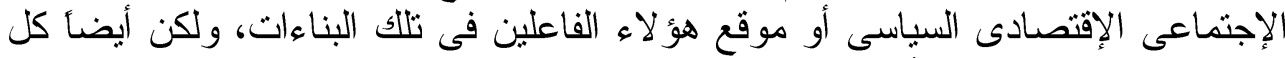

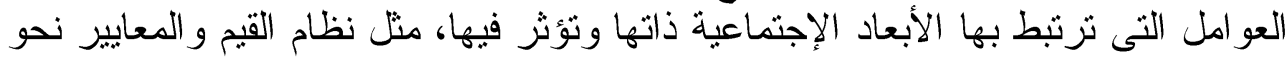

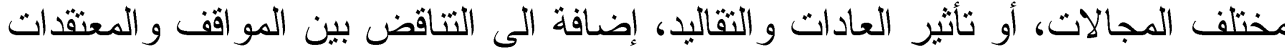

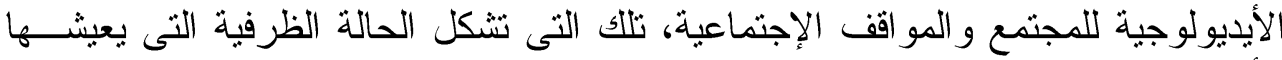

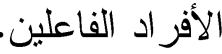

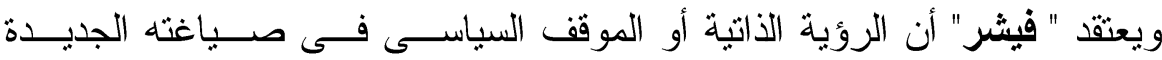

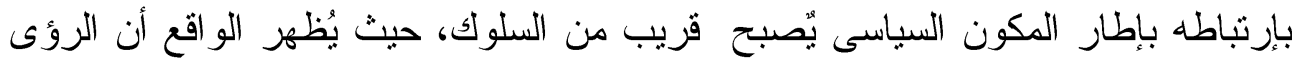

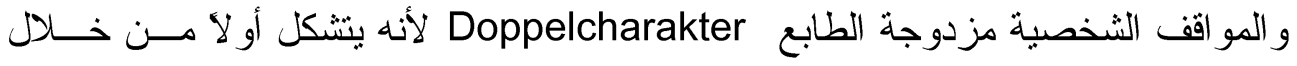

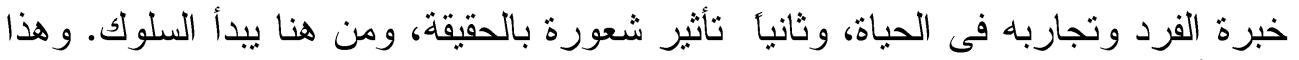

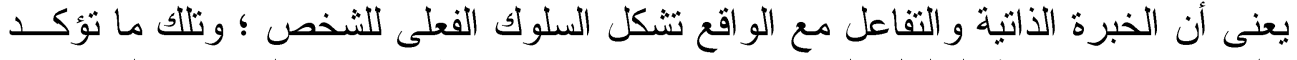

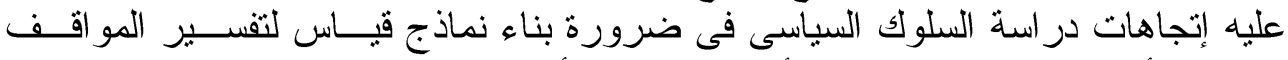

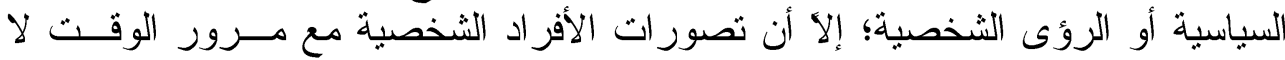

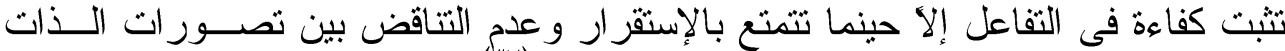

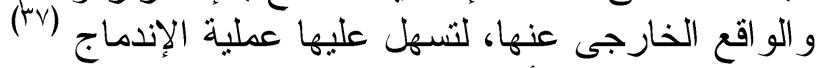

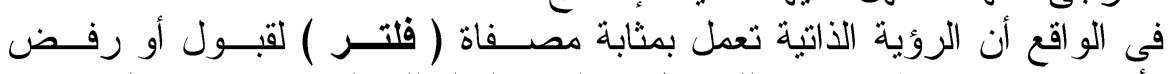

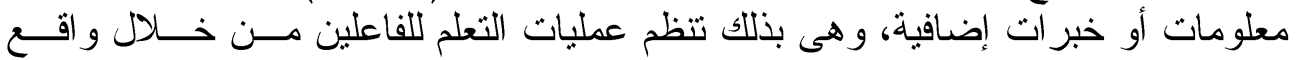

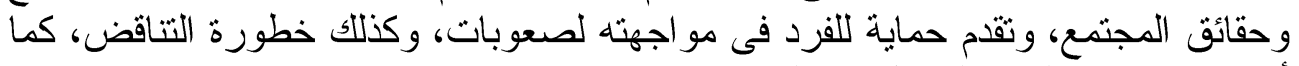

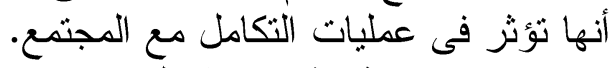

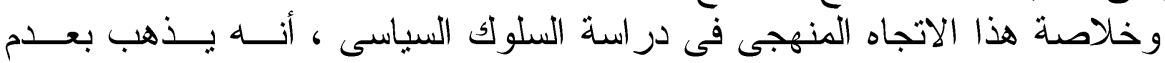

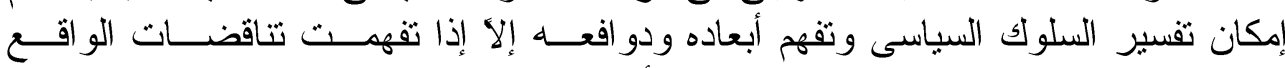

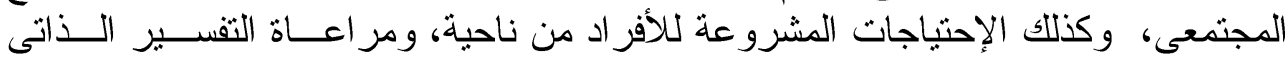

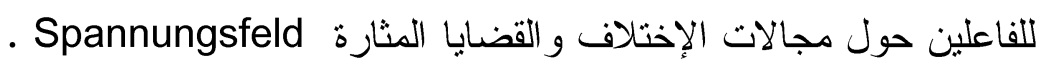

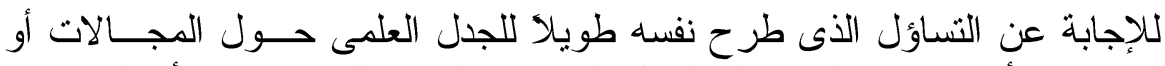

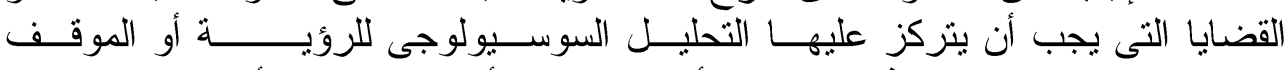

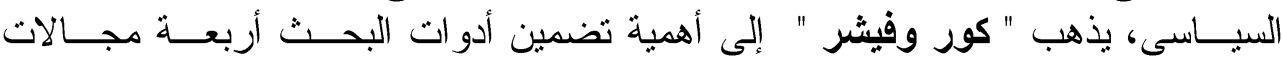

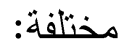

ا- مجال محتوى أو مضمون الرؤية أو الموقف الشخصى للفاعل السباسى نحو الســلوك r- شخصية الفرد سو اء كان فاعلا سياسى أو غير فاعل.

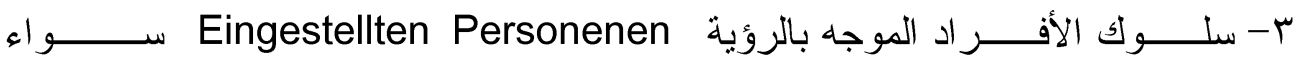

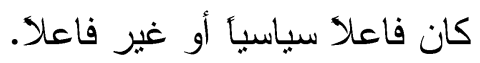

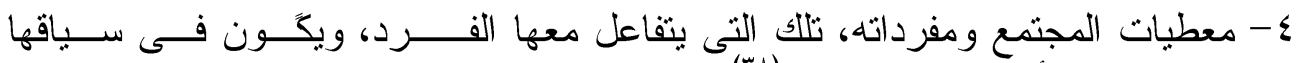

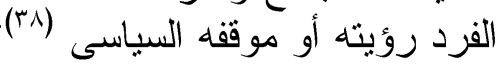

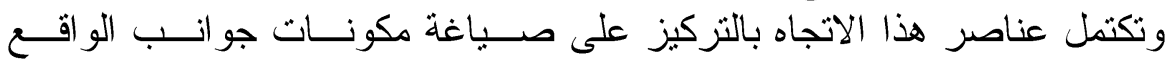
المجتمعى من خلال إختيار وبناء مؤشرات مؤثرة، مثل التعليم، الوظيفة، المهنة، .... الخ. 


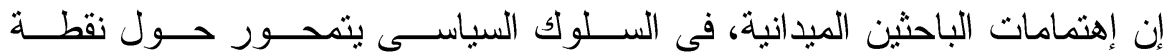

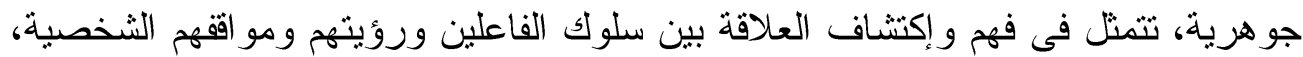

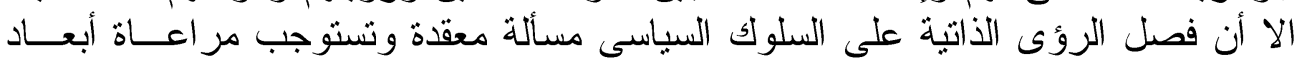

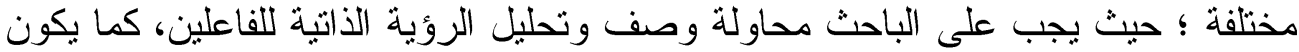

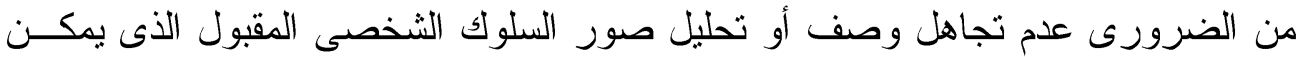

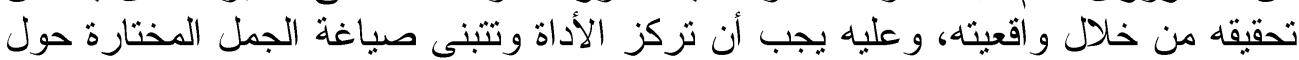

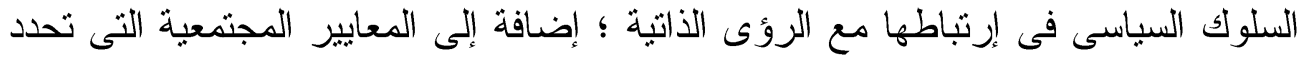

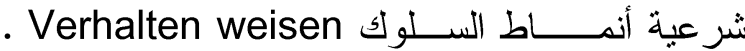

\section{خامسا: الأحزاب السياسية " تطور النشأة.. خلفية تاريخية}

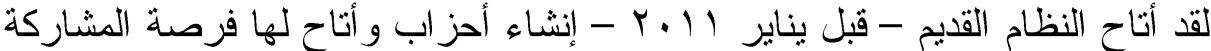

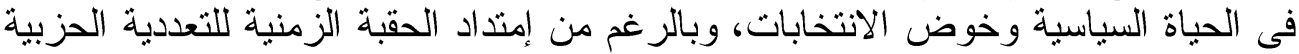

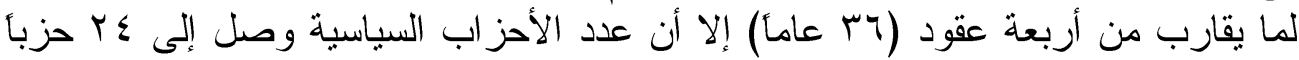

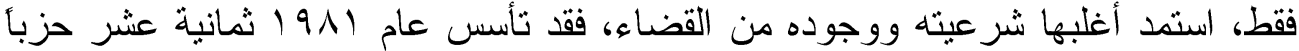

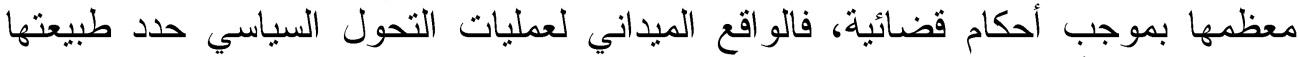

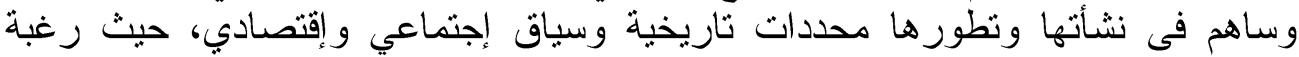

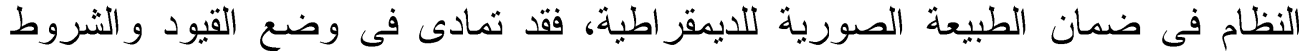

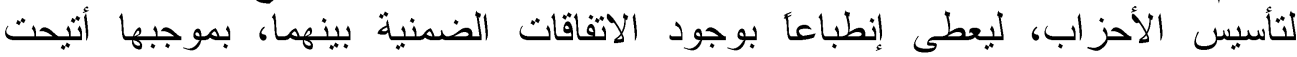

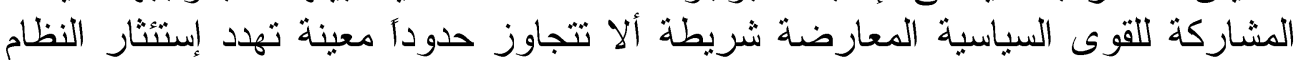

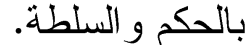

ووفقا لذلك يمكن فهم عدم إمنلاك تلك الأحز اب القدرة على التمثيل داخل البرلمان

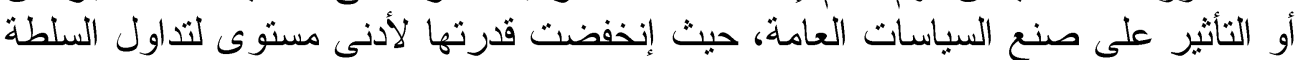
داخل الأحزاب ذاتها أو على مستوى نظام الحكم، وارتبط ذللك بسياسة توظيف الدولة الته ومؤسساتها لخدمة الحزب الحاكم والتزوويج لله أو بالتضيق على الأحزاب وتكبيلها و الحد الحد

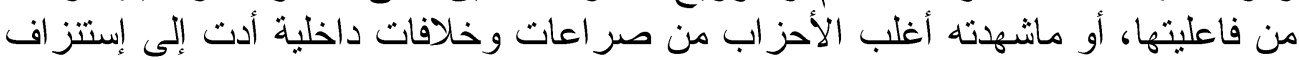

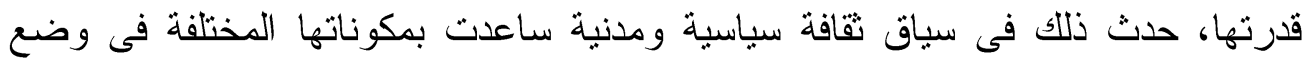
صياغة نظام حزبي صوري. ورغم تباين رؤى الباحشين و التحليلات السياسية حول و اقع النظام السياسى فى الحقبة

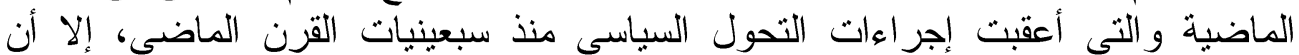
هنالك ثوافق حول وجود خلل فى دور ووظيفة الأحز اب المصرية دون إستثناء مما أبطأ

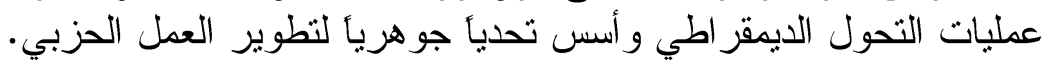

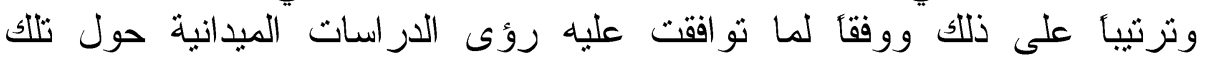
الظاهرة، فقد إعترى الأحزاب المصرية خلل بنائي مؤسسي أقصاها من مفأ مفهومه العلمي،

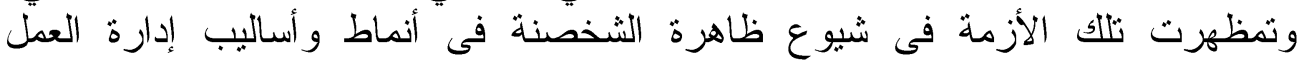

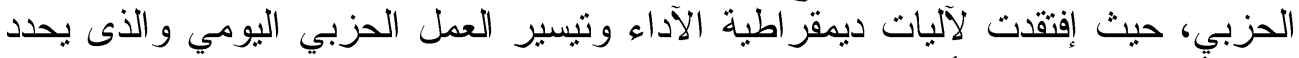
كيفية أداء وتوصيف الأدوار على كافة المستويات التنظيمية، إضافة إلى ذلك فقد إفتقدت

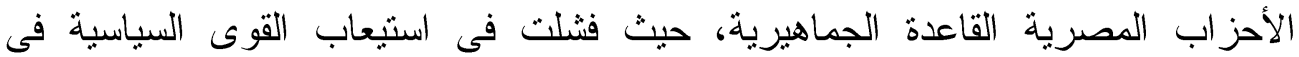

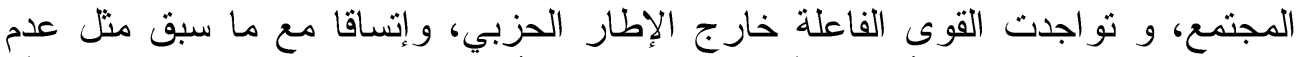

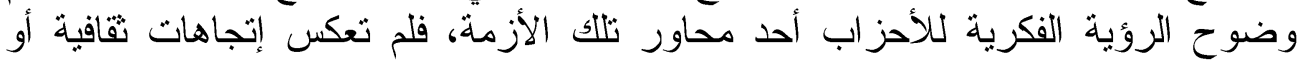
إجتماعية تميز فى إطار ها الثرائح أو القوى الاجنم الاجماعية التى تمثلها. 


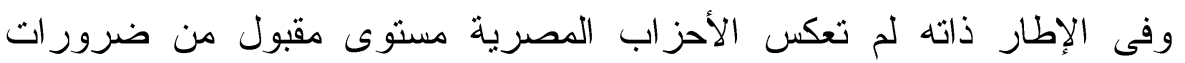

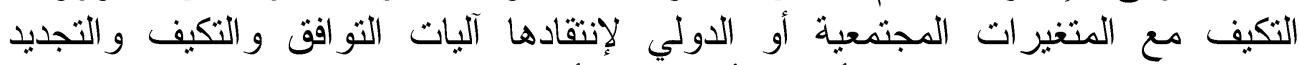

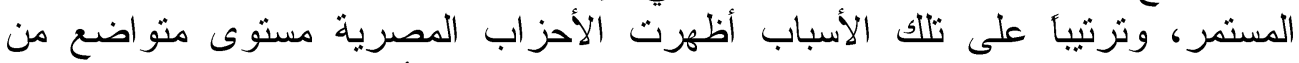

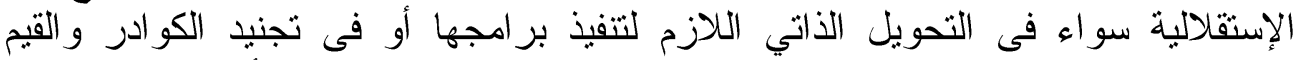

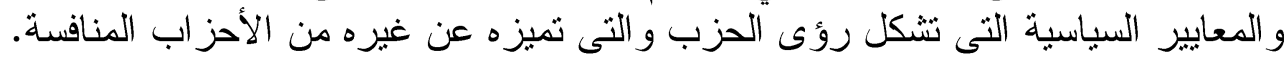

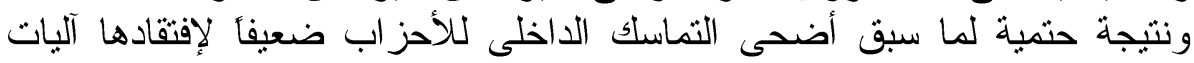

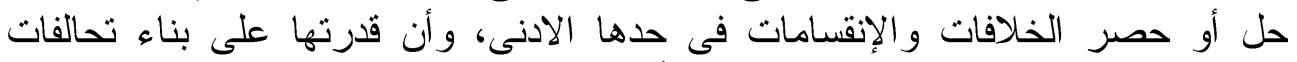

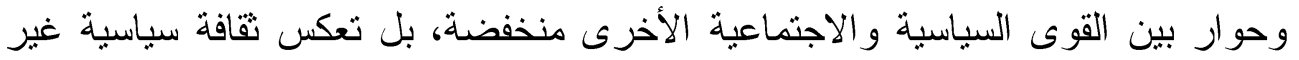

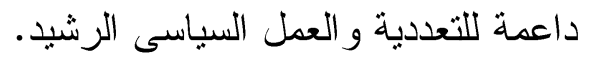

وخلاصة تلك المرحلة.. إذا كانت حالة الأحز اب السياسية من حيث القوه و والضعف

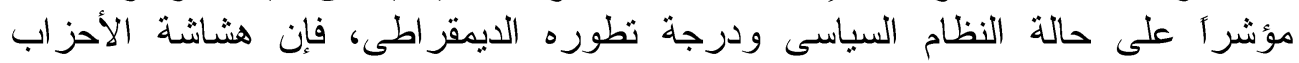

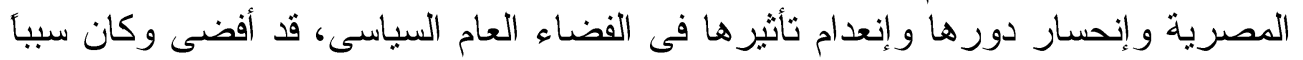

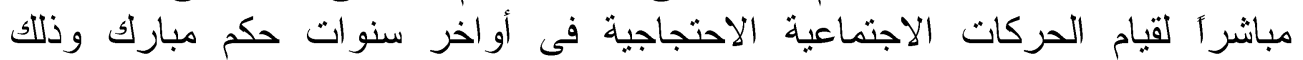

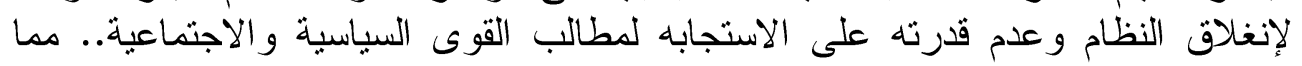
عجل بنهايته.

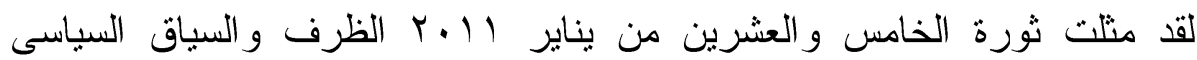

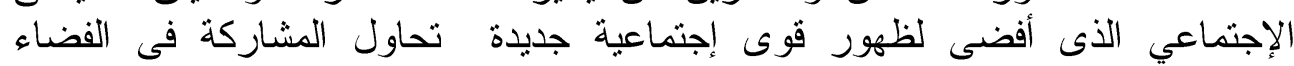

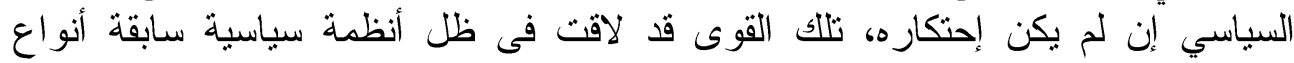

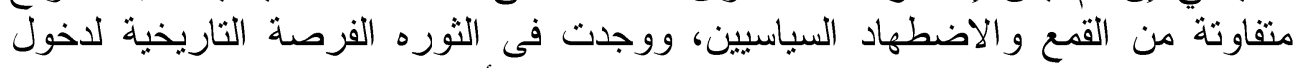

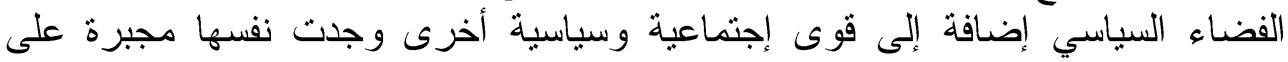

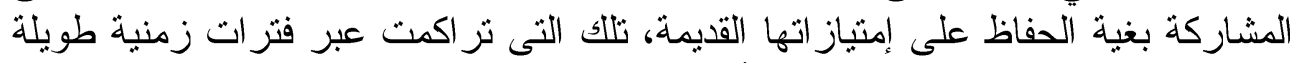

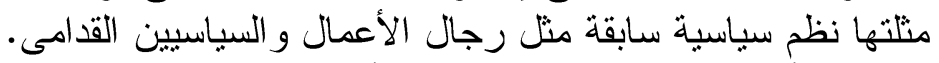

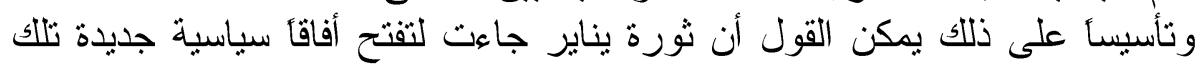

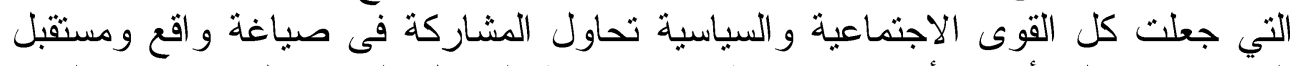

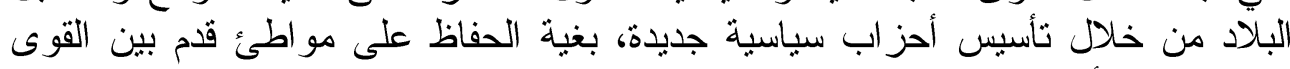

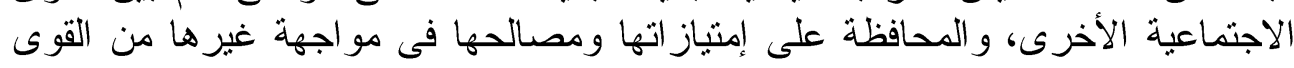
الاجتماعية الناشئة.

إضافه إلى ما سبق.. يمكن إرجاع الطفرة الحزبية بعد الثورة إلى تخفيض القئ القيود

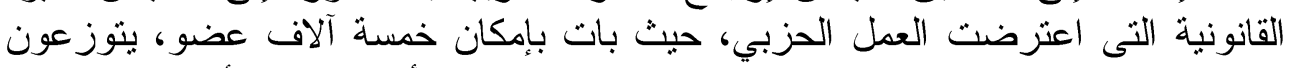

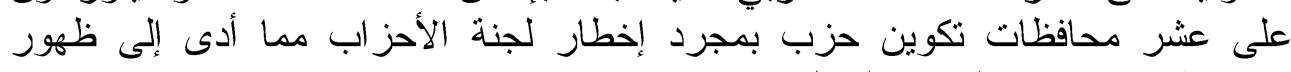
الحزبأ بعد صدور القانون المنظم مباشرة.

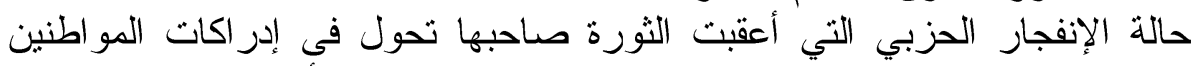

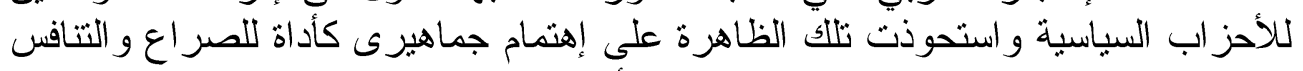

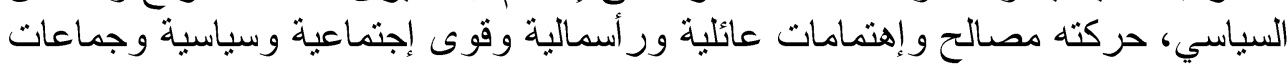

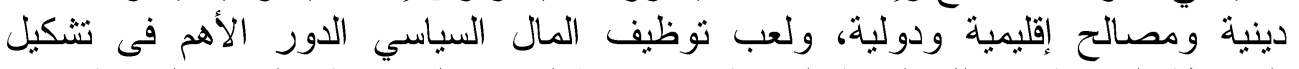

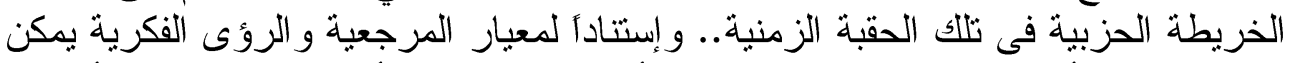

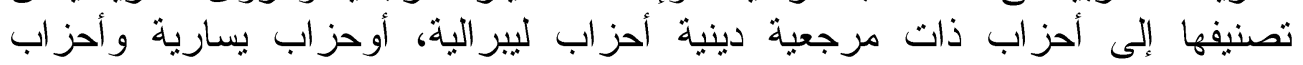
مختلطه التوجه و المصالح. 


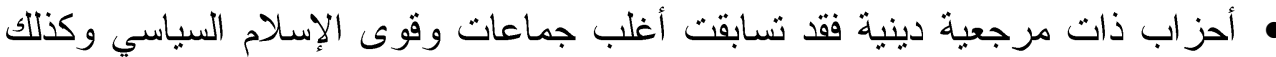

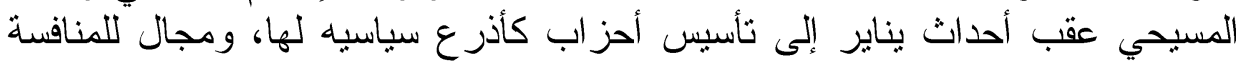
و الصرأع في المجال العام السباسي.

• فقد أسست الأخوان المسلمين حزب الحرية والعداله، كما كثفت الأحداث المصاحبة

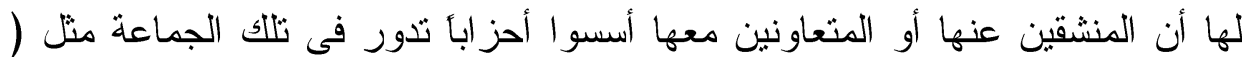

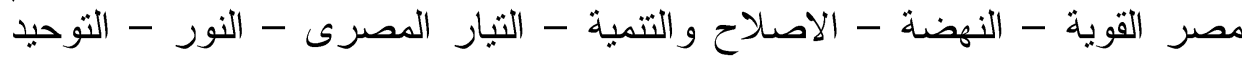
العربى - الفضيلة - مصر البناء - مصر الحرة - الإصلاح و النهضة - الألة الأصاله

• لم تترك الجماعات الإسلامية الفرصة وشاركت بفاعلية بتأسيس حزب البناء و التتمبة -

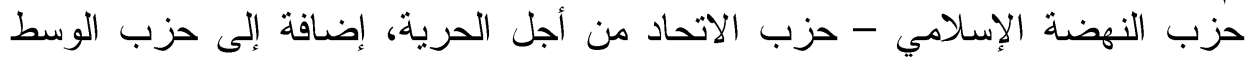

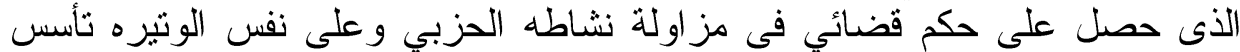

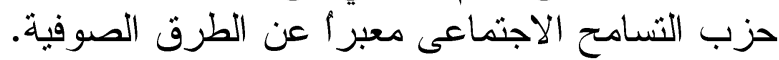

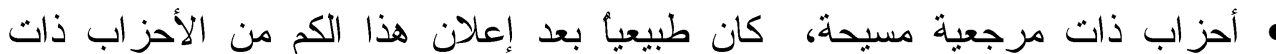

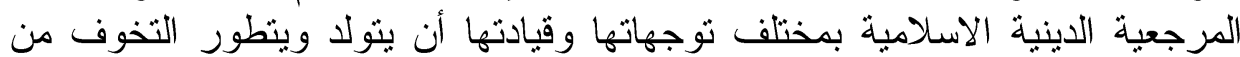

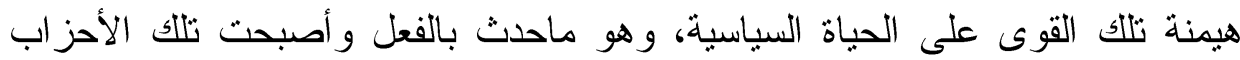

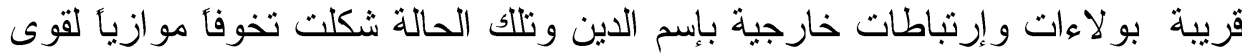

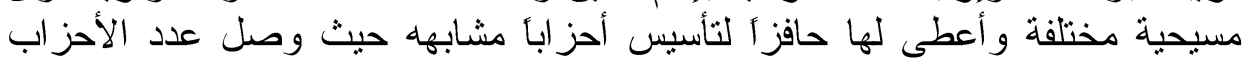

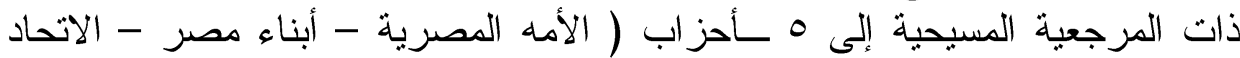

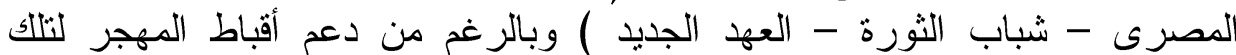

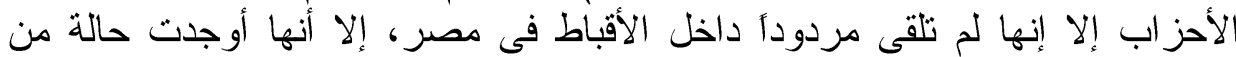

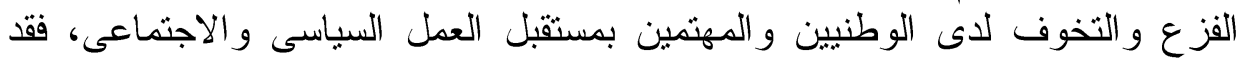

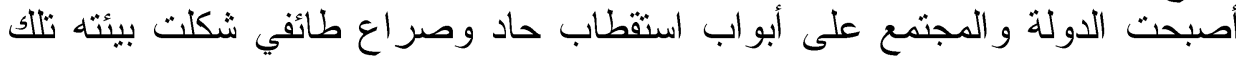

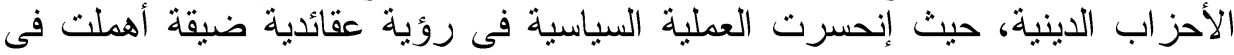

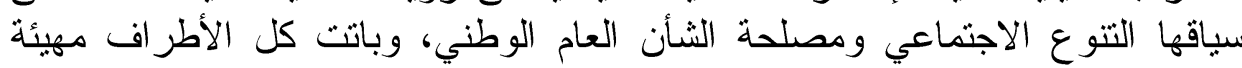

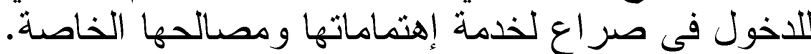

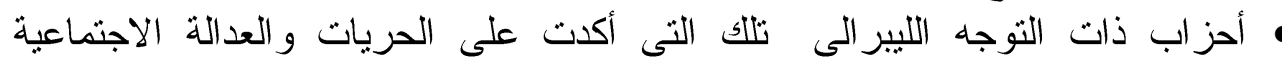

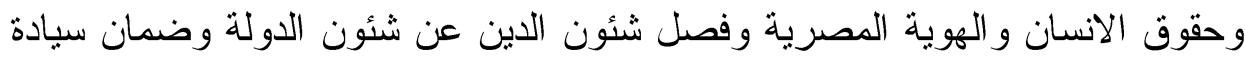
القانون و المساو اة بين أبناء الوطن وكل محددات وقيم الثقافة المدنبة بالدولة التئة الحديثة

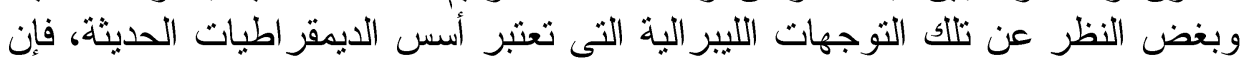

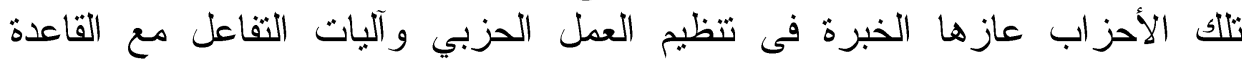

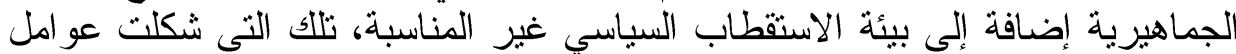

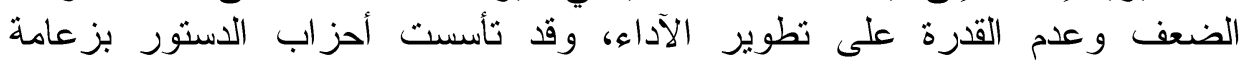

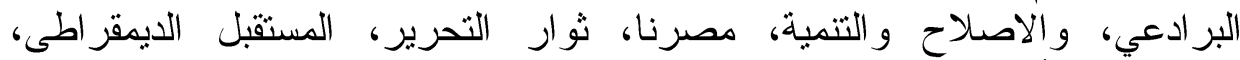

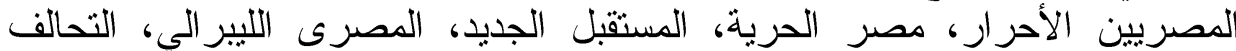

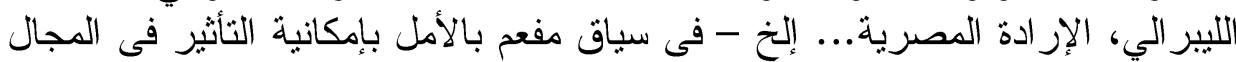

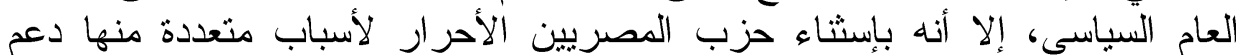

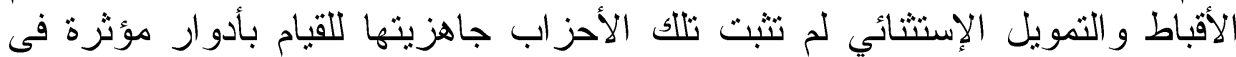


فى المقابل وجدت القوى البسارية فى الظرف السياسي والاجتماعي الذى أحدثته الثورة

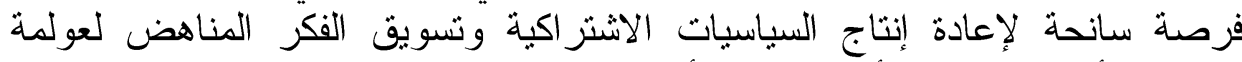

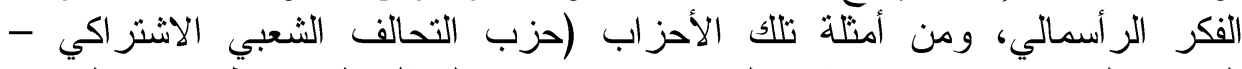

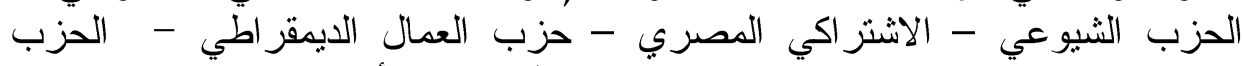

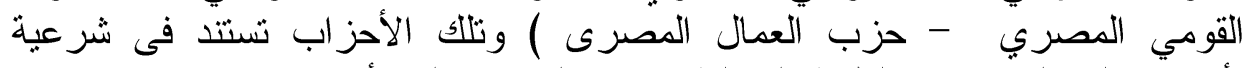

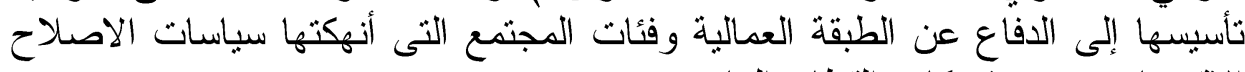
الاقتصادي وبين شركات القطاع القاع العام.

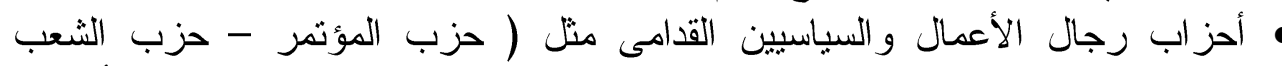

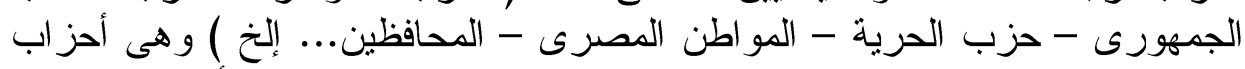

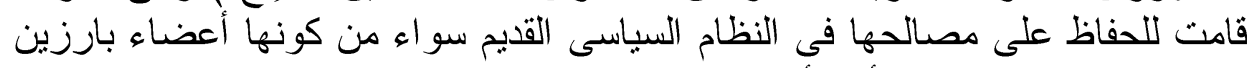
فى الحزب الوطنى القديم أو رأسمالية خاصنة.

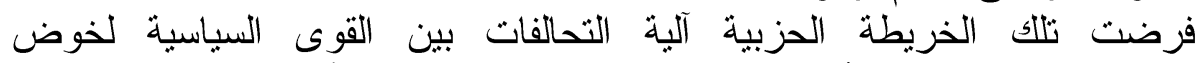

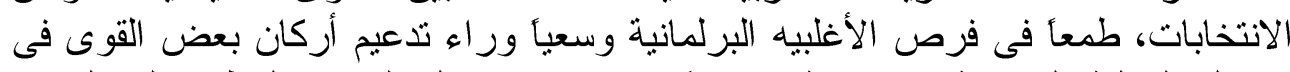

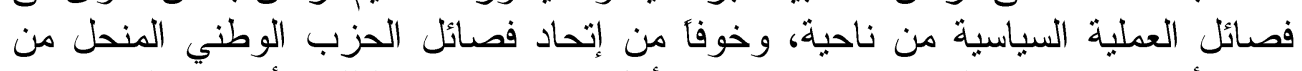

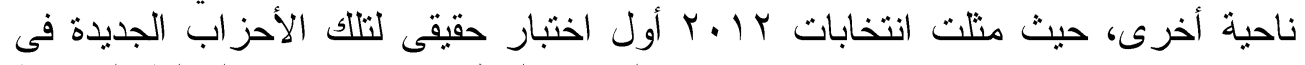

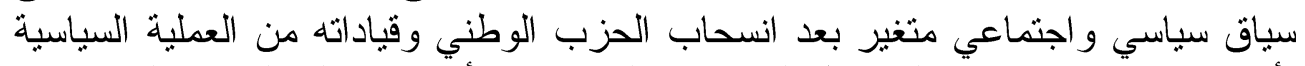

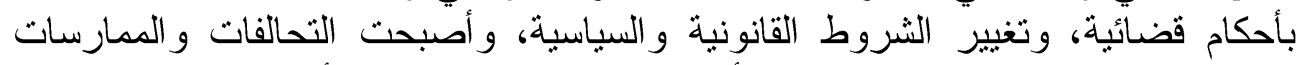

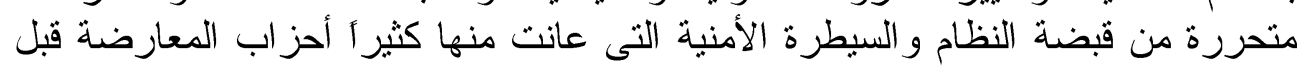
الثورة.

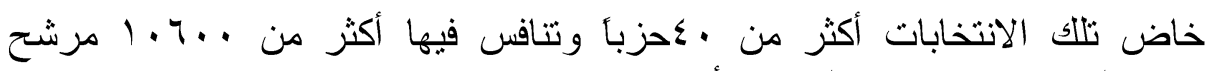

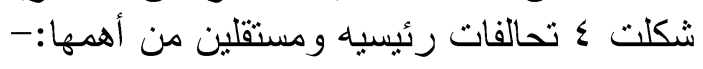

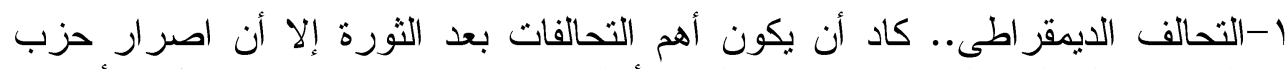

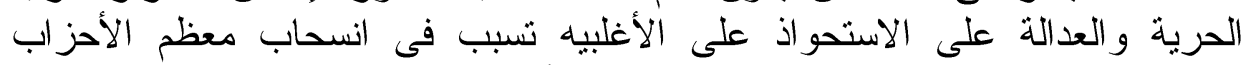

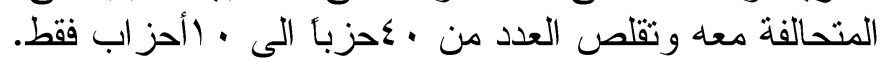

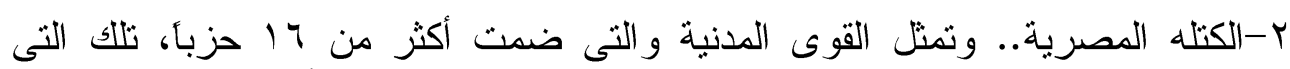

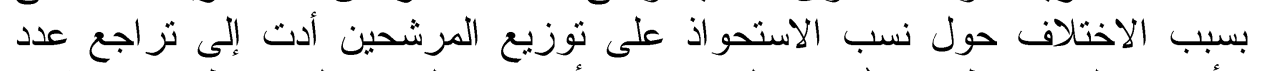

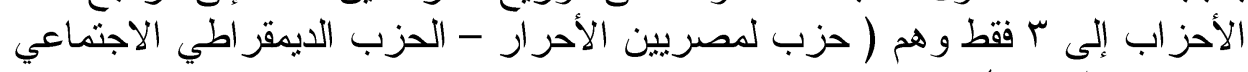

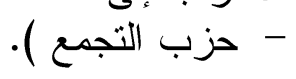

ب-الثورة مستمرة.. وضم الأحز اب التى انشقت من الكتلة المصرية، بقيادة ( حزب مصر

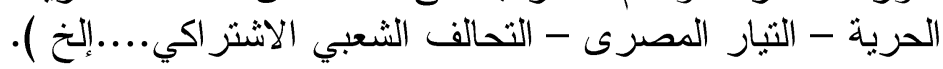

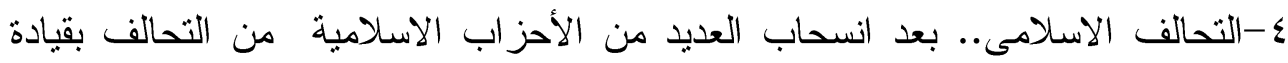

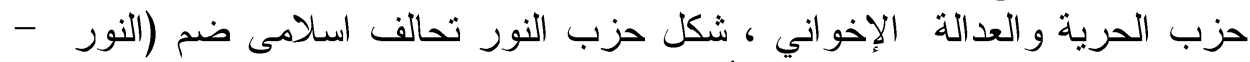

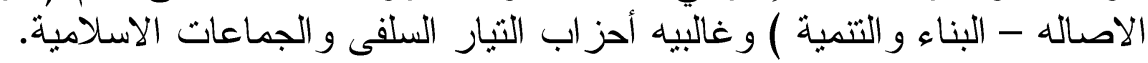

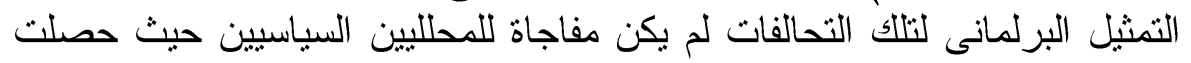

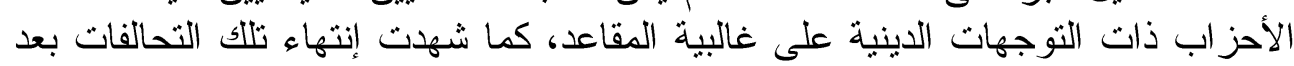

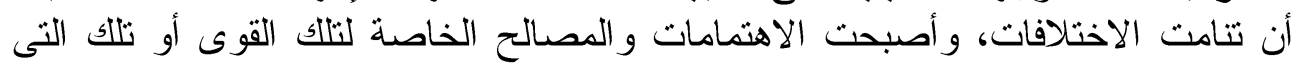

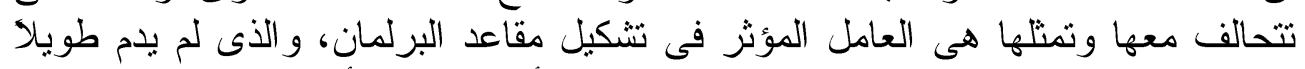
حيث حُل بحكم دسنورى لعدم دسنورية القانون الذى أجريت على لعى أساسه. 
ووفقا لما جاءت عليه نتائج تلك الانتخابات، فقد أكدت مجموعة من الحقائق توضح مدى تغيير واستمر ار دو افع التصويت و الثقافة السياسية للمجتمع المصرى التهى وحجم

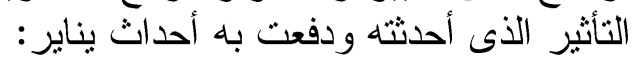

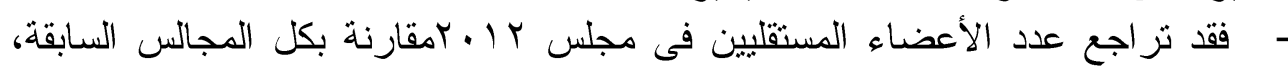

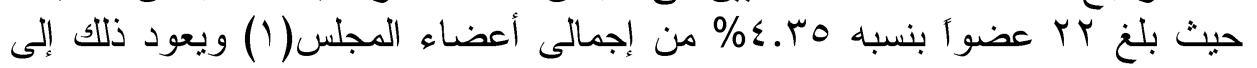

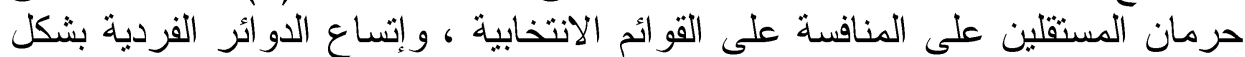

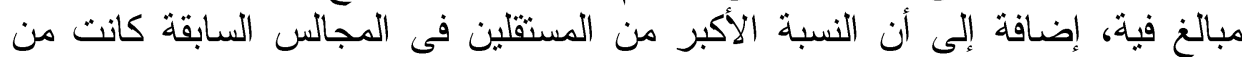

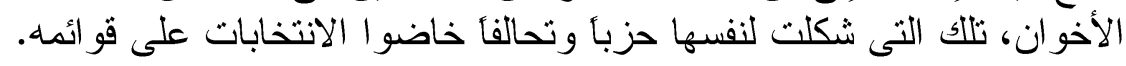

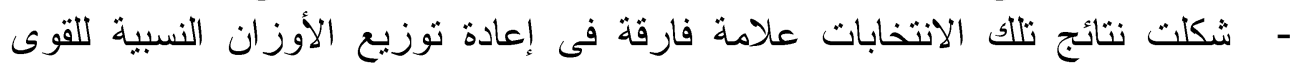

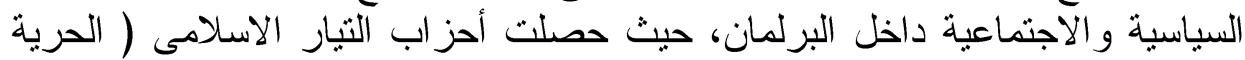

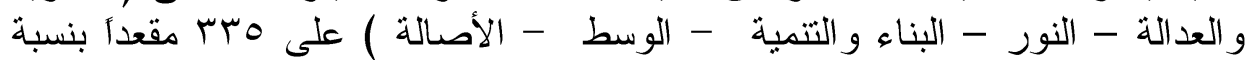

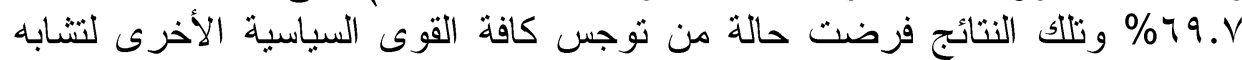

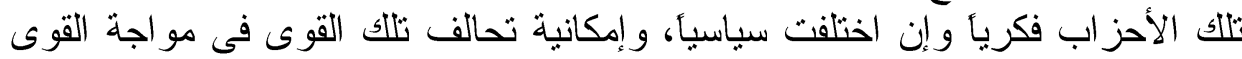

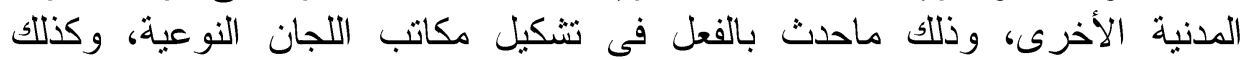

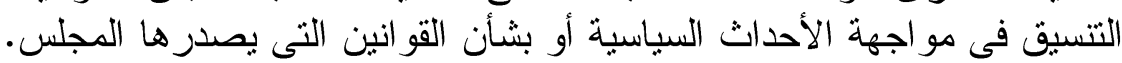

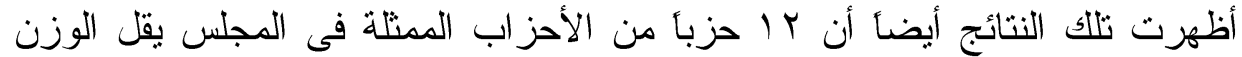

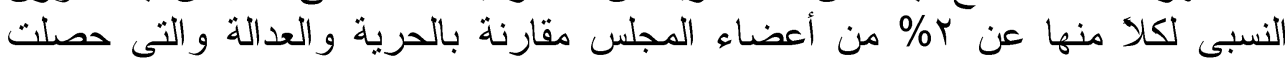

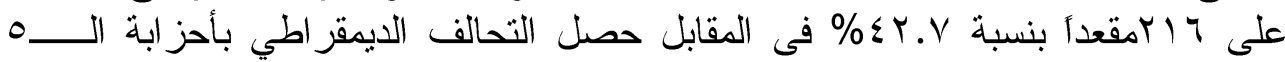

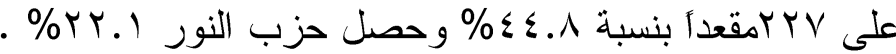

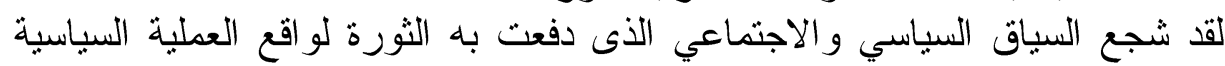

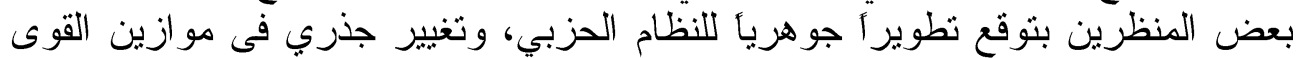

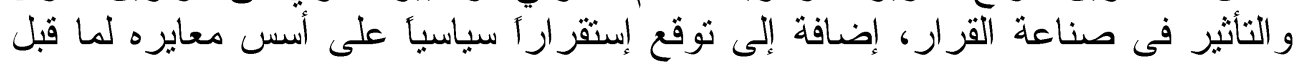

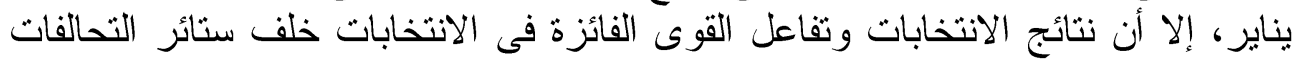

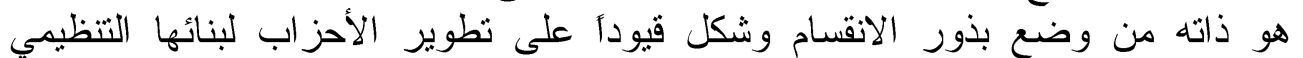

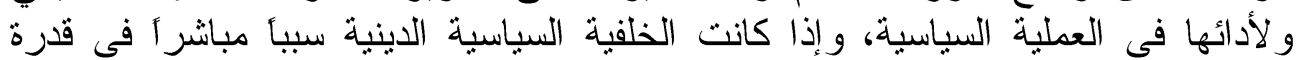

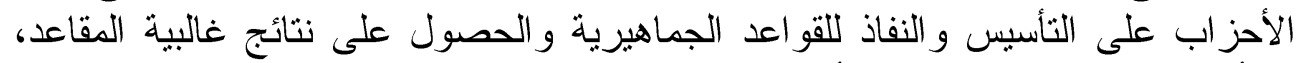

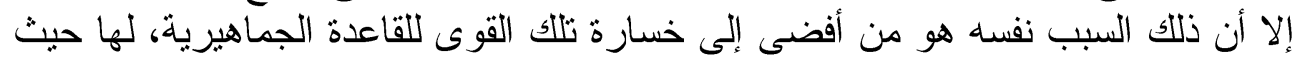

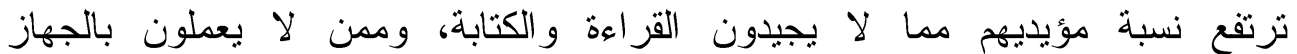

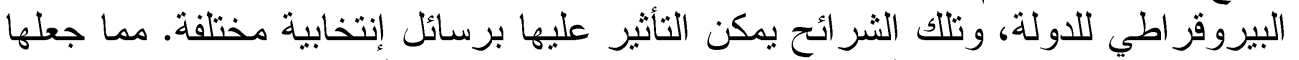

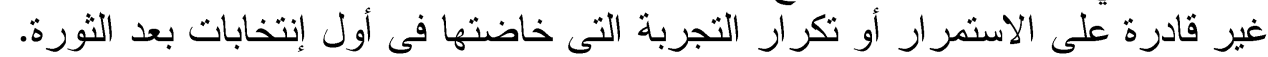

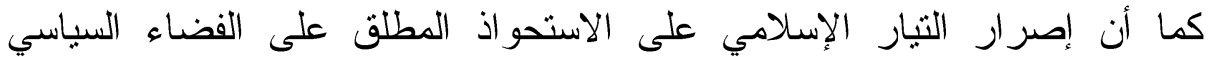

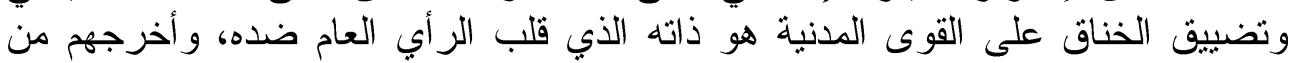

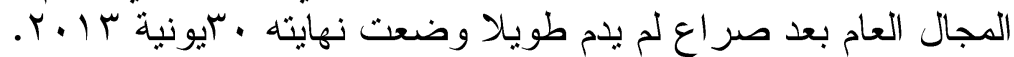

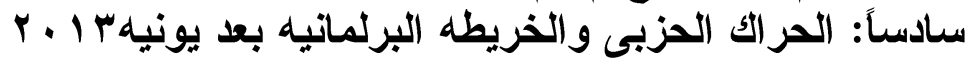

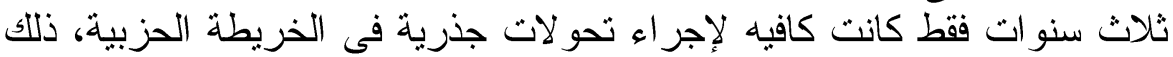

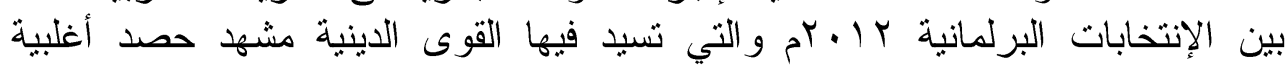

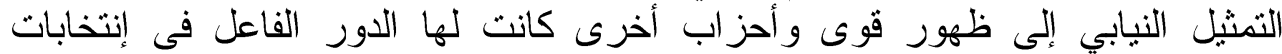

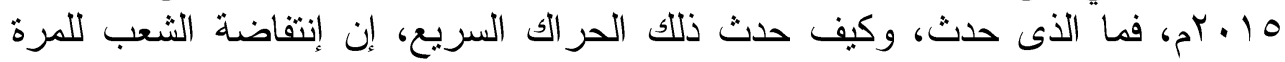




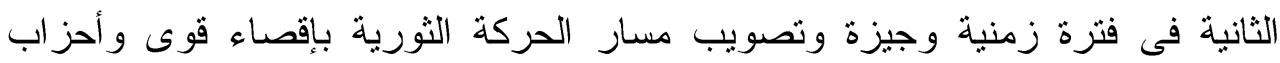

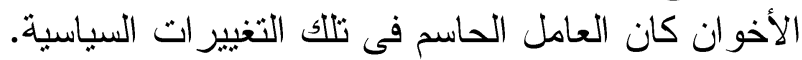

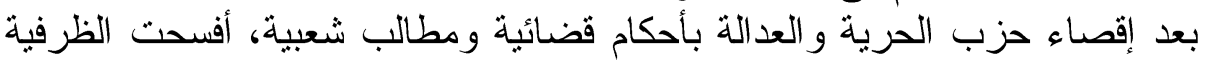

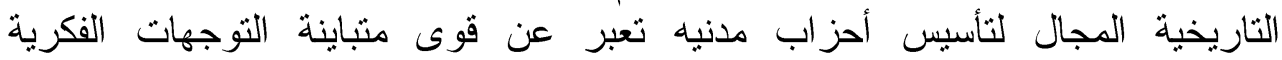

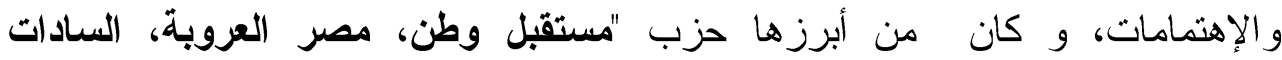
الايمقراطي، الحركة الوطنية، حماة وطن، الأحرار الاستورين، فرسان مصن، مصر، مصر

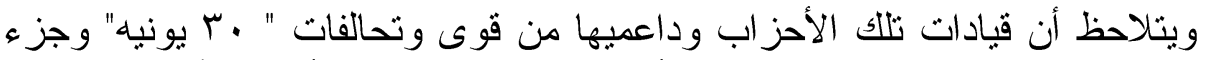

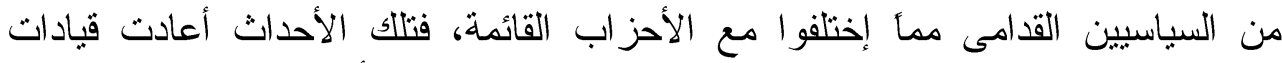

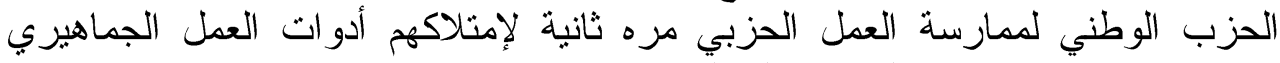

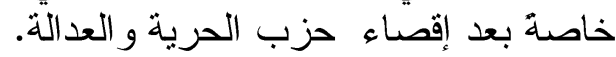

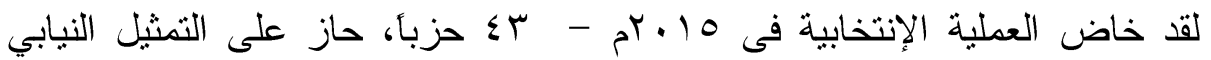

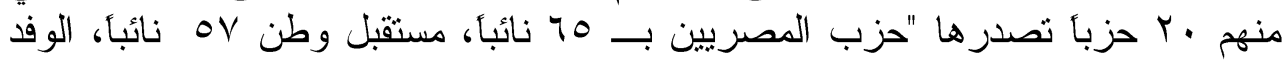

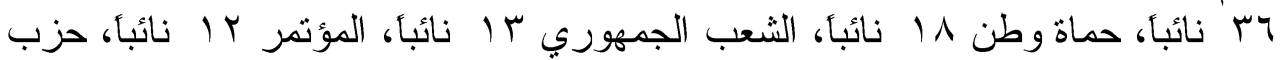

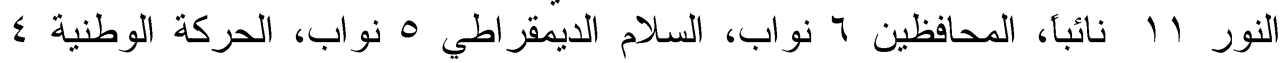

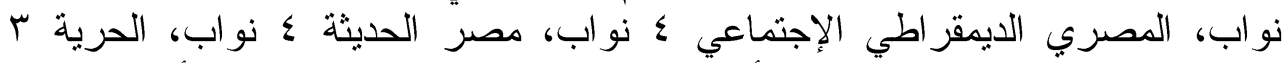

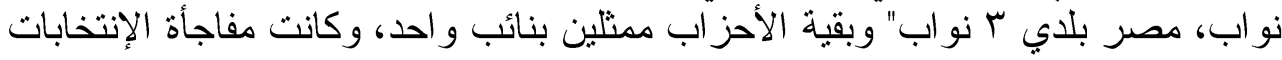

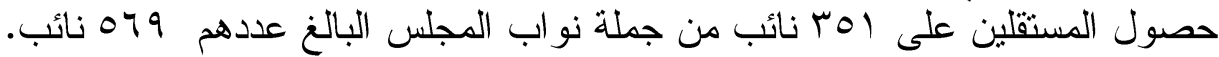

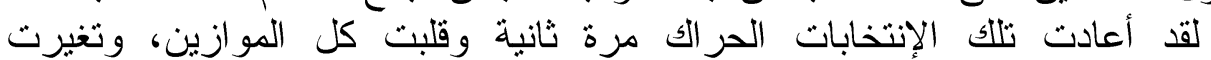

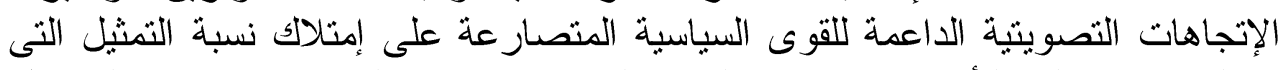

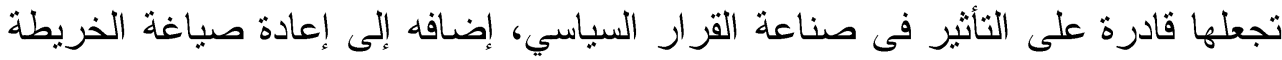

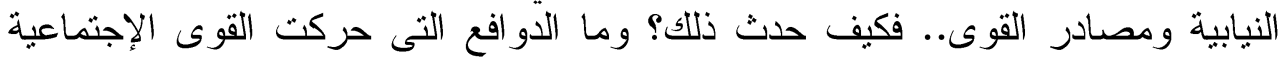
و السياسية لهذا التغبير . و فقأ لو اقع الأحداث، تداخلت فو اعل متعددة أفسحت لها ثورة يونية المجال لممارسة

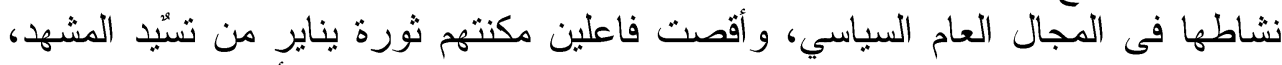

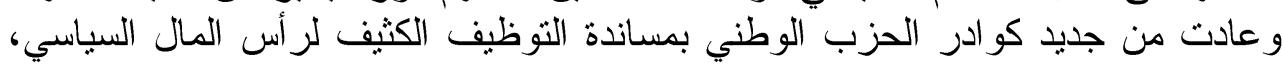
ويمكن توصيف تقاعل نلك الدو افع و الفاعلين فى الفضاء السياسي فى سياقه الجديد وفقاً للطر ح التالى: تودئ أو لاً: إن تحليل هذا المشهد يشير إلى أن عمليات الحرالك و التحول السياسي الجوهري غير

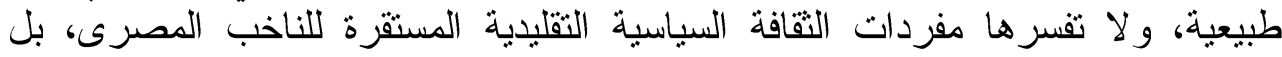

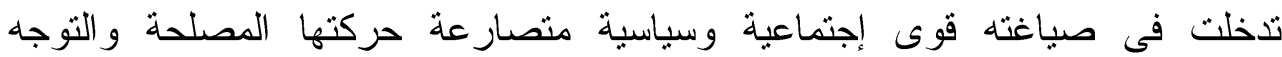

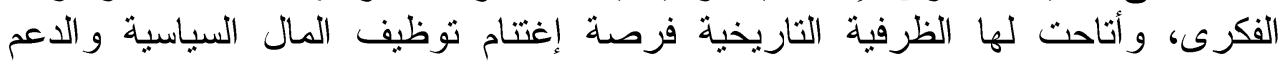

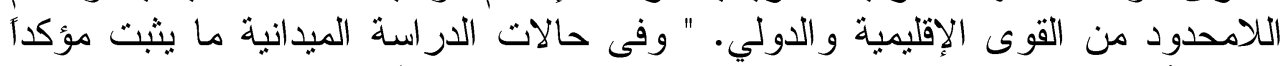

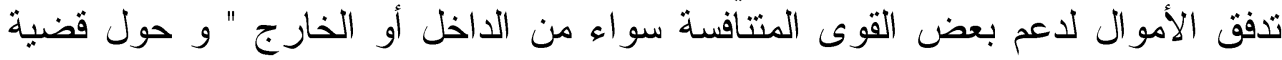

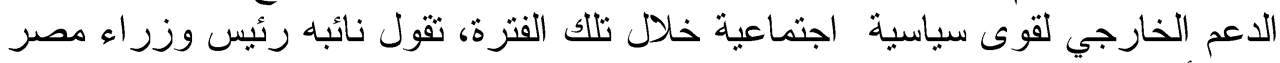

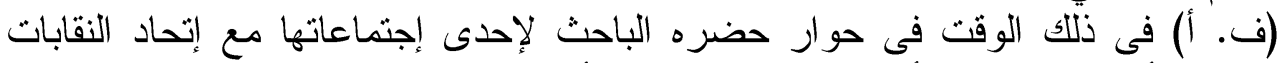

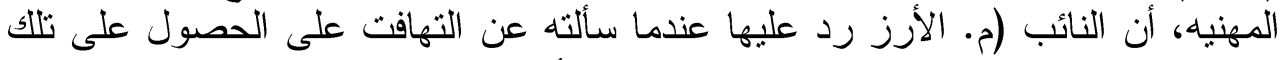

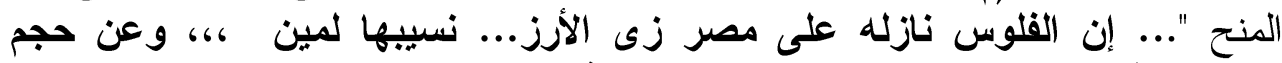

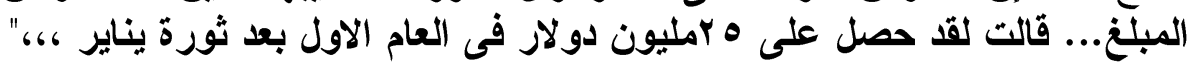




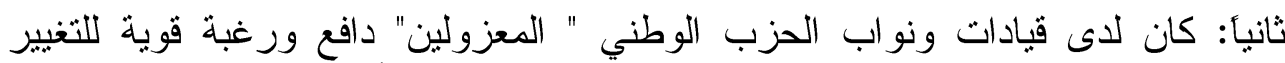

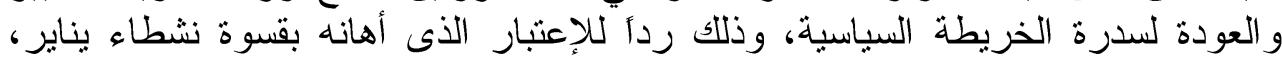

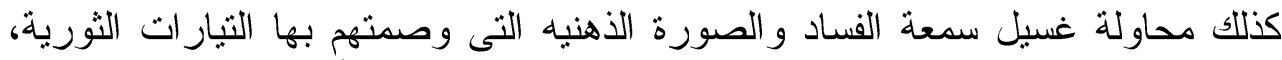

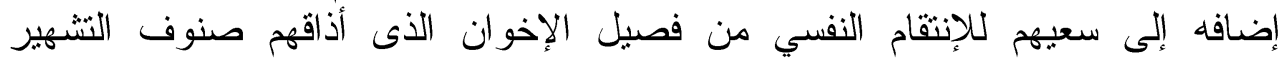

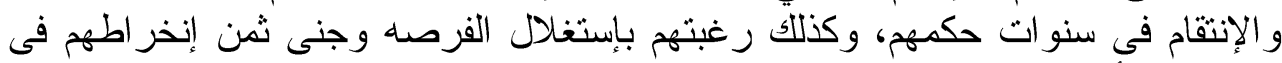
التحضير لأحداث يونيه.

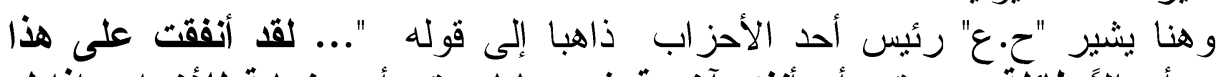

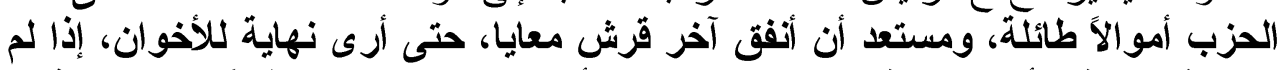

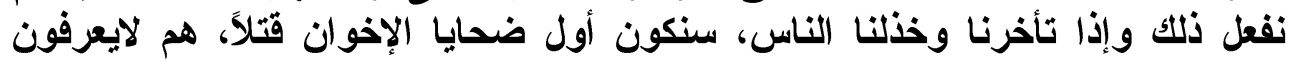

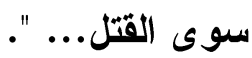

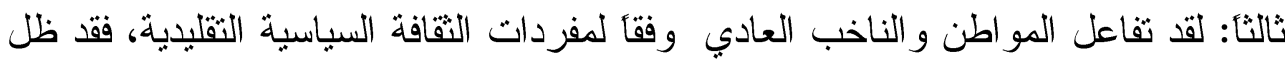

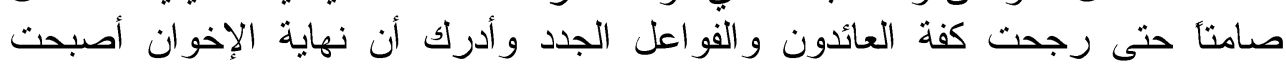

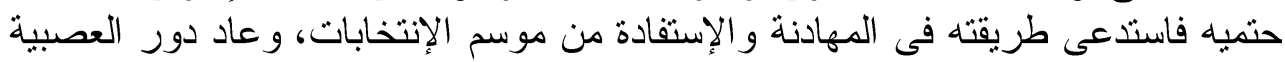

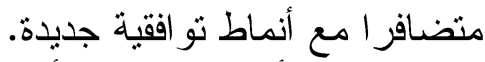

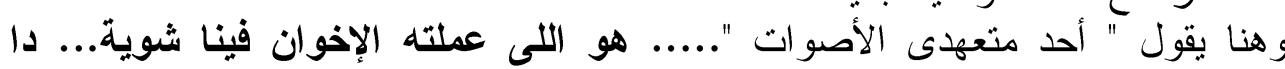

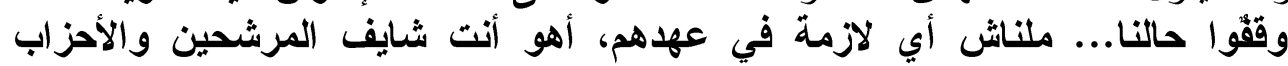
بتجرى ورانا وكله برزقهه....

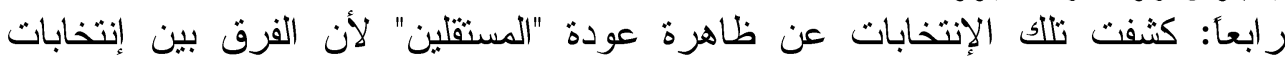

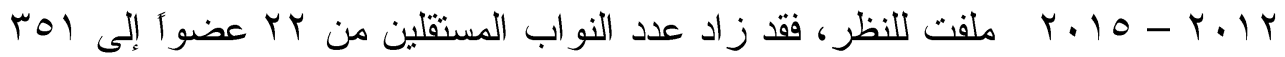

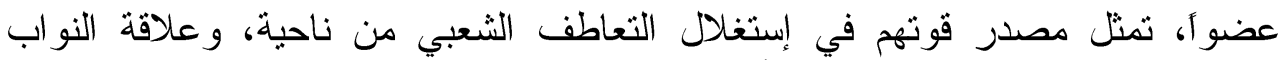

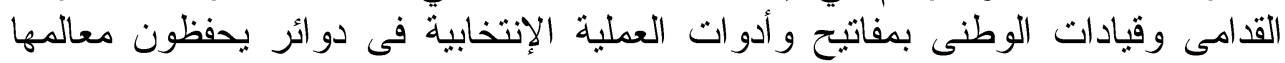

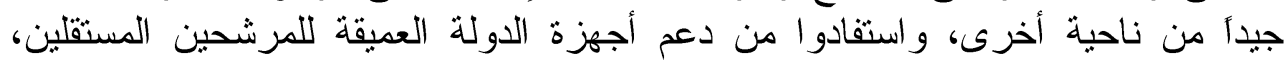
تحسبأ من حصول أحد الأحزاب مجهولة الهوية لأغلبية النواب.. إضافة الإلة إلى الإستثمار المكثف فى مجال العمل السياسي من فبل رجال رجال الأعمال و المؤسسات الخفية.

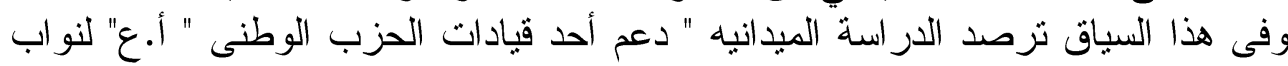

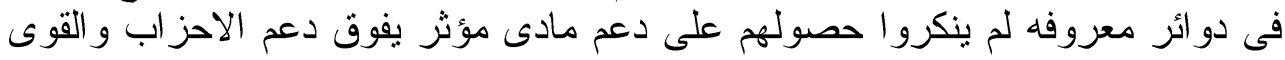

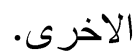

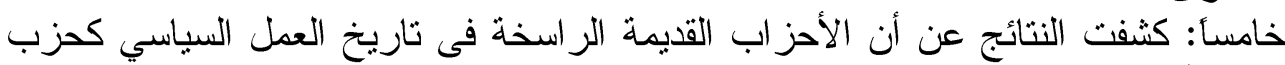

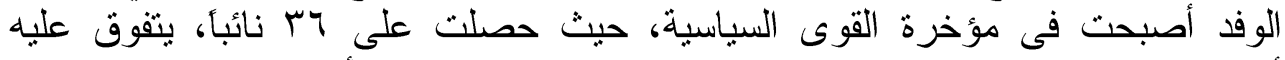

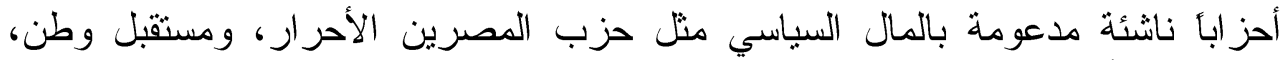
وقريبة من أحز اب لم تكن معروفة مثل الشعب الجمهوري و المولئ المؤتمر ، وحماة وطن.

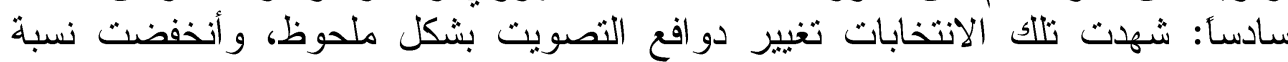

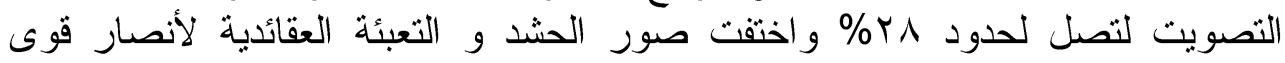

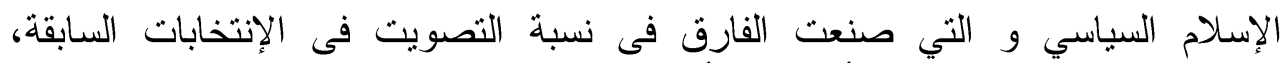

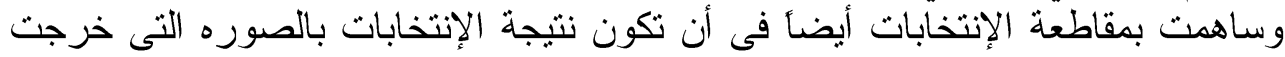

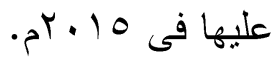

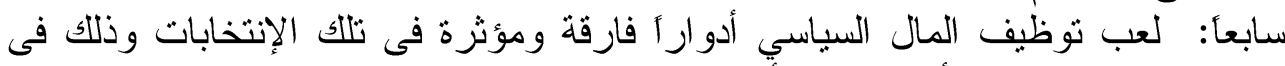

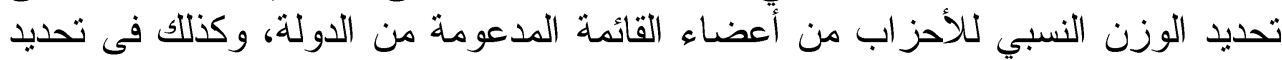
قدرة الحزب على إستقطاب مرشحين على قو ائمه أو دعم مستقلين تابعين لله، إضافة إلى إلى 


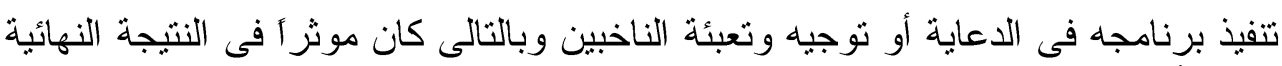
لقوة الأحز اب المتتافسه فى العملية الإنتخابية. ثامنأ: أظهرت تلك الحقبة القصيرة نسبياً في تاريخ الحياة الحزبية المصرية رغبة جهات

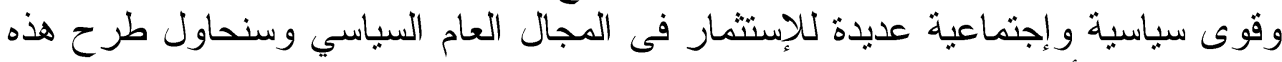

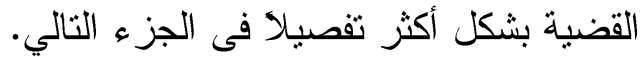
تاسعأ:- تبلورت فى العملية الإنتخابية وخلاّل مر احلها وتحالفتها المختلفة مفاهيم وظواهر

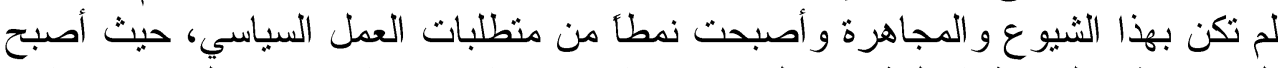

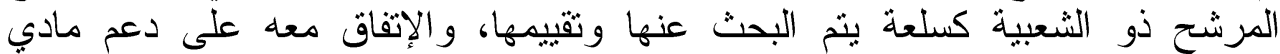

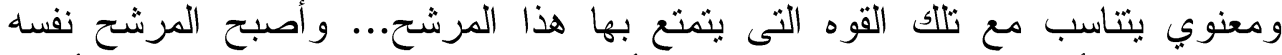

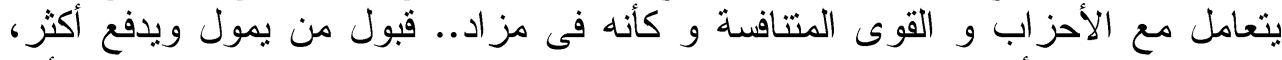

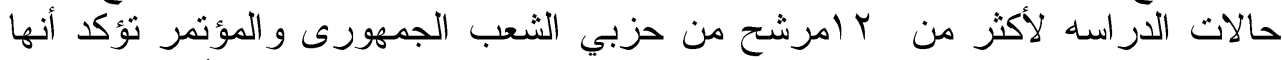

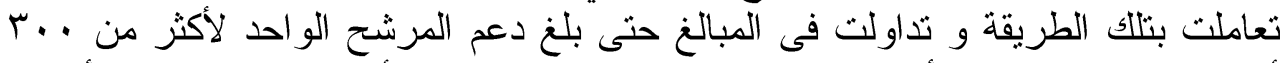

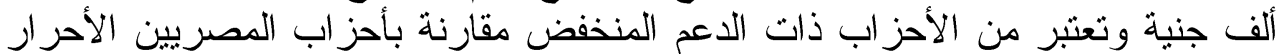
أو الأحز اب ذات ذات المرجبر من الاحزية الدينية.

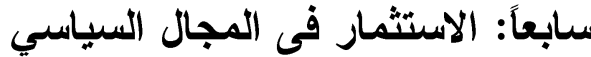

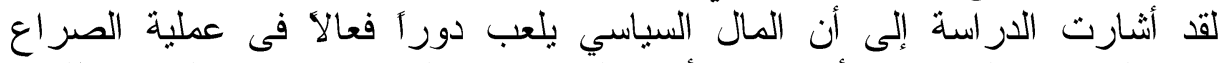

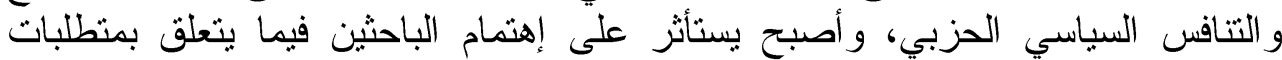
سلامة النظم الديمقراطية وتتتامي أهمية المال السياسي فى مجتمعات تمر بتحولات التات

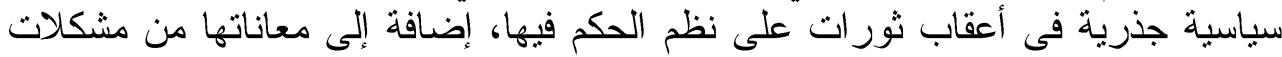

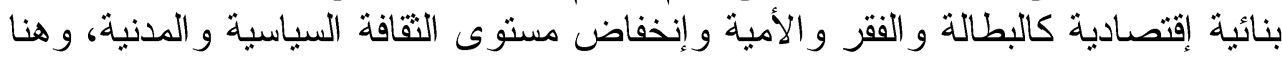

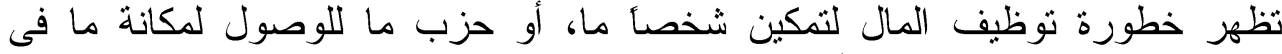

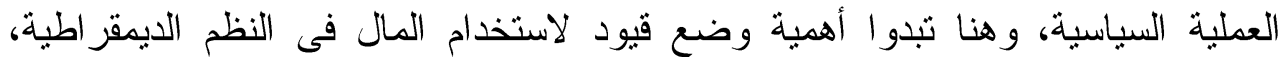

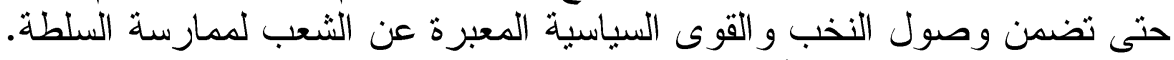
وفى سياق ذللك، أصبحت الثركات العملاقة، و القوى الاجتماعية و السياسية التعانة

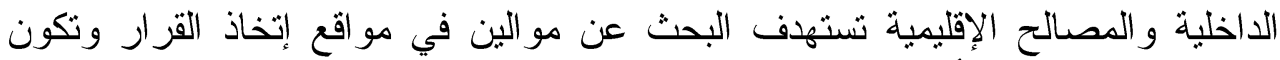

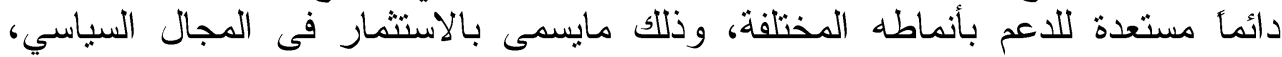

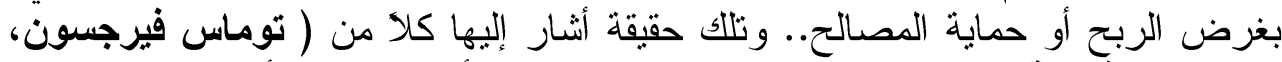

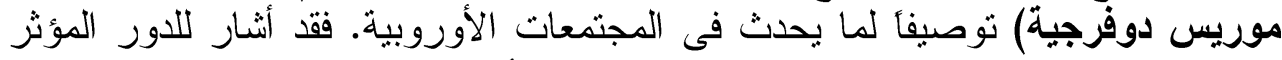

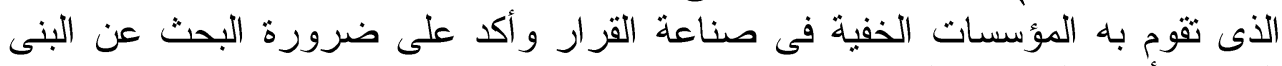

وفقأ لهذا الفه وتطبيقا على الحالة المصرية فى حقبة التحو لات السياسية الجوهرية

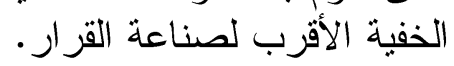

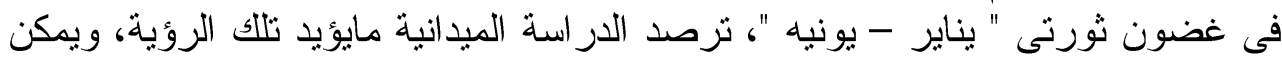

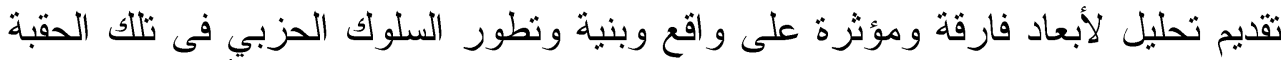

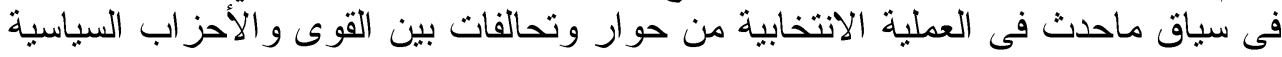

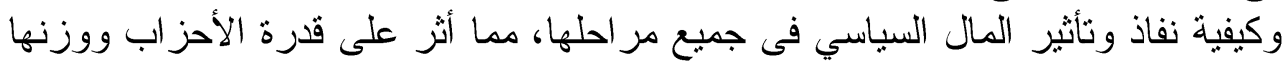
النسبي فى تحقيق النتائج النهائية.

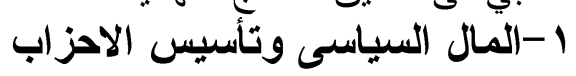

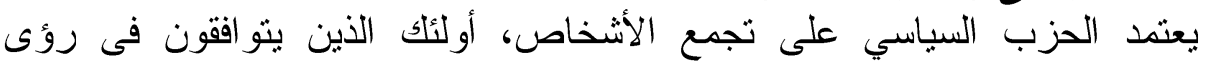

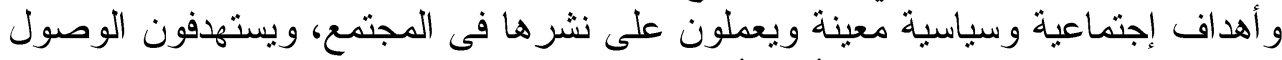
للسلطة لنشكيل النظام السياسي أو التأثير على السلطة القائمة فى إتخاذ القرارات، وروفأ 


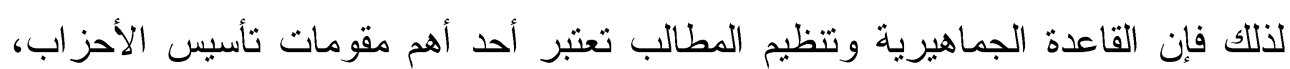

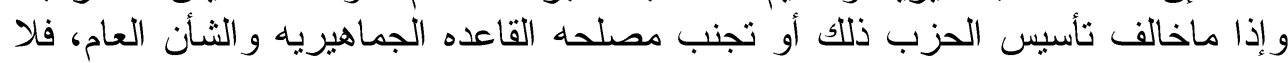

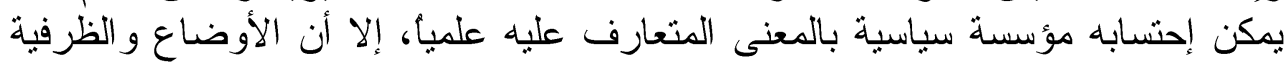

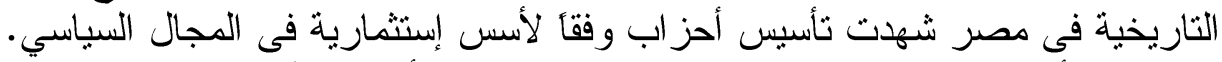

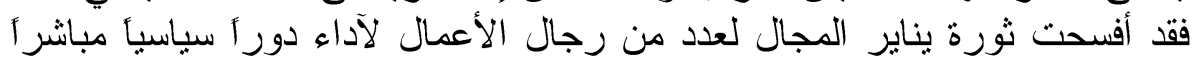

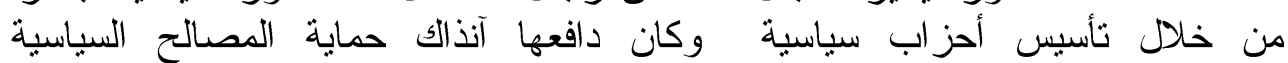

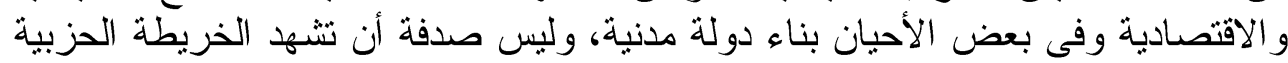

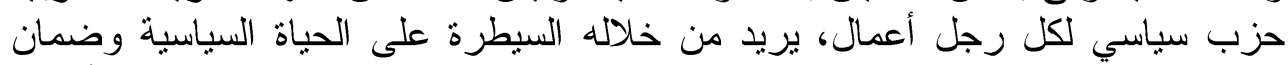

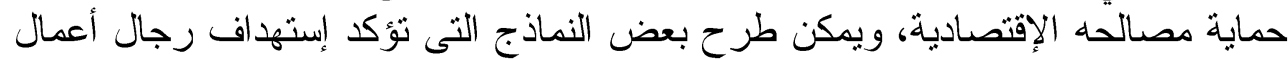
المجال السياسي بقوة منها يلئى

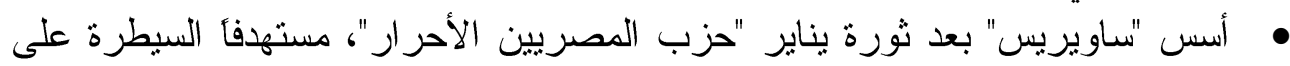

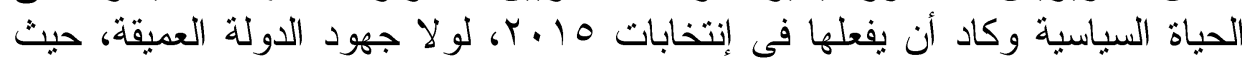
وقف حد تأثيره بحصد 10 مقعدأ متصدر أ كافة الأحز اب المتنافسه في لتلك الإن الإنتخابات.

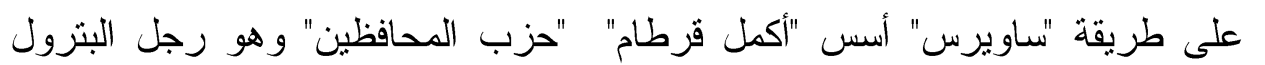

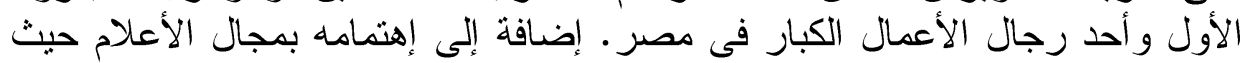

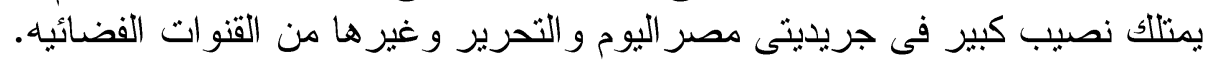
• أسس أيضا الربان "عمر صمبدة" " حزب المؤثمر" وهو وأيضأ من رجال الأعمال و القبائل العربية.

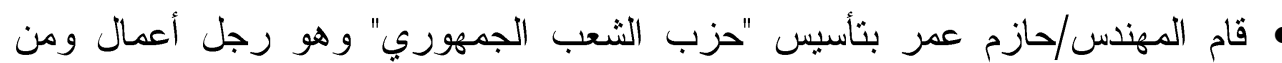

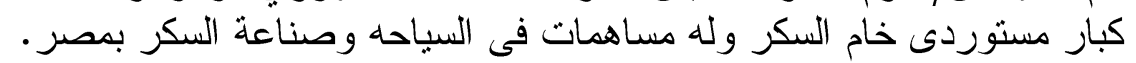

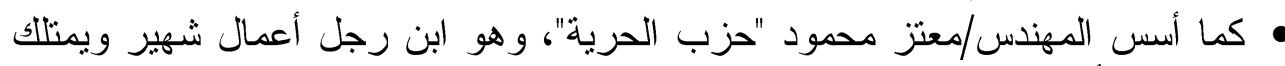

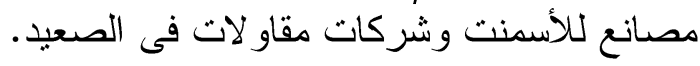

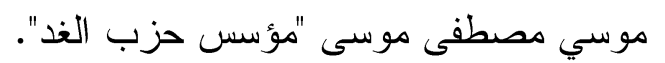

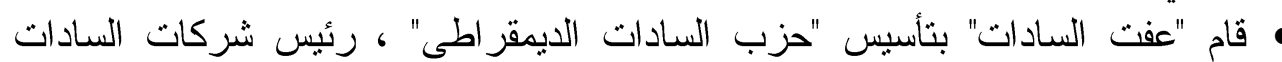

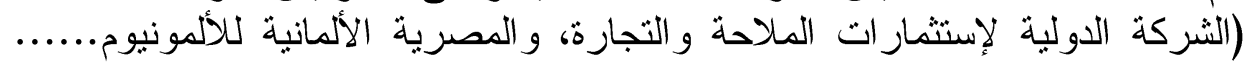

• قام " طارف نديم " بتأسيس " حزب الصرح المصرى"، وهو رئيس مجلس إدارة

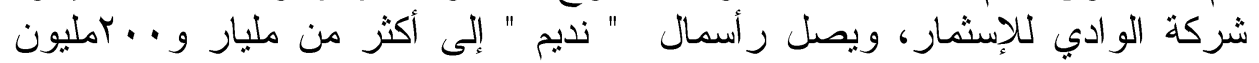

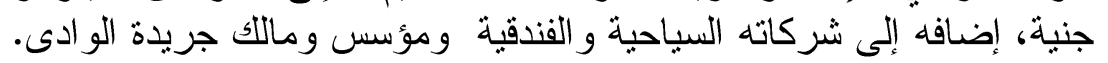

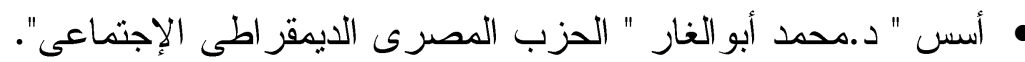

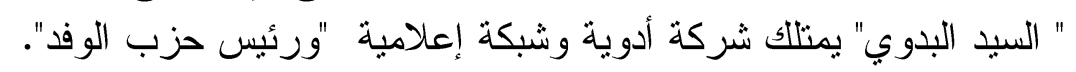

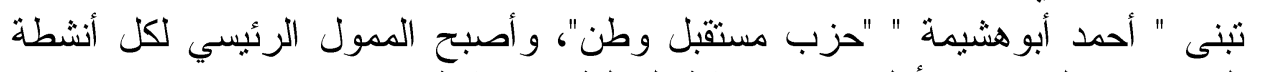
الحزب فى السنو ات الأولى وحتى نهاية العملية الإنتخابية.

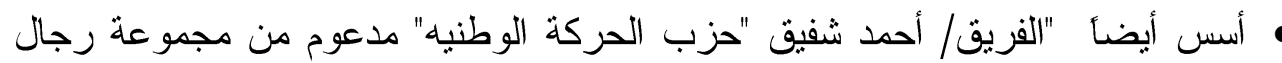

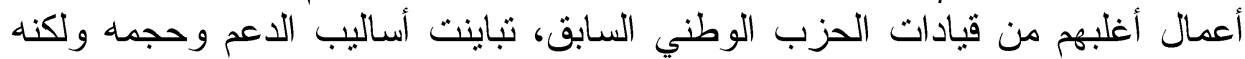

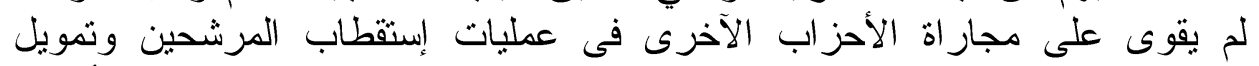

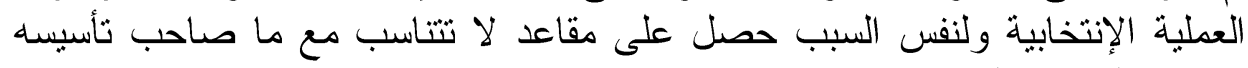
من ضجة إعلامية. 


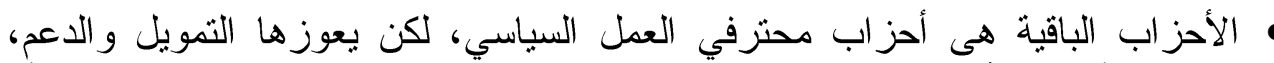

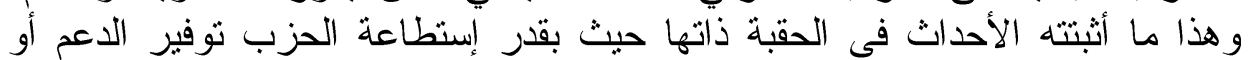
تسويق ذاته سياسيا إستطاع أن بحجز مكاناً فى الخريطة الحزبية.

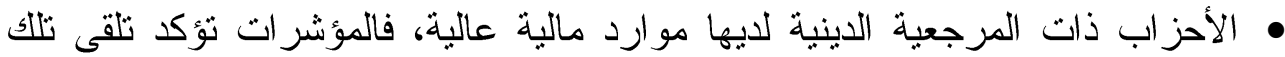

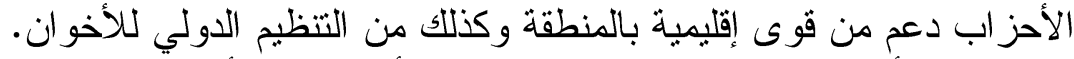

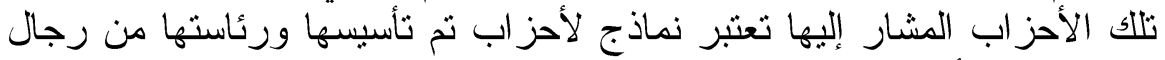

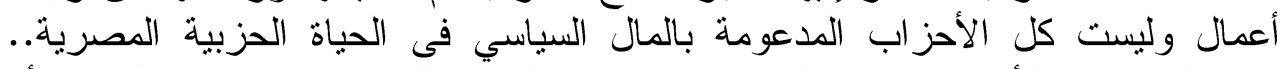

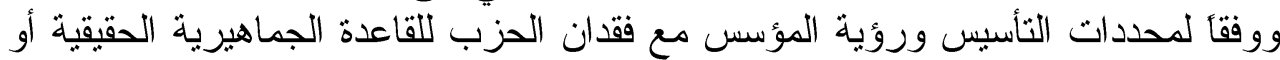

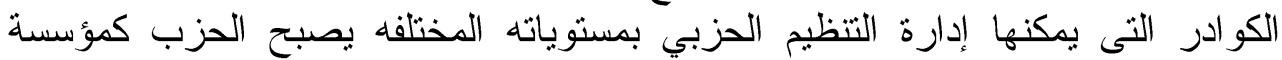

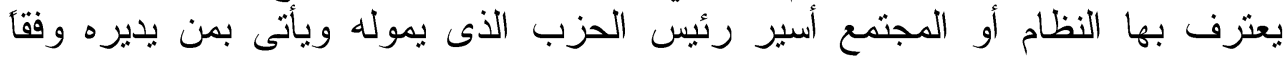

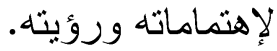

وفى هذا السياق يمكن عرضن بنه بعض نماذج الأحزاب التى إستعانت بمحترفى العمل

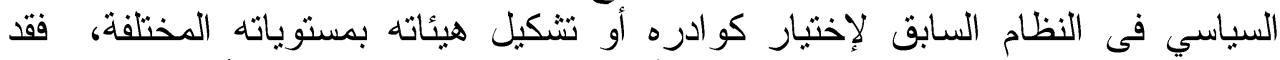

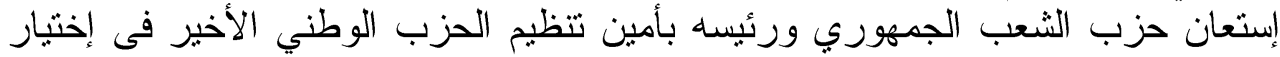

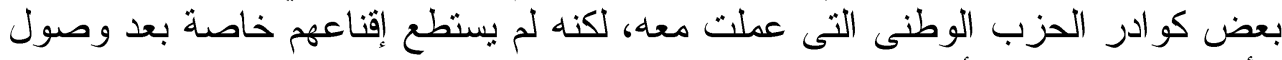

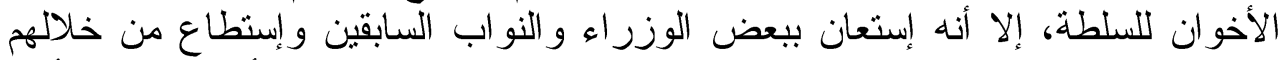

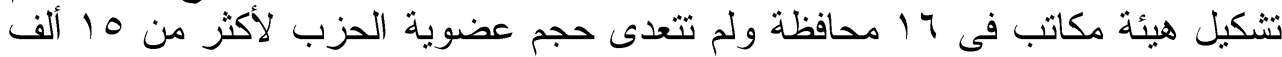
فى الو اقع. • بنفس الطريقة إستعان حزب المؤتمر بأحد النواب السابقين وبعض قيادات الوطنى ولم

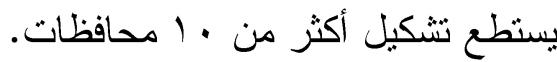

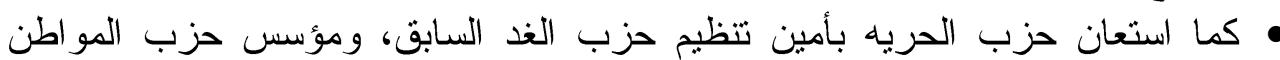

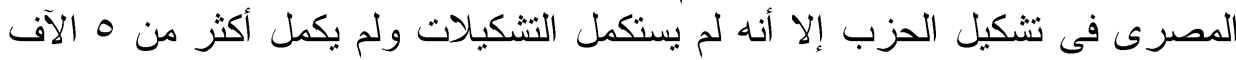
عضو عامل. • حزب المحافظين إستعان بنائب عابدين ومجموعة صحفية و إعلامية ولم بحقق على لـ مستوى التشكيل نجاحأ ملحوظأ.

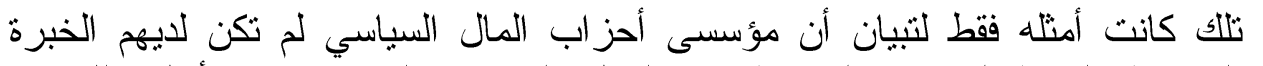

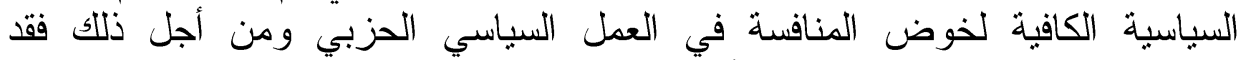

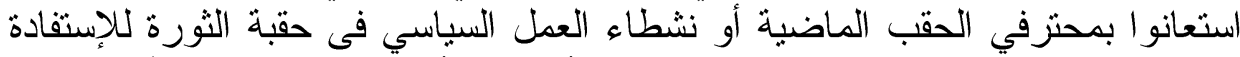

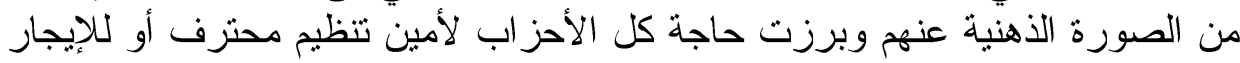
يقوم بإدارة تشكيلات الحزب الأبن بالوكالة.

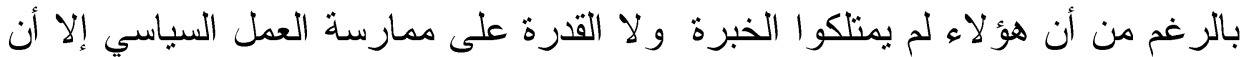

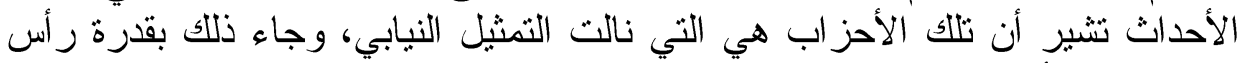

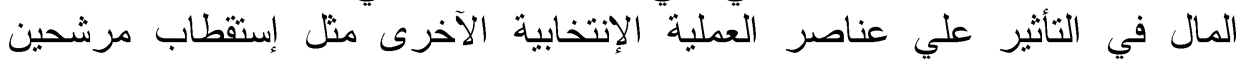
يمتلكون شعبية و الحصول على حصص من القو ائم، و القدرة على التّلى التسويق فى وسائل

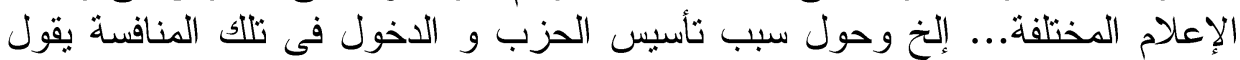

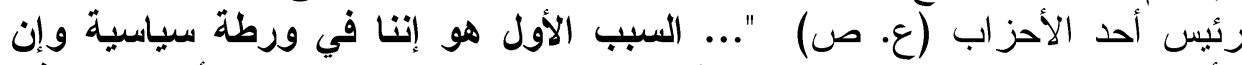

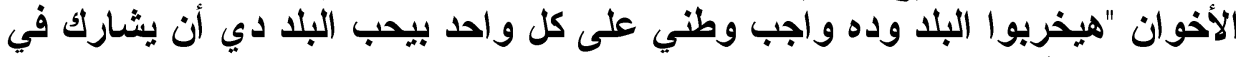
تكوين حزب أو تحالف عشان البلد متضعش ودئ.....". 
أما (أ.ف) فيقول "... من قبل الثورة و أنا بشارك في السياسية ولكن النظام كان

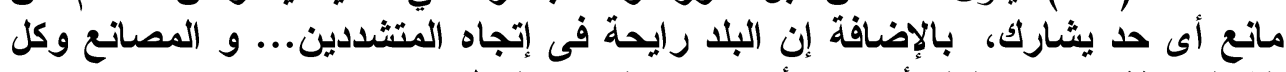

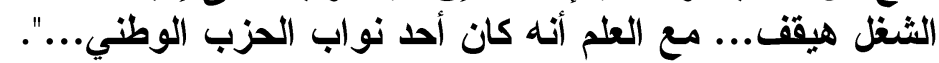

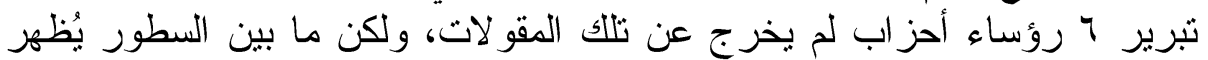

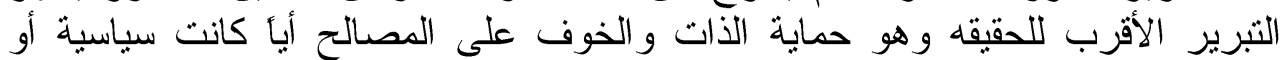

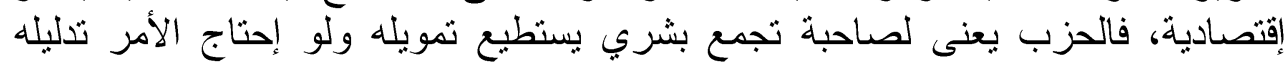

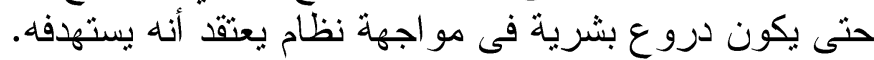

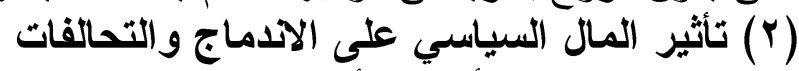

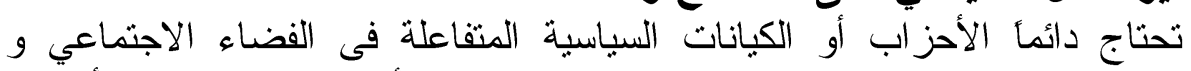

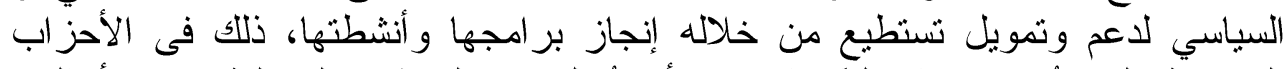

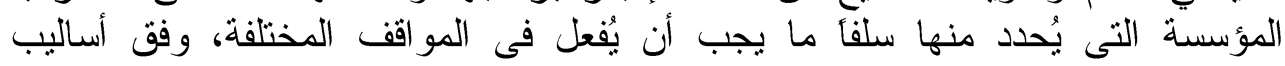

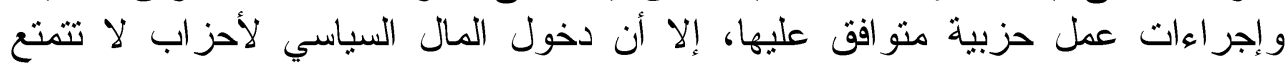

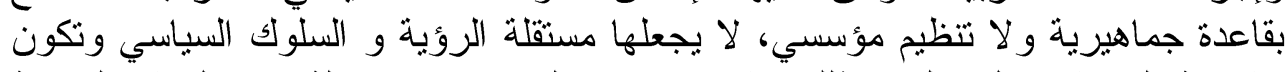

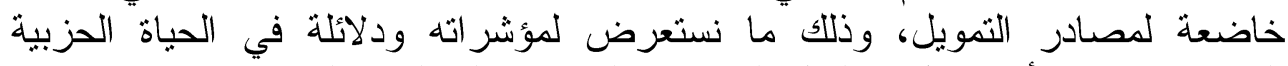

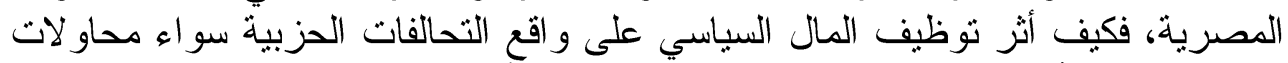

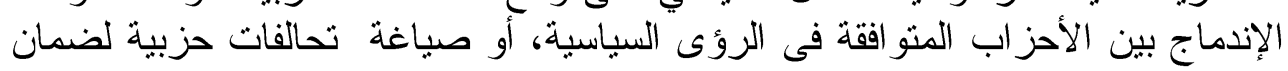

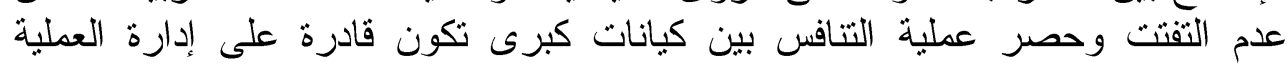

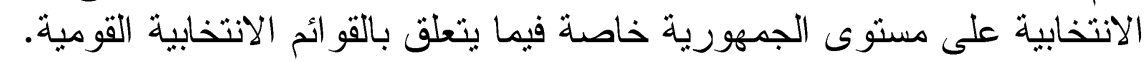

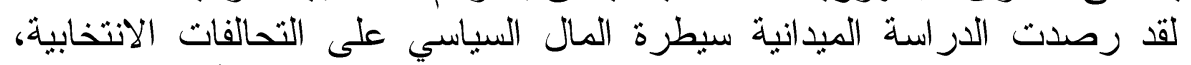

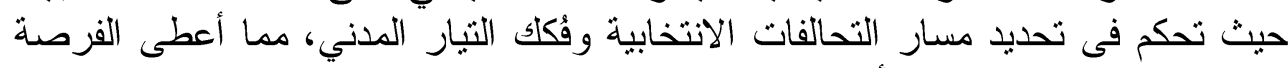

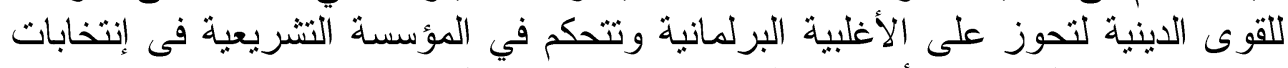

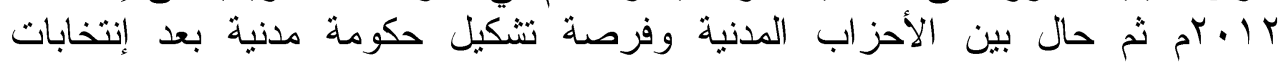

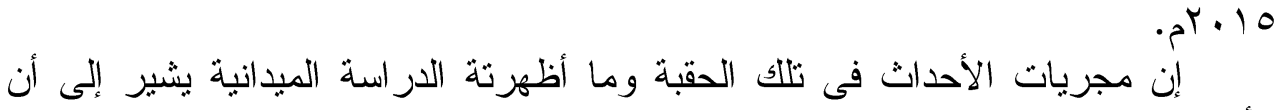

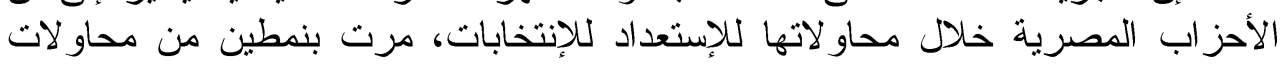

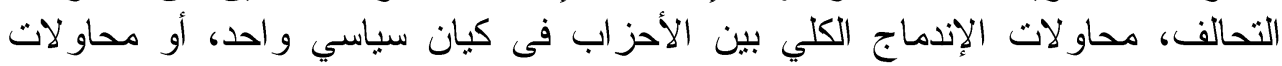

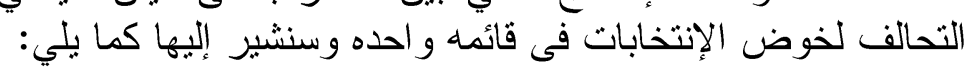

أ- محاولات الآدماج

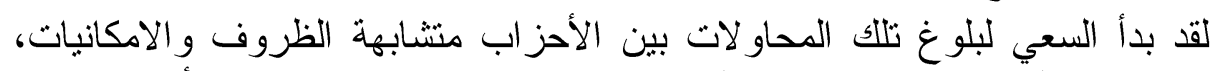

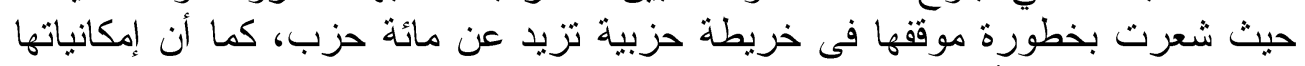

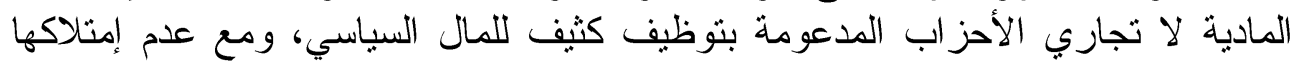

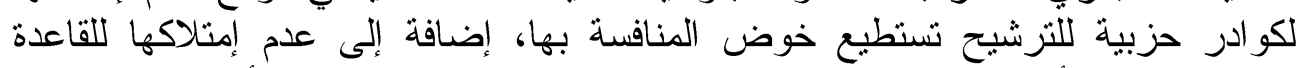

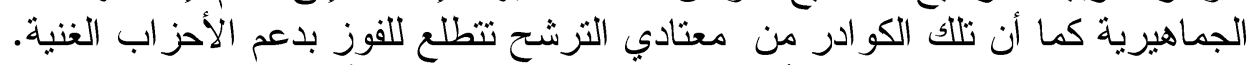

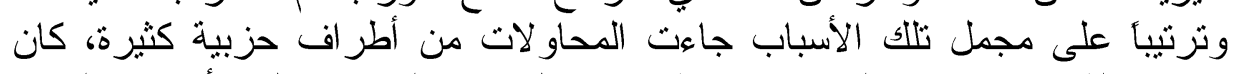

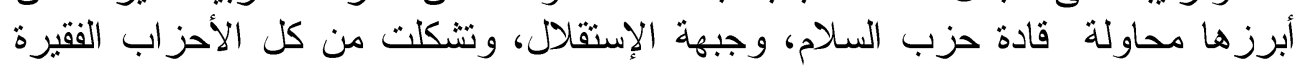

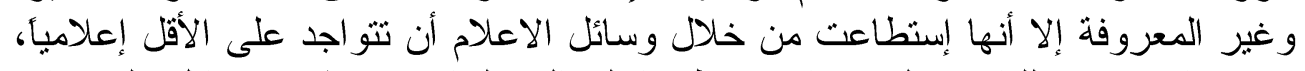

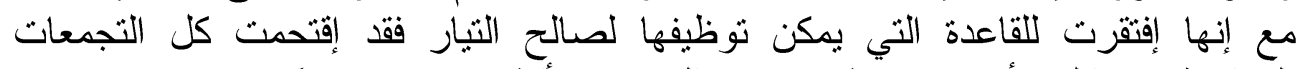
السياسية ووسائل الأعلام متحدثين عن تحالف يضم أكثر من لـ بـ حزبأ. 


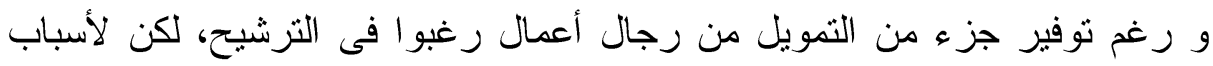

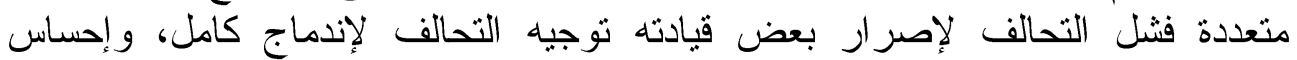

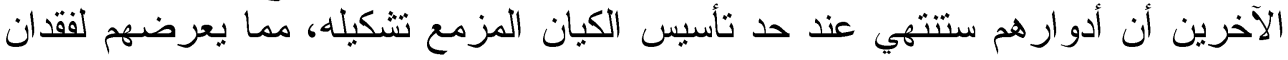
مو اقعهم القيادية.

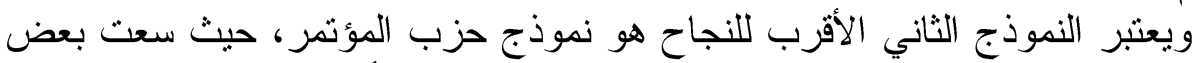

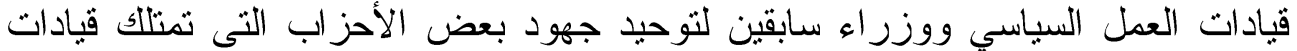

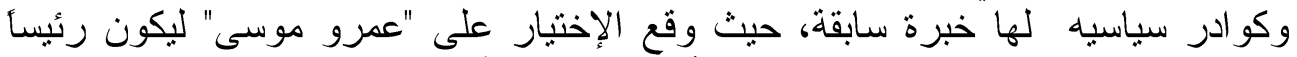

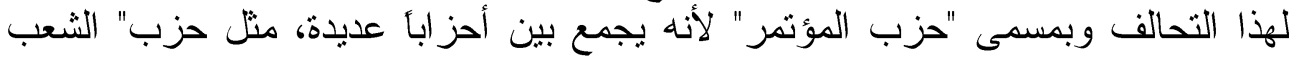

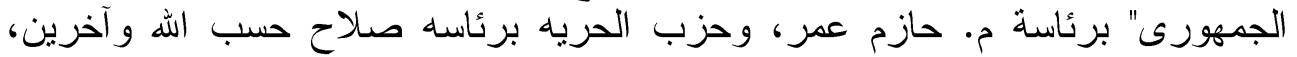

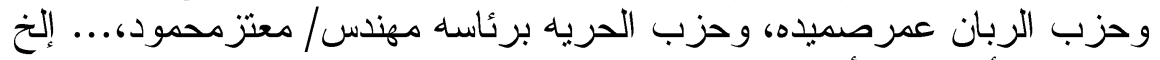

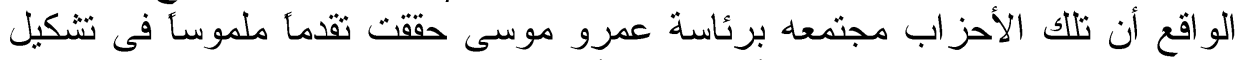

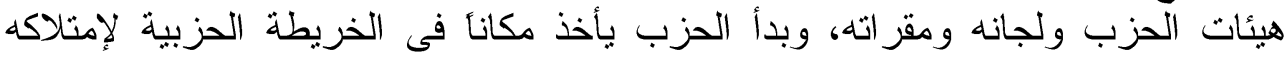

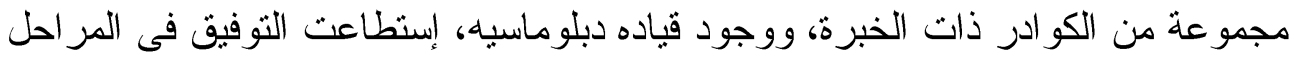

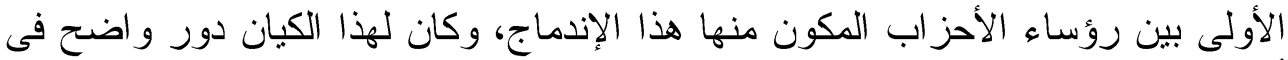

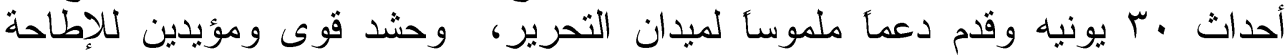

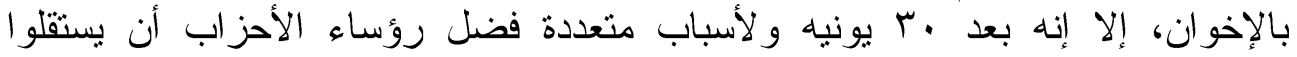

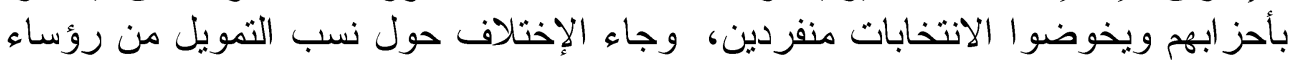

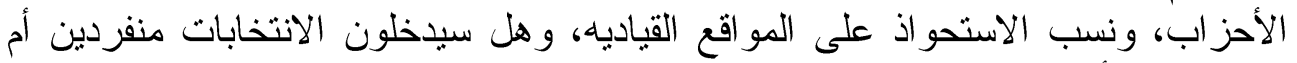

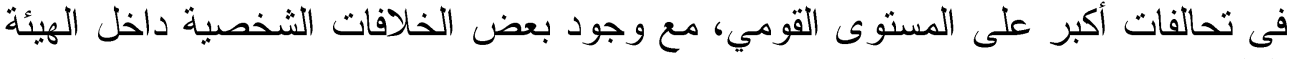
العليا.

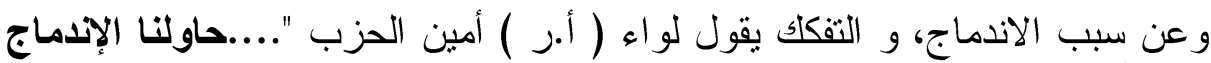

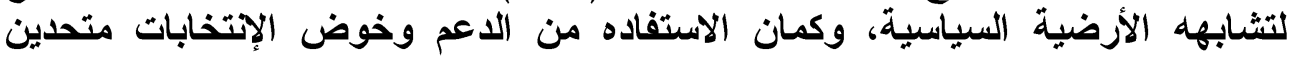

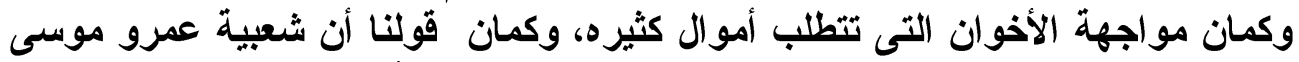

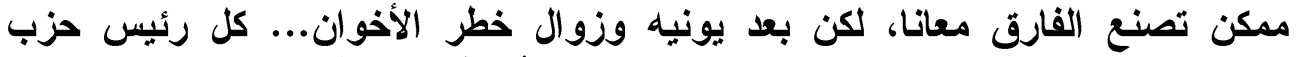

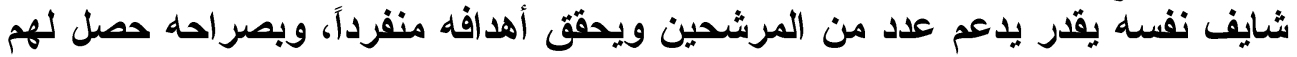

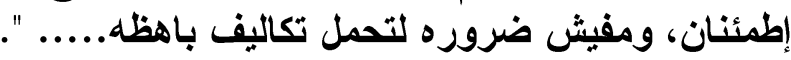

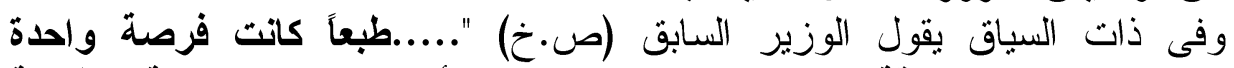

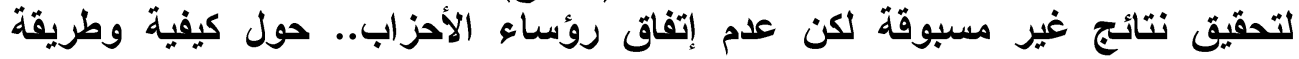

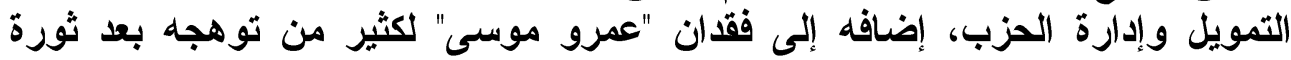

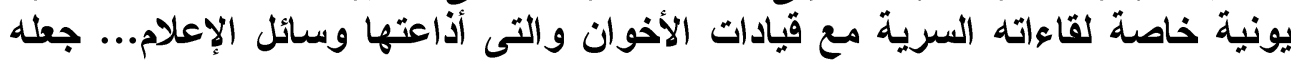

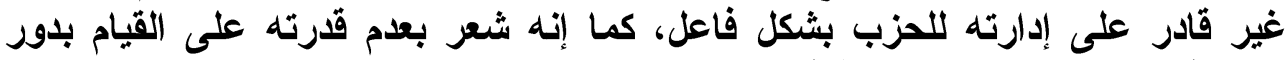

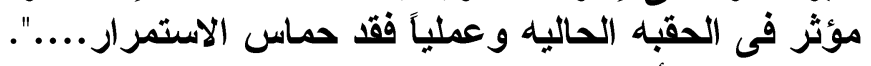

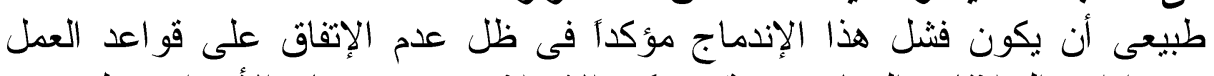

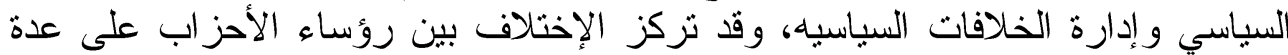
قضايا تحدد أولوية العمل الحزبي الحفات من أهمها:

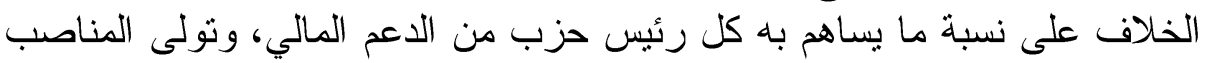

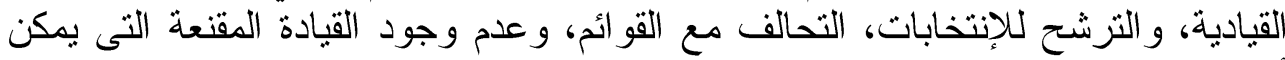

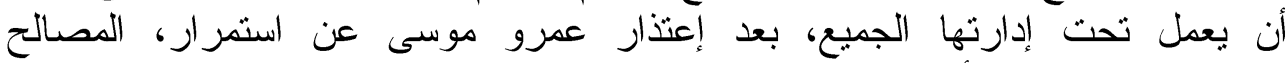

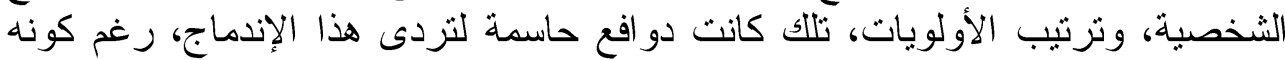

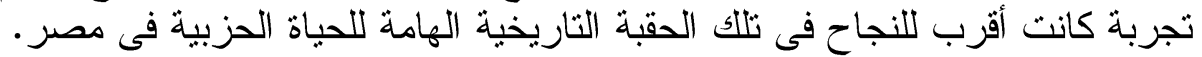




\section{ب- التحالفات الإتتخابية بين قبضة الدولة العميقة والمال السياسى:}

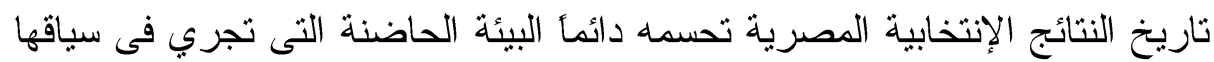

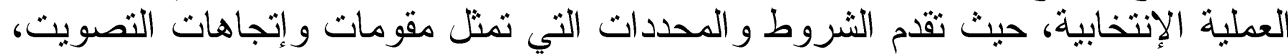

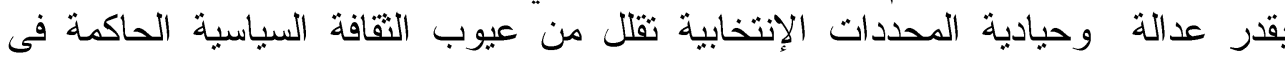

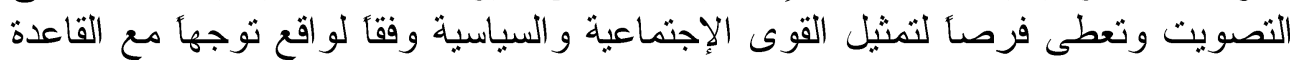

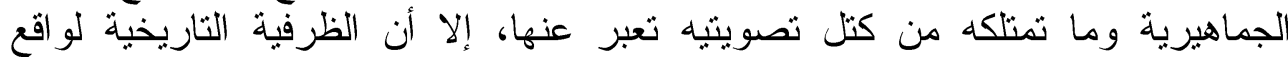

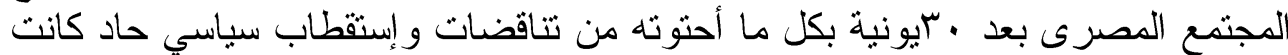

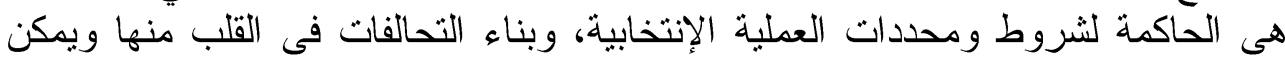

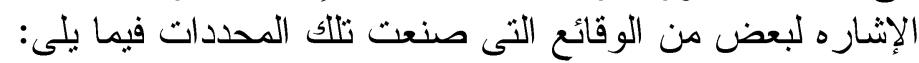

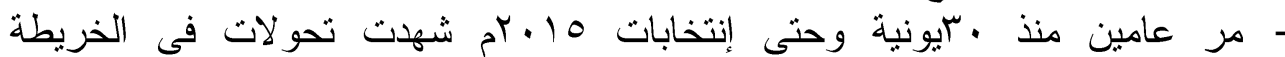

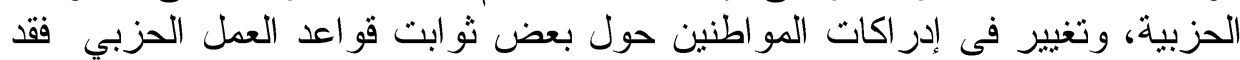

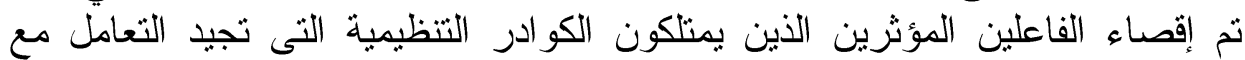

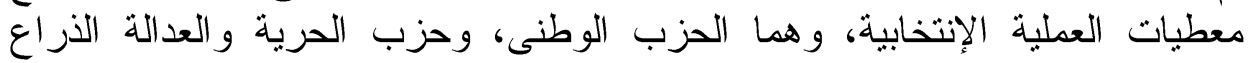

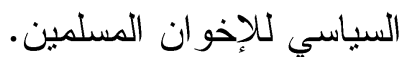

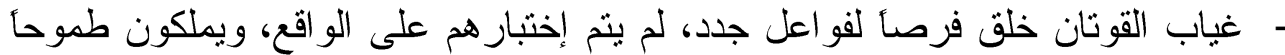

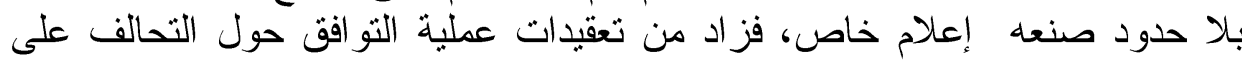

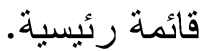

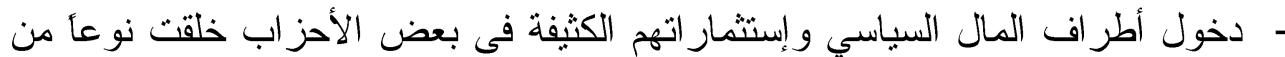

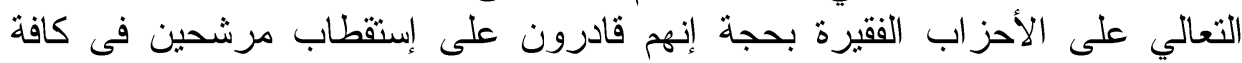
الدو ائر يحسمون بهم النتيجة الإنتخابيه. - تثشير الأحداث إلى حدوث تغيير فى معايير إختيار المرشح، فلم تعد شعبية المرشح الإنه

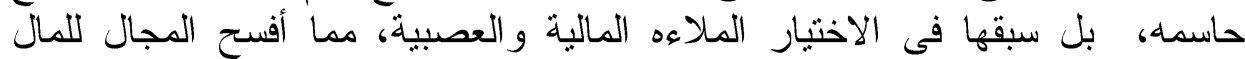
ـ السياسي فى إحتلال المعبار الأقوى فى الإختيار. - لعبت دوائر العلاقات غير الرسمية، ورأس المال الإجتماعى دورأ مؤثرأ فى الحوار وبناء التحالفات الإنتخابية.

- - دخل الإعلام الخاص بثقله فى حوار التحالفات، وساند بقوه بعض القوى القوى السياسية

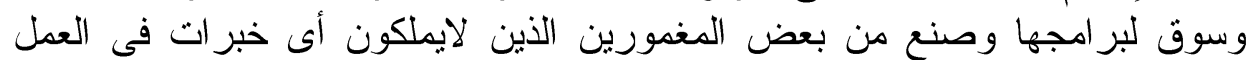

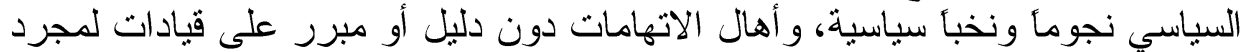

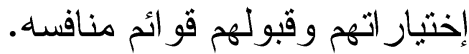

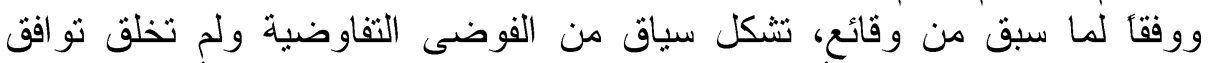

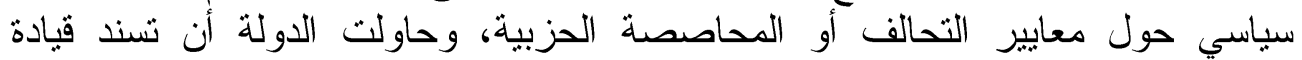

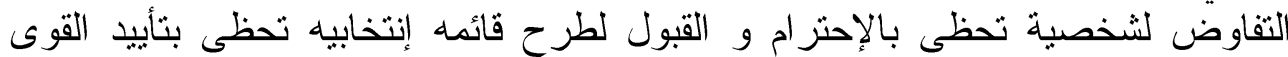

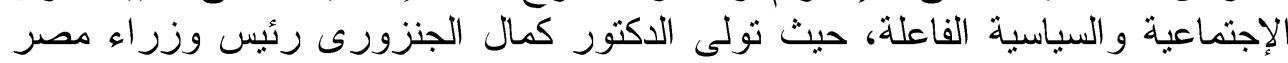

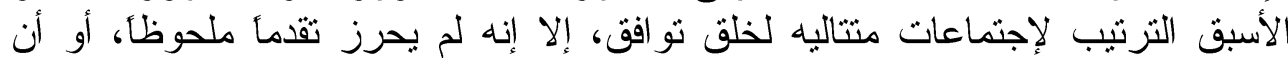

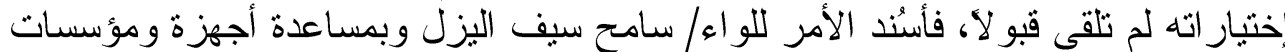

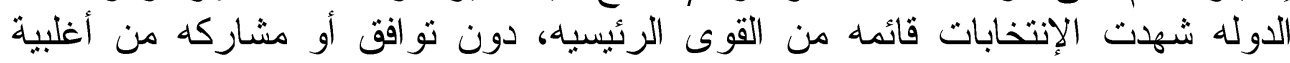
أحز اب الخريطه السياسيه آنذالك. 


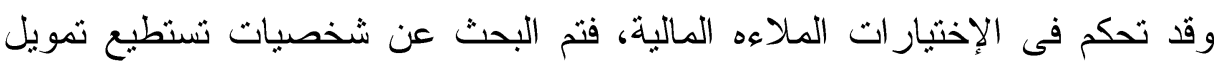

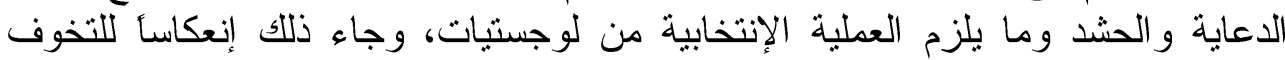

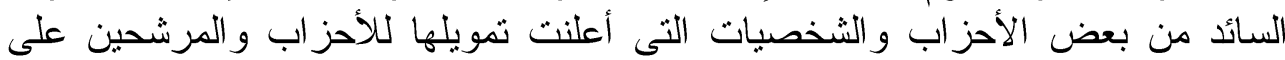

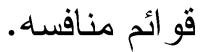

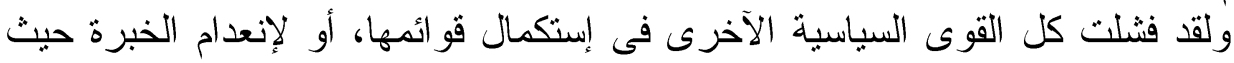

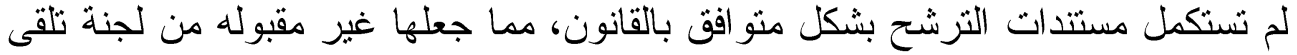

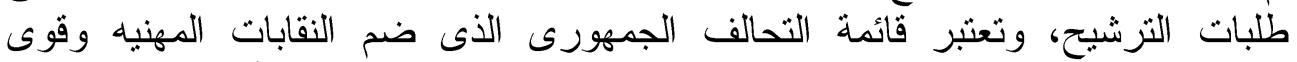

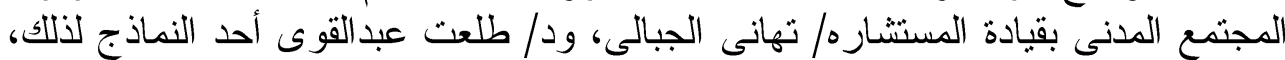

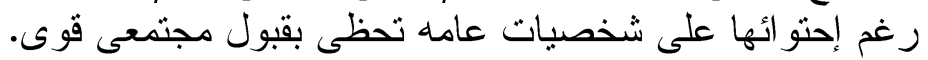

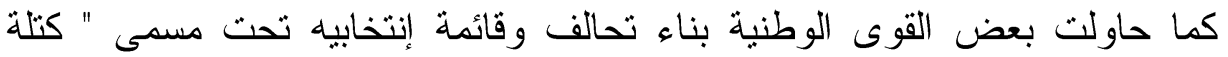

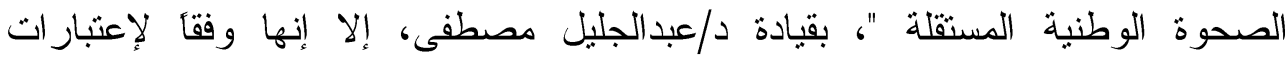

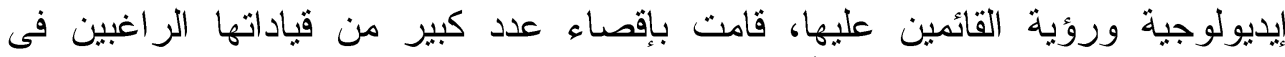

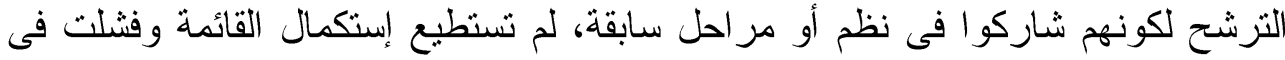

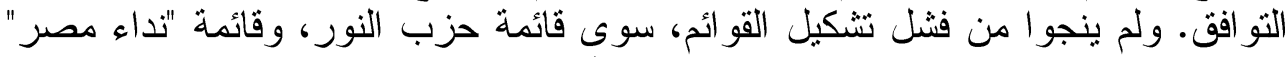

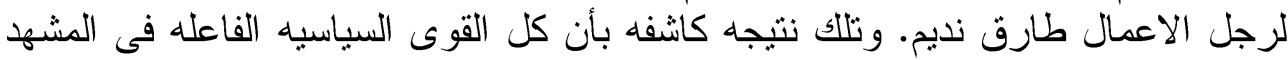

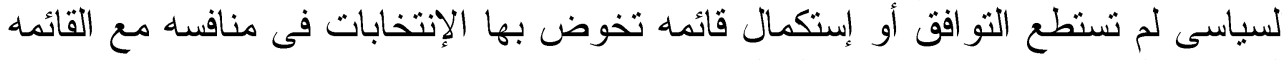

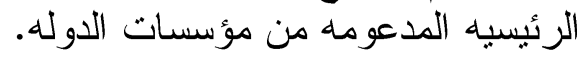

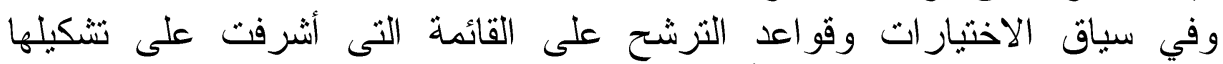

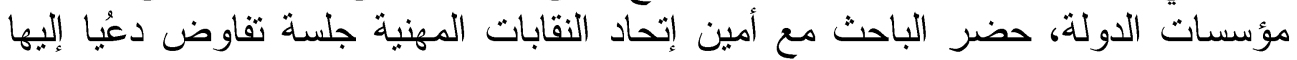

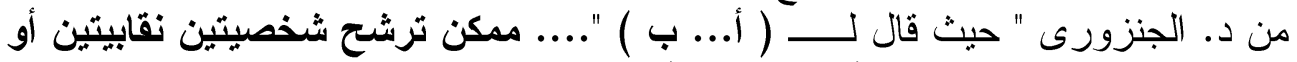

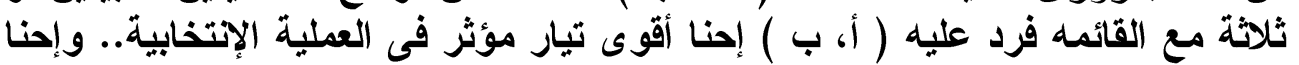

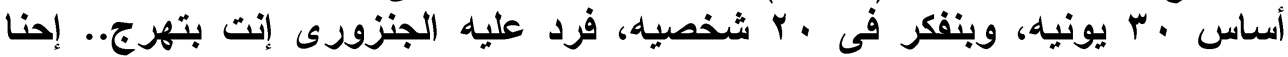

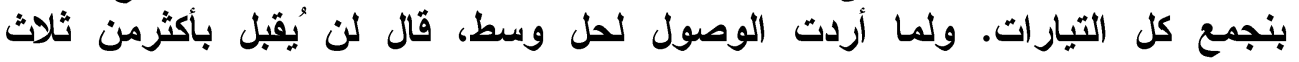

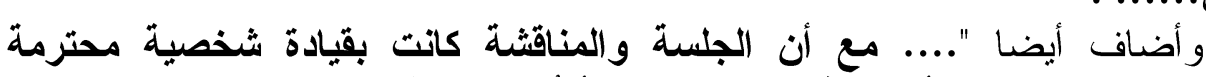

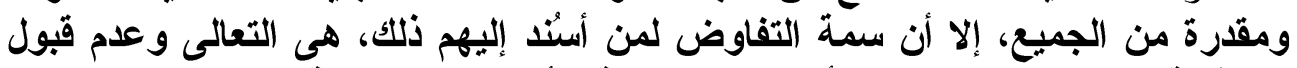

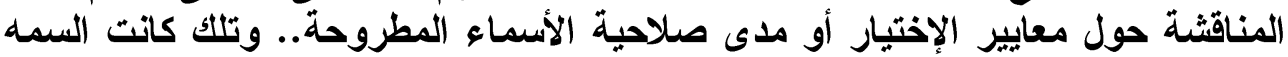

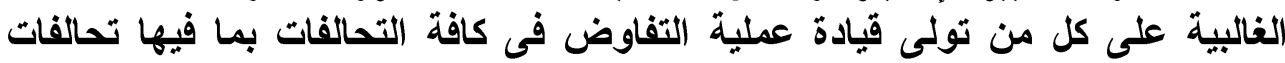

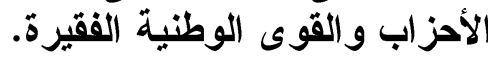

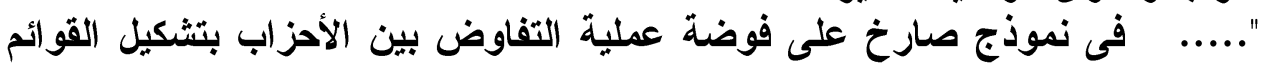

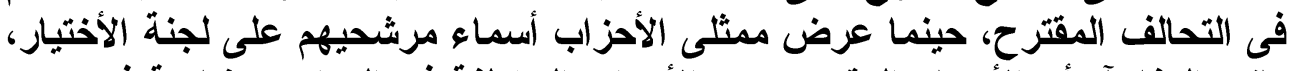

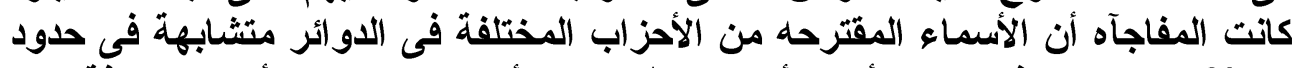

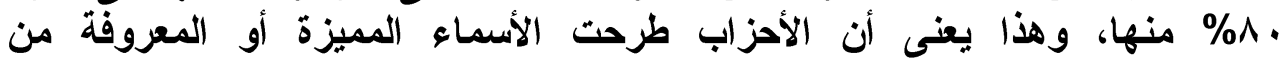

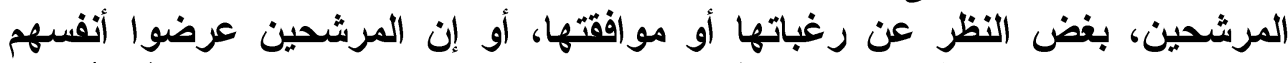

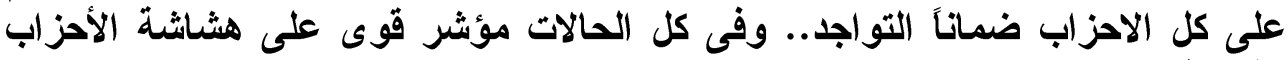

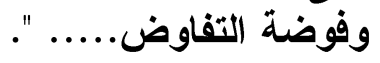

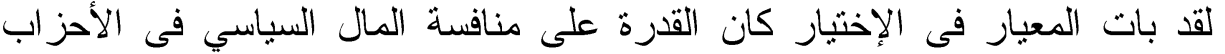

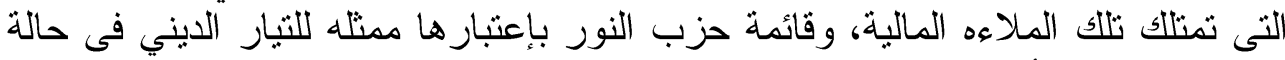
مشاركة الإخوان أو قبولهم التصويت لهالة لها. 


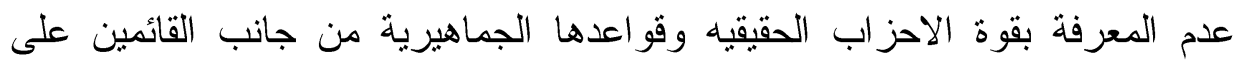

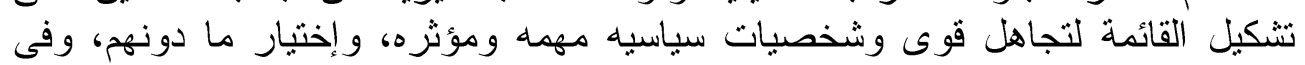
النهاية تم إنجاز القائمه بقوة الدولة التهلة العميقة.

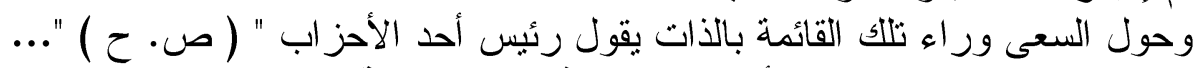

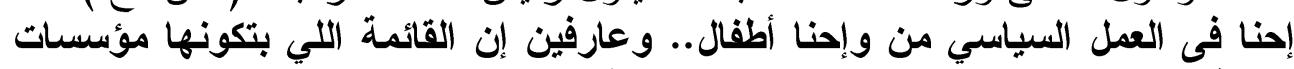

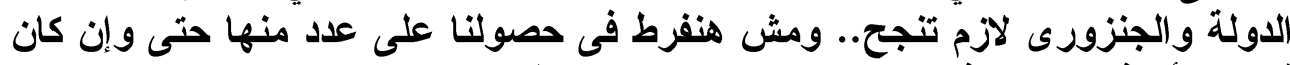

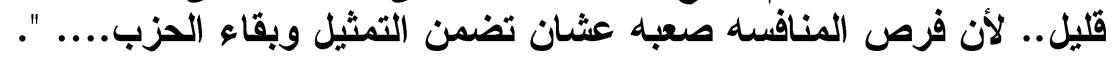

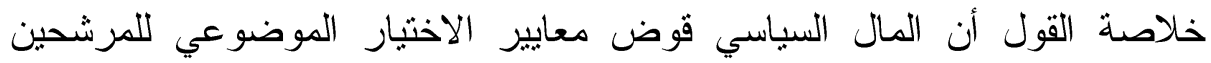

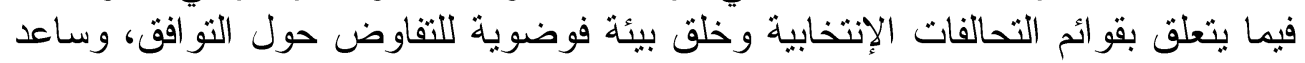

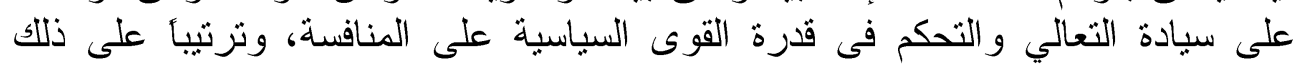

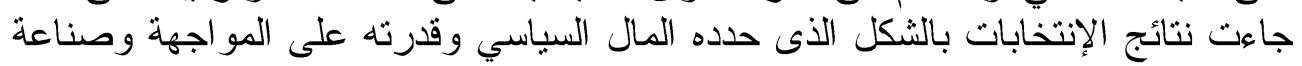
الفارق.

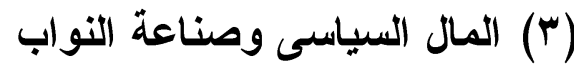

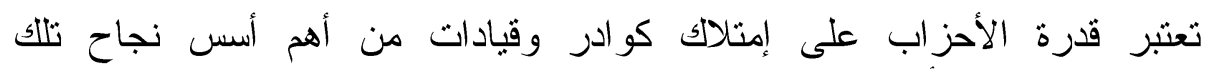

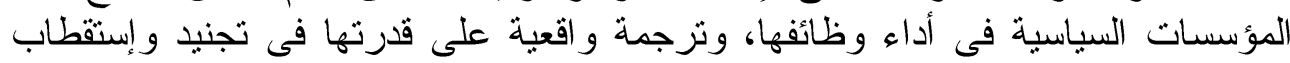

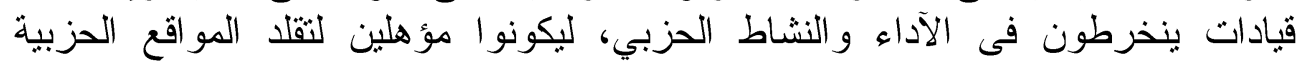

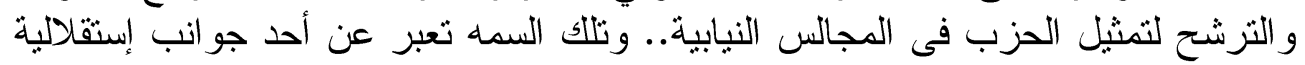

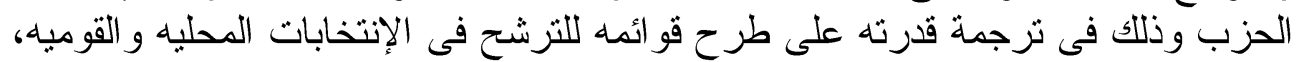

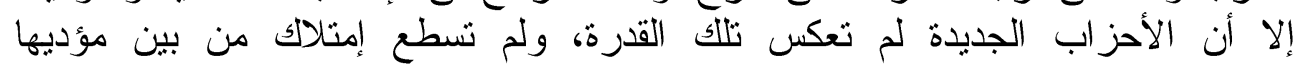

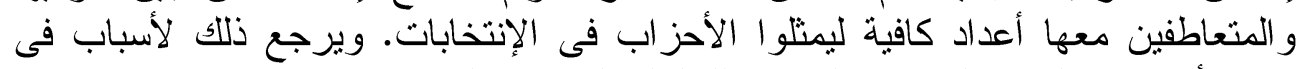

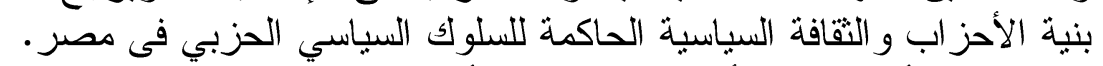

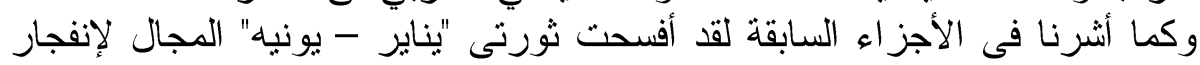

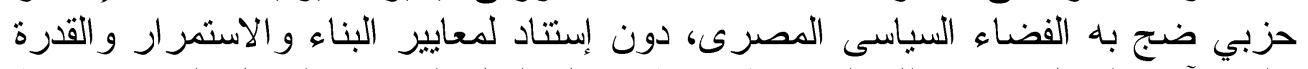

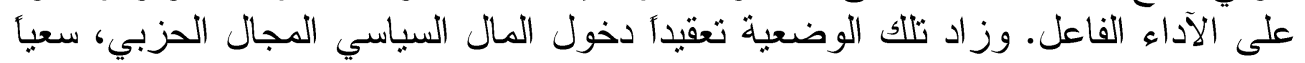

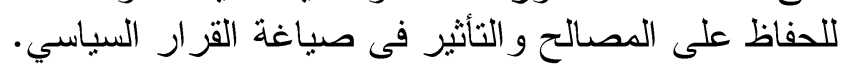

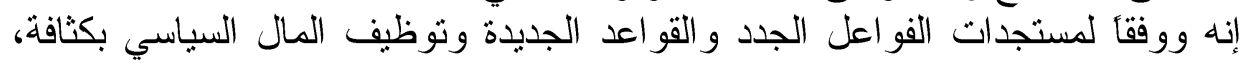

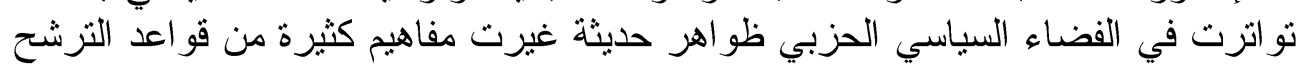

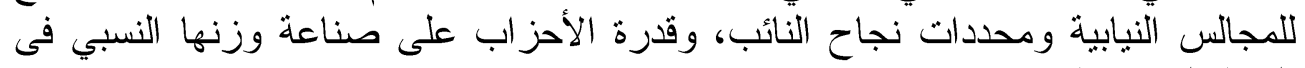
الهيئة النشريعية.

بالرغم من أن غالبية الأحز اب مدعومه بالمال البال السياسي مع إختلاف درجته، إلا أنها

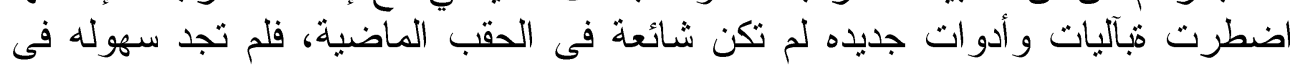

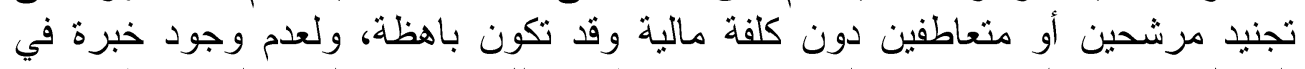

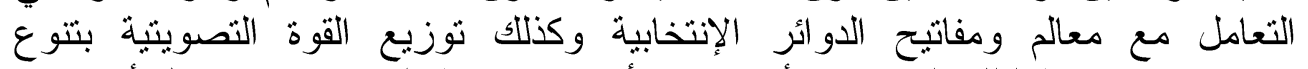

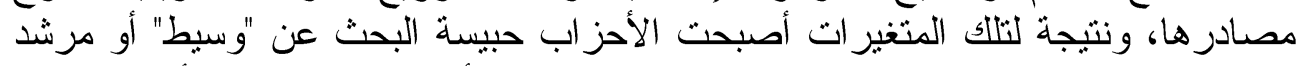

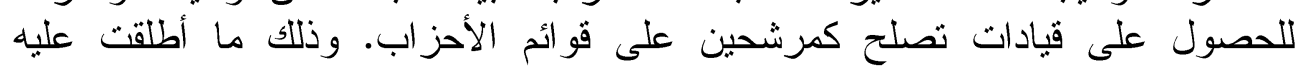

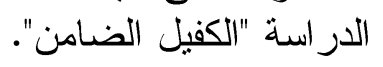

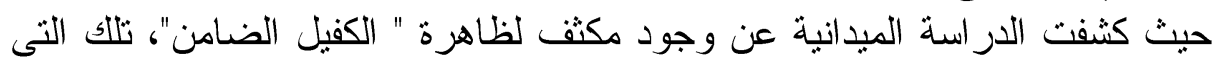

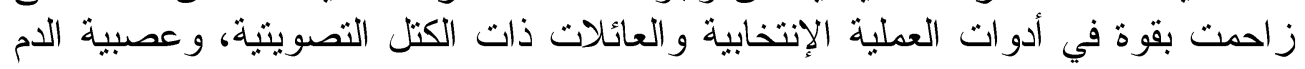
و المكان كعناصر بناء شعبيه المرشح، ومعطيات منطقيه لتوقع قدرته على الإنى النجاح، إلان انه 
بعد توظيف المال السياسى الكثيف ظهرت الحاجه " للكفيل الضامن" لعدم خبرة رؤساء

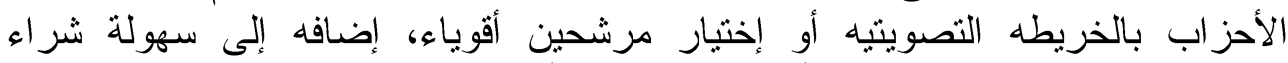

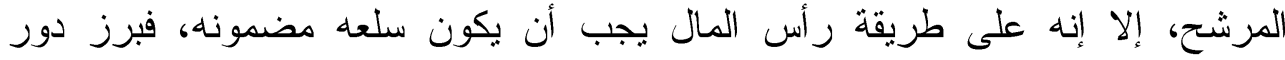

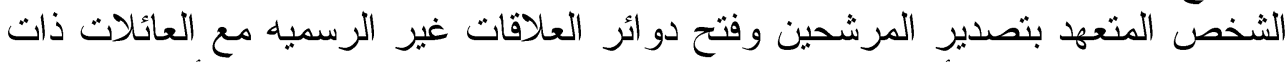

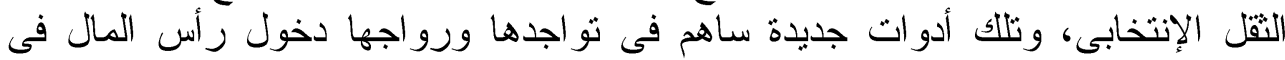

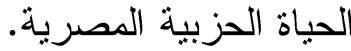
لقد ساهم فى تتامى تلك الظاهره تشبث الأحز اب بالتمثيل النيابي بأي ثن، فتعامل

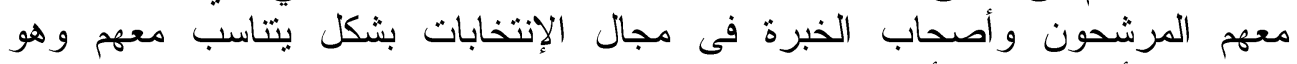
الابتز از، و أصبحت المسألة مز اد حول المرشح.

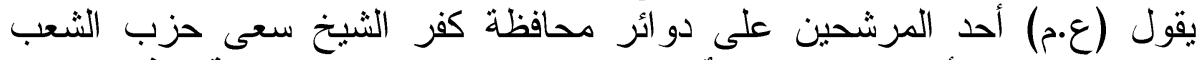

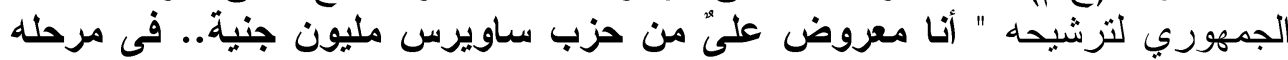

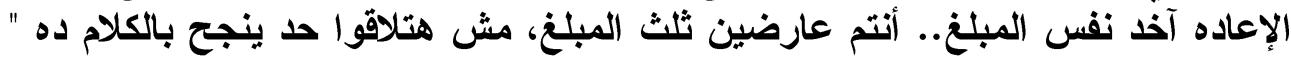

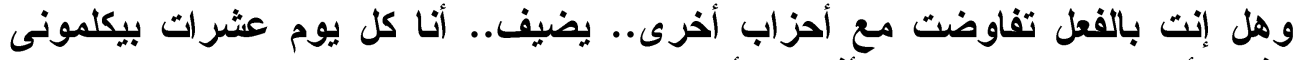

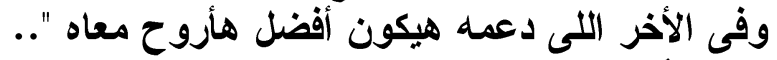

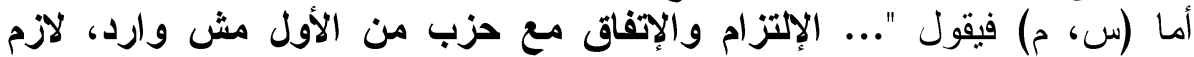

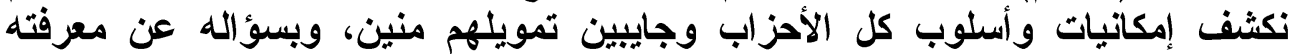

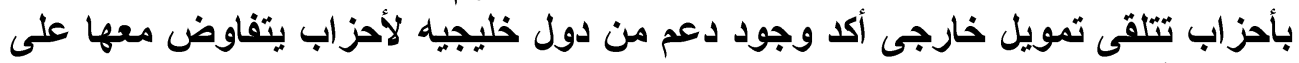

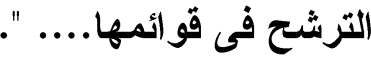

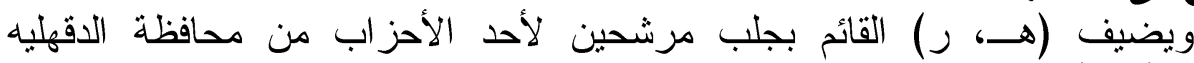
"الحقيقه أنا بأحب حزب الجبهة الوطنية عشان الفريق شفيق، بس حتى الآن مفيش

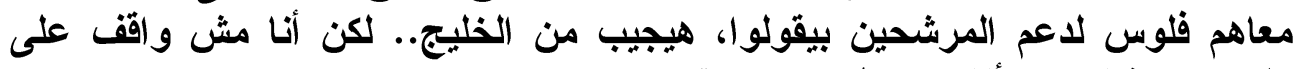

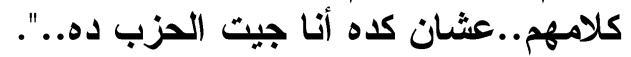
لقد وصلت درجة المساومة على المبالغ المدفوعة ألبات أن أن أحد متعهدى النواب بالفيوم

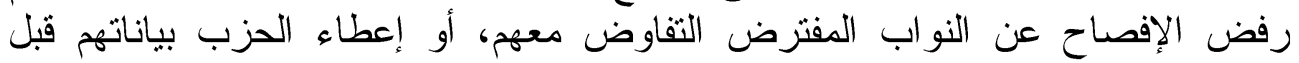

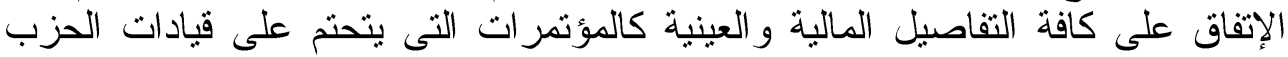
حضور ها بمستوى وزر اءو ومحافظين سابقين معروفين.

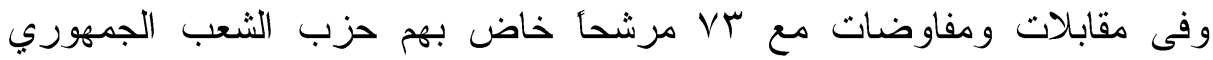

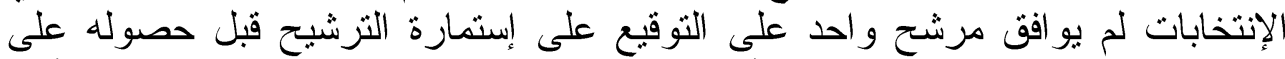

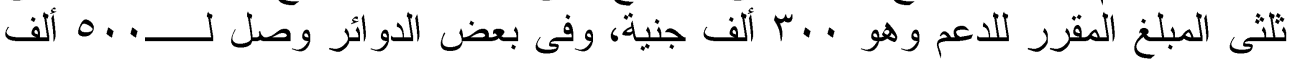

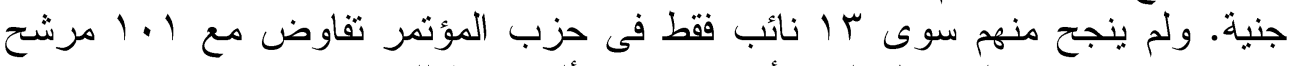

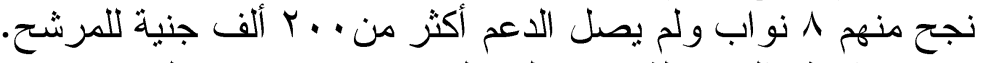

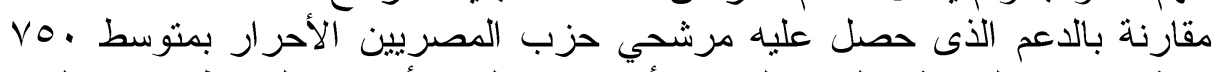

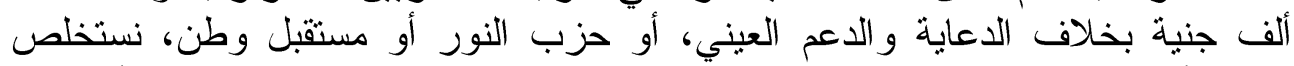
بنتيجة أن المال السياسي هو من صنع النّواب حتى و إن كانت النّان العملية الإنتخابية أصبحت مكلفة وباهظة الثن المن الثن الثن

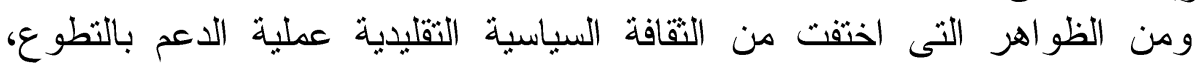

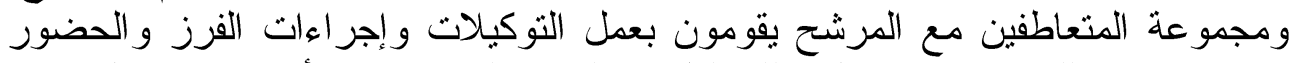

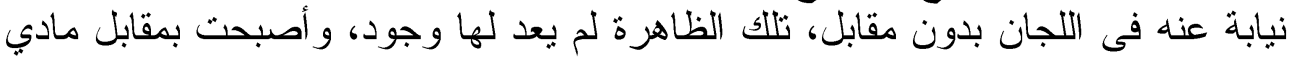
لا يستطيع المرشح التقليدي الوفاء بها. 


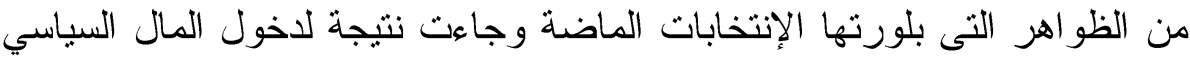

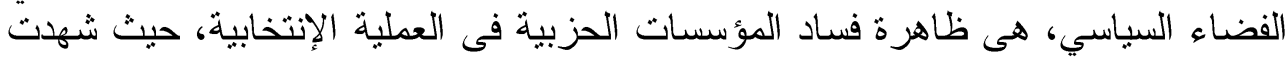

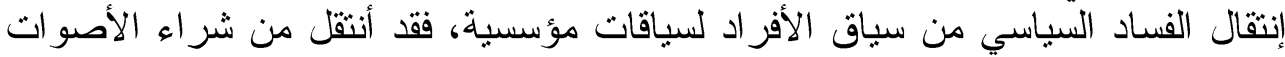

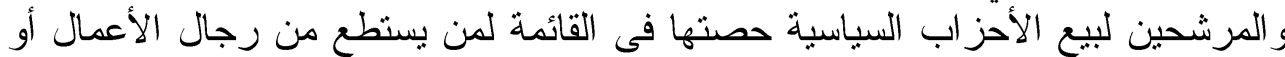

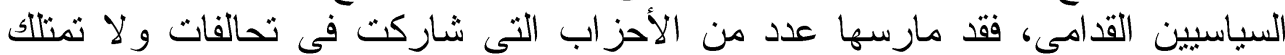
كو ادر أو قاعدة جماهيرية. وكشفت الدر اسة الميدانية أيضأ وجود ظاهرة البلطجية في تأمين المرشحين و إرهاب

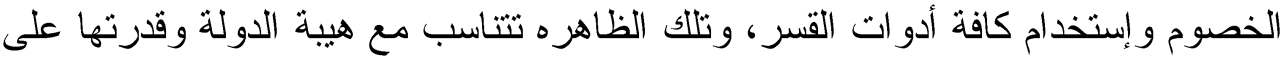
مو اجهة الخروج عن قو اعد النظام. (ع) المال السياسي والدعاية الانتخابية

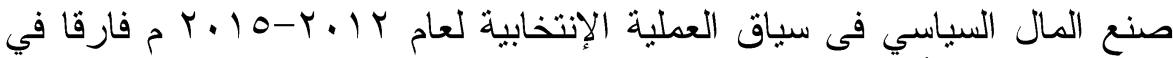

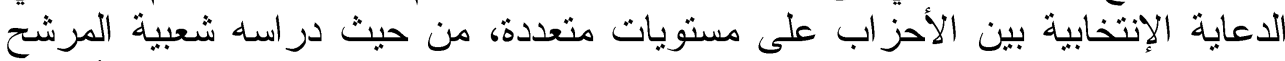

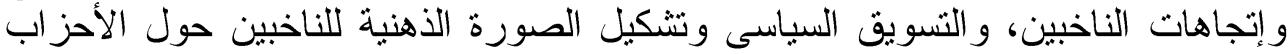

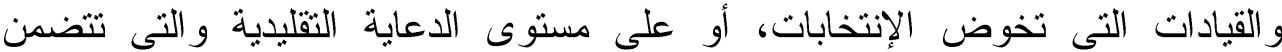

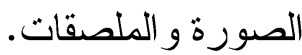

فإذا كانت الأحز اب قد خضعت لظاهرة "الكفيل الضامن" بمستويات مختلفة إلا

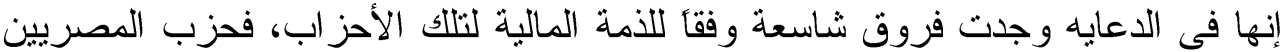

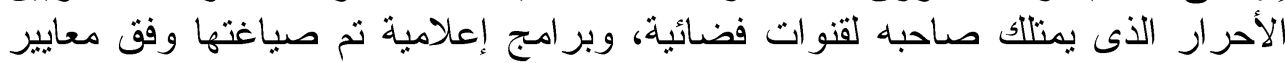

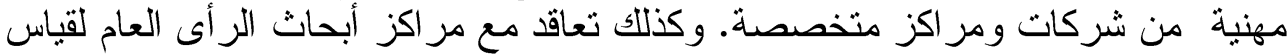

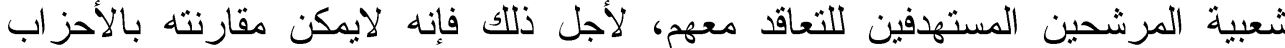

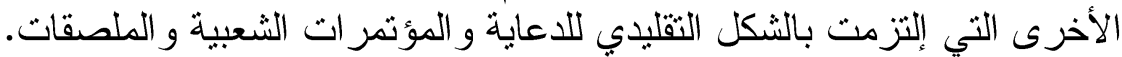

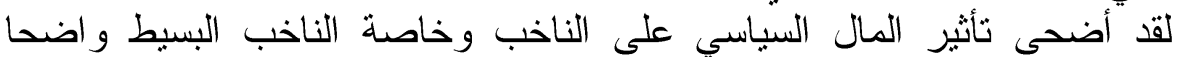
البته، وساهم في تشكل الإتجاهات لصالح الأحز اب ، فقي حقيقة الأمر إنه بدون الأستخدام

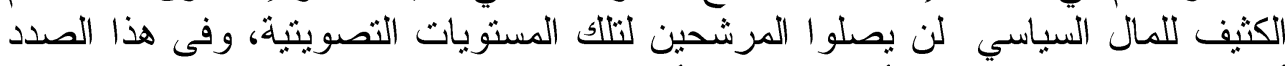

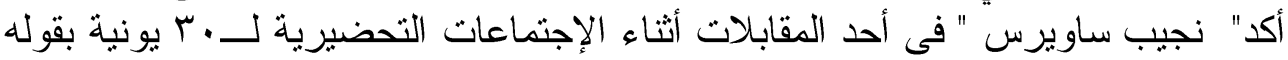

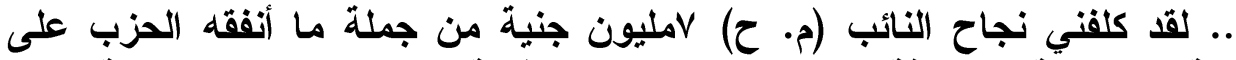

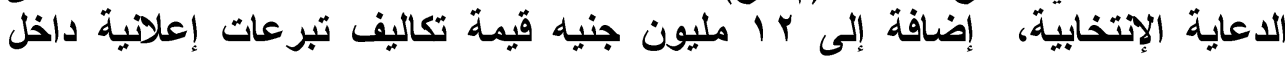

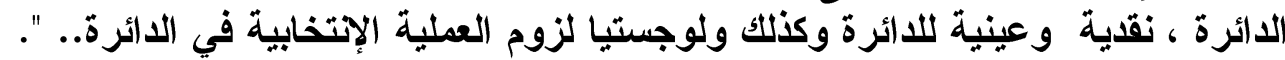

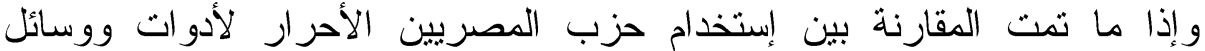

الأداية المختلفة باهظة التكاليف ومستوي تقنة الفي عالي من حيث الجوده و الإنتشار، وبين

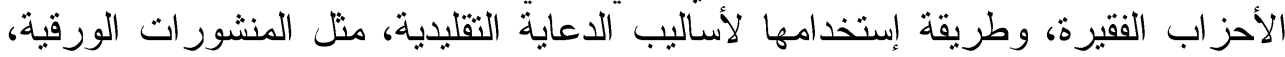
و المؤتمرات الثعبية، وزيارة العائلات المنزلية، نجد فروفأ صارخة فى توظيف المال المال

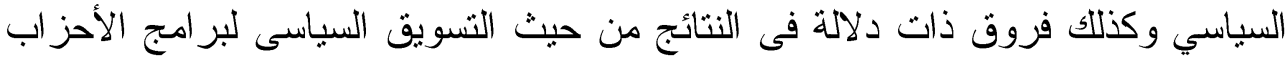

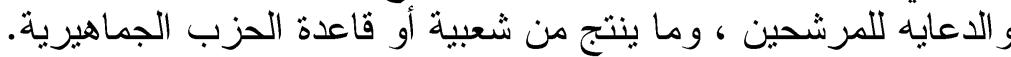

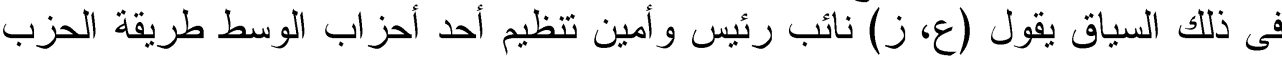

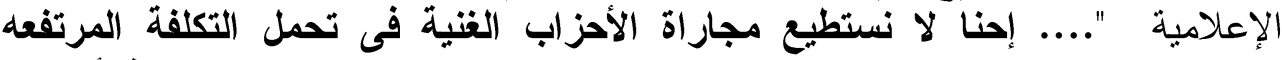

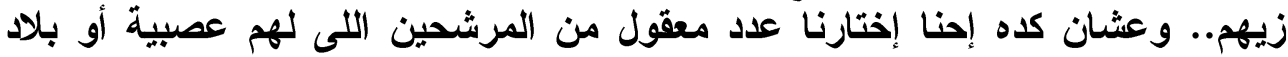

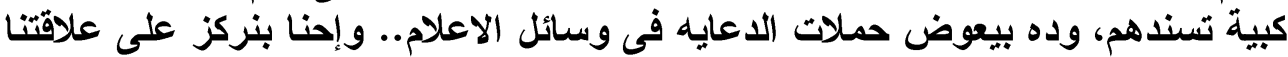

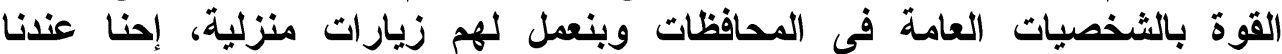




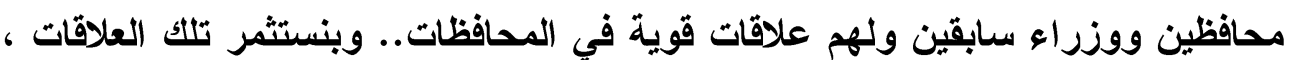

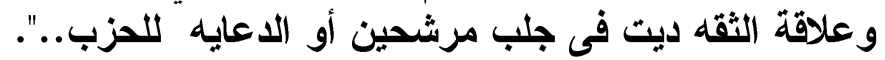

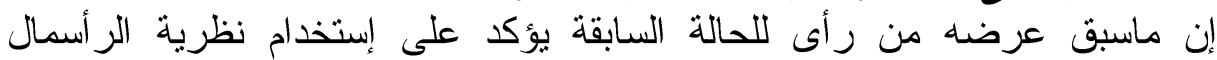

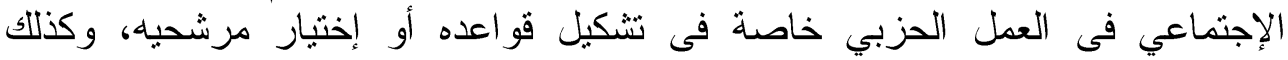

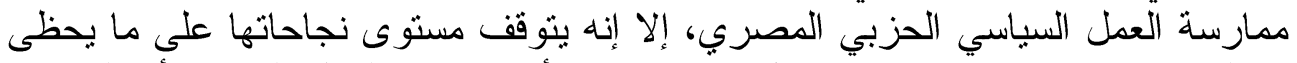

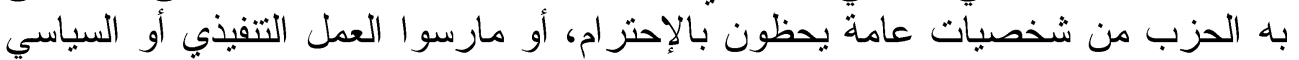

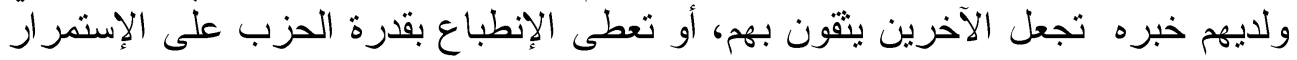
و التمثيل النيابى.

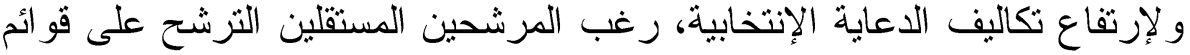

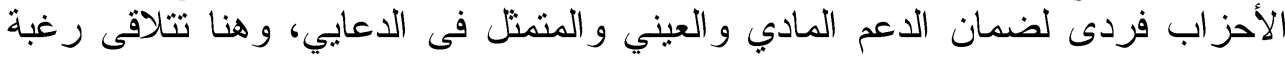

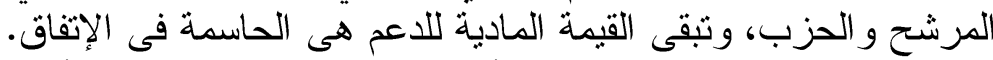

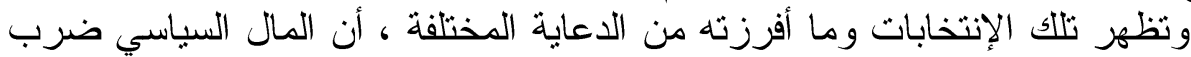

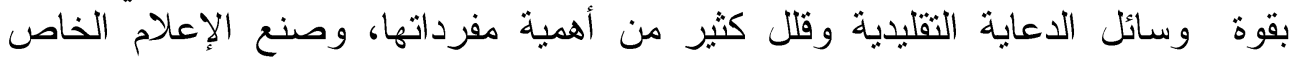

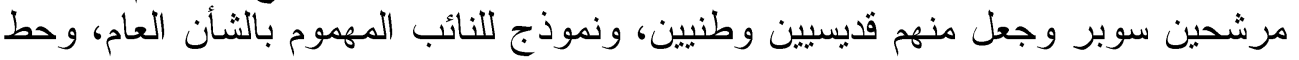
من قيمه شخصيات تثمتع بخبرة العمل الميدانى الوطنى، و والنماذج كثيره ونئ لاتحتاج لسرد وتبيان.

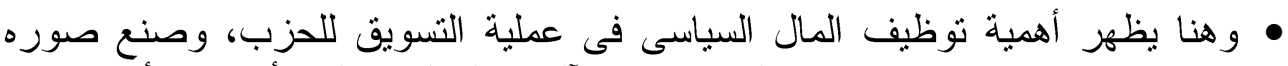
ذهنيه قد تكون بعيده تماماً عن الحقيقه وعن آليات العمل داخل الأحزاب، أنها تصنع

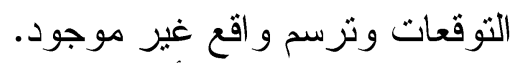

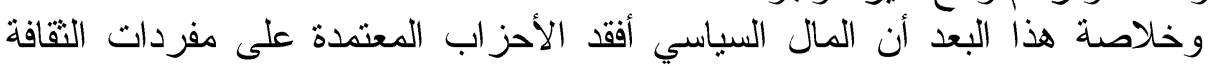

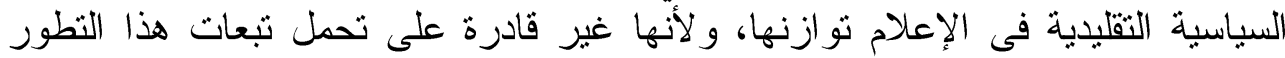

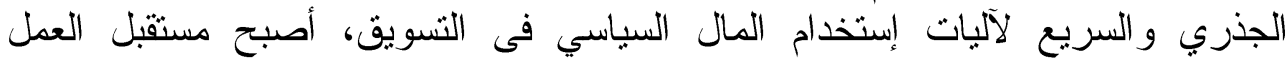

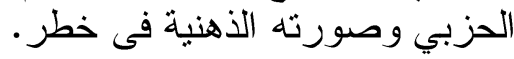

\section{(r) المال السياسي وتعميق أزمة المؤسسية للأحزاب الجديدة:}

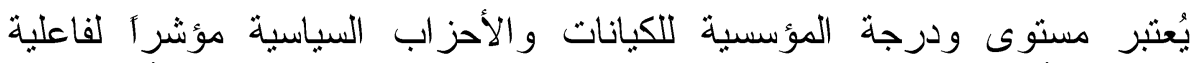

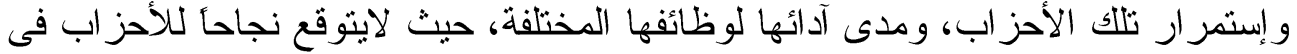

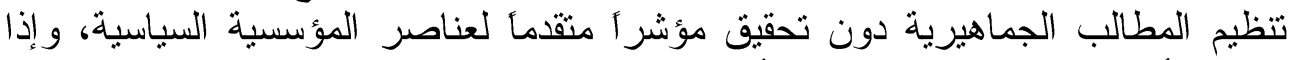

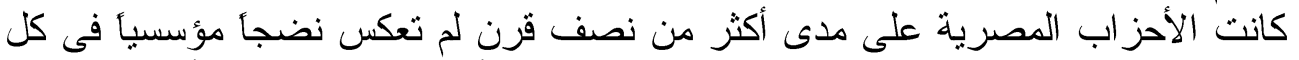

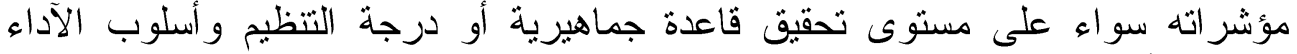

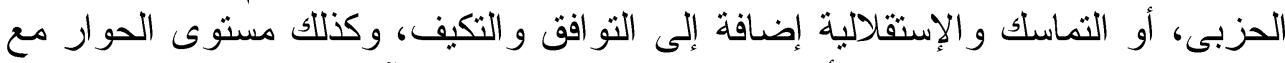

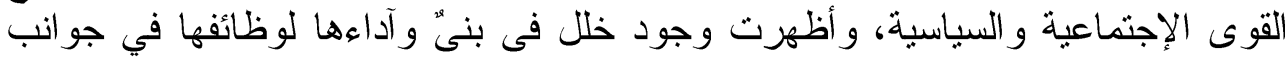

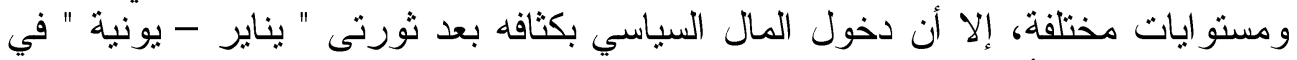

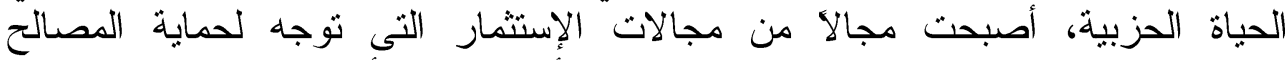

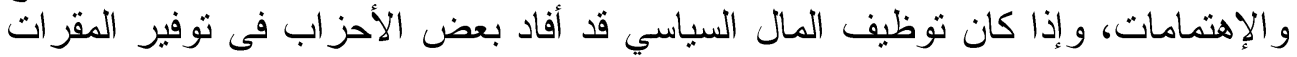

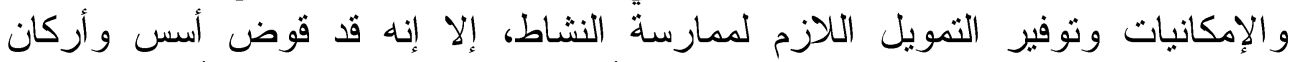

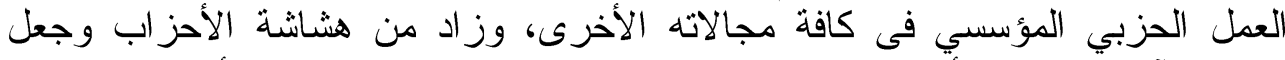

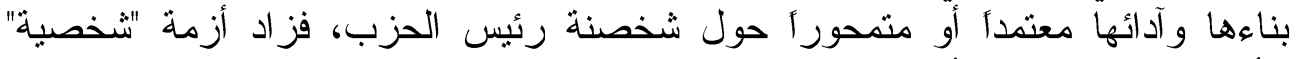

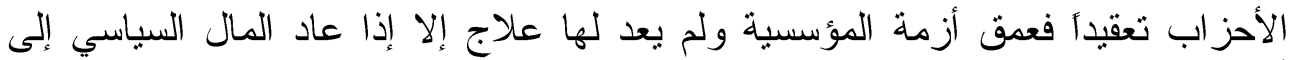
أدر اجه وتخلى عن إستثمار اته فى المجيدال السياسى. 


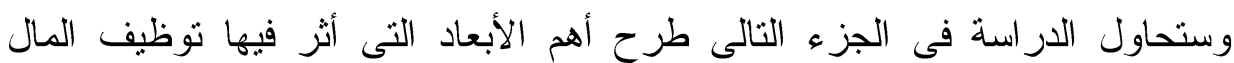

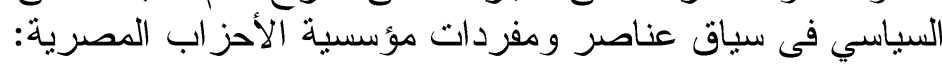

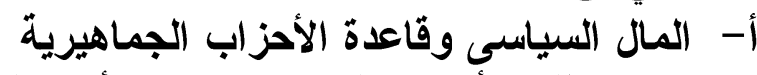

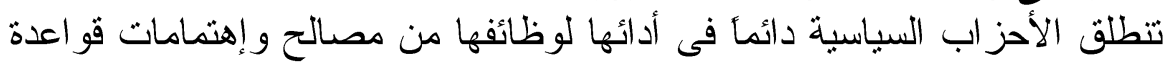

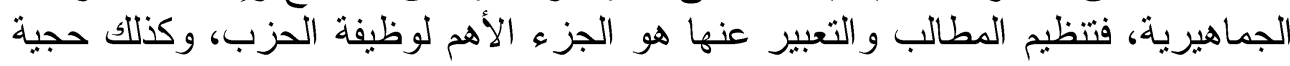

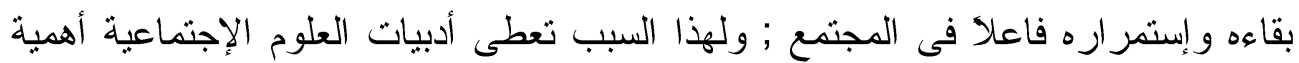

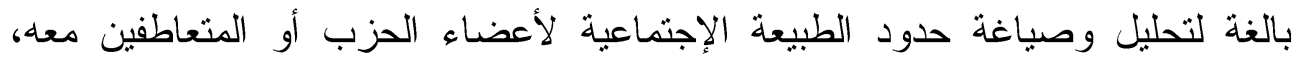

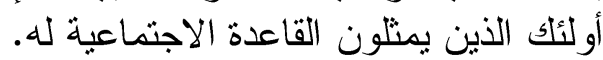

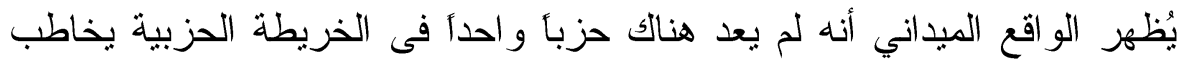

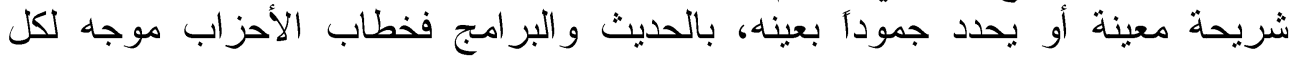

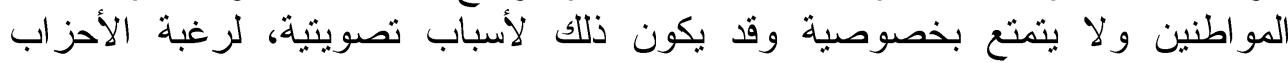

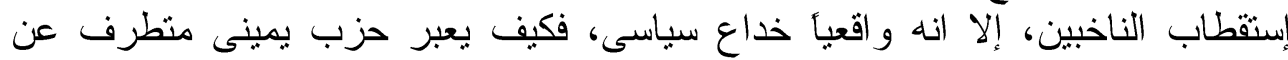

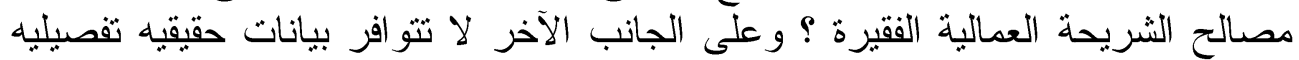

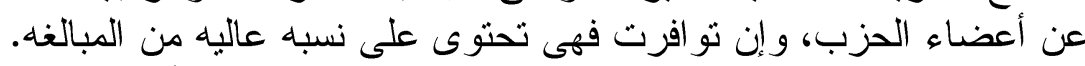

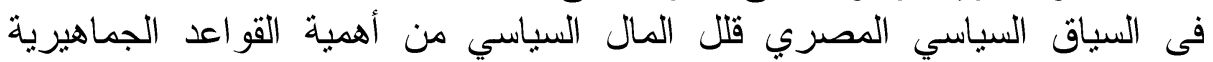

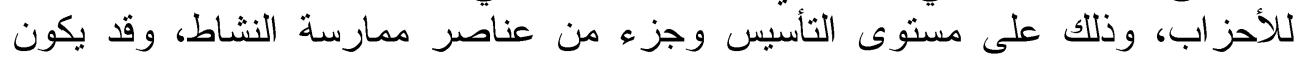

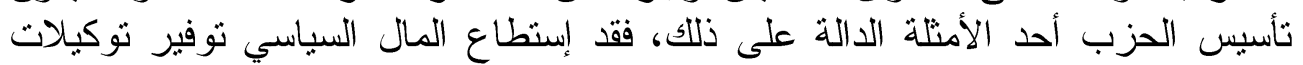

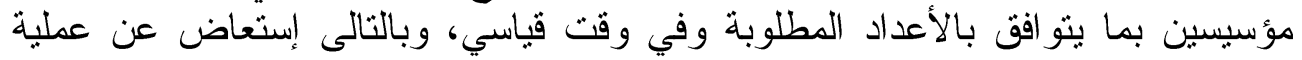

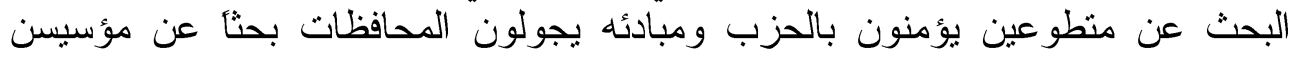

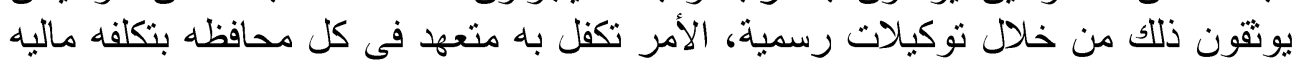
لا تاتعدى . ب. ب جنيه لكل توكيل.

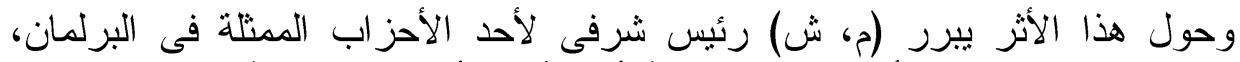

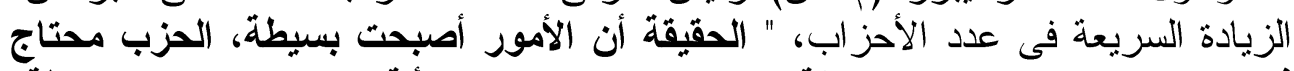

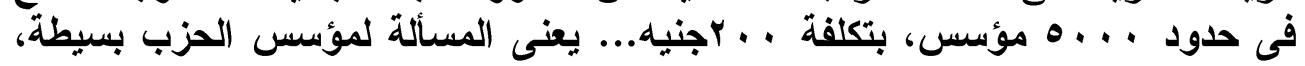

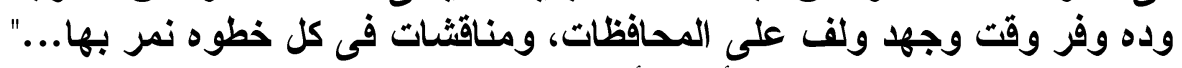

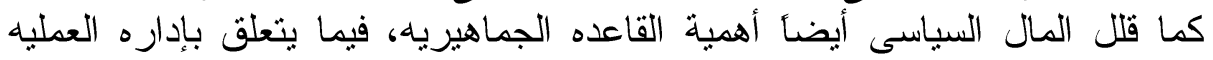

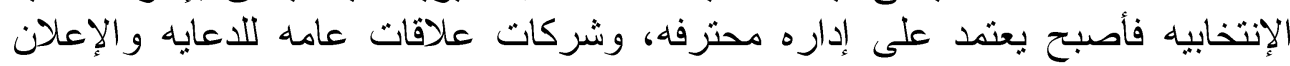

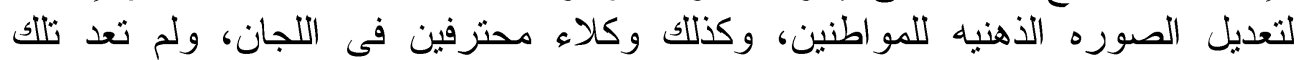

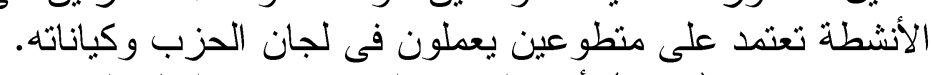

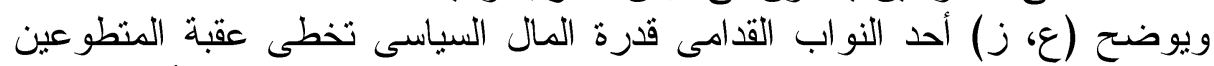

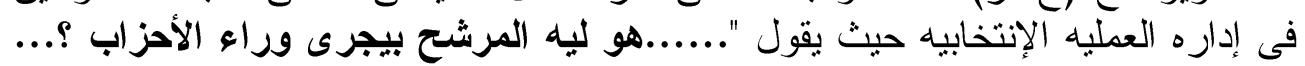

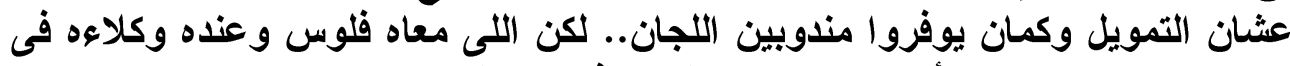

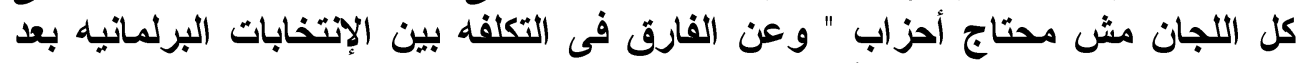

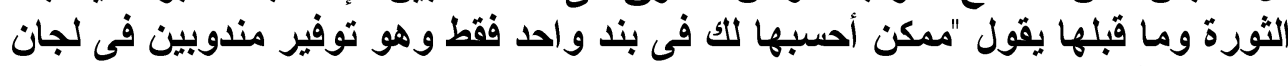

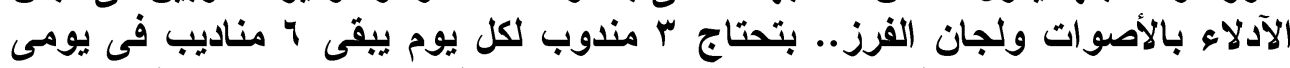

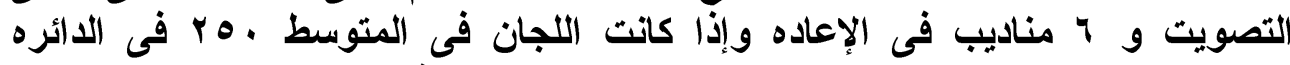

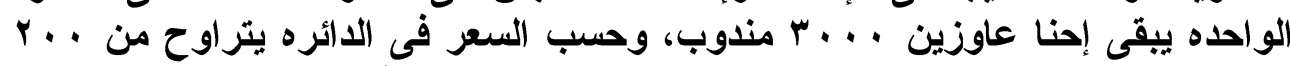

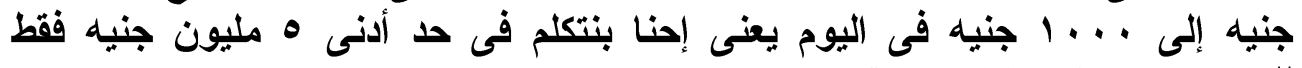
للمناديب يوم الإنتخابات.... ". فئه اليوم 


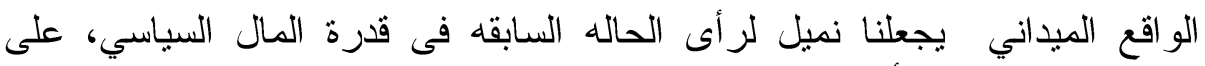

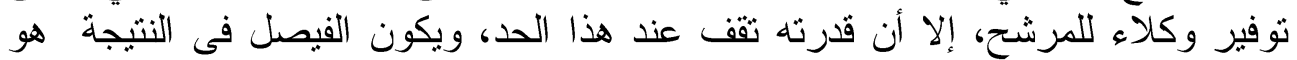

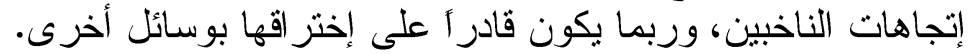

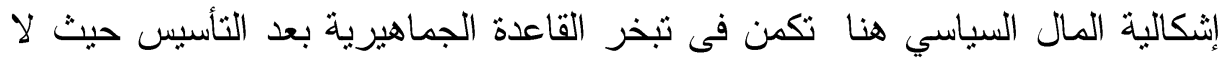

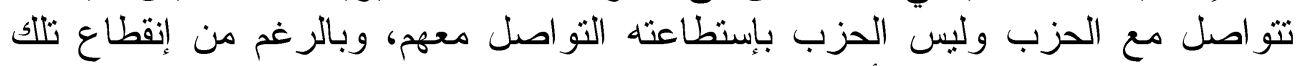

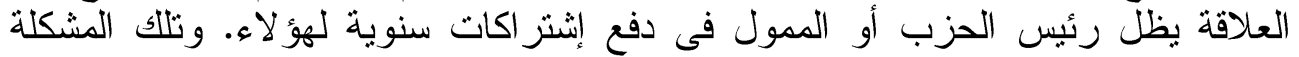

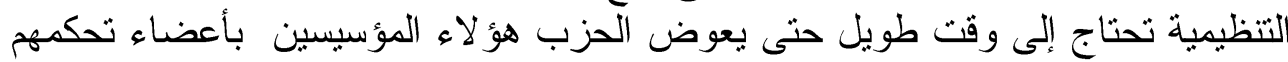

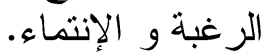

\section{ب- المال السياسي وتكيف الأحزاء الباء}

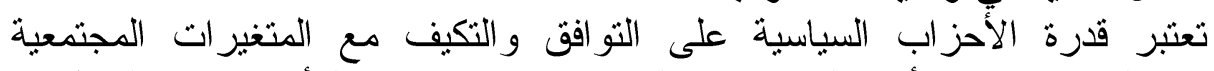

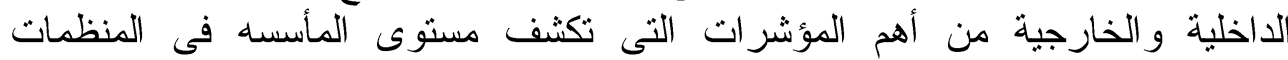

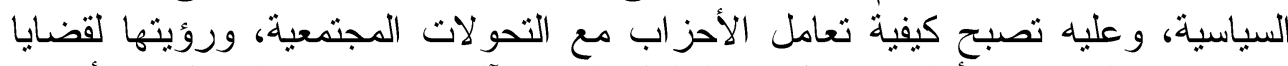

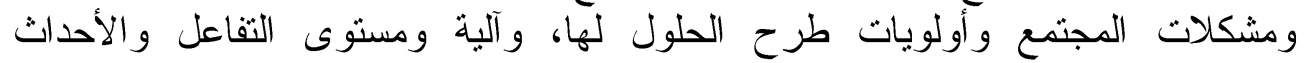
مؤشر ات كاشفه لدرجة تو افق وتكيف الحزب مع متطلبات التغيير الإجتماعى.

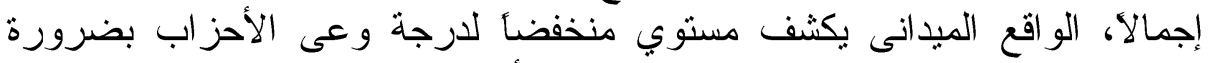

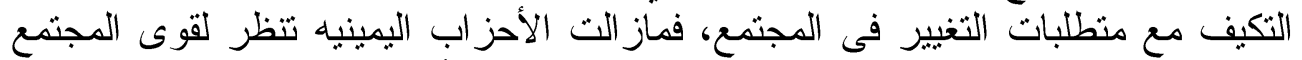

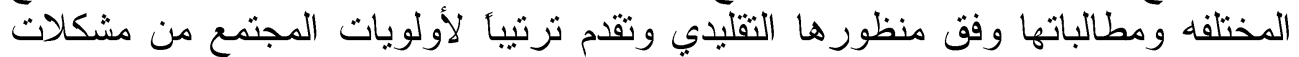

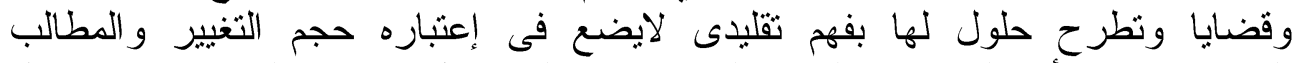

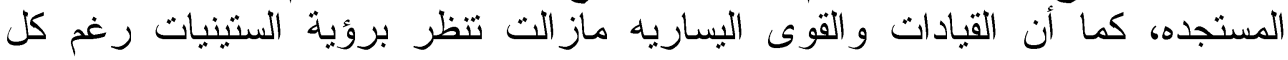

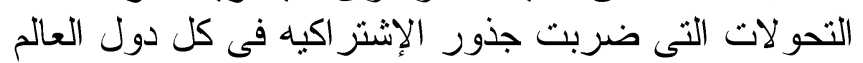

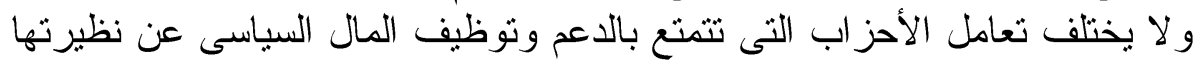

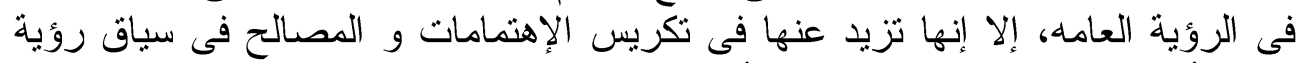

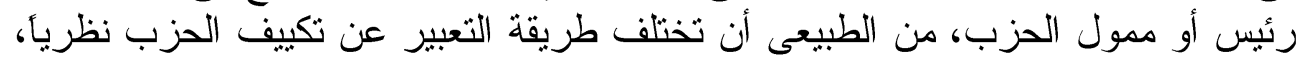

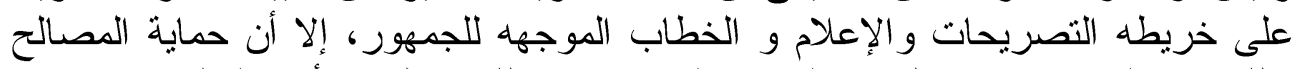

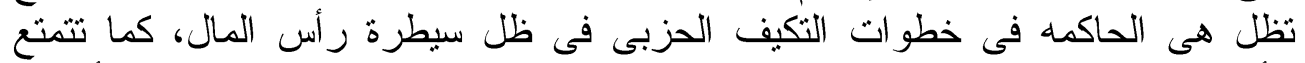

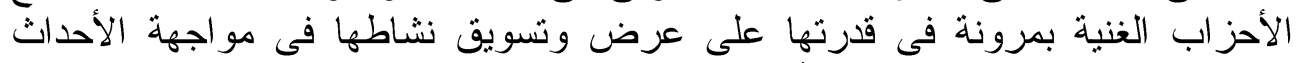
لقدرتها على الظهور فى وسائل الأعلام.

ت- المال السياسي وقدره الأحز اب التئي التظيمية.

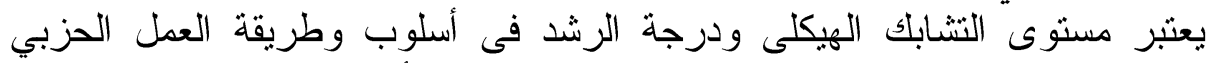

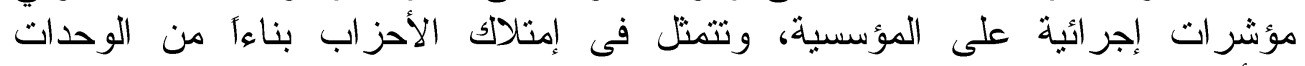

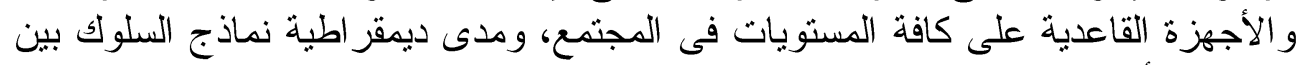

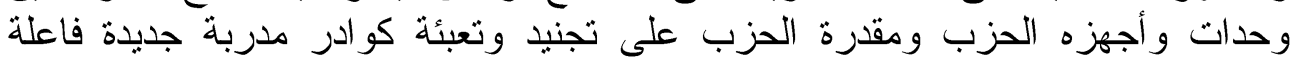

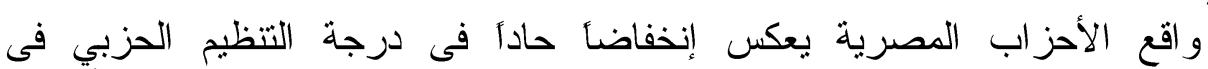
سباسياً.

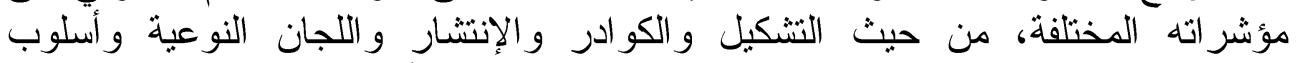

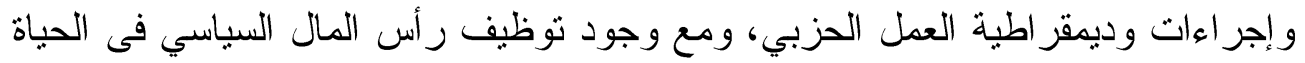

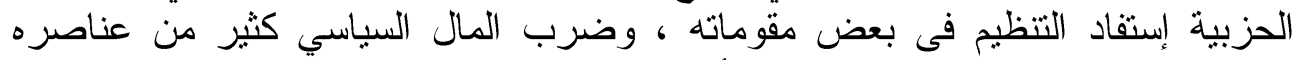

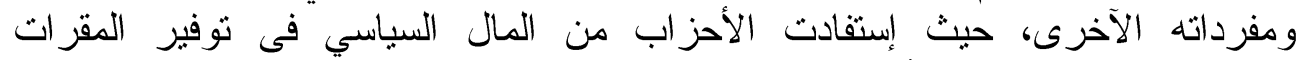

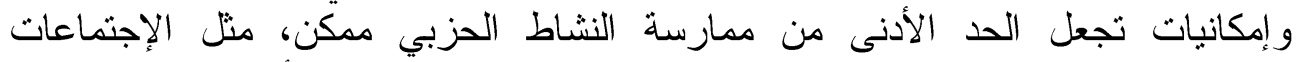

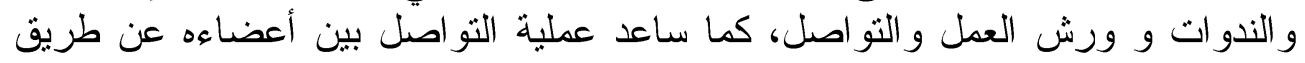




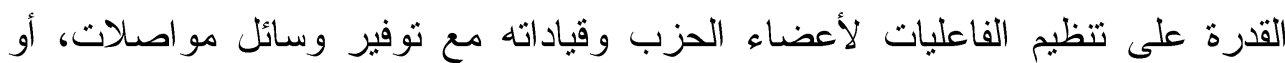
عمل مؤنمر ات وندو ات في في الأقاليه.

ورغم مكاسب توفير الإمكانيات في تيسير إجراءات العمل، إلا أن ثأثير المال

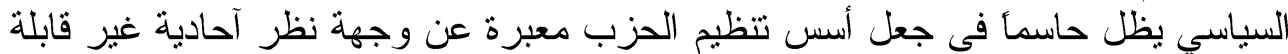

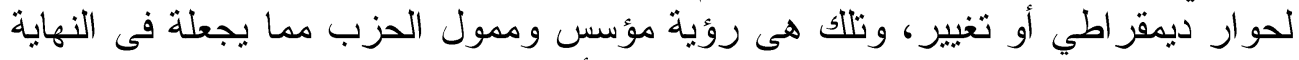

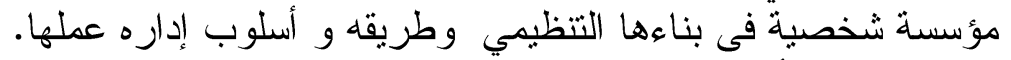

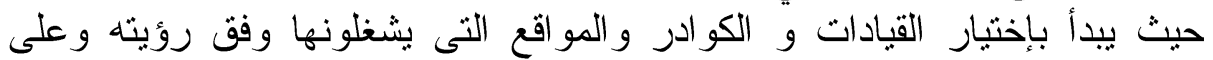

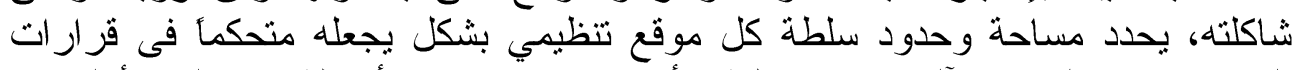

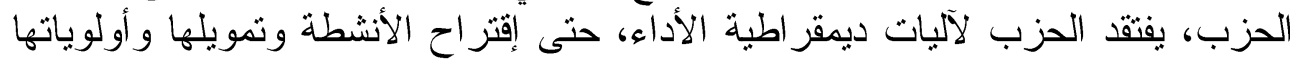

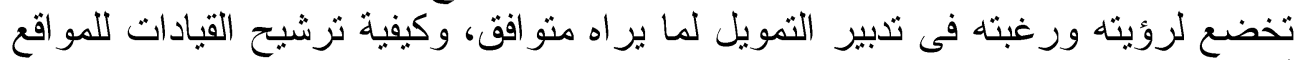

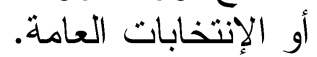

خلاصة ذلك أن الحزب فى ثلاك الحالة ييُنى وفق أسس وهياكل تنتاسب مع القدرة

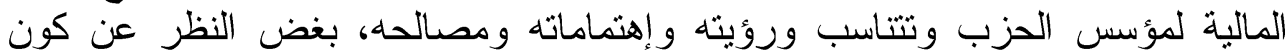
الحزب مؤسسة عامة مفترض أنها تخوص تنافسأ مع مثئلتها من أجل مصلحه الثنأن

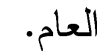

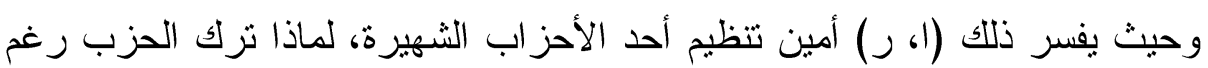

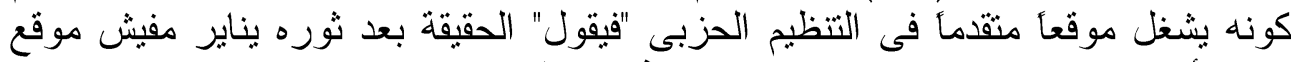

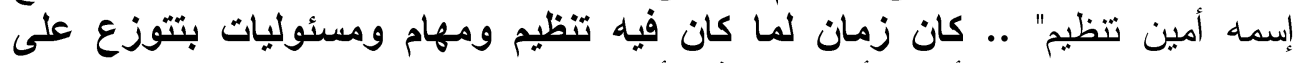

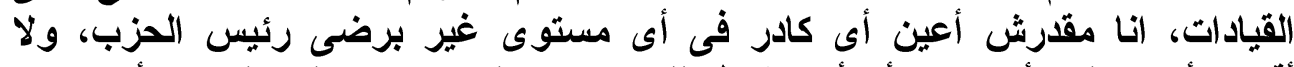

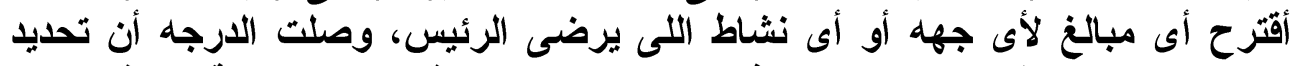

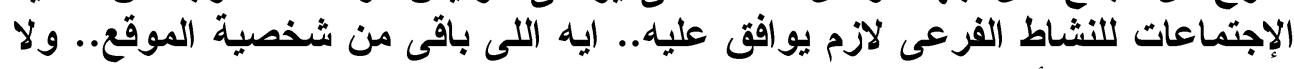
حاجه.. مينفش أكون صورهـ...".

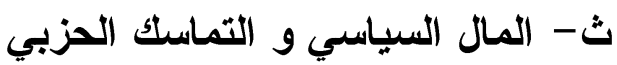

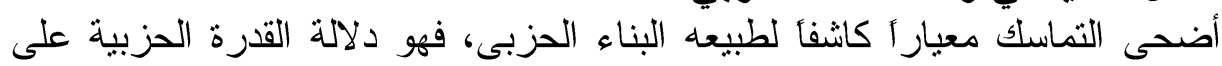

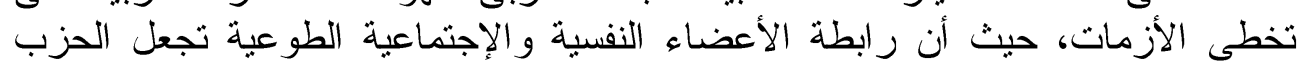

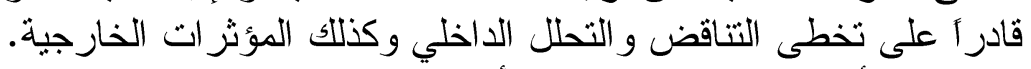

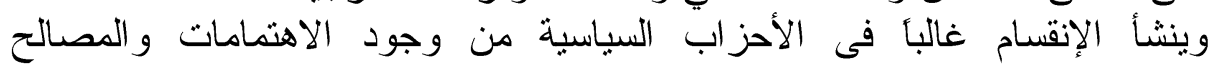

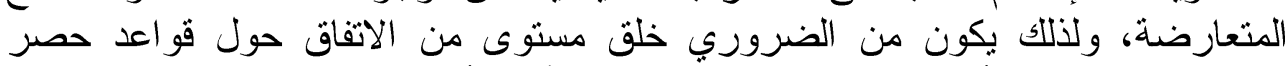

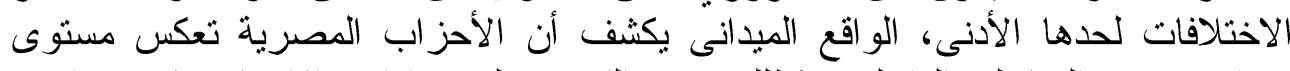

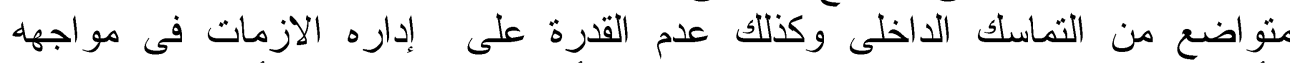

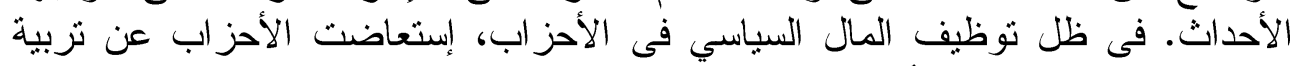

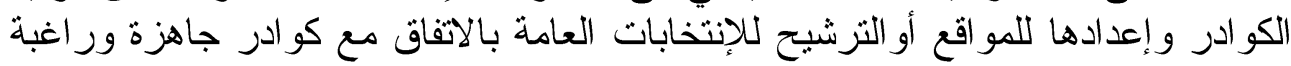

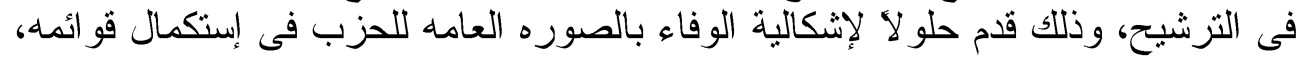

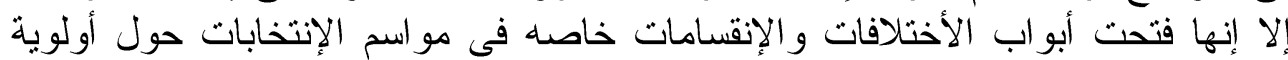

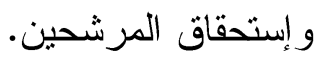

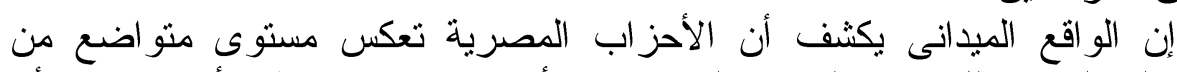

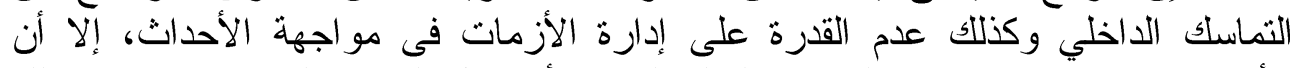

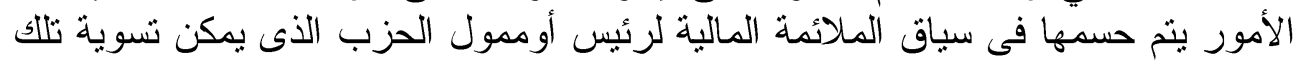
الخلافات بتزكية من يشاء. 


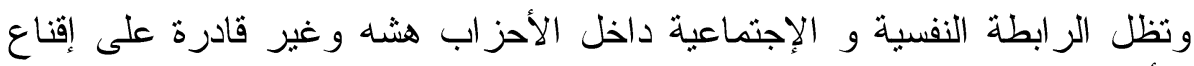

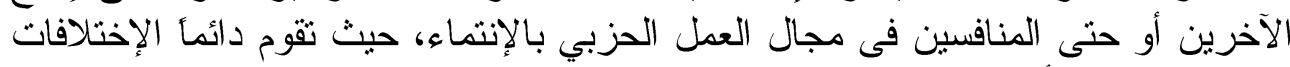

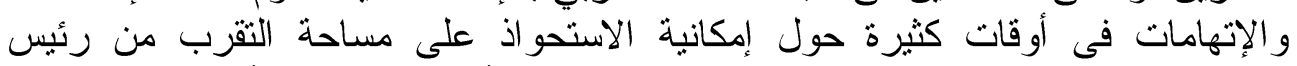

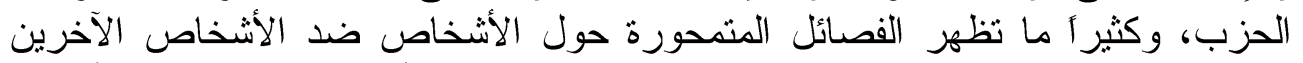

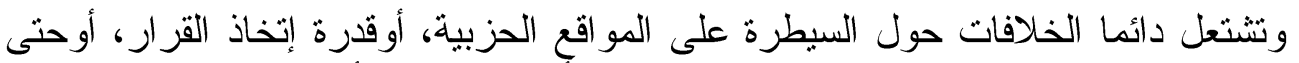

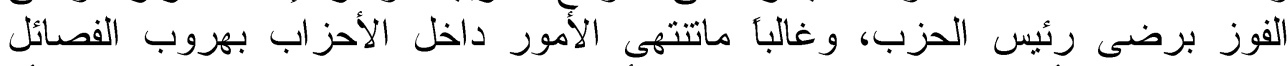

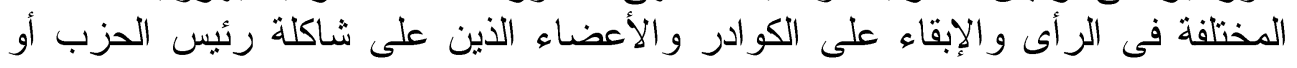
برضون برؤيته وتصرفاته - وهى إلى إحدى ملامح الثقافة السياسية المصرية فى التعامل مع الأي

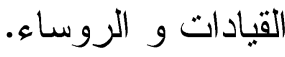

\section{ج- المال السياسي والإستقلاية الروباء الحزبية}

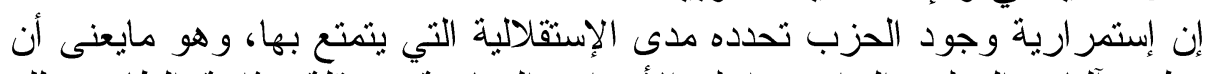

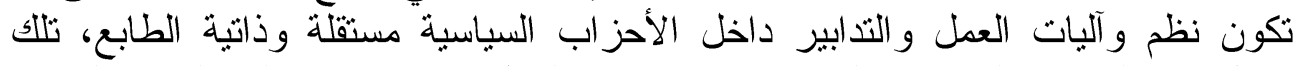

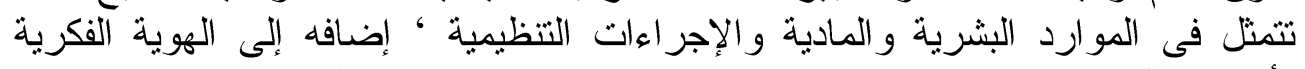

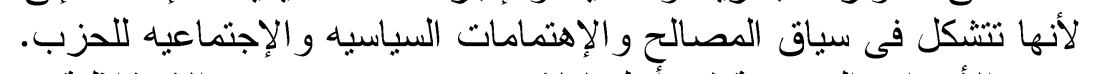

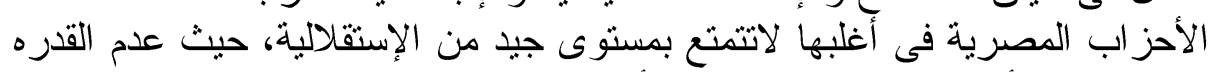

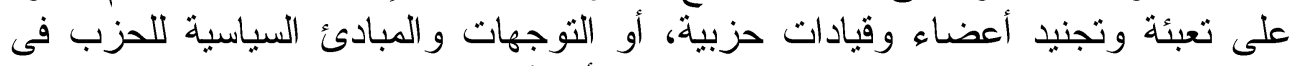

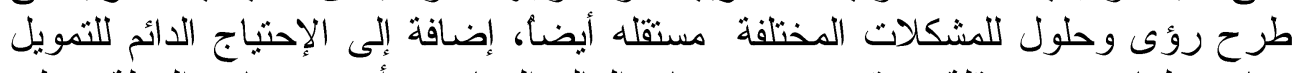

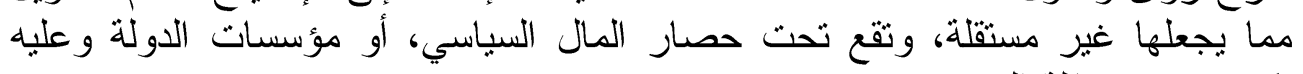
تكون غير مستقلة التوجه. بعد ثورة يناير ودخول المال السياسي لمعظم الأحز اب المصرية الممثلة فى المؤسسة

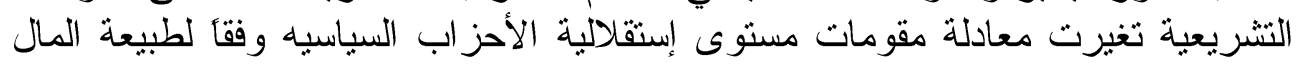

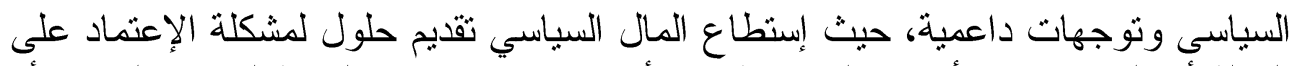

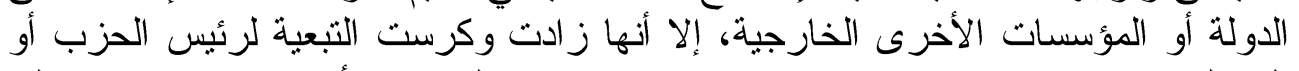

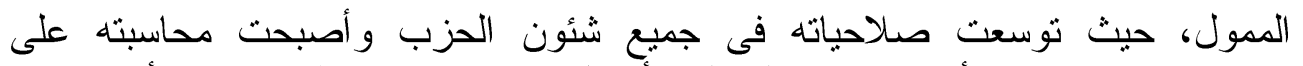

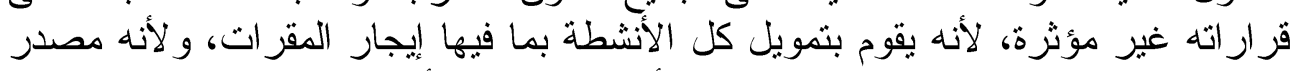

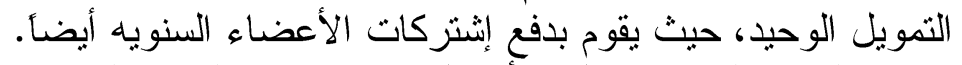

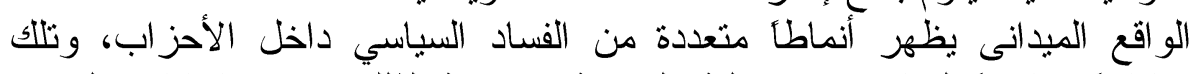

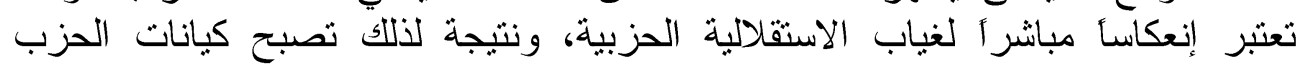

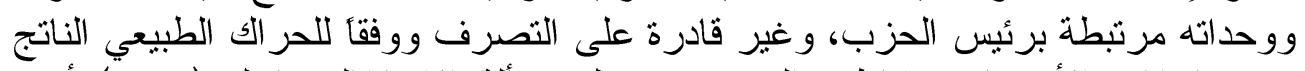

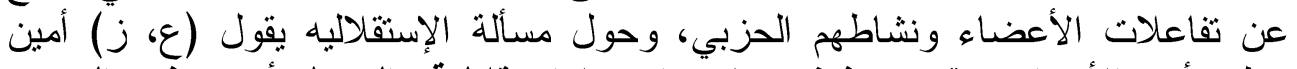

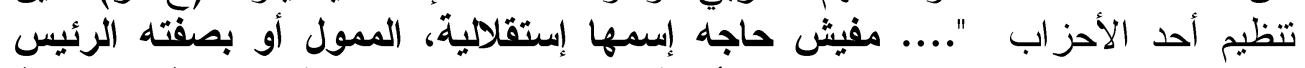

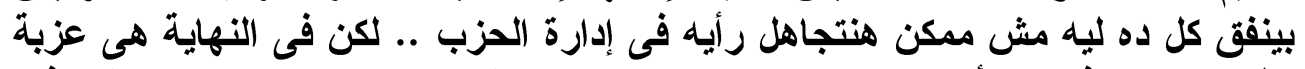

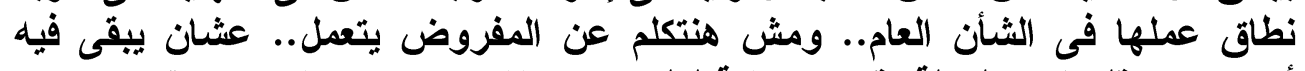

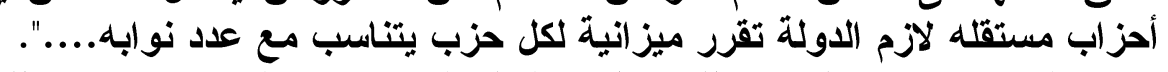

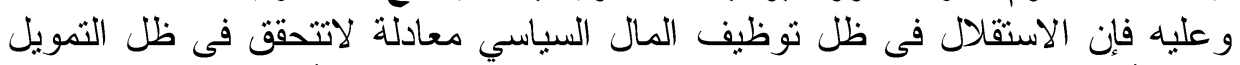

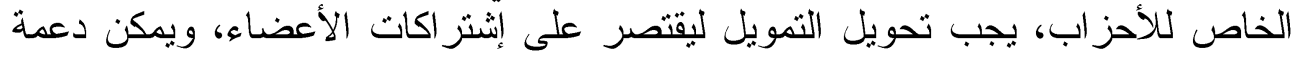
من ميز انبة الدولة. 
ا -لقد أظهرت الدراسة الحالية وجود تو افق بين المهتمين و المنظرين بالنظــام السباسـيـي

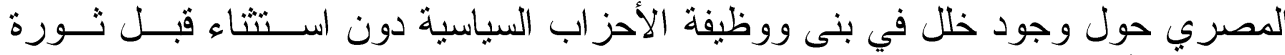

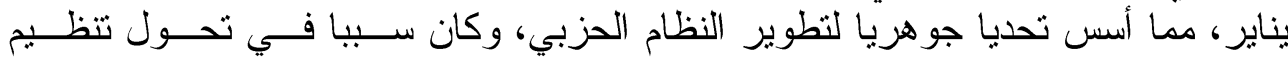

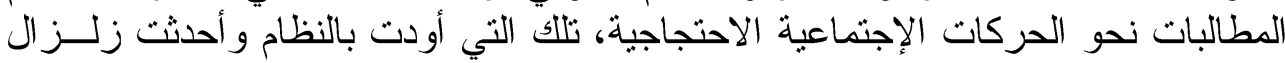

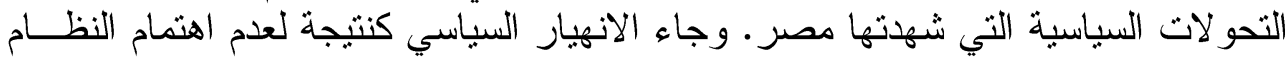

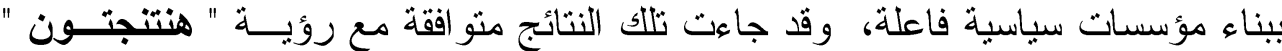

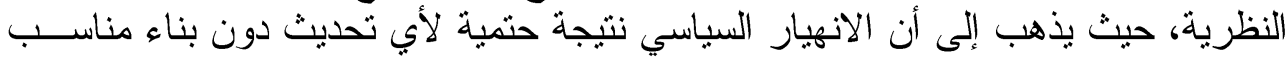

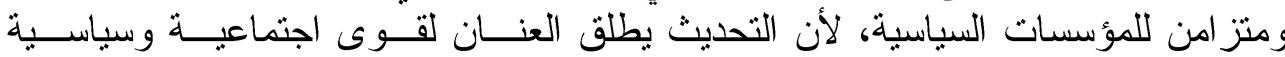
لاتستطيع المؤسسات التقليدية حجزهات الو السيطرة عليها ومن ثم لايمكن تجنب الانهيـار r-أثبت نتائج الدراسة المبدانية عدم قدرة الأحز اب السياسية على الاستمر ار و التماسك فقد

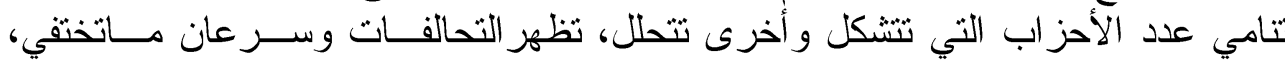
وتتجلى تللك الظاهرة حبنما نتز ايد درجة التسبس Politisierung لغياب المؤسسات، وتلك ونك

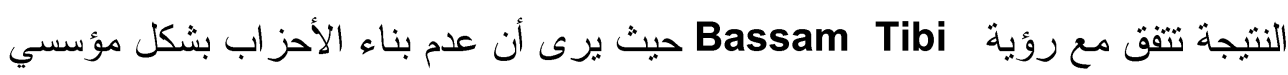

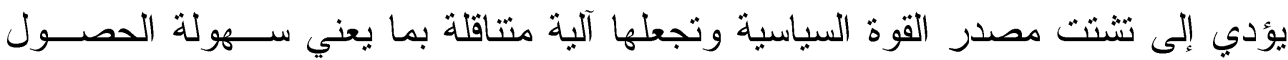

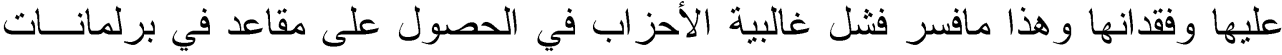

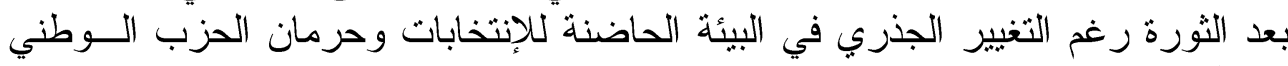

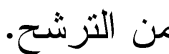

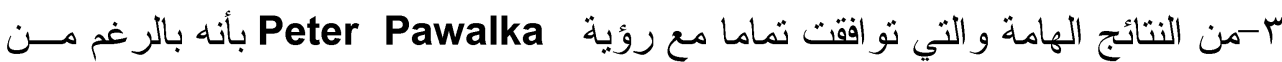
أن مصر تثتمع بنظام مجتمعي شديد التباين وفقا لمؤشر روتة مقات مقوماته في المجالات السباسية

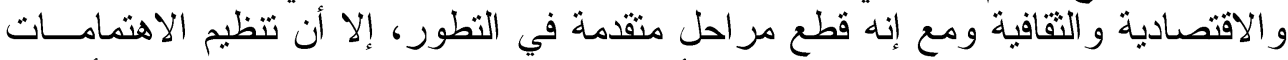

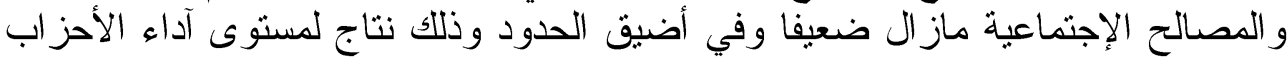
السياسية لوظائفها. ع-لقد أفادت الدر اسة أنه بالرغم من تعدد المداخل النظرية وتواتز المفهومات التي تحاول

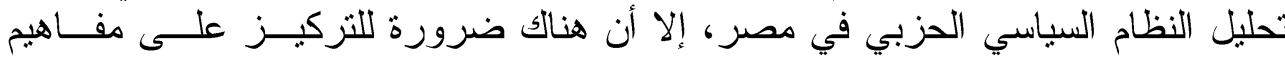

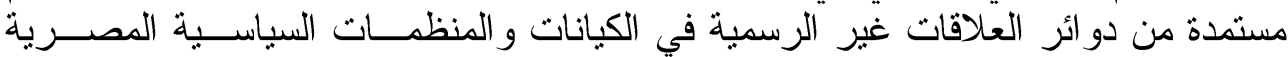

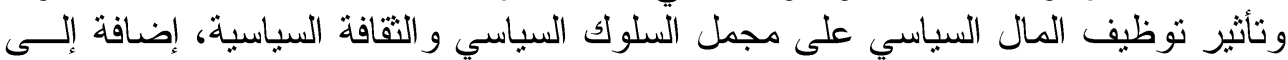
استغلال رأس المال الإجتماعي في بناء العلاقات السياسية.

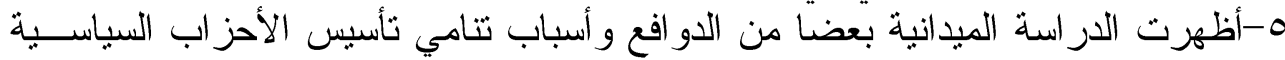

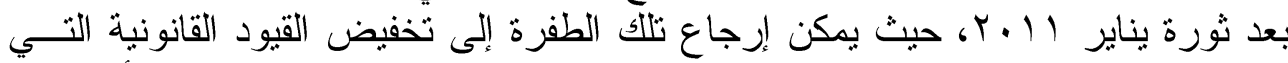

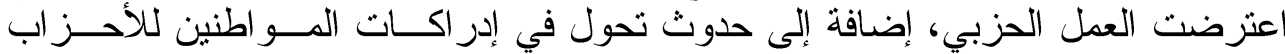

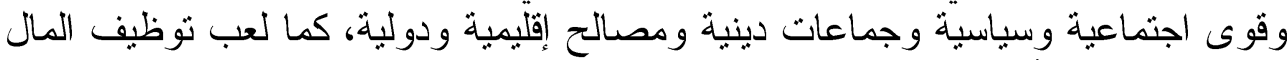

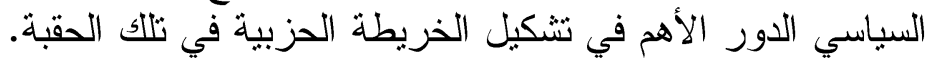

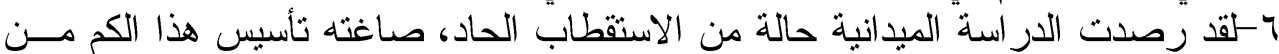

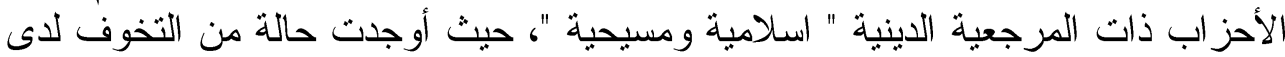

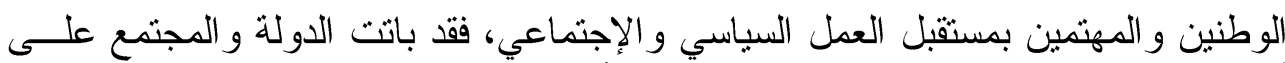

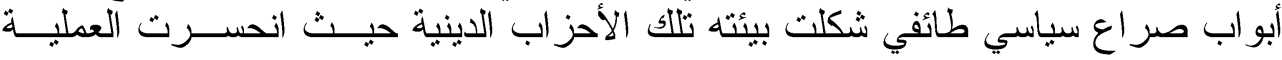




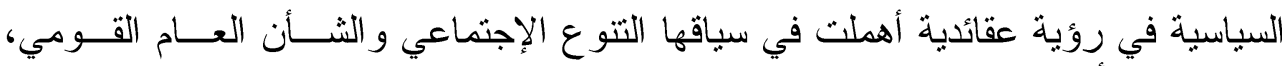

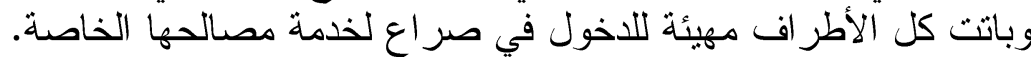

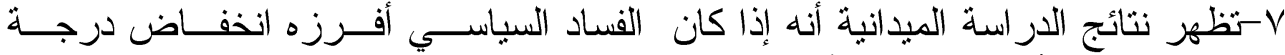

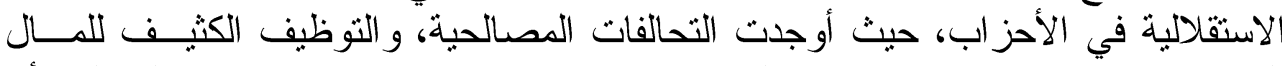

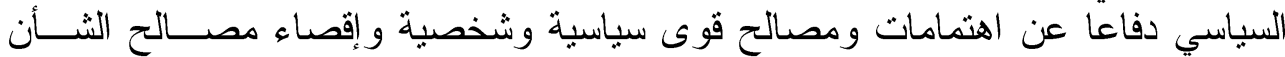

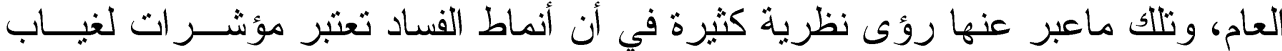
استقلالية المنظمات السياسية.

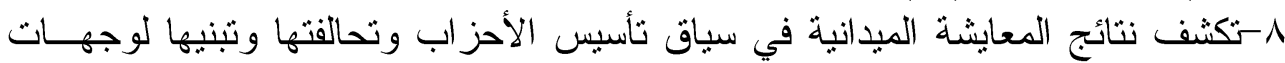

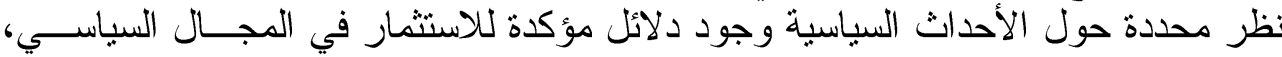

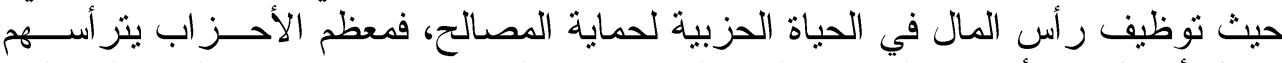

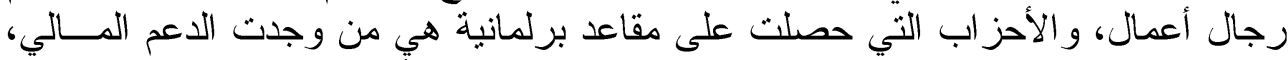

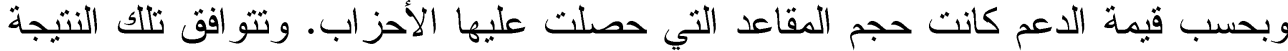

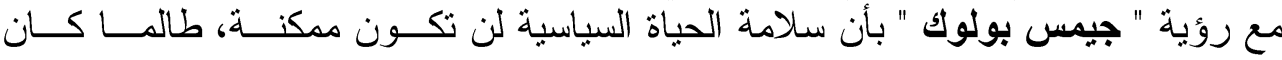

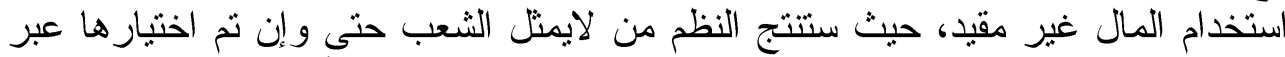

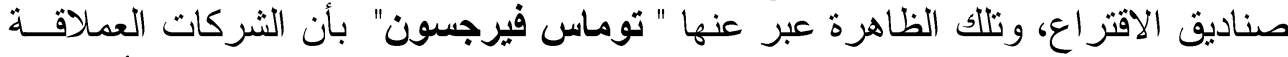

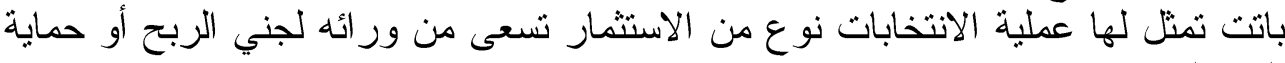

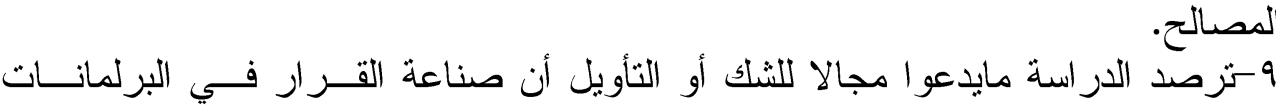

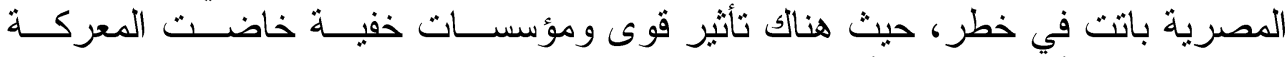

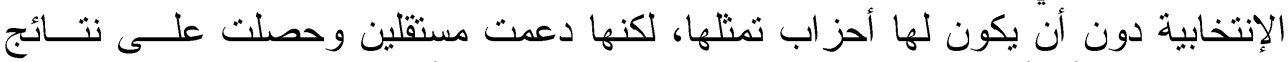

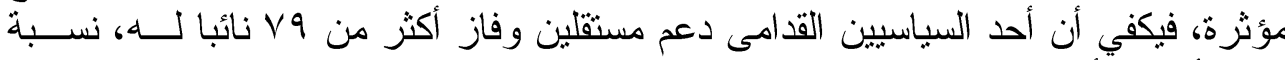

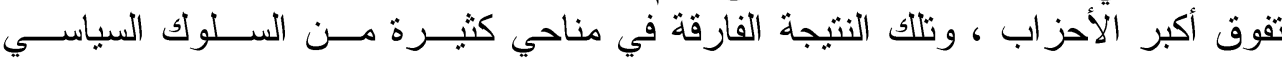

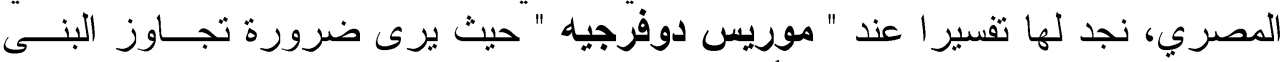

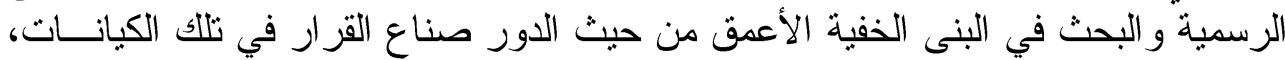

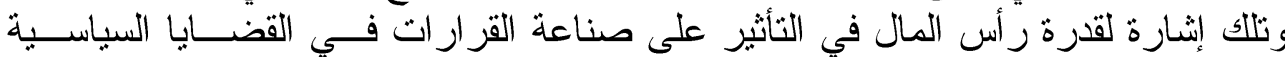

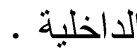

• 1-ثرصد الدراسة المبدانية سيطرة المال السياسي على التحالفات الإنتخابية، حيث تحكم

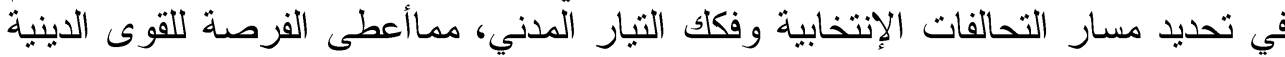

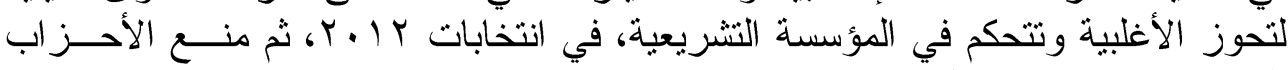

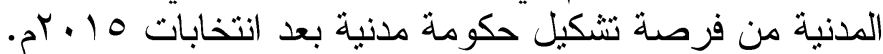

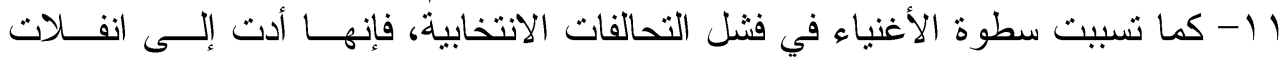

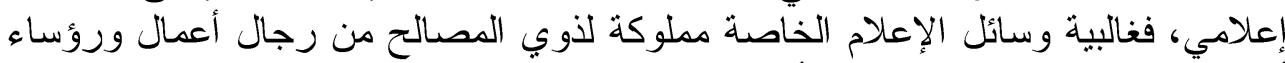

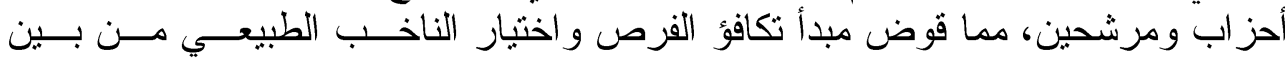

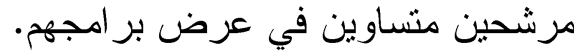

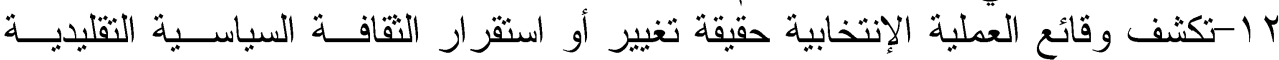

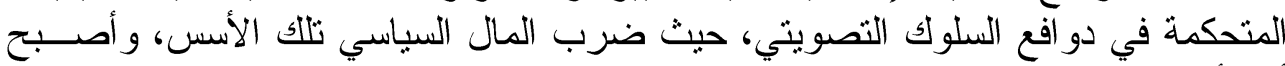

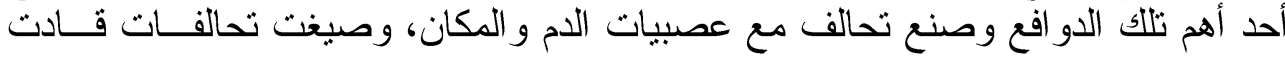

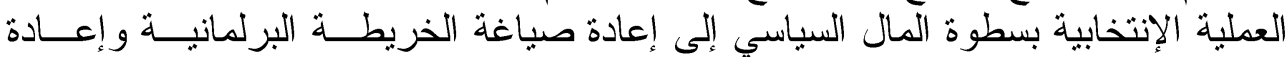

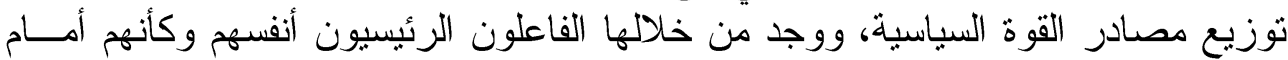
قو اعد جديدة تماما للعملية السياسية، قدلايملكون أدو ات أو مهار ات التعامل معها، فأقصت 


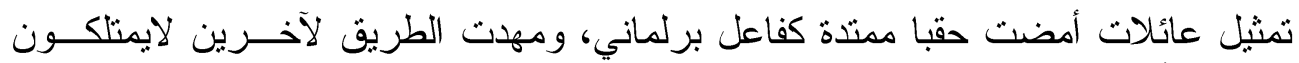

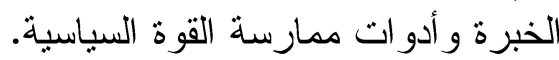

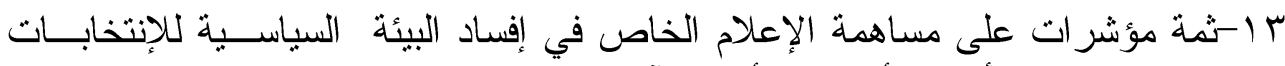

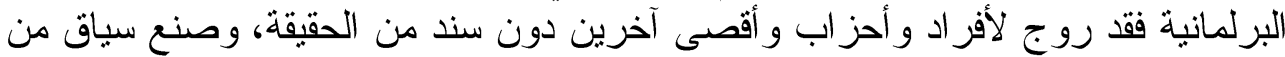
الثك و الريبة و الاتهامات المتبادلة بين القوى السياسية والفين والناخبيين..

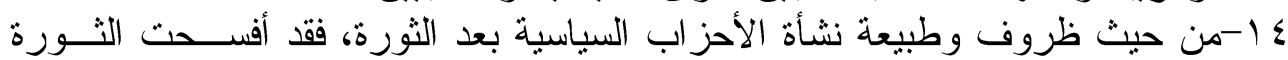

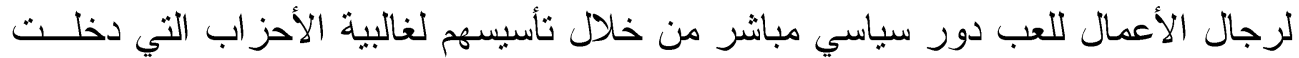

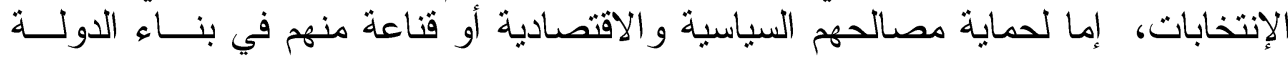

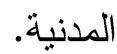

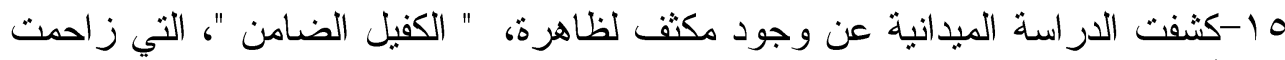

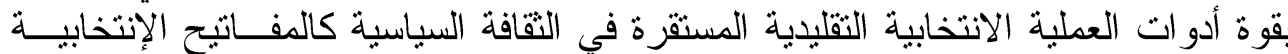

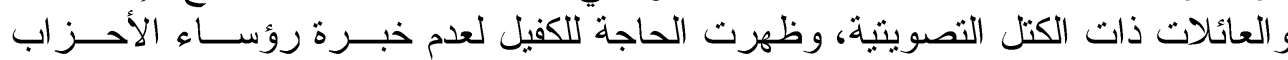

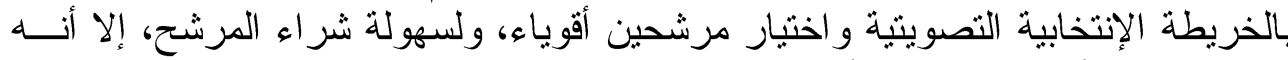

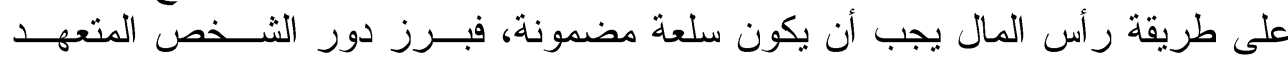

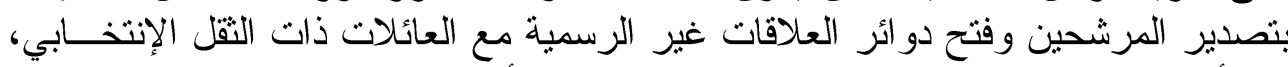

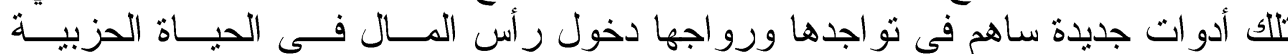

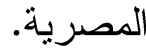

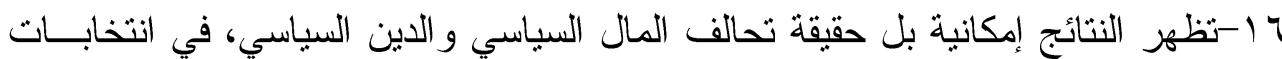

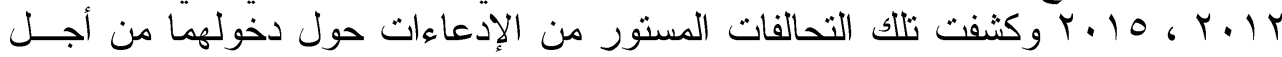

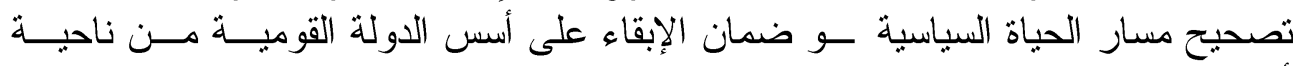

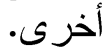

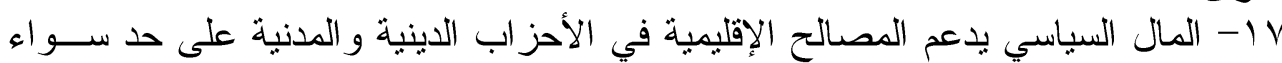

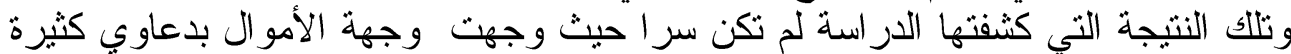

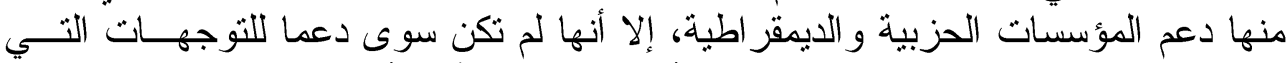

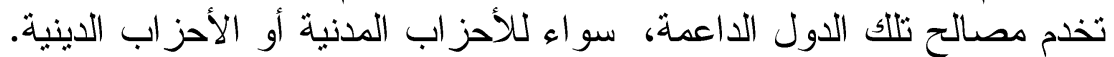

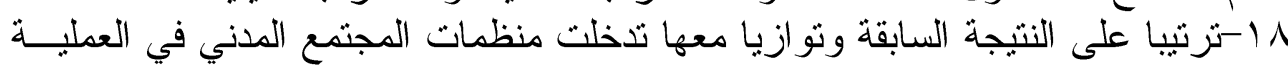

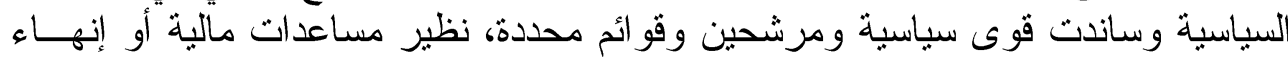

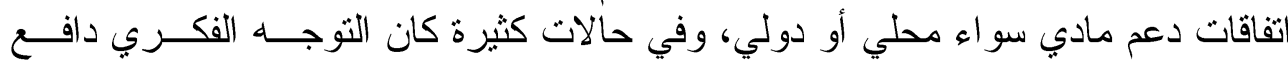

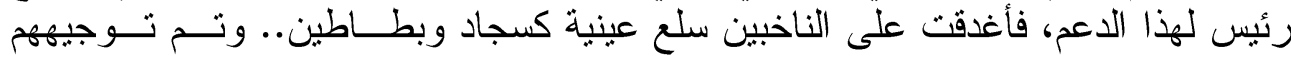
لمصلحة قوى معينة.

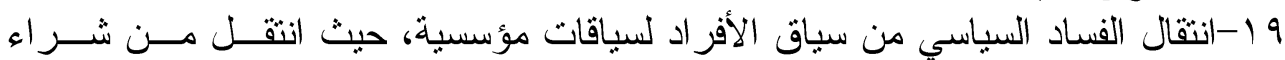

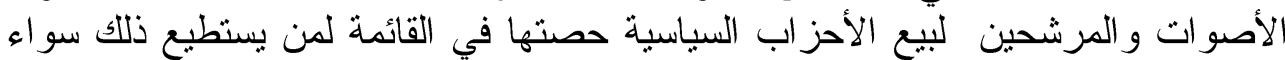

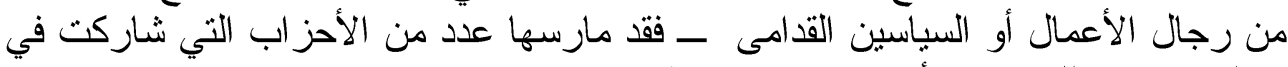
تحالفات و لاتمنالك كو الدر أو أو قاعدة جمانين التهيرية.

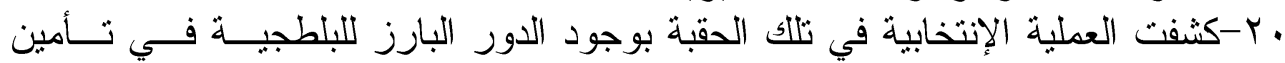

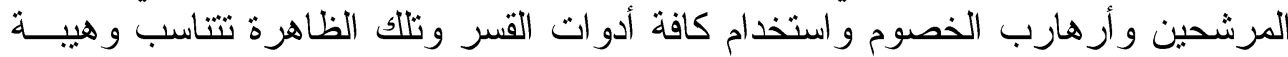
الدولة وقدرتها على مواجهة الخروج عن فو اعد النظام. 
Abstract

The political party movement after the January 2011 revolution

A field study of the impact of employing political money in political parties

\section{By Abdul Hamid Younis Zaid}

The current study examined the importance of studying and analyzing the reality and independence of the new political parties and their course of development. They formulated a new model for the party map, then used political money intensively in party work, and argued conflicting interests and interests to possess the ability to formulate a political decision in the future. The opportunity to build a democratic party system, deservedly deserved by a people who have made two revolutions, rid of political tyranny and religious obsession..

According to this understanding, the study aims at uncovering the impact of the process of employing political money on the reality of the new political parties and their course of development in the context of analyzing the obstacles to the development of these parties, in addition to the future of party performance in the context of the struggle of new powers and interests in the political transition after the January revolution and political culture Has contributed to its regional and international dimensions.

The study was based on an analytical approach based on an in-depth case study that was applied to twenty-three of the leaders of the political parties and the candidates for their power. They were conducted in depth and in multiple sessions. The sample included 5 party leaders, 2 general secretary, The number of two treasurer, and the number of 12 candidates on the lists of the two parties, in Cairo.

the most important results reached, the current study showed that there was a consensus between the Egyptian political system and the Egyptian political system that there was a flaw in the structure and function of the political parties without exception before the January revolution. This led to a fundamental challenge to the development of the party system. The social movements of the protest, those that led to the regime and caused an earthquake political transformations witnessed in Egypt. The political collapse came as a result of the regime's lack of interest in building effective political institutions. These results were consistent with Huntington's theoretical vision. He argues that the political collapse is the inevitable result of any modernization without the appropriate and simultaneous construction of political institutions because modernization unleashes social and political forces that traditional institutions can not To seize or control them and thus political collapse can not be avoided. 
(1) D. Claessens, O.stammer: Die Krise der parteiendemokratie und die parteiensoziologie, Berlin 1979 s. 71

(2) Alf. Mintzel: parteiensoziologie, in pipers worterbuch zur politik, Munchen, Zurich, 1989, s. $661-665$

(3) Rolf. Ebbighausen: Die krise der parteicndemokratie und die parteinssoziologie, Berlin, 1969. bib. s.73.

( 4 ) E,wiesendahl: parteien und demokratie. Eine soziologische Analyse paradigmatischer Ansatze der parteienforschung, Opladen 1980.

( 5) Fischer, Naschold: organisation und Demokratir m stuttgart Berlin, Koln, Mainz 1979 s 62 .

(6) Frieder, Naschold: Organistion und Demokratie, bib, s. 51.

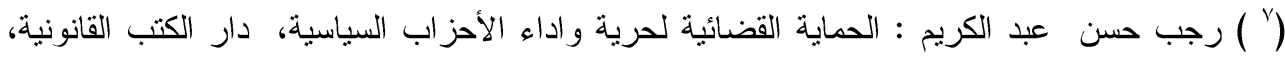

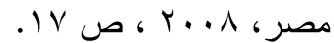

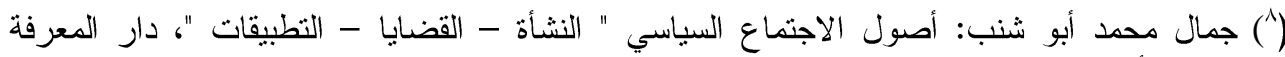

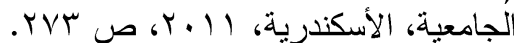

(9) Bruce S. , Yearly S. , the sage dictionary of sociology ,sage publications ,London ,2006, p234.

$$
\begin{aligned}
& \text { (•) (1) كامل الزهيري: موسوعه الهلال الاشتر اكية، نقلا عن طارق فتح الله دور الأحزاب السياسية في }
\end{aligned}
$$

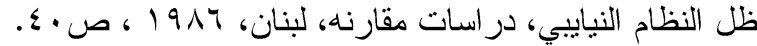

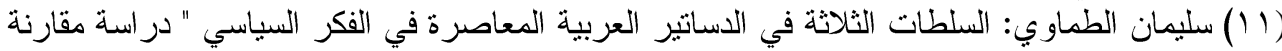

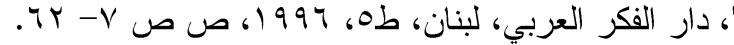

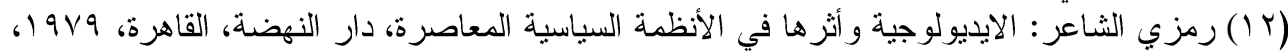

$$
\begin{aligned}
& \text { ص ז.1. } \\
& \text { (T) انطونيو جر امشي: قضايا علم السياسية في الماركسية ، ترجمة: و اهي شرفان وقيس الامي، دار }
\end{aligned}
$$

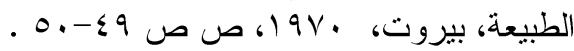

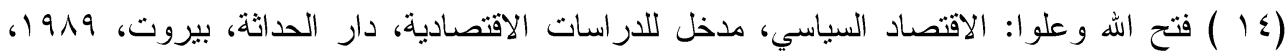

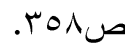

(15) James Kerr Pollok.Mony and Political Abroad University Of Machigan press ,1962,p63.

(16) Tomas Ferguson: Golden Rule - The investment theory of party competition and the Logic of Money - Driven Political System.Chicago press 1995 ,p42.

$$
\begin{aligned}
& \text { (IV) موريس دوفرجيه: علم اجتماع السياسة، ترجمة: سليم حداد، المؤسسة الجامعية للار اسات و النشر، }
\end{aligned}
$$

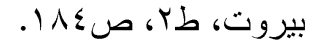

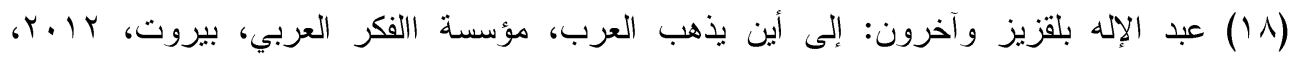

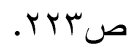

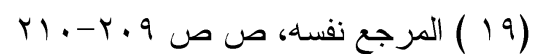

(20) Stephan Bell, "Institutionalism old and New", OP.Cit.

(21) - Hartfiel Gunter, bib, s. 341.

(Y r (Y) على الدين هلال: معجم المصطلحات السياسية، مركز البحوث و الدر اسات السياسية، كلية الاقتصاد

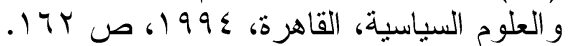

(23) Bassam Tibi: schwache insitutionalisierung ' als fall Agypten in verfassung und Recht in ubersse $1,1980$. 
(24) Harfiel Gunter und k.hollmann , worterbuch der soziologie knoner verlag Stuttgart.1982.

(25) Bassam Tibi : ibid ,pp13 -14.

(T) توم بوتومور : علم الاجتماع السياسي، ترجمة: وميض نظمي، دار الطليعة للطباعة و النشر ، بيروت،

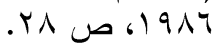

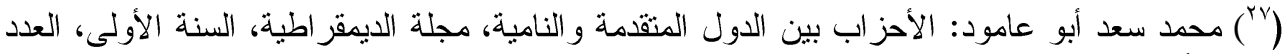

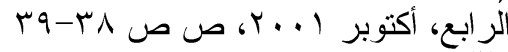

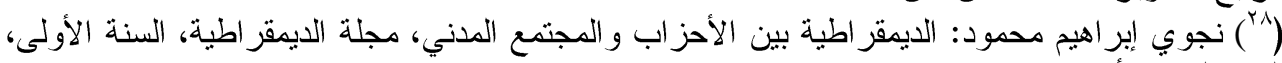

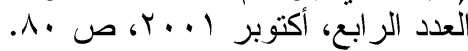

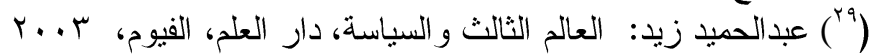

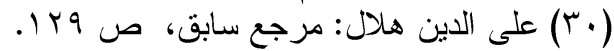

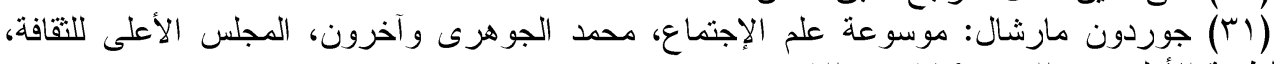

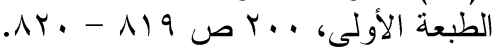

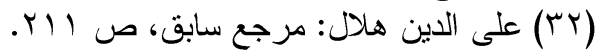

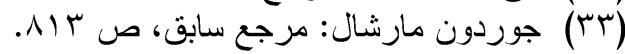
(34) Arthur fischer, Heinz- Ulrich kohr: Politisches verhalten und empirische sozialforschung, Juventa, verlag Munchen, 1980, S. 9.

(35) Arthur fischer, Heinz - Ulrich kohr: bib. S. 15

(36) Arthur Fischer, Heinz - Ulrich kohr: bib. S. 20.

(37) Arthur Fischer: bib. S.23.

(38) Arthur. Fischer: bib. 23.

\section{ملحقات الادر (سة}

\section{دليل مقابلة}

1- ماهى رؤيتكم حول الوضع السياسى القائم ؟ و الحياة الحزبية ؟ وحجم التغير ات التى حدث؟؟ دابه r- ماهى الأسباب التى دعنك لتأسيس الحزب أو أو الانضمام إليه ؟

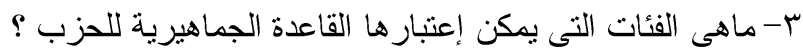

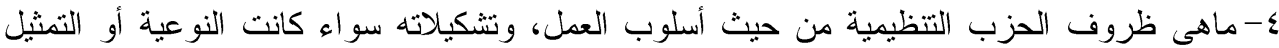
الجغر افي على مستوى المحافظات و المر اكز ؟عضوية الحزب، كيفية سداد الاشتر اكات؟

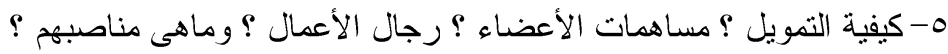

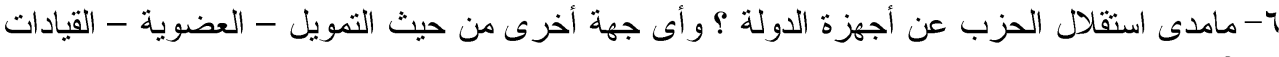
? V- ما كيفية تكيف الحزب مع المتغيرات المجتمعية والحالة الثورية التى كان عليها المجتمع، سواء فى الئ الفكر أو البرنامج أو أساليب الحوار و آليات العمل ؟

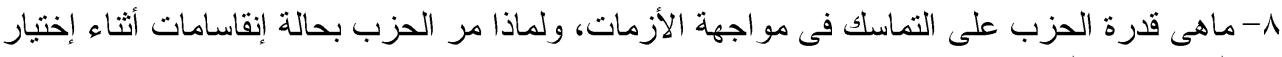
المرشحين و القو ائم ؟ بأب

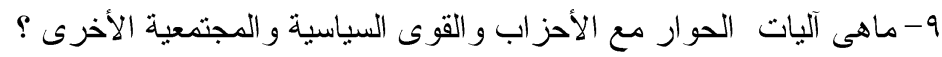
• 1- ماهى تحالفات الحزب مع قوى حزبية أخرى أو تحالفات مع المستقلين ؟ 11- ماهى رؤيتكم حول المال السياسي فى الانتخابات الأخرى ؟

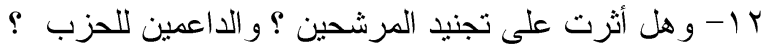

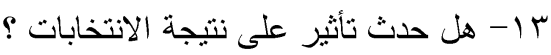

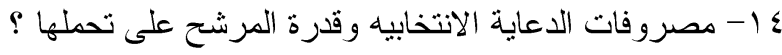

10- هل يمكن تحقيق نتيجه جيدة بدون استخدام المال السياسي ؟ 


\begin{tabular}{|c|c|c|c|c|}
\hline المحافظة & اسم الحزب & الصفه & الاسم & م \\
\hline الشرقيه & الشعب الجمهوري & رئيس حزب & حازم عمر سليمان & 1 \\
\hline الشرقيه & المؤتمر & رئيس حزب & الربان / عمر صميده & r \\
\hline قتا & الحريه & رئيس حزب & معتز محمود & $r$ \\
\hline القاهرة / القليوبيه & الشعب الجمهوري & شرفي & محمود شريف & $\varepsilon$ \\
\hline 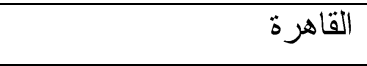 & المو اطن مصري & رئيس حزب & صلاح حسب الله & 0 \\
\hline الغربية / القاهرة & المؤتمر & امين عام & لو اء / امين ر اضي & 7 \\
\hline القاهرة & الشعب الجمهوري & امين عام & د. صفي الدين خربوش & 7 \\
\hline بورسعيد & المؤتمر & امين تتظيم & أ. حامد الشناوى & V \\
\hline الجيزة & الشعب الجمهوري & امين تتظيم & د. شريف و الى & $\Lambda$ \\
\hline دائرة مطوبس & المؤتمر & مرشح & أ. اسامه عمر شلبي & 9 \\
\hline الاسكندرية & الشعب الجمهوري & مرشح & حسن خير الله & 1 . \\
\hline سوهاج & الشعب الجمهوري & مرشح & هشام الشاطورى & 11 \\
\hline الاقهليه ( بني عبيد ) & الشعب الجمهوري & مرشح & رضو ان & IY \\
\hline كفر الثيخ ( قلين ) & الشعب الجمهوري & مرشح & ياسر منير عبدالجو اد & 14 \\
\hline ) كفر الشيخ ( بندر كفر الشيخ & الشعب الجمهوري & مرشح & مجدي محمود الشر اكي & $1 \leq$ \\
\hline القاهرة & الشعب الجمهوري & مرشح & صبري محمد طه & 17 \\
\hline كفر الشيخ & المصريين الاحرار & مرشح & على محمد العجو اني & IV \\
\hline مطوبس & المصريين الاحرار & مرشح & صلاح الدين المعداوى & 11 \\
\hline شبر اخيت & الشعب الجمهوري & مرشح & خالد & 19 \\
\hline بندر كفر الشيخ & المؤتمر & مرشح & توفيق محمد الشيتاني & $r$. \\
\hline البرلس & المؤتمر & مرشح & محمد يونس ابوزيد & YI \\
\hline سيدي سالم & مستقل & مرشح & سيد احمد ابومحمد & rY \\
\hline سيدي سالم & المصريين الاحر ار & مرشح & على احمد ابو علي & rT \\
\hline قلين & الجبهه الوطنية & مرشح & عمر دويز & rs \\
\hline دسوق & مستقبل وطن & مرشح & محمد الشهاوي & ro \\
\hline
\end{tabular}




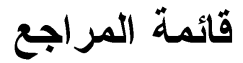

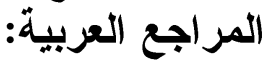

1-جمال محمد أبو شنب: أصول المعة الاجتماع السياسي " النشأة - القضايا - التطبيقات "، دار المعرفة

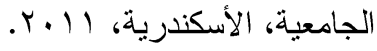

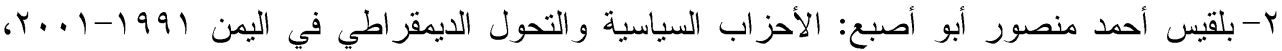

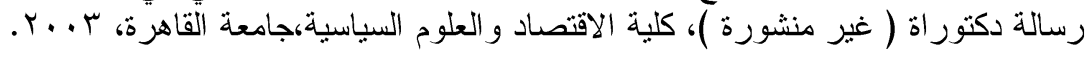

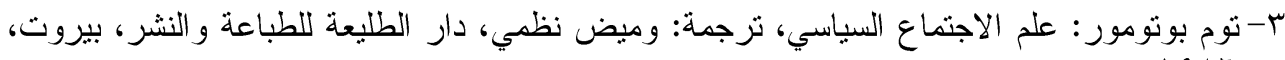
.1917

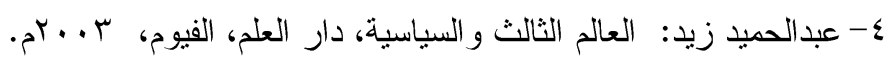

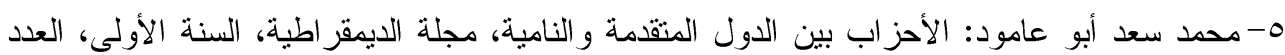

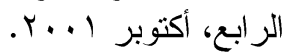

צ- نجوي إبر اهيم محمود: الديمقر اطية بين الأحز اب و المجتمع المدني، مجلة الديمقر اطية، السنة الأولى،

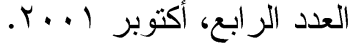

V- انطونيو جرامشي: قضايا علم السياسية في الماركسية ، نرجمة: واهي شرفان وقيس الامي، دار

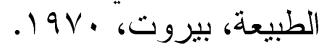

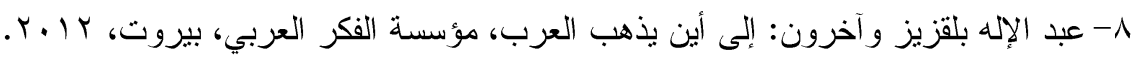

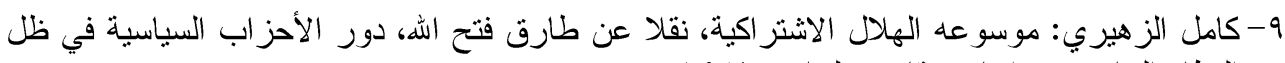

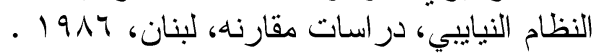

• 1- رجب حسن عبد الكريم : الحماية القضائية لحرية واداء الأحزاب السياسية، دار الكتب القانونية،

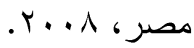

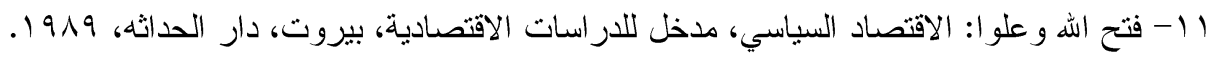
r ا سليمان الطماوي: السلطات الثلاثة في الدساتير العربية المعاصرة في الفكر السياسي " دراسة مقارنة الإنة

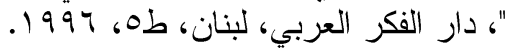

rا - موريس دوفرجيه: علم اجنماع السياسة، ترجمة: سليم حداد، المؤسسة الجامعية للار اسات و النشر،

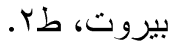

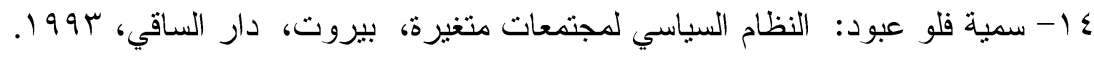

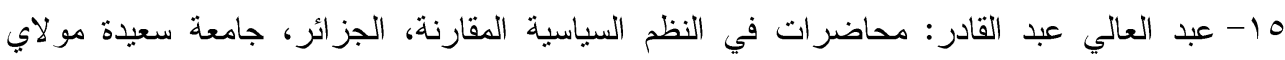

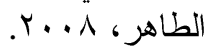

17 - 17

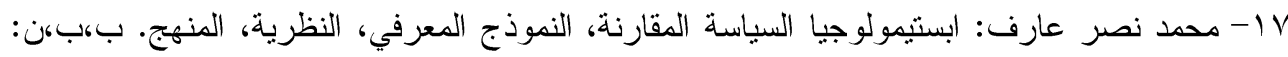

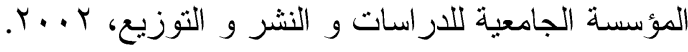

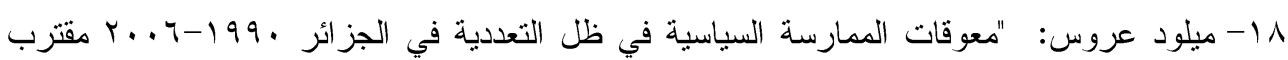

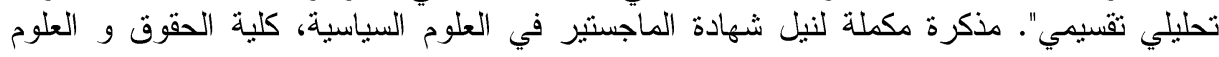

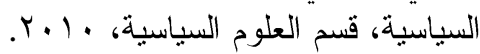

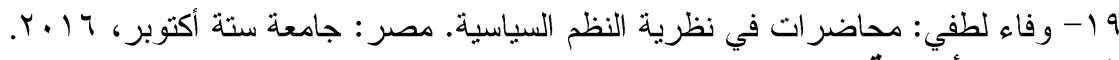

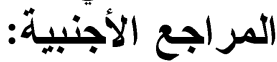

( 1 ) D. Claessens, O.stammer: Die Krise der parteiendemokratie und die parteiensoziologie, Berlin 1979 s.

( 2 ) E,wiesendahl: parteien und demokratie. Eine soziologische Analyse paradigmatischer Ansatze der parteienforschung, Opladen 1980. 
( 3) Fischer , Naschold: organisation und Demokratir m stuttgart Berlin, Koln, Mainz 1979.

(4) Tomas Ferguson: Golden Rule - The investment theory of party competition and the Logic of Money - Driven Political System.Chicago press 1995.

(5) Frieder, Naschold: Organistion und Demokratie, bib.

(6) Bassam Tibi: schwache insitutionalisierung ' als fall Agypten in verfassung und Recht in ubersse 1,1980 .

(7) Alf. Mintzel: parteiensoziologie, in pipers worterbuch zur politik, Munchen, Zurich, 1989.

(9) Bruce S. , Yearly S. , the sage dictionary of sociology ,sage publications ,London ,2006. (10) Rolf. Ebbighausen: Die krise der parteicndemokratie und die parteinssoziologie, Berlin, 1969,

11) Stephan Bell, "Institutionalism old and New", OP.Cit.(

12) James Kerr Pollok.Mony and Political Abroad University Of Machigan press ,1962,p63.( bib. 